\title{
Physical health, vascular risk factors, and age-related cognitive decline : studies into physical determinants of normal cognitive aging
}

Citation for published version (APA):

van Boxtel, M. P. J. (1997). Physical health, vascular risk factors, and age-related cognitive decline : studies into physical determinants of normal cognitive aging. [Doctoral Thesis, Maastricht University]. NeuroPsych Publishers. https://doi.org/10.26481/dis.19970516mb

Document status and date:

Published: 01/01/1997

DOI:

10.26481/dis.19970516mb

Document Version:

Publisher's PDF, also known as Version of record

Please check the document version of this publication:

- A submitted manuscript is the version of the article upon submission and before peer-review. There can be important differences between the submitted version and the official published version of record.

People interested in the research are advised to contact the author for the final version of the publication, or visit the DOI to the publisher's website.

- The final author version and the galley proof are versions of the publication after peer review.

- The final published version features the final layout of the paper including the volume, issue and page numbers.

Link to publication

\footnotetext{
General rights rights.

- You may freely distribute the URL identifying the publication in the public portal. please follow below link for the End User Agreement:

www.umlib.nl/taverne-license

Take down policy

If you believe that this document breaches copyright please contact us at:

repository@maastrichtuniversity.nl

providing details and we will investigate your claim.
}

Copyright and moral rights for the publications made accessible in the public portal are retained by the authors and/or other copyright owners and it is a condition of accessing publications that users recognise and abide by the legal requirements associated with these

- Users may download and print one copy of any publication from the public portal for the purpose of private study or research.

- You may not further distribute the material or use it for any profit-making activity or commercial gain

If the publication is distributed under the terms of Article $25 \mathrm{fa}$ of the Dutch Copyright Act, indicated by the "Taverne" license above, 


\section{Physical health, vascular risk factors, and age-related cognitive decline}


M. P. J. van Boxtel, Maastricht 1997

Physical health, wascular risk factors and age-related cognitive decline: studies into physical determinants of normal cognitive aging/ Martinus Petrus Johannes van Boxtel. - Maastricht Neuropsych Publishers Maastricht. - Ill.

Ools rekst in het Nederlands. - Proefschrift Maastricht. -

Met lit. opg.

ISBN $\quad 90-75579-04-7$

NUGI 716743

Prodhction: Datawyse I University Press Maastricht

Neuropych Prolishers is a non-profit organization which aims at promoting the science of Brain br $^{2}$ Behavior and imptoving the application of the products of this science in health care and education. Neuropsych Publishers accomplishes these aims by publishing books, dissertations and other products of scientific activity, dissemination of educational materials and publication of tests, assessment scales and other psychometric instruments in the field of Neuropsychology, Neuropsychiatry and other areas within the domain of Brain \& Behavior.

Postal anddres:

Neuropsych Publishers

Deparmene of Psychiatry and Neuropsychology

Secrion Neuropsychology and Psychobiology

University of Maastricht:

P.O. Box 616

NL-6200 MD Maastricht

The Netherfands 


\section{Physical health, vascular risk factors, and age-related cognitive decline}

Studies into physical determinants of normal cognitive aging

\section{PROEFSCHRIFT}

ter verkrijging van de graad van doctor aan de Universiteit Maastricht, op gezag van de Rector Magnificus, Prof. Mr. M. J. Cohen, volgens het besluit van het College van Decanen, in het openbaar te verdedigen op vrijdag 16 mei 1997 om 14.00 uur

door

Martinus Petrus Johannes van Boxtel 


\section{Promotor}

Prof. dr. J. Jolles

\section{Beoordelingscommissie}

Prof. d.t. J. A. Knottnerus (voorzitter)

Prof. dr. I. M. Bouter (Vrije Universiteit, Amsterdam)

Dr. D. J. H. Deeg (Vrije Universiteit, Amsterdam)

Prof. dr. H. G. Schmidt

Dr. F. R. J. Verhey

The studies described in this thesis were carried out at the Maastricht Brain \& Behavior Institute, the Department of Psychiarry and Neuropsychology of the University of Maastricht and the University Hospital Maastricht.

Financial support by the Netherlands Heart Foundation for the publication of this thesis is greatfully acknowledged. 
Panimiten

D. P.J. Houx

Drs. H. F. Swijgman 


\section{List of abbreviations}

\begin{tabular}{|c|c|}
\hline $\begin{array}{l}A_{1}, A_{1} 4 \\
A_{D}\end{array}$ & $\begin{array}{l}\text { Denotes one on more MAAS panel studies } \\
\text { Ayheirniers Disease (or - Dementia) }\end{array}$ \\
\hline ADPML & $\begin{array}{l}\text { Artbulatory Blood Presisure Monitoring; technique ro measure blood } \\
\text { pressure repeatedly under normal living condions }\end{array}$ \\
\hline APAQ & $\begin{array}{l}\text { Actual Physical Acrivity Questionnaire; proxy measure of caloric } \\
\text { expenditure }\end{array}$ \\
\hline BLE & $\begin{array}{l}\text { Biological Life Event; health factors potentially related to cogritive } \\
\text { dedine; ats identifed in the Mastricty Memory Study (MMS) }\end{array}$ \\
\hline BMI & $\begin{array}{l}\text { Body Mass Index body weight [kg]/ body length squared [m²]: index of } \\
\text { obesicy }\end{array}$ \\
\hline BRC & $\begin{array}{l}\text { Brain Reserve Capacity; theoretical model to describe functional reserve and } \\
\text { compensatory mechanisms in cognitive processes }\end{array}$ \\
\hline$C \times A$ & $\begin{array}{l}\text { Cerebrovascular Accidenc; irreversible meurological condition due to brain } \\
\text { hemorthage or infarction }\end{array}$ \\
\hline CVE & $\begin{array}{l}\text { Cardiovascular event; here: evidence of cardiovascular disease identified in } \\
\text { the medical history }\end{array}$ \\
\hline $\mathrm{CST}$ & Concept Shiftung Task; rask measuring simple and complex cognirive speed \\
\hline DART & Durch Adult Reading Test measure of premorbid (verbal) incelligence \\
\hline GIT & Groningeni Intelligence Test; Durch rest of formal intelligence \\
\hline$G \mathrm{P}$ & General Practicioner, or family doctor \\
\hline ICPC & $\begin{array}{l}\text { International Classifficarion of Primary Care; coding system of health } \\
\text { problems used in RNH }\end{array}$ \\
\hline (N)IDDM & (Non-) Insulin-Dependent Diabetes Mellirus \\
\hline ISH & $\begin{array}{l}\text { Inwentory of Subjective Healrh [ Wragewligt Omtrent Eruaren Gezondheid, } \\
\text { VOEG] }\end{array}$ \\
\hline LDST & Letrer Digit Substitution Test; test of information processing speed \\
\hline $1 . O A$ & $\begin{array}{l}\text { Level of Occupational Achiewement; proxy measure of general ability, or } \\
\text { imtelligence, used in MAAS as stratificarion variable }\end{array}$ \\
\hline MAAS & Maastrictnt Aging Study \\
\hline$M C R T$ & $\begin{array}{l}\text { Motor Choice Reaction Test; test of simple and complex information } \\
\text { processing speed }\end{array}$ \\
\hline MEMAC & 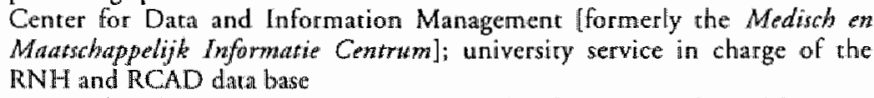 \\
\hline MMS & $\begin{array}{l}\text { Matastricht Memory Study preliminary seudy of MAAS petformed between } \\
198 \%-1990 \text { that introduced the concept of Biological Life Events (BLE) }\end{array}$ \\
\hline MMSE & Mini-Mental State Exminarion screening rest for cognitive impaiment \\
\hline $\mathrm{MH}$ & Magnetic Resonance lmaging; a brain imaging technique \\
\hline NESTOR & 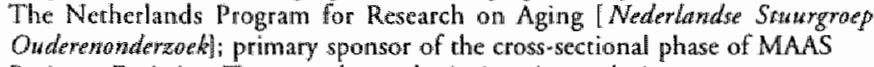 \\
\hline PET & Positron Emission Tomography; a brain imaging rechnique \\
\hline RCAD & Register of Cogntive Aging and Demenria; the MAAS research data base \\
\hline RNH & $\begin{array}{l}\text { Registration Nerwork Family Practices [Registratienet Hussartspraktijken]; } \\
\text { sample frame of MAAS }\end{array}$ \\
\hline SCSB & $\begin{array}{l}\text { Short Cognitive Screening Battery; ser of psychometric instruments covering } \\
\text { a wide array of cognitive abilities }\end{array}$ \\
\hline SPECT & Single Photon Emission Computed Tomography; a brain imaging technique \\
\hline SCWT & Stroop Color-Word Tes" test of cognitwe interference, or flexibility \\
\hline TIA & Transient Ischemic Actack" essentially reversible brain perfusion disorder \\
\hline $\mathrm{MO}_{2}-\max$ & Oxygen consumption of the body during maximal physical effort \\
\hline WAIS & Wechster Adult Intelligence Scale; the golden standiard in IQ assessment \\
\hline WIIR & $\begin{array}{l}\text { Waist-to-Hip Ratio tatio of body circumferences as a measure of fat } \\
\text { distribution }\end{array}$ \\
\hline WLT & $\begin{array}{l}\text { Word Learning Task; rest of primary (or immediate) and secondary (or } \\
\text { delayed mernory }\end{array}$ \\
\hline
\end{tabular}




\section{CONTENTS}

\section{Chapter}

1 General introduction $\ldots \ldots \ldots \ldots \ldots \ldots \ldots \ldots \ldots \ldots \ldots \ldots \ldots$

2 Physical health, wascular risk factors, and age-related cognitive dedine:

theoretical background . . . . . . . . . . . . . . . . . . . . . . . . . 15

I Physical health and cognicive aging .....................

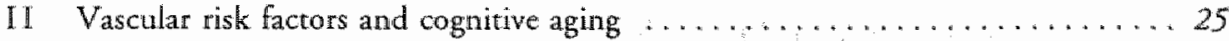

3 The Maastricht Aging Study (MAAS): rationale, objectiwes, design and methods . . . 41

3.1 Rationale and objectives $\ldots \ldots \ldots \ldots \ldots \ldots \ldots \ldots \ldots \ldots \ldots \ldots \ldots$

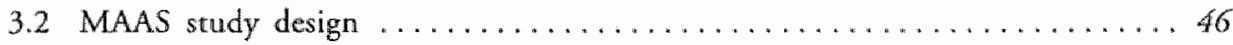

3.3 Methods I: Postal surwey . . . . . . . . . . . . . . . . . . . . . 53

3.4 Mechods 11 : Medical and neurocognitive assessment $\ldots \ldots \ldots \ldots \ldots \ldots$

4 Self-reported physical activity, perceived health, and cognitive performance

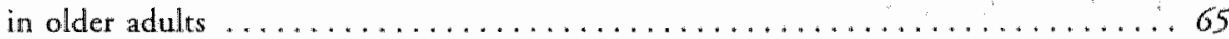

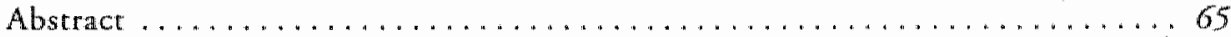

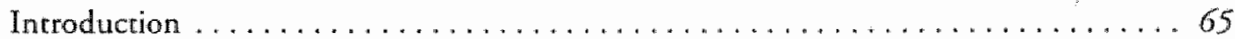

Methods ........................................ 67

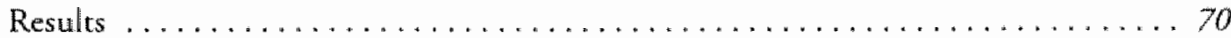

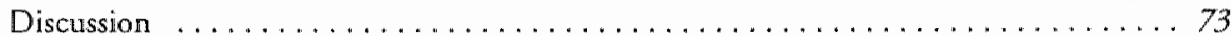

5 Aerobic capacity and cognitive performance in a cross-sectional aging study . . . . . . 77

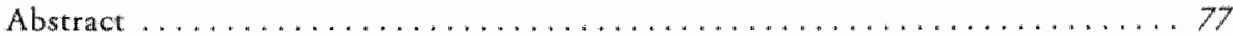

Introduction $\ldots \ldots \ldots \ldots \ldots \ldots \ldots \ldots \ldots \ldots \ldots \ldots \ldots \ldots \ldots$

Methods .......................................... 79

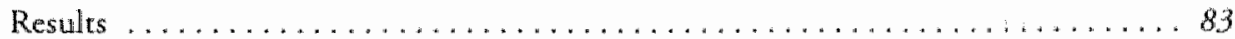

Discussion $\ldots \ldots \ldots \ldots \ldots \ldots \ldots \ldots \ldots \ldots \ldots \ldots \ldots \ldots \ldots \ldots$

6 Repeated automatic versus ambulant blood pressure measurement: the effects of age and sex in a normal aging population $\ldots \ldots \ldots \ldots \ldots \ldots$. . . .

Abstract $\ldots \ldots \ldots \ldots \ldots \ldots \ldots \ldots \ldots \ldots \ldots \ldots \ldots \ldots \ldots \ldots \ldots$

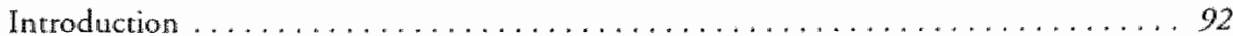

Merhods ....................................93

Results .................................... 95

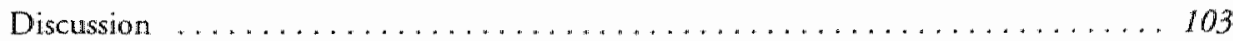


7 Can blood pressure predicr cognitive task performance in a healthy population sample? . . . . . . . . . . . . . . . . . . . . . 109

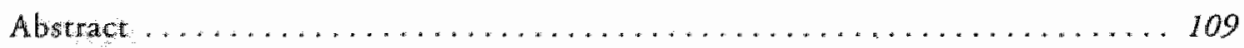

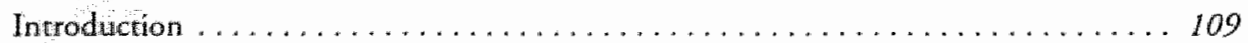

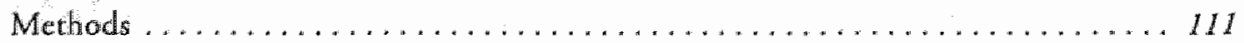

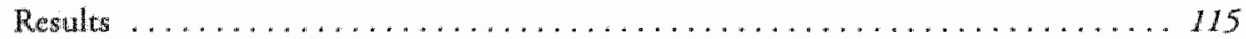

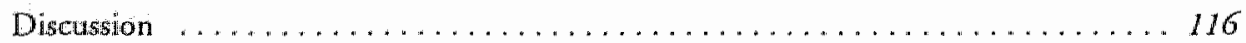

8 Is cognitive impairment related to a reduced nocturnall blood pressure drop? . . . . 123

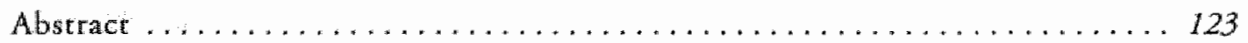

Introduction $\ldots \ldots \ldots \ldots \ldots \ldots \ldots \ldots \ldots \ldots \ldots \ldots \ldots \ldots \ldots \ldots \ldots \ldots \ldots$

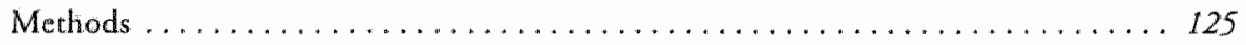

Results $\ldots \ldots \ldots \ldots \ldots \ldots \ldots \ldots \ldots \ldots \ldots \ldots \ldots \ldots \ldots \ldots \ldots \ldots \ldots \ldots \ldots 127$

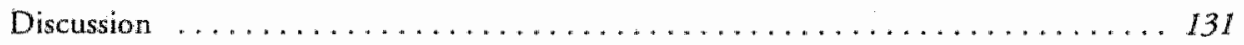

9 The relation between morbidity and cognitive performance in a normal aging population $\ldots \ldots \ldots \ldots \ldots \ldots \ldots \ldots \ldots \ldots \ldots$

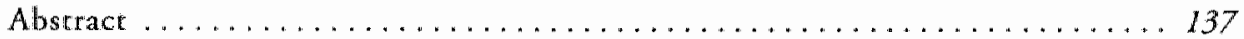

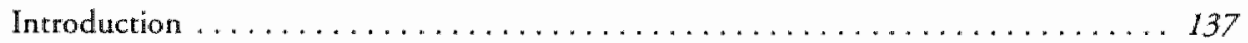

Methods ......................................... 138

Results ..................................... 140

Discussion $\ldots \ldots \ldots \ldots \ldots \ldots \ldots \ldots \ldots \ldots \ldots \ldots \ldots \ldots \ldots \ldots$

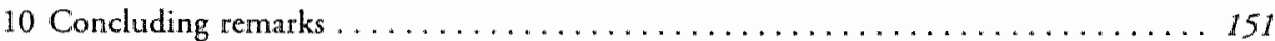

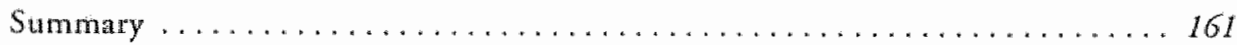

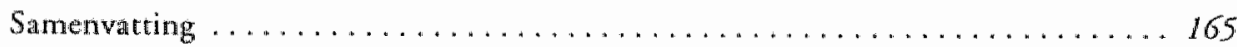

Curriculum vitae $\ldots \ldots \ldots \ldots \ldots \ldots \ldots \ldots \ldots \ldots \ldots \ldots \ldots \ldots \ldots$

Dankwoord $\ldots \ldots \ldots \ldots \ldots \ldots \ldots \ldots \ldots \ldots \ldots \ldots \ldots \ldots \ldots \ldots$

List of publications $\ldots \ldots \ldots \ldots \ldots \ldots \ldots \ldots \ldots \ldots \ldots \ldots \ldots$ 


\section{Chapter 1}

\section{General introduction}

Virtually all aspects of cognitive functioning in healchy individuals have been shown to deteriorate with increasing age (Birren \& Schaie, 1990). In fact, the majority of elderly people complain about forgetfulness and decreased concentration, which in many cases compromise their qualicy-of-life to such an extent that professional help is sought (Jolles, Verhey, Riedel 8 . Houx, 1996). Demographic projections indicate that the need for specialized health care facilities to deal with these health problems will rise dramatically, due to the increased life expectancy in Western societies (Fries, 1990).

One of the major problems in clinical practice is the differentiation of what may be regarded as an 'age-congruent' decline in cognitive capacities and the prodromal phase of a specific pathological syndrome, such as dementia. In prodromal stages of dementia the cognitive symptomatology may be similar to what may be considered the lowest extreme of normal cognitive function. Much research effort to date has thetefore been devoted to delineate the borderline berween normal cognitive aging and parhological conditions such as Alzheimer's disease (Jolles, 1996; Jolles et al., 1996), in order ro force the notion of the continuity of adult cognitive development into the dichotomy of the medical model. In the past decades several. atrempts have been made to conceptualize the prodromal phase of cognitive pachology (chapter 2). In the most recent version of the Diagnostic and Statistical Manual of Mental Disorders (DSM-IV, American Psychiatric Association, 1994) a new research category has been included as part of the class of cognitive disorders, called 'mild neurocognitive disorder'. Such widely accepted definitions are essential to clarify the natural history of cognitive disorders and may ultimately result in recommendations for the design of clinical drug trials and the planning and development of health care facilities.

\section{What do we know about notmal cogntitive aging?}

The knowledge we have about the normal aging of cognitive funcrions is far from complete and basic questions are as yet unanswered. For example, when in life do cognitive abilities stant to deteriorate, is this decline universal for all cognitive abilities or are there differences in the rate of decline, and, most importantly, are there individual differences in cognitive aging trajectories, and finally, if so, which factors mediate these differences (Rabbitt, 1990)? These questions lie at the heart of modern cognitive gerontology and their answers may have major implications for diagnostic and therapeutic strategies for cognitive disorders (Bromley; 1990).

Rowe and Kahn (1987) have suggested in their theoretical review that even in normal, disease-free populations a substantial variation can be observed in virtually any funcrional parameter, such as memory function, and that this variation may increase with age. They suggested a distinction between normal (or usual) and successful aging in several functional 
domains - such as cognicion - and encouraged the scientific pursult of the factors which can differentiate berween these two aging categories. With respect to cognitive aging, heallhrelated factors such as head trauma, prolonged psychotropic drug use or general anesthesia have in recent cross-sectional research been shown to moderate the relation between age and cognitive function (Houx \& Jolles, 1993; Honx, Vreeling \& Jolles, 1991; Jolles, Houx, Vreeling \& Verthey, 1993). It has been hypothesized that these somcalled Biological Life Events (BLE) constitute a biological substrate for the non-pathological cognitive deficiencies that are associared with normal aging. The importance of this notion was stressed quite recently in a multidisciplinary symposium devoted to diagnostic and therapeutic issues of cognitive impairment (Lancet Conference 1996, "The challenge of the dementias', Edinburgh, UK). In their consensus statement in The Lancet, the Writing Committee concluded that the challenge that is referred to begins by characterizing normal brain aging in terms of neuropathology, neuroimaging, and neuropsychology, preferably within a longitudinal framework (Writing Committee Lancet Conference, 1996). Without this knowledge the borderline berween normality and pathology cannot be determined in a satisfactory way. In particular, whe role of vascular risk factors in normal and parhological cognitive dysfunctions was addressed during this meeting ( $\$$ koog, 1996). It is therefore essential to carry out large-scale studies into normal cognitive aging to account for the different aging patterns in cognitive abilities and to distinguish normal cognitive aging from pathological cognitive aging such as occurs in an early phase of dementia.

\section{Longitudinal studies}

Longitudinal studies that specifically address normal cognitive aging are relatively scarce as they requite large human and financial resources (Deeg, 1989). The ongoing prospective population studies that include measures of cognitive funcrion are less suitable for studying normal cognitive aging for a variety of reasons. Most importantly, some of these studies do not cover the complete adult life span, which seems imperative to gain insight into further functional development after brain maturation is reached in young adulthood (Selkoe, 1992). For example, in the French Paquid study (Barberger Gateau et al., 1992), only individuals aged 65 years or older were included at baseline. The Longitudinal Aging Study Amsterdam (LASA; Deeg et al., 1993) included young-old individuals (55 years and oider) but only a limited ser of cognitive instruments is being used because the primary focus of the study is on autonomy and well-being. A multi-stage assessment of cognitive function was made in the Rotterdam study, the aim of which is to identify factors related to chronic diseases, such as dementia, in a geographically well-defined population aged 55 years and older (Hofman, Grobbee, de Jong \& van den Ouweland, 1991). Thus, specific cognitive domains were assessed in this study only when pathology was suspected. Studies that do cover the complete adult life span have other limitations. In the classical Baltimore Longitudinal Srudy of Aging (BLSA. Shock et al., 1984) cognitive tests were administered to the oldest participants only (60 years and older). The Betula study in Sweden shares with the Maastricht Aging Study (MAAS) the interest in health-related factors (Nillson, Winblad, Adolfsson, Bucht \& Bäckman, 1992), but the dependent variables pertain primarily to memory function. Finally, in the Seatrle studies 
no systematic assessment was made of health starus or morbidiry (Schaie, Labouve 8 Barreti 1973).

MAAS started in 1991 with the aim of providing answers to the core questions of cognitive gerontology cired above by providing fundamental data on individual aging rajectories in different cognirive domains, which are studied as functions of contextual and biomedical characteristics (Jolles, Houx, van Boxtel \& Ponds, 1995). The study cowers the full adult life span and is characterized by a cross-sequential design and in-depth neurocognitive and biomedical evaluation of a group of initially healithy individuals. For this purpose, participants were randomly recruited from a patient data base of collaborating general practices in the Maastricht region (Registration Network of Family Practices - RNH). The core population of MAAS consists 1,900 individuals at baseline measurement. The popularion was stratified for age, sex, and general level of functioning (based on prior education and actual vocational achievement), the latter two as the most important and acknowledged confounding variables in cognicive aging research (Lezak, 1995). Thus, the design of MAAS may be characterized as quasi-experimental, to facilitate the study of relations between potential determinants of cognitive aging and relevant demographical background characteristics.

\section{Outline of this thesis}

This thesis deals with the results of the cross-sectional phase of MAAS and relates to normal cognitive aging and health-related variables, with special reference to vascular risk factors, as potential predictors of cognitive decline. Three other aspects of cognitive aging are dealt with in PhD theses issued by Neuropsych Publishers that are based on MAAS data: cognitive aging in relation to surgery under general anaesthesia (J. Dijkstra, April 1997), traumatic brain injury (M. Klein, April 1997), and metacognition (R. Ponds, expected in 1998).

The first part of chapter 2 provides the theoretical background for the studies described in this thesis and provides concise introduction to the issues at stake in today's research in cognitive gerontology. An overview is given of research findings within the triangle of health, aging, and cognitive function, and some basic concepts are outlined. The construct of brain reserve capacity is introduced as an explanatory model for the hypothesized effects of health-related factors on cognitive function that are explored more in depth in the subsequent chapters. In the second part of this chapter the evidence is rewiewed for the role of cardiovascular and cerebrovascular risk factors in brain aging, several of which are evaluated in this thesis in relation to cognitive function.

Chapter 3 discusses the rationale and general outline of the MAAS study that provided the framework of the experimental studies described in the chapters 5 to 9 . Background information is presented about the sample frame, participant characteristics, the study design and the rype of measurements that are used. Basically, MAAS consists of four consecutive panel studies, referred to as $A_{1}$ to $A_{4}$, using independent subject samples of $440-480$ each. Data presented in chapters 5 to 9 are derived from one such panel study (chapters 5, 64 and 8) or from pooling several of such studies (chaprers 7 and 9), as indicated below.

Chapter 4 presents the first experimental dara and deals with a complementary study in an independently recruited sample, to evaluate the use of a habitual activities questionnaire 
(indexing daily caloric expenditure) in relation to cognituse function in 80 healthy indiwiduals aged 55 years and ovet. It is hypothesized that the the level of habitual physical activity and experienced health re related to higher levels of cognitive functioning.

In chapter 5 the hypothesis of chapter 4 is extended to actual physical firness as the outcome of thabitual physical activity. A submaximal endurance protocol is used to estimate the aerobic eapacity $\left(\mathrm{VO}_{2}\right.$ max $)$ of 132 participants in the first MAAS panel $A_{1}$, aged berween 24 and 76 years. Next, acrobic capaciry is used to predict performance on several neurocognitive tests, in particular those that require large attentional resources.

In chapter 6 the important methodological issue of blood pressure measurement in population studies is discussed. Bllood pressure status is a target variable in chapters 7 and 8 . Special attention was given to arrive at relatively unbiased estimate of blood pressure because only one measurement session was available for the evaluation of blood pressure. Particularly the potential bias of age, sex, and adaptation of blood pressure during the measurement session on the habitual blood pressure status is studied in this chapter. Data are presented that were obtained by repeated measurement of the blood pressure of 469 participants in MAAS panel study $A_{1}$. In addition, the habitual blood pressure measured in the laboratory was compared to that obtained by 24 -hour ambulant blood pressure monitoring (ABPM) in a subgroup of 115 subjects to derermine to what extent laboratory blood pressure is representative for bllood pressure under daily living conditions.

Blood pressure status and other vascular risk factors (including smoking habits, alcohol consumption, body mass index, and regional fat distribution) are studied in relation to to cognitive performance measures in chapter $7_{3}$ based on dara from MAAS panel studies $\mathrm{A}_{1}$ and $\mathrm{A}_{2}(N=936)$.

Chapter 8 reports on analyses in the ABPM subgroup in the MAAS $A_{1}$ panel $(N=115)$, which are comparable to those in chapter 7 , with respect to different indices of ambulant blood pressure. More specifically, the hypothesis is tested that the difference between day-time and night-time blood pressure (dipping) is inversely associated with brain dysfunction as measured with cognitive tests.

Chapter 9 presents the results obtained when data from the 1,360 participants of the MAAS panels $A_{1}$ to $A_{3}$ were pooled to analyze the impact of specific well-defined categories of morbidity, as reconded by the general practitioner, on cognitive function.

Finally, the experimental findings are assembled in chapter 10 , in which the various vascular risk factors are evaluated as possible mediators in the age-cognition relationship. The limirations of a cross-sectional merhodology are discussed with reference to research design and risk factor characteristics, and some final conclusions are drawn.

\section{REFERENCES}

American Psychiatric Association. (1994). Diagnostic and statistical mannal of mental disorders. DSM-IV. (4th ed.). Washington, DC: Amctican Psychiatric Association.

Barberger Gateatu, P., Chaslerie, A., Dartigues, J. F., Commenges, D., Gagnon, M., \& Salamon, R. (1992). Health measures correltates in a Frencin elderly community population: The PAQUID study. Journal of Gerontology, $47,588-95$.

Birren, J. E., \& Schaie, K. W. E. (1990). Handbook of the psycholagy of aging: (3 ed.). San Diego: Academic Press. 


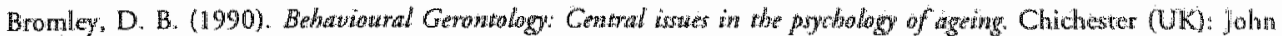
Wiley \& Sons.

Deeg, D. J. H. (1989). Experiences from Longitudinal studies of atging. (Vol. 3). Nijnegen. The Netherlands: Netherlands Institute of Gerontology.

Deeg, D. J. H., Jonker, C. I auner, L. J., Schellevis, F. G., Smits, C. H. M., wan Tilburig, T., Knipscheer, C. P. M., \& wan Tilburg, W. (1993). Change in autonomy and well-being: Background and preliminary proposal for the Longitudinal Aging Study Amsterdam. In D. J. H. Deeg, C. 12. M. Knipscheer, \& W. van Tulburg (Eds.).

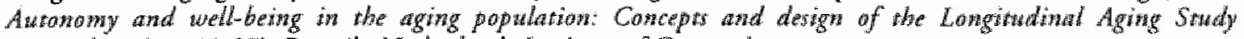
Amsterdam, (pp. 19-87). Bunnik: Netherlands Instituce of Cerontology.

Fries, J. F. (1990). Medical perspecrives upon successful aging. In P. B. Baltes \& M. M. Balres (Eds.), Strectafful aging: Perspectines from the behawioral sciences. (pp. 35-49y. Canbridge: Cambridge University Press.

Hofman, A., Grobbee, D. E., de Jong, P. T. V. M., \& van den Ouweland, F. A. (1991). Deteminants of disease and disability in the elderly: The Rotterdam elderly study. Evopoean Journal of Eppidemiology, 7, 403-422.

Houx, P. J., \& Jolles, J. (1993). Age-relared dedine of psychomonor speed: Effects of age, brain health, sex, and education. Perceptral and Motor Skills, $76,195-211$.

Houx, P. J., Vreeling, F. W $W_{*}$ \& Jolles, J. (1991). Age-associared cognirive decline is related to biological life events. In K. Iqbal, D. R. C. MeLachlin, B. Winblad, \& H. M. Wisniewski (Eds.), ALaheinter's ditsease: Basic mechanisms, didgnosis and therapeatic strategies, (pp. 353-358). Chichester, UK: Whiey.

Jolles, J. (1996). Age-related cognitrye decline and the borderland between normal agring and dementia. Paper presented at the Lancer Conference, 25-26 April 1996. Edinburgh, UK.

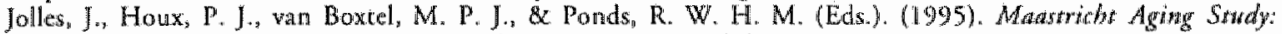
Determinamts of cognitive aging. Maastricht: Neuropsych Publishers.

Jolles, J. Houx, P. J. Vreeling. F. W., \& Verhey, F. R. J. (1993). Cognitive aging, biological life events and primitrve reflexes. Netroscience Research Communications, 13(sapplib), S47-50.

Jolles, J., Verhey, F. R. J., Riedel, W. I., \& Houx, P. J. (1906). Cognitive impairment in elderly people: Predisposing factors and implications for experimental drug studies. Drugs and Aging, 7, 459-479.

Leeak, M. D. (1995). Nentopsychological Assessment. (3rd ed.). New York: Oxford Universicy Press.

Nillson, L.,-G.x Winblad, B., Adolfsson, R., Bucht, G., \& Bïckman, L. (1992). Berula: En prospectiv undersölining om minnesfunction och hälsa [Betula: at prospecrive study of memory function and health]. Socidmedicinst: Tidskrift, 69, $193-198$.

Rabbitr, P. (1990). Applied cognitive gerontology: Some problems, methodology and data. Applied Cognitine Psychology, $4,143-149$.

Rowe, J. W., \& Kahn, R. L. (1987). Human aging; Usual and successful. Science, 237, 143-149.

Schaie, K. W., Labouvie, G. V., \& Barrett, T. I. (1973). Selective attrition effects in a fourteen-year study of adult intelligence. Journal of Gerontology, 28, 328-334.

Selkoc, D. J. (1992). Aging brain, aging mind. Seientific American, 267, 97-103.

Shock, N. W., Greulich, R. C. Andres, R., Arenberg, D., Costa, P. T, Lakatta, E. G., \& Tobin, J. D. (1984). Normal buman aging. Wishington DC: U.S. Government Ptinting Office.

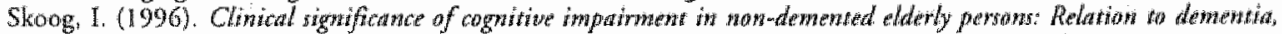
wascalar disorders and death. Paper presented at the Lancer. Confenence, 25-26 April 1996. Edinburgh, UK.

Writing Committee Lancer Conference. (1996). The challenge of the dementias, Lawet, 347, 1303-1307. 



\section{Physical health, vascular risk factors, and age-related cognitive decline: theoretical background}

\section{INTRODUCTION}

The preservation of cognitive skills at an adequate level is essential for the autonomy and independence of older individuals (Deeg et al, 1993). The rapidly growing proportion of elderly individuals in industrialized countries has given this notion high priority on the political and scientific agenda and has resulted in an increased research activity in the feld of cognitive gerontology.

The negative association berween different aspects of cognitive function - such as memory, attentional capacity and speed of information processing - and chronological age is one of the most consistent findings in the literature on the psychology of aging (e.g. Jolles, Houx, van Boxtel \& Ponds, 1995; Poon, 1985; Salchouse, 1989; Birren \& Birren, 1990). In adidition, consistent evidence suggests that the general physical condition or specific disease entities may have repercussions for brain health and thereby for cognitive abilities (Elias, Elias \& Elias, 1990a; Nolan \&. Blass, 1992), the effects of which may be difficult to distinguish from the intrinsic aging process. Both individual and environmental factors seem to be responsible to some extent for the increasing variation of cognitive function with age. Complex interrelations exist between aging, health or physical futness, and cognitive performance, and we are only beginning to identify and understand the mechanisms underlying these interrelations.

Part 1 of this chapter presents an overview of the issues at stake in cognitive gerontology and provides a theoretical framework for the experimental chapters 4 to 9 of this thesis. The potential role of vascular risk factors as precursors of disease in the context of age-rellated cognirive decline is addressed more specifically in the remainder of the chapter.

\section{1 - PHYSICAL HEALTH AND COGNITIVE AGING}

When discussing the concepts of age health, and cognitive function and their intertelationships, it may be helpful to outline common definirions and underlying assumptions to clarify the object of our study. In succession, the concepts of age, health and cognitive function atte discussed separately and in their mutual coherence. Abowe all, the discussion will be restricted to normal cognitive aging, although inevitably the bordertand between normal and pathological cognitive aging, as in dementia, will be rouched upon in the description of factors that are associated with an acceleration of the decline of cognitive abilities (for a review, see Jolles, Verhey, Riedel \& Houx, 1996 . 


\section{Concept definitions}

Health - The definition of health as the absence of disease, an approach that originated from the medical model, has evolved in the last decades towards a nore positive, mullidimensional operationalization (Konig-Zahn, Furer \& Tax, 1993; McDowell \& Newell, 1987). For example, depending on one"s disciplinary approach, health can be defined statistically in terms of a continum berween opposing extremes in physical functioning, biologically as an imbalance in physiological adaptation to environmental demands, sociologically as the optimal state to perform social roles, or psychologically as incorporating aspects of development, personality, or behavior. The term disease most commonly relates to the biomedical concept of intrinsic pathology in organ structures which may have functional consequences for the individual. Several scheme's have been proposed to denote the chain of events leading from disease to disability (e.g. WHO, 1980; Verbrugge \& Jette, 1994). The recent classification of the disablement process by Verbrugge and Jette (1994) discerns after discase or pathology an imparment (dysfunction and structural abnormality in a specific body system), which may be followed by functional limitations (restrictions in basic physical and mental actions), and disability as the final stage, which refers here to the difficulcies experienced in any domain of life caused by a health problem, resulting from the gap between personal capability and environmental demands. Risk factors are thought to modulate this process in all its different stages. This classification illustrares that health is not solely an attribute of the individual, but also bears strong environmental and societal connotarions. The walidity of the health concept, its operationalization, and the choice for an instrument to measure it is therefore largely depedending on the setting in which it is used (McDowell \& Newell, 1987, p. 26). All the mentioned dimensions of health may be uniquely related to age and to cognitive processes, an issue that will be touched upon later in this chapter.

Cognition - The term cognition is generally used to address the intellectual process by which we learn from experience (Bromley, 1990, p. 191). Cognitive processes refer to the mental activity that controls behavior, in other words to the intervening variables that link the stimuli or experiences from the environment to the responses or behaviors that can be observed directly (Maddox et al., 1987, p. 121). However, for research purposes such definitions are too broad. Cognition from a newropsychological perspective may be defined operationally (Colsther \& Wallace, 1991) and incotporates distinet domains of function that can be labeled as intelligence, attention, language abiliry, learning and memory, visuospatial ability, and problem solving (LaRue, 1992). Special tests have been developed to probe the performance within these domains of function (Lexak, 1995).

Cognitive processes are primarily mediated by neocortical areas in the brain, which distinguish man from lower vertebrates. However, most other brain structures have a role in cognitive processes as well. Although no distinct brain substrate can be identified for specific cognitive domains, damage to certain brain structures may produce dramatic domain-specific changes. For example, damage to the hippocampal region (e.g. as the result of stroke or exposure to a toxic compound) may lead to an amnestic syndrome characterized by failure of long-term retention of novel information (Kolb \& Whishaw, 1990, p. 539). Indeed, a large 
part of our current knowledge on the relarion between the brain and cognitive behavior is derived from studies with brain-damaged parients.

Age and aging - Aging can also be defined along different theoretical lines, and although most commonly it is understood in a biological sense, it has also psychological and sociat connotations. It was described comprehensively by Birren and Birren as "... the rime-related transformation of the structures and functions of the organism with a resulting decline in selfregulating biological, social, and behavioral capacities ..." (Birren \& Birren, 1990). Biological aging is characterized by a steady reduction of physiological reserve capacity after the age of 30 , resulting in an increasing susceptibility to chronic disease and probability of death (Kirkwood, 1994). It is considered to be primarily intrinsic in nature, due to restrictions laid down in the genome, to immunological or neuroendocrine changes, or to insufficient mechanisms of cell repair, but environmental insults such as lifestyle variables or exposure to toxic agents also affect the rate of bodily change (Hayflick, 1985; Yates, 1993). From an evolutionary standpoint, the fact that the investment in somatic maintenance in humans is less than required for indefinite survival car be explained by the relatively high death rate due to environmental causes and the priority given to rapid and prolific maintenance (Kirkwood, 1994). However, in spite of many prevailing "aspect theories", no comprehensive model of human aging is as yet available.

After briefly considering the single concepts of health, aging, and cognition, some pairwise interrelations between these concepts are now discussed - each covered by a distinct research area - before they are brought together in a final discussion.

\section{Aging and bealth}

As age increases there is a typical rise in the prevalence of diseases of virtually all organ systems (Figure 2.1). However, as stated earlier, a definition of health as the absence of clinically overt disease is limited in that it discards the subclinical change in organ systems with age.

Figure 2.1. Percentage of sibjects with at: lewast one active medical problem as recorded by the general practithorer in MAS panels $A 1$ to $A 3(N=1,373$; see chapter 9$)$

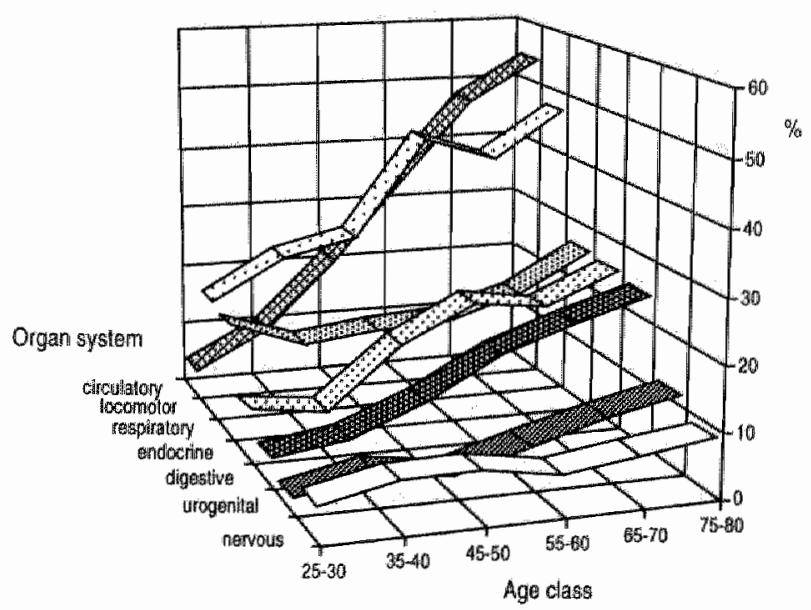


There is a considexable overlap between the concepts of biological aging and health when the latrer is understood as a continum instead of the dichotomy of disease $/$ no disease. For example, risk Gacrors or a genetic make-up that are associated with morbidicy in later life can be present in individuals who are dinically healthy. In many disease entities, such a predisposition is expressed as subelinical changes at a cellular or organ level. These degenerative changes may become chically apparent as chronic diseases that accompany old age. The general loss of functional reserve capacity in organ systems with age eventually has a serious impact on behwior and in the resilience to cope with the demands of everyday life. However, there is a remarkable diversity in individual aging patterns and in the age-related loss of funcrional capacicy. The interindividual variability in most bodily functions increases with age (Fozard, Merter, Brant, Pearson \& Baker, 1993). To account for the hererogeneity in individual aging trajectories, several authors have suggested a hierarchy in subtypes of aging (Jolles et al, 1996; Rowe \& Kahn, 1987; Stones, Kozma \& Hannah, 1990; Table 2.1).

Table 2.1. Four rypes of aging patterns.

\begin{tabular}{|c|c|}
\hline fypa & Furation of \\
\hline 1 Primary (or successful) aging & agemeincrinsic chamges \\
\hline 2. Usual aging & 1 + nonpathological deficiencies \\
\hline 3 Secondary (or pathological) aging & 2 + parhology-iclated functional decline \\
\hline 4 Terriaty aging & $3+$ effects of terminal illness \\
\hline
\end{tabular}

The successive aging subtypes are typical for the rare of functional decline in individuals at a certain point in time. Transition from one type to a subsequent type can take place during the life span. Thus, successful aging reflects the fortunate - but latgely hypothetical -- situation where only age-intrinsic factors contribute to a decline in physical (or mental) funcrion when other risk factors for disease-related processes are eliminated or controlled for. Identification of the determinants of suceessful aging is one of the major challenges of contemporary gerontology (Fozard, Metrer \& Brant, 1990) and ways to limit the functional decline and manifestation of chronic diseases to the shortest possible interwal before death is one of the challenges facing the medical sciences (Fries, 1990).

\section{Aging and ognition}

Parallel ro the decline in physical reserve capacity there is a general trend towards a reduction in several basic cognitive abilities (Botwinick, 1981; Poon, 1985). The individual reduction in cognitive test performance at any point in life is however subde when performance in young adulthood is taken as a reference, and proceeds only in some to a functional impaiment, mostly at advanced ages. However, tasks that involve some form of processing of unfamiliar information, the use of longterm memory, some forms of abstract reasoning, visuospatial abilities, or complex attentional processes show an age-related decline which can be already decected in early adulhood (LaRue, 1992, pp. 47-77). These aspects of cognitive function that are particularly sensitive to age reflect maturational growth and are often referred to as 
belonging to the domain of "fluid intelligence" (Horm \& Catrell, 1967). They are highly senitive to a decay of neuronal structures (the cognitive "hardware"). In contrast, crystallized abilities, consisting of the accumulated formal and informal experiences of life, which are mainly verbal in nature, remain relatively unaffected during the aging process (Borwinick, 1981; LaRue, 1992, pp. 47-77).

A general slowness of behavior is associated with age, especially when performance tasks are demanding or performance is measured under time constraints (Bromley, 1990, pp. 185-196). The most influential and comprehensive construct today that explains age-relared cognitive decline is the resource limitation model in which cognirive processes are defined in terms of the energetic demands placed on the central information processing capacity, or resources (Salthouse, 1985; 1988; 1992). Salthouse hypothesizes that slowing of the rate of information processing (or, to use a computer metaphor again, a decreased "cycle-time") may act as the causal determinant of a decline in all cognitive systems, with only relatively minor contributions of peripheral (sensory or motor) processes. "The model predicts that effortful, controlled processes require more resources than overlearned, automatic processes (see also Hasher \& Zacks, 1979). It is suggested that age is accompanied by a depletion of resources which constitutes the main reason why controlled processes are more strongly affected by age.

Several age-related changes in the central nervous system may underly this resource reduction, e.g. progressive loss of large neurons (that are in a post-mitotic phase from childhood onward), changes in dendritic branching and complexity, formation of degenerative plaques and tangles, deposition of amyloid, microvascular changes, and, on a funcrional level, depletion of neurotransmitter substances such as acetylcholine, dopamine, or catecholamines (LaRue, 1992, pp. 25-46; Selkoe, 1992). On a molecular level, processes which accompany old age, such as free-radical formation and oxidative stress, somatic mutation, increase in macromolecular errors, loss of unique genetic information, and molecular cross-linking, all may aggravate the decrease in brain integrity and funcrional loss (Calne, Eisen, McGeer \& Spencer, 1986).

\section{Health and cognition}

As the brain has no metabolical buffer capacity, it depends on the integrity of multiple organ systems for the supply of energy (glucose and oxygen) and nutrients (Tarter, Edwards \& van Thiel, 1988a). Effective brain function relies on a stable and intact internal environment. It can therefore be readily understood that factors related to physical health, which may disturb this delicate relation, have been associated with nonpathological decrements in cognitiwe function (Table 2.2). Some of these factors may also induce a dementia syndrome (LaRue, 1992, p. 53156). Evidence comes for the Jargest part from epidemiological and case-control studies and thas been reviewed extensively elsewhere (Birten \& Schaic, 1990; Colsher \& Wallace, 1991; LaRue, 1992; Nolan \& Blass, 1992; Tarter, van Thiel \& Edwards, 1988b, or more specifically in dedicated reviews referred to in Table 2.2). At least in theory, prevention or treatment of these conditions in individuals should limir (or even reverse) clinically significant cognitive decline when as yet no structural brain damage has developed (Nolan \& Blass, 1992). Large scale evaluation of physical health status in cognitive aging studies is laborious and expensive. 
Tabife 2.2. Health-related factors that have been associated with cogrivive dysturnctions.

Clowic disuses (Colsher we Wallace, 1991; Tarter et al. 1988b)

Hypertension (Starr \& Whallew, 1992; Waldstein, 1995)

Cardiovascular diseases (Elias et al.; 1900d; Herzog ex al., 1978; Skoog*1994)

Obstrucrive pulmonary disease (Incalzi et al., 1993)

Diabetes (U'ren, Riddle Lezalk Benningron-Davis, 1990; Widom \& Simonison, 1990)

Renal fulure (Moe \& Sprague; 1994)

Liver failure (Tanter et al. 1988ay)

Cancer (Berg, 1988)

Thyroid hypo- Hyperfunction: (Beckwith \& Tucker, 1988)

Endocrine disorders (Cushing's syndrome, Addison's disease, hypopituatarism)

Merdication wse

Anxiolytic/bypnoric drugs (Barbee, 1993)

Antidepressants (Knegrering, Eijck \& Hui isman, 1994)

Antipsychotic drugs (Bilder, Turkel, Lipschurz Broch \& Licberman, 1992)

Antilippertensives (Muldoon, Waldstein \& Jennings, 1995b)

Anticonvalsants (Dodrill, 1992)

Antiarthythmic druggs (Bowen \& Larson, 1993)

Biginalis and related compounds (Bowen \&c Larson, 1993)

Any drugs with articholinergic activity (e.g. scopolamine; Riedel \& Van Praag, 1995)

Chemotherapeuric agents (Bowern \& Larson, 1993)

Jntoxications (Hartman, 1988)

Alcohol (Molina et al., 1994)

Merals (c.g. Pb, Mn, A; Lewis, Worobey, Ramsay \& McCormack, 1992)

Organic solvents (Ganzevles \& Geus, 1991)

Pesticides (Mearns, Dunn \& Lees Haley, 1994)

\section{Dofuiencies}

Vitamins (e.g. B-series, E; Carney, 1990; Kleijnen \& Knipschild, 1991)

Micronutrients (e.g. zinc, cobalt; Sandstead, 1986)

\section{Other}

Physical inactivity (Chodzko-Zajko, 1991; Chodzko-Zajko \& Moore, 1994)

Anesefhesia / surgery (Dekhuijzer \& de Lange, 1993)

Head trauma (Morrimer et al., 1991: Satz 1993)

As an alternative, it has been suggested that subjective rating of physical health can be used as a proxy measure in the study of healdh and cognirve function as subjective health ratings are highly related to physicians health ratings (LaRue, Bank, Jarvik \& Hetland, 1979). Several atuthors indeed report significant - though modest - relations between subjective health scales and objective cognitive test performance in relatively healthy adult population samples (e.g. Hultsch. Hammer \& Small, 1993; Perlmutrer \& Nyquist, 1990) bur others failed to do so (Salthouse, Kausler, \& Sauls, 1990). It should be realized, however, that subjective health scales are rellarively unspecific and often reflect the impact of disease on the individual (McDowell \& Newell, 1987), or index satisfaction with life. Such scales may be systematically biased when they are used as general health measures, particularly in studies with a wide age range, as older subjects may rate their health differently than younger individuals (Hooker \& Siegler, 1992; Salthouse et al., 1990; Sígler, 1990). 


\section{Aging bealth, and cogritive function}

There is a remarkable increase in the variability of scores for measures of cognive performance within birth cohorts as a function of age, even though the partern that enterges from cross-sectional studies of cognitive aging suggerts that there is antinuou dectivin in performance. However, the rate of decline may differ between individuals of the same age cohort, or within individuals at different stages of the life span. To explain this, it has bean suggested that the continuous decline in cognicive abilities can be regarded as an artifact that results from pooling the cognitive aging trajectories of different individuals (Rabbitr, 1990). Longitudinal data support this view as they show less outspoken trends towards lower performance with age (Rabbir, 1993) and also demonstrate that in older individuals an abrupt decline in cognitive abilities can predict mortality (terminal drop", see Deeg. Hofman \& van. Zonneveld, 1990; Riegel \& Riegel, 1972). This sudden decrease in performance is particularly" prominent for abiliries that as a rule are only marginally affected in nomal aging, such as vocabulary and other verbal skills (White \& Cunningham, 1988).

Scatrered but ample evidence supports the role of physical health as a mediating factor in the cognitive decline with age (LaRue, 1992). For example, Launer et al. investigated the relation between age, selected health conditions, and borderline to poor cognitive functioning as measured on the Mini-Mental State Examinarion (MMSE; Folstein, Folstein Bx McHugh, 1975) in a large population-based study of 3,974 individuals, aged between 65 and 84 years (Launer, Drinkgreve, Jonker, Hooijer \& Lindeboom; 1.993), In this study, Parkinson"s disease, diabetes, and stroke, but not a history of heart attack, negatively affected the cognitive outcome, independent of age, education, and vision or hearing impaiments. The odds-ratio's for cognitive impairment associated with age and education were attenuated up to $6.5 \%$ by these health conditions. The relevance of health-characteristics of a subject for cognitive decline with age was demonstrated by Houx and coworkers in a cross-sectional study (Maastricht Memory Study (MMS), Houx \& Jolles, 1993; Houx \& Jolles, 1994; Houx, Jolles \& Vreeling, 1993a; Houx, Vreeling \& Jolles, $1991 \mathrm{a}$ Houx, Vreeling \& Jolles, $1991 \mathrm{~b}$; Houx, Vreeling \& Jolles, 1993b). A group of 247 apparenty healthy subjects was stratived for age, sex, and educational background: Biological Life Events (BLE) were defined as those factors experienced in time that are related to physical or mental health that may induce a temporary decline in performance, but which have no serious after-effects. Examples are surgery under general anesthesia, mild head injury, long-term (but not actual) use of psychotropic drugs, or a substantial intake of alcohol (Houx et al., 1991b). Subjects with one or more BLE in their history performed consistently worse than other subjects did on tasks of memory storage and retrieval, sensorimotor speed, and information processing capacity. The differences in performance between BLE and non-BLE groups increased with age, suggesting that the impact of BLE is more pronounced in older individuals.

However, as the study population could have represented an elice group of older subjects, and in order to evaluate the contriburion of specific BLE categories to the explained vatiance in performance, the Maastricht Aging Study (MAAS; see chapter 3 and Jolles et al., 1995) of the same research group ser out to replicate the earlier findings and to explore them in greater detail in a larger population. In short, this ongoing cross-sequintial study into determinants of 
cognitive aging recruited subjects from a computerized patient register of collabotating general practices (Mersemakers, Höppener, Knottnerus, Kocken \& Limonard, 1992). Four independent and virually idencical panel studies were performed with healthy subjects aged between 23 and 82 , stratified for age, sex, and level of general ability. Medical exclusion crituria were defined as those active of inactive medical problems documented by the general practitioner that could interfere with actual cognitive function, such as cerebrovascular disease and other chronic netrological or psychiatric disorders. Preliminary results from the first panel study with 469 subjects on a setection of tests that were used allso in the MMS, failled to corroborate the cartier findings with respect to BLE. Only minor effects of BLE on the immediate recall of words and on simple and incompatible movement time in a choice reaction time paradign were observed, wich no significant age by BLE interaction (Houx, van Boxtel \& Jolles, 1995). Cohort differences in terms of health status or educational background (resulting from a different inclusion procedure) could be partly responsible for this discrepancy: This underscores the necessity for longitudinal follow-up of these studies to enable definite condusions on the importance of BLE for cognitive aging.

\section{Brain reserve capacrity in normal and pathological cognitive aging}

The implicit assumption in research on BLE and cognitiwe aging is that the impact of these health-related factors differs between individuals and will depend on the individual's vullnerability to specific challenges, which in turn tends to increase with age. There are few longitudinal studies which address this issue. With respect to psychotropic drug use, there is some empirical evidence that long-term users of benzodiazepines perform worse on memory and speeded performance tasks than benzodiazepine-free anxious patients and normal controls, who were matched for age, sex and education (Gorenstein, Bernik, Pompéia \& Marcourakis, 1995). The between-group differences in this study were present at three weeks and ten months after cessation of benzodiazepine use and could not be explained by differences in anxiety or depressive synuptomatology. A typicall study that reported on longaterm effects of brain crauma compared World War II veterans 30 years after they had sustained a penetrating head injury with controls who suffered from peripheral nerve injury, matched for age, education, and (premorbid) intelligence level (Corkin, Rosen, Sullivan \& Clegg, 1989). The head injury group showed an accelerated decline on several cognitive tests (including arithmetic, vocabulary, and figure-ground discrimination) and this decline was greater in older patients. The authors suggested that the cumulative loss of 'redundancy in the CNS' may precipitate clinical coginitive defects.

The condusion of Corkin ex al. fully supports the concept of brain reserve capacity (BRC) - a hypothetical construct that was proposed to denote the amount of functional brain tissue (Mortimer, 1988) - which was recently redefined from a neuropsychological perspective as a theoretical model for cognitive defects after brain injury (Satz, 1993). However, BRC may also provide a helpful theorecical framework to understand the impact of other types of morbidity on cognition. It can be understood as the maximal cognitive energy that is available for central information processing, in which case a parallel can be drawn with the resource concept of Salthouse which also implies a central processing capacity (Salthouse, 1985). The 
model of Sarz presumes that protectiwe factors or wulnerability to negative factors can extend or reduce the BRC. Satz cites evidence from autopsy and brain imaging studies that factors such as brain size, cortical surface area, and metabolic and neuronal efticiency are potential neurobiological correlates of $B R C$. Age reduces $B R C$, because aging affects virtually all these factors, which has a direct consequence for central nervous system efficiency. Furthemore; indirect measures, such as psychometric intelligence or educational level, can be regarded as proxies of $B R C$, as individuals at the lower end of the distribution are more at risk for the development of cognirive defects (Huppert, 1991; for a review, see Stern, Alexander, Prohovnik \& Mayeux, 1991). Accumularion of brain-related morbidity can therefore result in a reduction in BRC chat will become clinically apparent as dementia when a critical value or threshold is reached (Mortimer, 1994; Figure 2.2).

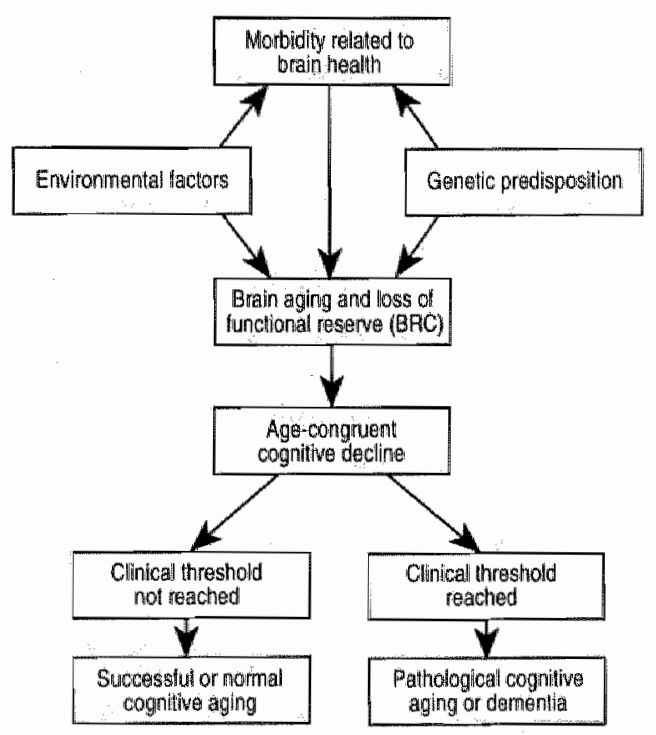

Figure 2.2. Hyporhesized clain of events in age-reated cognitive decline. with brain reserve capacity as the cone construct (adapted from Satz, 1993).

The dementia syndrome is characterized by a progressive impaiment of higher cortical functions, in particular memory, and eventually by loss of independence (McKhann et al., 1984). Alzheimer dementia (AD) causes over $70 \%$ of all dementia's, followed by dementia of a primary vascular origin and several other, more rate forms with a distinct clinical picture, like Pick's or Creutzfeldr-Jacob disease (Ott et al., 1995; Selkoe, 1992). AD afflicts 10\% of the population aged 80 years, after which the prevalence rises steeply to $27 \%$ in individuals of 85 years and older (Ott et al., 1995). There may be a genetic (autosomal dominant) predisposition, and a history of hyporhyroidism, brain trauma, depression, or a family history of parkinsonism or Down's syndrome all have been associated with an increased risk for AD (Breteler, Claus, van Duijn, Launer \& Hofman, 1992; Kokmen, 1991 ). 
Many neurobiological and cognituve-behavioral changes that are observed in nomal aging are also found in dementia (Huppere \& Brayne, 1994). In fact, dementia in an early stage is often difficult to distinguish from nomal cognitwe aging. This notion gawe way in the past 30 years to multiple diagnostic labels for this borderand' between normal and pathological cognitive aging; such as bengn or malignant senescen forgetfulness (Kral, 1962), age-associated memory impurtint (AAMI, Crook et al, 1986), aging-associated cognitive decline (AACD; Levy, $1994 \%$ or cogritwe impaiment no dementia (CIND; Writing Committee Lancer Conference, 1996). However, the fact that no single marker for $\mathrm{AD}$ has yet been identified and because the population distriburions of variables associated with this disease (e.g. neuritic plaques and neurofibrillary tangle formation) are essentially continuous made some researchers suggest that $\mathrm{AD}$ is the end stage of normal brain aging: any person who lives long enough will eventually devalop dementia ("continuity hypothesis", Brayne \& Calloway, 1988; Huppert \& Brayne, 1994). It has been known for some cime that degeneration of functionally related systems in the CNS may be selective and at different rates with increasing age, a process referred to as abiotrophy (Gowers, 1902). It has been hypothesized that in AD neuronal atrition in the medial basal forebrain remains subclinical for decades as the result of an impressive brain plasticity, on the analogy of the selecrive and progressive decay of dopaminergic neurons in the substantia nigra leading to Parkinson's disease (Calne et al., 1986). Thus, only when compensatory mechanisms fail - like neuronal sprouting or increase of transmitter substances in presynaptic neuron - and a critical threshold is reached, the functional decline becomes symptomaric (Satz, 1993). Extrapolation from prevalence figures of dementia would suggest in support of the continuity hypothesis that virtually everyone is afflicted by dementia if one lives to be a hundred (Huppert \& Brayne, 1994).

\section{Conclusions}

The existence of age-sensitivity in BRC is analogous to the generally observed reduction in functional reserve capacity of other organ systems with age, like the heart (cardiac ourput) or Whe kidneys (glomerular filtration rate; Yates, 1993). The comprehensive model of BRC is atractive because it provides the conceptual link between normal and parhological cognitive aging, as many observarions from neurobiological, clinical and behavioral studies on the aging of the brain fit elegantly within this framework $(5 \mathrm{atz}, 1293)$. Research effort can be defined in terms of factors that may augment or reduce BRC in order to to predict at what point in time an individual's chreshold for pathologic cognitive function is reached. It was demonstrated that factors which are related to brain health (like BLE, or specific types of physical morbidity) potentially have a mediating role in cognitive decline with age. It remains unclear however to what extent a reduction of intellectual veserve is mediated directly by clinically observable morbidity, or if to some extent age-related disease and age-related cognitive decline are both linked to the same causative factor. The progressive change in structure and function of the systemic vascularure during adulthood paves the way for many chronic vascular diseases and may also have implications for cerebral functioning (Mortimer; 1994). In the next section the evidence is explored for a relationship between risk factors for wascular disease and impaiment of intellectual funcrion, in normal and pathological cognitive aging. 


\section{II - VASCULAR RISK FACTORS AND COGNITIVE AGING}

Whereas the evidence for the continuity hypothesis in $\mathrm{AD}$ is as yet incondusive, a stronger case can be made in this respect for dementia of vascular origin (Skoog, 1994; 1996), "The cerebral vascular system changes slowly but progressively with age, and these changes, such as atherosclerosis of large and small vessels, hyperplasia of vascular smooth muscle, multiple microinfactions, and altered cerebral blood flow, may lead to brain ischemia (Figure 2.3).

\begin{tabular}{|c|c|c|}
\hline $\begin{array}{l}\text { Vascular risk factors: } \\
\text { - Hypertension } \\
\text { - obesity } \\
\text { " physical inactivity } \\
\text { - other }\end{array}$ & $\begin{array}{l}\text { Pathologleal changes in cerebral } \\
\text { physiology \& morphology: } \\
\text { - atherosclerosis } \\
\text { - decreased perfusion } \\
\text { - metabolic disturbances } \\
\text { - white matter lesions (infarction) }\end{array}$ & $\begin{array}{l}\text { Cognitive decline } \\
\text { \& } \\
\text { (primary vascular') } \\
\text { dementia }\end{array}$ \\
\hline
\end{tabular}

Figure 2.3. Proposed mechanism of cognitive decline as a function of exposure to vaseular risk facrors. (Adapted from Starr \& Whalley, 1992; Swan, Carmelli \& LaRue, 1996).

Regional cerebral blood flow studies ( $\mathrm{rCBF}$ ) and brain imaging studies using positron emission tomography (PET) demonstrate only small reductions in cerebral blood flow or

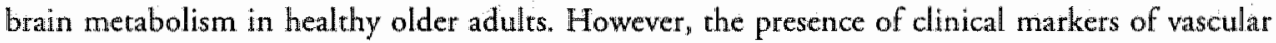
disease (e.g. hypertension, diabetes, or heart disease) has been associated in older adults with larger reductions in rCBF over a 3.5-year period (Meyer \& Shaw, 1984). Vascular risk factors were found to be correlated with white matter abnormalities on magnetic resonance imaging (MRI; Breteler et al., 1994a), and white matter abnormalities were shown to be accompanied by a reduced speed of mental processing (Junqué et al, 1990; Schmidt er al, 1993). Comparable observations were made with electrophysiological methods that measure brain activity, such as electroencephalography (EEG) or event-related potentials (P300): age-related changes in healthy individuals are minor, but appear to be augmented by vascular risk factors or vascular disease and are reflected by slowing of the dominant alpha rhythm in EEG or increased P300 latency, which may be indicative of a reduced efficiency in neuromal processing (LaRue, 1992).

Given the strong assiociation between cerebrovascular disease and neurobehavioral deficits (Bornstein 8 Kelly, 1991), it seems a logical step to study in. greater depth the relevance of risk factors associated with vascular disease for age-related cognitive decline (Nolan 80 Blass, 1992). The relevance of indicators of vascular disease as predictors of cognitive dysfunction was illustrated recently by Breteler et al. (Breteler, Claus, Grobbee \& Hofman, 1994b). They found in a large population study involving 4,971 subjects of 55 years and older negative associations berween signs of peripheral artery disease (ankle/brachial blood presisure ratio and presence of atherosclerotic plaques in the internal carotid arteries) and an index of global cognitive function (Mini-Mental State Examination, or MMSE; Folstein, Folstein \& McHugh, 
1975). Clinically established primary risk factors such as hypercholesterolemia, hypertension, diaberes mellitus and cigaretre smoking, alone or in combination, are related to vascular degeneration and thereby possibly also un producing mental dysfunctions (Table 2.3; Clowes, 1989; Gorlick, 1995; Skoog, 1994). The evidence for a role of each of these factors in cogninive decline will now be briefly rewiewed. Although it may be argued that clinical signs of cardiovasculan or cerebrovascular disease are risk factors in their own right (Gorelick, 1995), they also represent the outcome of pathological changes due to acrual ethological factors. They can therefore at best be regarded as 'secondary' risk factors in that the chance of worsening of vascular disease is increased when the first dinical signs are ewident. Therefore, the following discussion is restricted only to 'primary' risk factors.

Table 23. Risk factors for vascular disease: dererminants of cognicive impairment?

\begin{tabular}{ll} 
Genctic factors & Obesity \\
Thrombogenic factors & Physical inacrivicy \\
Hypertension & History of smoking \\
Diaberes mellius & Alcohol consumption \\
Hyperlipidemina & \\
\hline
\end{tabular}

Genetic factors - Late-onser AD has recently been associated with presence of the apolipoprotein-E4 (apo-E4) allele on chromosome 19 (Poirier et al., 1993; Saunders et al., 1993). Apo-E4 plays a role in the redistribution of lipids after deafferentation and neurodegeneration in the brain and is related to plaque and tangle formation and amyloid deposition in cerebral blood vessels. In 25 percent of the population one or both alleles on chromosome 19 are of the E4 subrype. The mean age of onset of $\mathrm{AD}$ decreases from 84 to 68 in direct proportion to the number of apo-E4 alleles (none, one, or two; Corder et all, 1993 ). Virtually all apo-E4 homozygotes in familial cases will develop AD by age 80 (Saunders er al., 1993). In a rocent study with ellderly men aged 70-89, the prevalence of cognitive impairment (MMSE score $\leq 25$ ) was higher in apo-E4 carriers and the decline in MMSE score over a three year period was proportional to the number of apo-E4 alleles present (Feskens et al. 1994).

Variations of the apo-E genorype are linked to hyperlipidemia (Walden \& Hegele, 1994) and to stroke (Coudere et al., 1993). Other genetic facrors may be involved in the potentiation of specific wascular risk factor levels (e.g. hypertension, diabetes, fat merabolism, and thrombogenic factors).

Thrombogenic factors - The role of specific thrombogenic factors (in particular fibrinogen, De la Serna, 1994) in the etiology of cardiowascular disease is well established. Adequate anticoagulant therapy is effective in ischemic heart disease but also in the secondary prevention of cerebrovascular disorders such as transient ischemic attack (TLA) or stroke (Gorelick, 1995). In the Rotterdam study involving a group of 111 subjects (age $65-84$ years) evidence was found for a relation between thrombogenic factors (VIIC, VIIIc, and fibrinogen) and white matrer lesions on MRI on the one hand, and between white matter lesions and composite cognitive test score (CAMCOG) on the other, after control for age and education (Breteler et al., 1994a). 
Hypertenion - Hypertension is the most importan risk factor for brain hemorhage or infarction (population-attribuable risk of 49 percent, Gorelick, 1995) and vascular dementia (Skoog, 1994), the respective risks being directly proportional to the mean blood pressure. Evidence suggests that subjects with essential hypertension have reduced cerebral blood tow (Rodriguez et al, 1987) and show more white matter lesions on MRI (Breteler et al., 1994a; Kawamoto et al., 1991; Van Swieren et al, 1991). In one study these lesions were accompanied by reduced performance on the MMSE and on several complex cognitive tasks compared to that of age- and sex-matched hypertensive controls with no lesions, and compared to normotensive subjects (Van Swieten et al., 1991). These findings were corroborated in a more recent study with 150 healthy elderly subjects with and without white matter hyperintensicies on MRI (Schmidt et al, 1993). The same authors have demonstrated in a case-control sudidy with hypertensives that the lower level of attentional and visuopractical skills in hypertensives was associated with more white matter hyperintensities and ventricular enlargement on MRI (Schmidt at al., 1995).

The general trend in a large corpus of case-control studies indicates that hypertension is associated with lower scores on tests of attention, mental flexibility, learning and memory, and abstract reasoning while scores on rests of other cognitive domains remain relatively unaffected (Waldstein, 1995). Results from the Framingham Heart Study have shown that in particular chronic exposure to elevated blood pressure predisposes stroke-free subjects to neuropsychological deficits (Elias, Wolf, D'Agostino, Cobb 8x White, 1993; Elias, D'Agostino, Elias 8x Wolf, 1995; Farmer et al., 1990). On a group level, the effects of hypertension seem subtle and deficits are never in the clinical range indicaring brain injury. However, one cross-sectional study with 301 subjects aged 20 to 72 years produced some evidence that blood pressure in the normal to borderline range may even be predictive for a performance reduction that would otherwise be ascribed to primary aging (Elias, Robbins, Schultz \& Pierce, 1990b).

It is noteworthy that performance on neuropsychological rests that are sensitive to the effecrs of hypertension for a large part relies on brain areas that are most afflicted by hypoperfusion and hypometabolism in hypertensive subjects (Waldstein, Manuck, Ryan \& Muldoon, 1991). In fact, these deficits are commonly atributed to changes in brain perfusion and metrbolism that are secondary to arteriosclerotic changes in the large and small cerebral blood vessels, or to mulriple microinfarctions caused by microemboli that are released from more distal arteriosclerotic sources (e.g. the atrial wall or carotid arteries; Starr \& Whalley, 1992). Individual differences in physiological reactions to stress have often been implicated in atherosclerotic diseases. Interestingly, it has recenty been suggested that short-term hypertensive episodes caused by psychological stress may produce a transient increase in blood levels of factors that are associated with atherogenesis and thrombosis. Healthy young subjects who were exposed to a stressful and complex task (Stroop Color-Word test) showed increases in blood lipids, hemostatic factors, and blood viscosity, due to hemoconcentration (Muldoon et al., 1992; Muldoon et al., 1995a). However, other mechanisms may be inwolved in the etiology of hypertension related cognitive decline. For example, subjects with a parental history of hypertension, but no actual hypertension, have been shown to perform worse on memory search tasks than control subjects with no such history (Pierce \& Elias, 1993). Some 


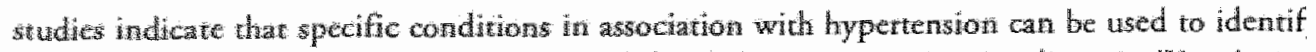

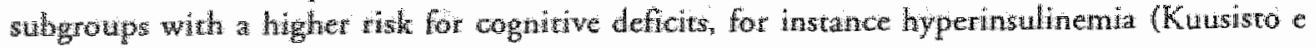
1., 1993) or plama revin activity (Light 1975 ).

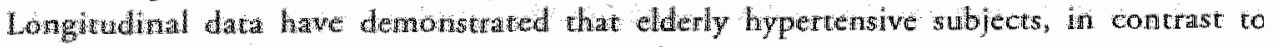

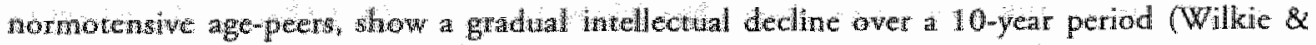

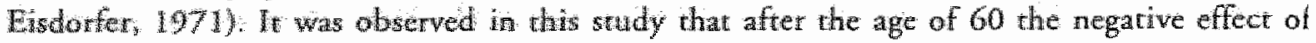
Wigh blood peressure on cognitwe function wacreased. In young adul and middle-aged subjects We pertomance scores terided to be lower in young hypertensive subjects than in normotensive contw subjews, but the diferences berwen these caregories were less striking in the midle-aged subiects (Elas et al. 1995). Taken together, these data suggest a U-shaped distribution of the cortelation between hypertension and test performance across the life-span, but further evidence is needed to substantiate this (Waldstein, 1995).

In summaty. chronically elevared blood pressure can promore structural brain damage which can wimarely be picked up by neuropsychological testing, but further pathophysiological and clinteal evidence needed to determine age- or tisk factor-related high risk subgroups. The avalabiling of rechiques to measure blood pressure repeatedly under daily living conditions may enhance our knowledge of which aspects of blood pressure dynamics are relevant for cognition (1ckerng, 1993). Indeed, studies with ambulant blood pressure monitoring have suggested that the classical casual measurement in the doctors office do not always yield blood pressure whises which are measured under daily living conditions (Pickering, 1993). For this discuszion may therefore be important first to address the methodological issue of how blood pressure mensutement should be standardized in population-based studies to yield rellable estimates of habitual blood presure (see chapter 6).

Dimbetes - Diabetes mellitus is characterized by an inadequate control of blood glucose level, as the result of insufficient production of insulin, or a relative insensitivity of body tissues to insulin. The resulting hyperglycemia causes structural damage to organs, including the brain, as the result of to metabolic disturbances, arteriosclerosis, and neovascularization. Diabetic patients have an increased risk for (ischemic) stroke that can be explained in part by the increased prevalence of cardiovascular disease in these individuals. Cerebral disorders associated with diabetes have been demomstrared at a neurachemical, electrophysiological, structural, and cognitive level (Biessels, Kappelle, Bravenboer, Erkelens \& Gispen, 1994). Alterations in cerebral blood supply and metabolic changes may play a role, but the exact pathophysiology is as yet uncertain. Recurrent episodes of hypoglycemia and poor metabolic control may produce transient decreases in mental efficiency (Draelos et al. 1995) bur are also related to permanent performanee decrements, in particular when there is evidence of polyneuropathy (Ryan, Williams, Finegold \& Orchard, 1993; Sachon et al., 1992). Diabetic subjects generally perform worse on tasks of learning and memory, psychomotor speed and problem solving than healthy control subjects, but the affected cognitive domains and the extent of performance deficit vary widely across studies. A strong association has been found between age of onset and general intelligence (Biessels et al, 1994) but elderly late-onset diabetic patients have repeatedly performed worse chan control subjects on verbal and complex cognivive asks (Reaven, Thompson. Nahum \& Haskins, 1990; U'ren et al., 1990; Womall, Moulton \& Briffetr, 1993). However, these deficiencies are usually mild. The evidence to date 
suggests that therapeutic interventions amed at blood glucose regulation within narrow limits will prevent most, but not all diaberic damage to the central nervous system (Btessels et all, $1994)$.

Hyperlipidernia - Cholesterol is a major constituent of cell membranes, hormones, bile sallts, and vicamins and is largely of endogenous origin. More dhan $70 \%$ is distributed in low density lipoproteins (LDL), and in this form cholesterol has been associated with ischemic heart disease. Smaller fractions are transported from peripheral tissues back to the liver as high-density lipoprotein (HDL): a low HDL-cholesterol level (in particular the HDL, subfraction) is also an independent risk factor for cardiovascular disease. Interestingly, as mentioned above, apo-E lipoprotein may differentially affect the tocal cholesterol level in the blood and thereby the vascular risk profile; apo-E2 lowers chollesrerol while apo-f 4 has the opposite effect (Walden \& Hegele, 1994). There is some evidence that ellewated cholstierol levels and low apo-E are more prevalent in older subjects with cerebrovascular discase (Couderc et al., 1993). A lower HDL-cholesterol lewel, in association with hypertension, was found in a group of older subjects with evidence of (neurologically asymptomatic) multiple lacunar infarctions on MRI (Kawamoto et al, 1991). These results were not replicated in the earlier mentioned Rotterdam study (Breteler et al., 1994a), although in this study total cholesterol was related to white matter lesions in the younger half of the study group (65-74 years).

Several studies have directly addressed the relation between blood lipids and cognitive funcrion. Dementia has been described in relation to hyperlipidemia; the symptoms of dementia improved after pharmacological reduction of the blood lipid level (Heilman \& Fisher, 1974). In an early study with 156 healthy men who were treated with cholesterol lowering agents for 12 months, subjects of 40 years and older who responded to treatment showed an improved performance on a battery of netrocognirive tests, while older nonresponders and younger subjects showed no effect (Reitan \& Shipley, 1963). Reversal of a glabal cognitive deficit in elderly patients with cerebrowascular disease and hypertriglyceridemia was possible with an antilipemic agent (gemfibrozil; Rogers, Meyer, Shaw \& al., 1985). These changes were associated with an improwement in grey matter perfusion. Better performance on mental status testing was related to higher HDL-chollesterol levels in a gertarric population (mean age 87 years; Postiglione et al., 1989). In a study of 249 healthy elderly subjects (mean age 70.8 years), hypercholesterolemia increased the chance of a subject being in the group with poor memory performance by a factor of three, while performance on tasks for other domains (verbal functions, visuospatial abilities, atrention) remained unaffected (Desmond, Tatemichi, Paik \& Stern, 1993). However, conflicting evidence came from two other studies. An aging twin study (44 pairs, mean age 57 years) where disconcordance in performance changes on a complex rask over a 5 year period (decline / no decline in digit-symbol substitution) was related to total cholesterol level: in decliners lower cholesterol levels were found than in the paired non-decliners (Swan, LaRue, Carmelli, Reed \& Fabsicz, 1992). In a recent study of 89 nuns, aged 77-99 years, associations between a low rotal cholesterol level and mild cognitive imparment were found and a substanciall dectine of cognirive test performance over a 1-2 year period in participants wich toral chollesterol levels below the median at baseline measurement (Snowdon, Belcher, Tully \& Greiner, 1996). The 
results of the last two studies therefore make a straightorward role of blood lipids in cognitive decline less likely.

Obesity - Overweight is generally associated with an unhealthy life style and an unfavorable vascular risk profile. Obesie individuals are less physically active, have lawer HDL-cholesterol and higher toral cholesterol levels, and are more often afflicted by diabetes or hypertension (Berns, 1995). A concentration of bodily fat in the abdominal region (measured in the waisto-thip ratio) has proven to be an independent risk factor of cardiovascular disease (Despres et al., 1990). In the above-mentioned Rotterdam study obesity was unrelated to white matter lesions in 111 subjects between 65 and 74 years of age (Breteler et al., 1994a). Srudies on body composition in relation to cognirive function are scarce and inconclusive (see also Nolan \& Blass, 1992). In a prospective study in 2,584 largely hypertensive individuals aged 65-74 years no association was found between body mass index and decline in performance on a cognitive test (Paired Associate Learning) within a 54 month period (Prince, Lewis, Bird, Bhard \& Mann, 1996).

Physical inatutity - Physical activity during work or leisure time can promote physiological firness and thereby increase general health (Bouchard, Shepard, Stephens, Sutton \& McPherson, 1990). In contrast to body weight, physical activity attenuates the vascular risk profile by reducing obesiry and insulin-insensitivity (in late-onset diabetes) and by improving the Jipoprotein profile (LDL reduction and HDL increase), thereby slowing the process of atherosclerosis (Wood \& Stefanick, 1990). Other factors related to activicy may further improve the vascular risk profile. For example, physical activity is often linked to healthy life styles like a whole-food diet, non-smoking, and alcohol abstinence. Subjects with essential hypertension can lower their blood pressure up to 10\% with endurance training (Hagberg, 1990). Regular aerobic training protects against cardiovascular diseases but no direct protective link has been demonstrated with cerebrovascular pathology. However, in a 4-year prospective cohort study of retired elderly subjects in the age of 62-70 years, the inactive group showed a gradual decline in regional cerebral blood flow and overall cognitive performance, while tetirees who engaged in regular sporting activiries maintaned both cerebral perfusion and cognitive performance measures at approximately their baseline level (Rogers, Meyer \& Mortel, 1990). It has been suggested that neuromuscular acrivity may alter cerebral circulation (oxygen bypothesis) or may directly enhance the efficiency of higher brain centers (newrotrophic stimtation bypothesis, Spirduso, 1980, Stones \& Kozma, 1988). Ample support for either view can be found in the literature (for a review, Chodzko-Zajko \& Moore, 1994).

Studies that compared fit and unfit elderly subjects generally report between-group differences in complex and attention demanding task paradigna but findings are less consistent on more simple, automatic rasks (Chodzko-Zajko, Schuler, Solomon, Heinl \& Ellis, 1992). However, results of these studies can be confounded by differences in background characteristics
berween fit and unfit individuals, such as health habits (Spirduso, 1980) and psychological
variables (anxicty or depression. Brown variables (anxicty or depression, Brown, 1990). Short-term exercise (up to four months) does not seem to improve cognitive processes, although the few studies on exercise and cognition are 1992, for a discussion. Lom stistical power (see Buchner, Beresford, Larson, LaCroix \& Wagner, 1992, for a discussion). Long-term randomized intervention studies have demonstrated 
increased differences in simple and choice reacrion time berween groups of sedentary and aerobic trained women of 57-85 years over a 3-year period in favor of the active group (Rikli \& Edwards, 1991) and improvement on several simple and complex tasks after a 4 -month aerobic training program in previously sedentary older subjects aged 55-70 years (Dustman er al., 1984); while others reported no effect of acrobic intervention (Blumenthal et al., 1991; Hill, 1989; Madden, Blumenthal, Allen \& Emery, 1989). In summary, there may be some protectiwe effect of physical activity on age-relared cognirive processes if the exercise is strenuous enough to improve and maintain aerobic finess at a high level for a prolonged period of time. This effect is probably mediated through several different parhways.

Smoking - A rypical reason given by smokers to explain their habit is that smoking improves concentration and mental efficiency. This clam is indeed party confirmed in empirical research. Acute administration of nicorine has been shown to have a small but significant effect on attention, memory, and sensorimotor function, or reverse experimentally induced cognitive decrements (with the anticholinergic compound scopolamine), while cessacion of smoking may induce cognitive withdrawal effects (Sherwood, 1993). However, smoking produces carbon monoxide which has a high affinity for hemoglobin - the oxygen transporting protein in red blood cells. The resulting stable carboxyhemoglobin complex causes a prolonged state of mild hypoxemia in regular smokers which, at least theoretically, could impair performance. Chronic smoking produces a reduction in regional cerebral blood flow (Rogers, Meyer, Shaw \& al., 1983), which could bring about intellectual changes in elderly subjects.

Interestingly, the mild agonist effect of nicotine on the cholinergic system has beet suggested as an explanation for the protective effect of smoking on the development of $A D$ (which is characterized by a central acetylcholine deficiency), by increasing the number of nicotinic receptors (Van Duijn \& Hofman, 1991). However, the epidemiologic evidence for a protective effect of smoking in $\mathrm{AD}$ has not been confirmed in other studies (Fratiglioni, 1993) and may have been the result of confounding variables such as occupational background (Letenneur et al., 1994), or of selection bias when patients with mixed AD or vascular dementia were excluded (Mortimer, 1988).

The vasicular risk profile is negatively affected by smoking in that smoking promores hypertension and a reduction in blooc levels of the protective HDL-colesterol (Reitsma, 1995). Stroke risk increases with the number of cigarettes smoked daily (Gorelick, 1995), and there may be a role of smoking in the etiology of vascular dementia (Skoog, 1994). In a snall prospective study of elderly patients with vascular dementia, cessarion of smoking was related to improved cognitive scores after 3 to 48 months (Meyer, Judd, Tawakina, Rogers \& Mortel, 1986). Normal aging studies have not yielded consistent evidence in favor of or against a mediating effect of smoking on cognitive funcrion. Older smokers performed worse than non-smokers on speeded performance tasks, but not on a wide range of other measures (Hill., 1989). Current smoking habits were unrelated to changes in cognitive performance scores in a group of 1,201 individuals (aged 65 and older) over a 3-year period (Hebert et al, 1993), suggesting that smoking behavior does not accelerate normal cognitive aging. 
Alcohol consumption - Epidemiological evidence reveals that $4.7 \%$ of all strokes are primarily the result of heavy drinking (Gorelick, 1995). No dear relation has been found between chronic alcohol intake and vascular dementia (Skoog, 1994) or AD (Graves er al., 1991). Alcohol exerts a direct toxic effect on the brain and other vital organs, leading to irreversible rissue damage, and may negatively affece cerebral blood flow. (Rogers et al., 1985). In chronic alcohol abuse, the blood urea nitrogen may rise as the result of liver damage to a level that interferes with adequate brain function (Tarter, Arria \& Van Thiel, 1991). In addition, chronic users may have a lower incake of vital nutrients such as B-vitamins (e.g. thiamine). This may result in specific neurocognitive disorders such as dementia or Wernicke-Korsakow encephalopathy, which is characterized by profound memory dysfuncrions which is primarily caused by hippocampal damage (Butterworth, 1995).

The hippocampus seems particularly vulnerable to neurotoxic insults caused by alcohol or hypoxia (Stoltenburg-Didinger, 1994). Clinical studies report that 50-70\% of chronic alcohol users show mild to moderate cognitive impairment, in particular in visuo-sparial abilities, abstract reasoning, learning, and memory (Molina et al., 1994). Results from normal population studies are mote equivocal. In a 3-year longitudinal study of 1,201 subjects aged 65 and older, low-to-moderate alcohol intake did not predict change in memory function (Hebert et al., 1993). Mild to heavy alcohol intake was unrelated to different aspects of cognitive function in 249 stroke-free subjects (Desmond et al, 1993). However, in the Framingham study moderate alcohol intake was weakly associated with better overall performance in a stroke-free cohort of 1,702 subjects aged between 55-88 years (Elias et al, 1993). The long-term effects of chronic alcohol use on cognitive function seem therefore not to be large on a population level, but may be difficult to detect due to a curve-linear relation between intake and performance.

\section{Conclusions}

A combination of vascular risk factors will enhance the risk of morbidity more than would be expected on the basis of individual risk factors alone. Moreover, the prevalence of any combination of such risk factors rises matkedly with age (and lower educational level), thereby putting elderly individuals in a particularly vulnerable position (Reitsma, 1995).

It has been shown that a broad, range of health-related factors has been linked to a reduction in cognitive abilities. As a result, it has been recognized that cognitive aging studies should include adequate descriptions of the health status of the participants (Christensen, Moye, Armson \& Kern, 1992: Houx et al, 1991b). However, rigorous health screening aimed at the identification of physical disturbances that could possibly be related to brain function will restrict the study population to the successfull aging category and will inevitably result in quite unrepresentative older age groups. To gain insight into the predictors of normal aging, it is therefore necessary to include a representative cross-section of different birth cohorts that is described in rems of prevalent morbidity, but that is also screened for potentially relevant precursors of disease. Owing to the complexity of risk factor interactions, the most attractive way to elucidare vascular mechanisms in age-relared cognitive decline would be to study prospectively as many different independent vascular risk factors as possible in large population samples, in combination with thorough medical and cognirive screening. It can be 
readily conceived that such an approach reguires a great amount of human and financial resources and raises many ethical issues. Howewer, the evidence for a role of vascular risk factors in age-related cognitive dysfunctions is suggestive enough to justify further research on how these factors can differentiate (in the long run) berween successful, nomal, and pathological cognitive aging.

\section{REFERENCES}

Barbee, J. G. (1993). Memory, benzodiazepines, and anxiety: Integration of theoretical and clinicall perspectives. Jourmal of Clinical Psychiarry, 54(Suppl). 86-97.

Beckwith, B. E, \& Tucker, D. M. (1988), Thyroud disorders. In R. E. Tarter, D. H. van Thiel, \& K. L. Edwards (Eds.), Medical Neuropsychology: The Impart of Disease on Behativar (pp. 197-218). New York: Plenum Press.

Berg, R. A. (1988). Cancer. In R. E. Tarrer, D. H. van Thiel; \& K. L. Edwards (Eds.), Medical Nerwopychology: The Impact of Diseatse on Behavior, (pp. 265-290). New York: Plenum Press.

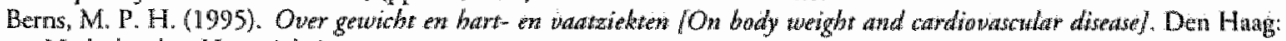
Nederlandse Hartstichting.

Biessels, G. J., Kappelle, A. C., Bravenboer, B., Erkellens, D. W., \& Gispen, W. H. (1994). Cerebral funcrion in diaberes mellitus. Diabetologia, 37, 643-650.

Bilder, R. M., Turkel, E, Lipschutz Broch, L., \& Lieberman, J. A. (1992). Antipsychotic medication effects on neuropsychological functions. Psychophismatology Bulletin. 28, 353-366.

Birren. J. E., \& Birren, J. A. (1990). The concepts, models and history of the psyclaology of aging. In J. E. Birren \& K. W. Schaie (Eds), Handbook of the pychology of aging, (3 ed., pp. 3-20). San Diego: Academic Press.

Birren, J. E., \& Schaie, K. W. E. (1990). Handbook of she prychology of aging (3 ed.). San Diego: Academic Press.

Blumenthal, J. A., Emery, C. F., Madden, D. J., Schniebolk, S., Walsh-Riddle, M., George, L. K., McKee, D. C., Higginbotham, M. B., Cobb, F. R., \& Coleman, R. E. (1991). Long-term effects of exercise on psychological functioning in older men and women. Jowrial of Gerontology, 46, P352-361.

Bornstein, R. A., \& Kelly, M. P. (1991). Risk factors for stroke and neuropsychological performance. In R. A. Bornstein \& G. G. Brown (Eds.), Neturobebavioural axpects of cerelinavascular disedse, (pp. 182-201). New York: Oxford University Press.

Botwinick, J. (1981). Neuropsychology of aging. In S. B. Filskov (Ed.), Handbook of Clinical Neuropsyabology, New York: John Wiley \& Sans.

Bouchard, C. Sthepard, R. J., Stephens, T., Sutton, J. R., \& McPherson, B. D. (1990). Exercise, fittness and health: The consensus statement. In C. Bouchard, R. J. Shepard, T. Srephens, J. R. Sutton, \& B. D. McPherson (Eds.), Exercise, fitness and health: A consensus of cwrrent knowledge, (pp. 3u28). Champaign, Ill: Human Kinetics Books.

Bowen, J. D. Le Larson, E. B. (1993). Drug-induced cognitive impairments Defining the problem and fithding solutions. Dougs and Aging, 3, 349-357.

Brayne, C., \& Calloway, P. (1988). Nomal ageing, impaired cognitive function, and senile dementia of the Alzheimer's type: A continum? Lancet, 1(8597), 1265-1267.

Breteler, M. B. B., wan Swieten, J. C., Bors, M. L., Grobbee, D. E, Chaus, J. J., vain den Hout, I. H. W, van Harstamp, F., Tanghe, H. L. I., de Jong, P. T. V. M., van Gijn, J., \& Hofman, A. (1994a). Cerebral white matter lesions, vascular risk facrors, and cognitive function in a population-based study: The Rotterdam Study. Netrotogy, fA, $1246-1252$.

Breteler, M. M. B., Claus, J. J., Grobbee, D. E., \& Hofman, A. (1994b). Cardiovascular disease and distribution of cognitive function in elderly people: The Rotterdam study. British Medical Journal, 308, 1604-1608.

Breceler, M. M. B., Claus, J. J., van Duinn, C. M., Launer, L. J., \& Hofman, A. (1992). Epidemiology of Alaheimer's diseasc. Epidemiologic Revieuss, 14,59-82.

Bromley, D. B. (1990). Behavioural Gerantology: Central issues in the psychology of ageing. Chicthester (UK): John Wiley.

Brown, D. R. (1990), Exereise, fitness, and mental health. In C. Bouchard, R. J. Shepard, T. Scephens, J. R. Sutron, \& B. D. McPherson (Eds), Exercise, fitmess and health. A consenstes of currens knowledge, (pp. 607-626). Champaign, Ill.: Human Kinetics Books.

Buchner, D. M., Beresford, S. A. A., Larson, E. B., LaCroix, A. Z., \& Wagner, E. H. (1992). Effects of physical activity on healch starus in older adults. II: Intervention studies. Annual Review of Public Heatths 13,469w188.

Butterworth, R. F. (1995). Pathophysiology of alcoholic brain damage: synergistic effects of ethanol, thiamine deficiency and alcoholic liver disease. Metabolic Bratin Diserases, 10, $1<8$. 
Cahe, D. B., Eiscr, A., MaGeer; E, G Spencer, P. (1986). Alzheimer's disease, Parkinison's disease, and

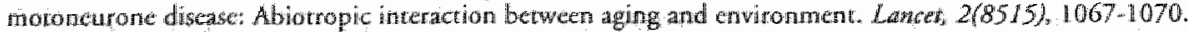

Carney, M. W. (1990). Vitatrin deficiency and mental symproms. British Journal of Psychiarry, 156, 878-882.

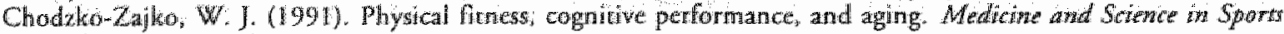
And Exercise, 23,868-872.

Chodzo-Zajko, W. $\mathrm{I}$, Moore, K. A. (1994). Physical futness and cognitue functioning in aging. In ). 0 . Hollosty (Ed), Exercise and sport sciences reviews, (Vol 22, pp. 195-220). Batimore: Willians \& Writkins.

Chodzko-Zajko, W. J, Schuler, P., Solomon, J. Heinl, B., \& Ellis, N. R. (1992). The influence of physicall

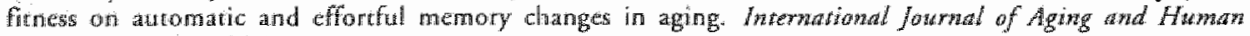
Developement, $35,265 \mathrm{-B5}$.

Christenset, K. J. Moye, J, Armson, R. R., \& Kern, T. M. (1992). Health sereening and random fecruitment for cognitive aging research. Psychology and Aging, 7,204-208.

Clowes, A. W. (1989). Theories of arherosderosis. In R. A. White (Ed.), Atherosclerosis and arkeriosderssis. Huspam pathology and experingentat animal methods and models, (pp. 4-15). Boca Raton. Fla.: CRC Press.

Colsher, P. L., Wallace, R. B. (1991). Epidemiologic considerations in studies of cagnitive function in the

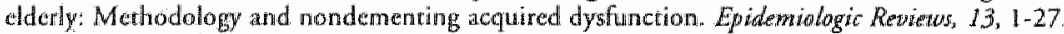

Corder, E. H., Saunders, A. M., Scritrmacher, W. J., Schmechel, D. E, Gaskell, P. C., Small, G. W., Roses, A. D., Haines. J. L., \& Pericak-Wance, M. A. (1993). Gene dose of apolipoprotein E rype 4 allele and the risk of Alaheimer discase in late onser familicts Sctere, 261,921-923.

Corkin, S., Rosen, T. J., Sullivan, E. V., \& Clegg, R. A. (1989). Penetrating head injury in young adulthood exacerbates cognitiwe decline in later years. Journal of Neuroscience, $9,3876-3883$.

Couderc, R., Mahieux, F. Bailleul, S., Fenelon, G., Mary, R., \& Fermanian, J. (1993). Prevalence of apolipoprorein $\mathbb{E}$ phenotypes in ischemic cerebrovascular disease: $A$ case-control study. Stroke, 24, 661-664.

Grook, T., Barnus, R. T., Ferris, S. H., Whitehouse, P., Cohen, G. D., \& Gershon, S. (1986). Age-associated memory impairment: Proposed diagnostic criteria and measures od clinical change - report of a National Institute of Mental Heald Work Group. Dewelopmesnital Neuropsywhology, 2, 261-276.

De la Serna, G. (1994). Fibrinogen: a new major risk factor for cardiovascular disease: A reviow of the literature. journal of Family Pracice, $39,468-477$.

Deeg, D. J., Hofman, A., \&x van Zonnexdd, R. I. (1990). The association berween change in cognirive function and longevity in Dutch elderly. American Jownal of Epidemiology, 132, 973-82.

Deeg, D. J. H., Jonker, C., Launer. L. Ju, Schellevis, F. G., Smits, C. H. M., wan Tilburg, T., Knipscheer, C. P. M., 8c van Tilburg, W. (1993). Change in auronomy and weli-being: Background and preliminaty proposal for the Longitudinal Aging Study Amsterdam. In D. J. H. Deeg, C. P. M. Knipscheer, \& Waru Tilburg (Eds.), Antonony and wellsbeing in the aging population. Cancepts and design of the Langitudinal Aging Snudy Amsterdam, (pp. 19-87). Bunnik: Netherlands Institure of Gerontology.

Dekhuijzen, L.. $S_{*,} \&$ de Lange, J. J. (1993). De rol van algehele of regionale anesthesie bij her oncstaan wan cognirieve stoornissen bij oudere mensen. Literarutroverzicht [The role of general or regional anesthesia in the etiology of cognitive disorders in elderly subjects. Liceranure tewicw]. Thidsternifo voor Gerentologie en Geratrie, $24.193-199$.

Desmond, D. W. Tatemichi, "T. K., Paik, M. \& Stern, Y. (1993). Risk factors for cerebrowascular disease as corrctares of cognitive function in a stroke-free cohort. Archives of Newrology, 50, 162-166.

Despres, J. P., Moorjani, S., Lupien, P. J., Trumblay, A., Nadeau, A., \& Botchard, C. (1990). Regional distribution of body fat, plasma lipoproteins, and cardiovascular disease. Arterioscleroris, 10, 497-511.

Dodrill, C. B. (1992). Neutopsychological aspects of epilepsy. Pychiatric Clinics of North Amertica, 15.383-394.

Drados, M. T., Jacobson, A. M., Weinger, K., Widom, B., Ryan, C. M., Finkelsrein, D. M., \& Simonson, D. C. (1995). Cognitive function in patients with insulindependent diaberes mellitus during hyperglycemia and hypoglycemia. American Jourmil of Medicine, $98,135-144$

Dustrian, R. E., Ruhling, R. O.. Russell, E. M.. Shearer, D. E., Bonekar, H. W., Shigeoka, J. W, Wood, J. 5., 8 Bradford, D. C. (1984). Aerobic exercise training and improved neurapsychological function of older individuals Nenrobiolog of Aging, 5, 35,42.

Elias, M. F., Elias, J. W., \& Elias, P. K. (1990a). Biological and health infuences on behawiour. In J. E. Birren \& K. W. Schaie (Eds.), Handbow of the pyoholng) of aging (3 ed. pp. 79*102). San Dicgo: Academic Press.

Elias, M. F. Robbins, M. A., Schuliz, I. N. R., \& Pierce, T. W. (1990b). Is blood pressure an imporanc variable in research on aging and reuropsychological test performance? Jourmal of Gerontology, 45, P1 $28-135$.

Elias, M. F., Wolf, P. A., D Agostino, R. B, Cobb, J., \& White, L. R. (1993). Unneared blood preassure level is inversely related to cognitive functioning. The Framingham Study. American Journal of Epidensology, 138 ,
$353-364$.

Hitia, P. K., D'Agostino, R. B., Elias, M. F, \& Wolf, P. A. (1995). Blood pressure, bypertension, and age as risk faccors for poor cognitwe performance. Experimental Aging Resestrch, 21, 393-417. 
Farmer, M. E., Kitner, S. J., Abbott, R. D. Wole, M. M, Woll, P. A., Q White, Lo R. (1990. Longitudinally measured blood pressure, antihypertensive medication use, and cognitive performance: The Framingham Srudy. Joumal of Clinical Eprdemiology, 43, 475-480.

Feskens, E. J. M., Hawekes, L. M., Kalmijn, S. de Knijf, P. Launer, L. J., \& Kromhout, D. (199.4. Apolipoprorein ef allele and cognirive decline in elderly men. Britigh Medical Journal, 309, 1202-1206.

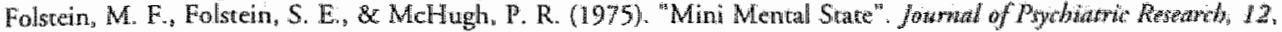
189-19g.

Fozard, J. L., Metrer, E. J., \& Brant, L. J. (1990). Next steps describing aging and disease in longitudinal studies. Journal of Gerontology, 45, P1 16-127.

Fozard, J. L., Metcer, E. J. Brane, L. J., Pearson, J. D., \& Baker, G. T. (1993). Goals for the next generation of longitudinal srudies. In J. J. F. Schroots (Ed.), Aging tyealth and competente, (pp. 35.52), Annsterdam: Elseviter.

Fratiglioni, L. (1993). Epiderniology of Alzheimer's disease: Issues of eviology and validity. Acra Newrologica Scatrdinavica, $87,3 m 70$.

Fries, J. F. (1990). Medical perspectives upon successful aging. In P. B. Balles \& M. M. Baltes (Eds.), Sucresyfful aging: Perspectives from the bebatwioral sciences, (pp. 35-49). Cambridge: Cambridge University Press.

Ganzevles, P. G. I., \& Geus, B.W. J. (1991). Clinical neuropsychological assessment of patients chronically exposed to organic solvents. Arechives of Toxicology Suppl, 15, 54-57.

Gorelick, B. B. (1995). Stroke prewention. Archives of Nearalogy, 52, 347-355.

Gorenstein, C., Bernik, M. A., Pompeta, \$., \& Marcourakis, T. (1995). Impairment of performance associated with long-term use of benzodiazepines. Journal of Pyschopharmatotogy, 9, 313-318.

Gowers, W. R. (1902): A lecture on abiotropy. Lancet, $i_{1}$ 1003-1007.

Graves, A. B., van Duijn, C. M., Chandra, W., Fratiglioni, L., Heyman, A., Jorm, A. Foo Kokmen, E., Kondo. K., Mortimer, J. A., Rocca, W. A., Shalat, S. L., Soininen, H., \&e Hofruian, A. (1991). Alcohol and wobacco consumption as risk factors for Alzheimer's disease: A collaborative reanalysis of case-control studies. International Joumal of Epidemiology, 20,\$48-\$57.

Hagberg, J. M. (1990). Exercise, Firness, and lappertension. In C. Bouchard, R. J. Shepard, 'T. Stephens, J. R. Sutton, \& B. D. McPherson (Eds), Exercise, finess and bealth: A consenses of current knowledge, (pp. 409-424). Champaign, Ill: Human Kinerics Books.

Hartman, D. E. (1988). Newropsychological toxicology: Jdentifications and assessment of busman neurotoxic syndromes. New York: Pergamon Press.

Hasher, L., \& Zacks, R. T. (1979). Automatic and effortful processes in memory. Joumal of Experimental Psychology: General, 108, 356-388.

Hayflick, L. (1985). The aging process: Current theories. Drug Notrient Interactions, 4, 13-33.

Heberr, L. E., Scherr, P. A., Beckett, L. A., Albert, M. S., Rosner, B., Taylor, J. O., Re Evarns, D. A. (1993), Relation off smoking and lownto-moderate alcohol consumption to change in cognitive function: A longitudinal study in a defined community of older persons. American Joumal of Epidemiology, 137, 881-891.

Heilman, K., \& Fisher, W. R. (1974). Hyperlipidemic dementia. Archives of Netrology, 31, 67-68.

Herzog, $C_{*}$, Schaic, K. W. \& Gribbin. K. (1978), Cardiovaseular disease and changes in intellectual functioning from middle ro old age. Jownal of Gerontology, 33, 872-883.

Hill, R. D. (1989). Residual effects of cigarette smoking on cognitive performnce in normal aging. Piyd dology and Aging, 4, 251.254.

Hooker, K., \& Siegler, 1. C. (1992). Separating apples from aranges in healch ratings: Perceived hetalth indudes psychological well-being. Behatsior, Heatth and Aging, 2, 81.92.

Horn, J. C. \& Carteli, R. B. (1967). Age differences in fluid and crystallized incelligence. Acta Psychiartica Scandiravica, $26,107-129$.

Houx, P. J., \& Jolles, J. (1993). Age-telated decline of psychomator speed: Effects of age, brain health, sex, and education. Perceprual and Motor Skills, 76, 195-211.

Houx, P. J., \& Jolles, J. (1994). Vulnerability faccors for age-relaced cognicive decline. In R. L. Istacson \& K. F. Jensen (Eds.), Toxirys in atir and awater, (pp. 25-41). Now York: Plenum Press.

Houx, P. J., Jolles, J. \& Vreeling, F. W. (1993a). Stroop interference: Aging effects assessed with the Stroop Collor Word test. Experimental Aging Research, 19, 209-224.

Houx, P. J., van Roxtel, M. P. J., \& Jolles, J. (1995). Cognitive performance, age, and health-related factors. In J. Jolles, P. J. Houx, M. P. J. van Boxtel, \& R. W. H. M. Ponds (Eds.), The Madstricht Aging Stady: Determionants of cognitive aging (pp. 95-103). Maastricht: Neuropsych Publishers.

Houx, P. J., Vreeling, F. W., \& Jolles, J. (1991a). Age-associated cognirive decline is related to biological life events. In K. Iqbal, D. R. C. McLachlin, B. Winblad, \& H. M. Wisniewski (Eds.), Alabeimer"s disedse: Bastic mechanisms, diagnosis and therapeutic strategies, (pp. 353-358). Chichester, UK: Wiley.

Houx, P. J., Vreeling, F. W., \& Jolles, J. (1991b), Rigorous health screening reduces age effect on memory scanming task. Brain and Cognitson, 15, 246-260. 


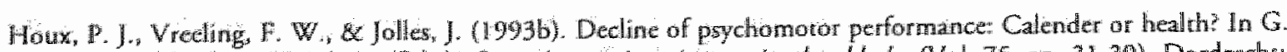
E. Scelmach \& V. Homberg (Edx.), Sensorimotor imparment in the elderly, (Nol. 75. pp. 31-39). Dordreche: Kluwer.

Hultish, D. F. Hammer, D., \& Snall, D. J. (1993). Age defferences in cognitiwe performance in later life:

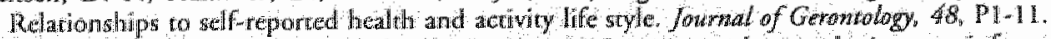

Hopper, F. A (1991). Age-related changes in memory Learning and temembering new information. In F. Boller

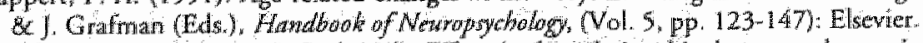

Huppert, F. A, \& Brayne, C. (1994). What is the relationship between demencia and normal aging? In F. A.

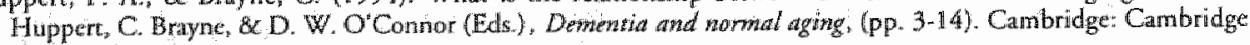
University Press:

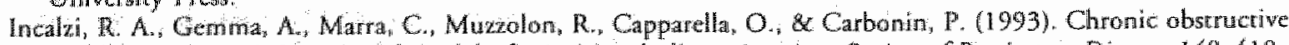
putmonary disexse: An ariginal model of eogninive dedine. American Review of Respiratory Disease, 148, 418424.

Johles; $\mathrm{J}_{2}$, Houx, P. J. van Boxtel, M. P. J., E Ponds; R. W. H. M. (Eds.). (1995). Matastricht Aging Study: Determituants of cognitive aging. Maastricht: Neuropisych Publishers.

Jolles, J., Verhoy, F. R J. Riedel, W. J., \& Houx, P. J. (1996). Cognitive impairment in elderly people: Predisposing factors and implications for experimental drug studies. Drags and Aging ,7, 459-479.

Jurqué, C. Iujol, J., Vendrell, P., Bruma, O, Jódar, M., Ribas, J. C., Viñas, J.. Capdevila, A, \& Marti Vilaita, J. L. (1990). Leukowaraiosis on magnevic resonance imaging and speed of mental processing. Archives of Neurology. $47,151-156$.

Kawamoto, A., Shimada, Ko Matsubayashi, K., Nishinaga, M. Kinnura, $S_{\text {, }} 8$ Ozawa, T. (1991). Factors associated with silent multiple lacunar lesions on magnetic resonance imaging in asymptomatic elderly hypertensive patients. Clinital and Experimental Phamatology and Physiology, 18, 605-610.

Kurkwood, T. B. L. (1994). How do risk factors for dementia relate to current theories on mechanisms of aging? In F. A. Huppert, C. Brayne, \& D. W. O'Connor (Eds,), Dementic and nomal ageing, (pp. 230-243). Cambridge: Cambridge Universiry Peess.

Kleijnen, J., \& Knipschild, D. (1991). Niacirn and vitamin B6 in mental funcrioning: A review of controlled trials in humans. Biological Psychiatry, 29, 931-941.

Knegreting, $H_{n}$, Eifick, $M$, \& Huijsman, A. (1994). Effects of antidepressants on cognitive functioning of elderly partients: A review. Drugras and Aging 5, 192-199.

Kokmen, E. (1991). The Eurodem collaborative reanalysis of case-control studies of Azheimer's disease: Implications for clinical research and practice. International Journal of Epidemiology, 20, 565-567.

Kolb, B., \& Whishaw, I. Q. (1990). Fundamenuth of buman nearopoychology. (3rd ed.). New York: W. H. Freeman \&ompany.

König-Zahn, C., Furer, J. W. \& Tax, B. (1993). Het metert wam de gezondheidstoestand. Bexchrijuing en evaluatie wan wrogenlipsten. 1. Algemene gezandheld. The assessment of bealth staws. Description and ewaluation of gutestionratres. I. General healhoh. Assen: Van Gorcum.

Kral, V. A. (1962), Senescenr forgerfulness: Benign and malignant. Ganadiat Medical Association Jourwat, 86, 257 . 260.

Kutusisto, J., Kovvisto, K., Mykkänen, L.. Helkalla, E., Vanhanen, M., Hànninen, T., Pyörällä, K., Rickinen, P., \& Latkso, M. (1993). Essential hypertension and cognicive function: The rolle of leyperinsulinemia. Aypertension, $22,771.77 \%$.

LaR Ruce, A. (1992). Aging and neawapsychological assersswent: New York: Plenum Press.

LaRue, A. Bank, L., Jarwik, L., Hetland; M. (1979). Health in old age: How do physicians' ratings and selfratings compare? Jowral of Gerontolagy, 346, 687 -691.

Lawner, L. J., Dinkgreve, M. A., Jonker, C., Hooijer, C., \& Lindeboom, I. (1993). Are age and educarion independen correlates of the Mni-Mental State Exam perfornance of community-dwelling elderly? Jow of Geratholog, 48, $1271-277$.

Letenncur, L., Dartigues, J. F., Commenges, D. Barberger Gateau, P., Tessier, I. F, \& Orgogozo, J. M. (1994). Tobacco consumption and cognivive impairnent in elderly people. A population based srudy. Annals of Epidemiology, $4,449-454$.

Levy, R. (1994). Aging-Associated Cognitive Decline: Working party of the lnternational Psychogeriatric Associacion in collaboration with World Health Organization. Pnterrational Pyshogeriatrics, 6, 63-68.

Lewis, M. Worobey, J., Ramsay, D. S. \& McCormack, M. K. (1992). Prenatal exposure to heavy metals: Effect on childhood cognitive skills and health status. Pediatrics, 89, 1010-1015.

Lezak, M. D. (1995). Newropsyethatogical Assessment. (3rd ed.). New York: Oxford Uniwersity Press. Light, K. C. (1975). Slowing of response rime in young and middle-aged hypertensive patients. Experimental Aging
Resedmh, 1,2090227 .

Madden, D. J.. Blumenthal, J. A., Allen, P. A., \& Emery, C. F. (1989). Improwing aerobic capaciry in healthy older adults does not necessarily lead to improved cognirive performance. Pychology and Aging, 3, 307-320. 
Maddox, G. L., Archley, R. C., Poon, L. W., Rork, G. S., Siegler, I. C., Le Steinberg, R. M. (Eds) (1987), The encylopedid of aging: New York: Springet.

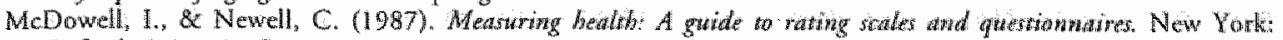
Oxford University Press.

Mckhann, G., Drachmann, D. Folstein, M. Katzman, R., Price, D., \& Stadlan, E. (1984). Clinical diagnosis of Alzheimer's disease: Report of the NINCDS/ADRDA workgroup under the auspices of the department of Health and Hurnan Services task force on Alaheimer"s disease: Newrology, 34, 939.944.

Mearns, J., Durn, J.; \& Lee Haley, P. R. (1994). Psychological effeces of organophosphate pesticides: A review and eall for research by psychologists. Joumal of Clmical psycholugy, 50, 286-294.

Messemakers, J. F. M., Höppener, P., Knottruerus, J. A., Kocken, R. J. J.x \& Limonard, C. B. G. (1992). Computerized health information in the Netherlands A registration network of farrilly practices. Britists Journal of General Practice, $42,102-106$.

Meyer, J. S., Judd, B. W., Tawakina, T., Rogers, R. L., 8c Mortel, K. F. (1986). Improved cogrnition after control of risk factor of mulri-infarct demetia. Journat of the American Medical Associntion, 256, 2203-2209.

Meyer, J. S., \& Shaw, T. G. (1984). Cerebral blood flow in aging. In M. L. Albert (Ed.), Clivical newrology of aging, (pp. 178-196). New York: Oxford University Press.

Moc, S. M. \& Sprague, S. M. (1994). Uremic encephalopathy. Clinical Mephrology. 42, 251-256.

Molina, J. A., Bermejo, F., del Ser, T., Jiménez-Jiménez, F. I., Herranz, A., Fernández Calle, P. Ortuño, B.s Villanueva, C, \& Sainz, M. J. (1994). Alcoholic cognitive deterioration and nurritional defieiencies. Aerat Neutrologica Scandinatica, $89,384-390$.

Mortimer, J. A. (1988). Do psychosocial risk factors contribute to Alaheimer's disease? In A. S. Henderson \& I. H. Henderson (Eds.), Etrology of dementia of ALLheimer's type, (pp. 39-52). Chichester: John Wriley \& Sons.

Mortimer, J. A. (1994). What are the risk factors for dementia? Ln F. A. Huppert, C. Brayne, \& D. W. O'Connor (Eds.), Dementia and normal aging, (pp. 2088-229). Cambridge: Cambridge University Press.

Mortimer, J. A., van Duign, C. M., Chandra, V., Fratiglioni, L., Graves, A. B., Heyman, A., Jerm, A. F., Kokmen, E., Kondo, KK., Rocca, W. A., Shalat, S. L., Soininen, H., \& Hofman, A. (1991). Head rrauma as a risk for Alzheimer's disease: A collaborative reanalysis of case control studies. International foumal of Epidemiohogy $20,528-535$.

Muildoon, M. F., Bachen, E. A., Manuck, S. B., Waldstein, S. R., Bricker, P. L., \& Bennetr, J. A. (1992). Acute cholesterol responses to mental stress and change in posture. Archives of Interyal Medicine; 152, 775-780.

Muldoon, M. F., Herbert, T. B., Patterson, S. M., Kamenewa, M., Raible, R., \& Manuck, S. B. (1995a). Effects of acute psychological stress on serum lipid lewels, hemoconcenrration $n_{i}$ and blood wiscosity. Archives of Internat Medicine, 155, 615-620.

Muldoon, M. F. Waldstein, 5. R., \& Jennings, J. R. (1995b). Neuropsychological consequences of antihypertensive medication use. Experimental Aging Researdy, 21, 353-368.

Nolan, K. A. \& Blass, J. P. (1992). Preventing cognitive dedine. Clinics in Geriantic Medicine, 8, 19-34.

Ote, A., Breteler, M. M., wan Harskamp, F., Claus, J. J, van der Cammen, T. J., Grobbee, D. E, Hofman, A. (1995). Prevalence of Alzheimer's disease and vascular dementia: association with education. The Rorterdan study. British Medical Jotsmal, 310,970-973.

Pertmutrer, M., \& Nyquist, L. (1990). Relationships becween self-reported physical and mentail healri and intelligence performance across adul thood. Jowinal of Gerontology, 45, 12145-155.

pickering, T. G. (1993). Clinical walue of ambulatory blood pressure measurement in the elderly. Cardiology in the Elderly, $490-493$.

Pierce, T. Elias, M. F. (1993). Cognitive funcrion and cardiovascular responsivity in subjects with a paremtal history of hypertension. Fournal of Behawioral Medicine, $16,277-294$.

Poirier, I. Davignon, J., Bouthillier, D. Kogan, S., Bertrand, P., \& Gauthier, S. (1993). Apolipoprotein E polymorchism and Alzheimer's disease. Lancet, 342,697.99,

Poon, L. W. (1985). Differences in human memory with aging: Narure, causes and clinical implicarions. In J. E. Birren \&e K. W. Schaie (Eds.), Hazndbook of the psychology of aging. New York: Van Nostrand Reinhold.

Postiglione, A., Cortese, C., Fischetri, A., Cicerano, U., Gnasso, A., Galonta, G., Grossi, D. i Mancini, M. (1989). Plassma lipids and geriatric assessment in a very aged population of South Italy. Atherosclerosis, 80, 63-68.

Prince, M., Lewis, G., Bird, A., Blizard, R., \& Mann, A. (1996). A longirudinal study of factors predicting change in cogrinive aest scores over time, in an older hypertensive population. Psychalogical Medicine, 26, 555.568.

Rabbint P. (1990). Applied cognirive gerontology: Some problems, merhodology and data. Applied Cognarive Psychology. 4, 143-149.

Ralibit, P. M. A. (1993). Methodological and theoretical lessons from the university of Manchester loongitudinal Studies of Cognitive Changes in Normal Old Age. In J. J. E. Schroors (Ed.), Aging, health and connpetence" (pp. 199-219). Amsterdam: Elsevier.

Reaven, G. M., Thompson, L. W., Nahum, D., \& Haskins, E. (1990). Relationship between hyperglycaemia and cognitive function in older NIDDM pacients. Diabetes Care, 13,16-21. 
Reiran, IC M. Shipley, R. E (1963). The relation of serum cholesterel changes to psychological abiliries. Jowmal of Gerontology. $18,350-357$

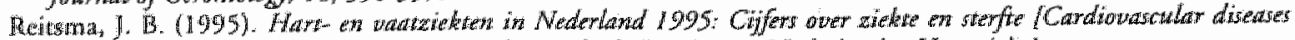
in the Netherdands: Fugwers on disease and mortality. Den Haag: Nederlandse Harrsticheing.

Redel, W. I. \& Van Praag. H. M. (1995). Avoiding and managing anticholinergic effects of antidepressants. CNS Drugs, 3, 245-259.

Riegel, K. E, \& Riegel, R M. (1972). Development, drop, and death Developmental Pyetsology, 6, 309-316.

Rikili, R. E;, \& Edwards, D. J. (1991). Effects of a thece-year exercise program on motor function and cognitive processing speed in older women. Reseanch Quarterly far Exercise and Sport, 62, 611.67.

Rodriguez, G., Arvigo, F. Marence, S., Nobili, F., Sandini, G. \& Rosandini, G. (1987). Regional blood flow in cessential hyperterision: Data evaluation by a mapping system. Stroke. 18, 13-20.

Rogets, R. L., Meyer, J. S., \& Morre!. K. F. (1990). Afeer reaching retirement age physical activity sustains cerebral perfusion and cognition. Jonmal of the American Geriatrics Society 38, 123-128.

Rogers, R. L., Meyer, I. S., Shaw, T. G., \& al., e. (1983). Cigarerte smoking decreases cerebral blood flow suggesting increased risk for stroke. fournal of the Americas Medical Association, 250, 2796-2800.

Rogcts , R. L., Meyer. J. S., Shaw, T. G., \& al., e. (1985). Reductions in cerebral blood flow associated with chronic alcohol consumption. fourmal of the American Geriatrics Soctety, 31, 540-543.

Rowe, I. W., \& Kahn, R. L. (1987). Human aging: Usual and successful. Science, 237, 143-149.

Ryan, $C$. M., Willians, "T. M. Finegold, D. N., \& Orchard, T. J. (1993). Cognivive dysfuncrion in adults with Type 1 (insulin-dependent) diaberes mellitus of long duration: Effeces of vecurrent hypoglycaemia and other chronic complications. Diabetologia, 36, 329-334.

Sachon, C, Grimaldi, A, Digy, J. P., Pillon, B., Dubois, B., \& Thervet, F, (1992). Cognicive function, insulindependent diaberes and hypoglycaemia. Joumual of Internal Medicine, 231, 471-475.

Salthouse, T. A. (1985). Speed of behavior and irs implications for cognition. In J. E. Birren \& K. W. Schaie (Eds)), Handbook of the Psycholagy of Aging (pp. 400-427). New York: Van Nostrandt Reinhold Co.

Sulthouse, T. A. (1988). Resource-reduction interpretations of cogritive aging. Developmental Review, 8, 238-272.

Salchouse, T. A. (1989). Age-related changes in basic cognicive processes. In M. Srorandr \& G. R. Vandeabos (Eds.). The adult years: Contrinaty and change, (pp. 5-40). Washingron: APA..

Salthouse. T. A. (1992). Mechanisms of age-cognition relations in adulthood Hillsdale NJ: Lawrence Eribaum.

Salthouse, T. A., Kausler, D. H., \& Scott Saulrs, J. (1990). Age, self-assessed health stanis, and cognition. Journal of Gerontalogy, 45, P156-160.

Sandsread, H. H. (1986). A brief history of the influence of trace elements on brain function. American Journal of Clinical Nunition, 43, 293-298.

Satz, P. (1993). Brain reserve capacity on symptom onset after brain injury: A formulation and teview of exidence for ereshold theory. Newropsychology, , , 273-295.

Saunders, A. M., Schrnader, K., Breirner, J. C. S., Benson, M. D., Brown, W. T., Goldfarb, L., Goldgaber, D., Manwaring, M. G., Szymanski, M. H., McCown, M., Dole, K. C., Schmeidel, D. E., Stritrmatter, W. J., Pericak-Vance, M. A., \& Roses. A. D. (1993). Apolipoprotein E ét allele distriburions in late-onser Alaheiner's disease and in other amyloid-formith diseases, Lancet, 342, 710-11.

Setrinidr, R., Fazekas, F, Offenbacher, H., Dusek, T., Zach, E., Reinhart, B,, Grieshofer, P., Freidl, W., Eber, B., Schumacher, M. Koch, M. \& Lechner, H. (1993). Neuropsychologic correlates of MRll white matter hyperintensities: A study of 150 normal volunteers. Neuralogy, 43, 2490-2494.

Schumido, R., Fazekas, F, Koch, M., Kapeller, P., Augustin, M., Offenbacher, H., Fazekas, G, \& Lechner, H. 11995). Magneric tesonance imaging exrebral abnormalities and neuropsychologic test performance in elderly hypertensive subjects: a cassecontrol study. Archives of Newrology, 52, 905.910.

Sellko, D. 1. (1992). Aging brain, aging mind. Scientific American, 267, 97-103.

Sherwood, N, (1993). Elfects of nicotine on human psychomotor performance. Fioman Psychopharmacology, \& 155 184,

Stegher, 1. C. (1990). Paradigms in developmental bealth psychallogy - From theory to applicarion: Introducrion to special issue Journal of Gerontology, 45, P113-115.

Skoog, 1. (1994). Risk factors for wascular dementia: A review. Dementia, 5, 137-144.

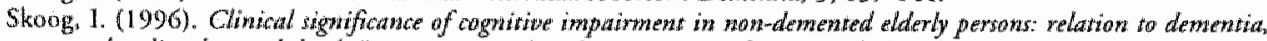
watcutar dirorders and denth. Paper presented at the Lancer Conference, Edinburgh, UK.

Snowdon, D. A. Belcher, J. D. Tully, C. L \& \& Greiner, L. H. (1996). Plasma dholesteral and cognitive funcrion in the elderly: Findings from the num stwdy. Paper presented at the 6th Cagritive Aging Conference, 25-28 April 1996, Aulanta, GA.

Spirduso, W. W. (1980). Physical fitness, aging, and psychomotor speed: A review. Jownul of Gerantology 35, P850865.

Starr, J. M., \& Whalley, L. I. (1992). Senile hypertension and cognitive impairment: An overview, Journal of Hypertension (Suppl), 10, $\$ 31-\$ 42$ 
Stern, Y., Alexander, G., Prohovnik, I., \& Mayeux, R. (1991). Educarion provides a cognitive reserwe ngainst he dinical nanifestations of Alaheimer's disease. Society for Neturosctence Abstrats, $17,1258$.

Stolrenburg-Didinger, G. (1994). Neuropathology of the hippocanpus and its suscepribility to neurotoxic insult. Neatroxicology, $15,445-450$.

Stones, M. J., \& Kozma, A. (1988). Physical activity, age and cognitive/moror performance. In M. Howe $8 x$ C. Brainard (Eds). Cogratiowe dewelopement in addulthood, (pp. 273-322). New York: Springer.

Srones, M. J., Kozma, A. \& Hannah, T. E. (1990). The measurement of individual differences in aging: The distinction between usual and successful aging. In M. L. Howe, M. J. Srones, \& C. J. Brainerd (Eds.), Cogytitive and behawiowal performance factors in atypicat aging, (pp. 181-218). New York: Springer-Verlag.

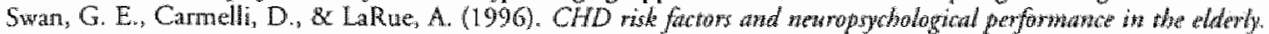
Paper presented at the Paper presented at the Annual Meeting of the International Neuropsychological Sociery. 16 February 1996, Chicago.

$\operatorname{Swran}_{1}$ G. E. LaRue, A., Carmelli, D. Reed, T. E, \& Fabsitz, R. R. (1992). Decline in cognitive performance in aging twins: Heritability and biobehavioral predictors from the National Heart, Lung, and Blood Institute "T'win Srudy. Archites of Neurology, 49, 476-481.

Tareer, R. E., Arria, A. M., \& Van Thiel, D. H. (1991). Heparic encephalopathy coexistent with alloholism. Recent Developments in Alcololism, 9, 205-224.

Tarter, R. E., Edwards, K. Lu, \& van Thiel, D. H. (1988a). Perspective and rationale for neuropsychological assessnent of medical disease. In R. E. Tarter, D. H. van Thich, \& K. L. Edwards (Eds.), Medict Newropsychology: The Impact of Dinease on Behatsior, (pp. 1-10). New York: Plenum Press.

Tarter, R. E., van Thiel, D. H., \& Edwards, K. L. (1988b). Medical Nerrepsycholggy: The impact of disease on behavior. New York: Plenum Pliess.

U'ren, R. C., Riddle, M. C. Lezak, M. D., \& Benningron-Davis, M. (1990). The mental efficiency of the elderly person with Type II diabetes mellitus. Journal of the American Gervatrics Sockety, 38, 505-510.

Van Duijn, C. M., \& Hofman, A. (1991). Relation between micotine intake and Alzheimer's disease. British) Medical Journal, 302, 1491-1494.

Van Swieten, J. C., Geyskes, G. G., Derix, M. M. A., Peek, B. M., Ramos, L. M. P., van Latum, J. C., 8c van Gijn. I. (1991). Hypertension in the elderly is associated with white maturer lesions and with cognitive decline. Aknals of Neutolog;, 30, 825-830.

Verbrugge, L. M., \& Jette, A. M. (1994). The disablement process, Social Science and Medicine, 38, 1-14.

Walden, C. C., \& Hegele, R. A. (1994). Apolipoprotein $\mathbb{E}$ in hyperlipidemian. Annals of Internal Medicine, 120, 1026-1036.

Waldstein, S. R. (1995). Hypertension and neuropsychological funcrion: A liferime perspective. Experimental Aging Research, 21, 321-352.

Waldstein, S. R., Manuck, S. B., Ryan, C. M., \& Muldoon, M. F. (1991). Neuropsyclological corretares of hypertension: Review and methodological considerations. Psycholagical Bulletin, 110, 451.469).

White, N. \& Cunningham, W. R. (1988). Is terminal drop pervasive or specific: Journal of Gerontology, 43, P141144

Widom, B., \& Simonson, D. C. (1990). Glycemic control and neuropsychologic function during hypoglycemia in patients with insulin-dependent diaberes mellikus. Annals of Internal Medictier, 112, 904-912.

Wilkie, F. L. \& Eisdorfer, C. (1971). Intelligence and blood pressure in the aged, Science, 172, 959-962.

Wood, P. D. \& Stefanick, M. L. (1990). Exercise, fieness, and atheroselerosis. In C. Bouchard, R. J. Sliepard, TH.

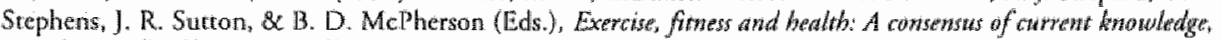
(pp. 409-424). Champaign, Ml.: Human Kinerics Books.

World Health Organisation. (1980). International classiffoasion of impaiments, disabilitite, and handicaps. Geneva: WHO.

Worrall, G., Moulon, N., \& Briffetr, E. (1993). Effect of type II diabetes mellitus on cognitive funcion. Jownal of Family Practice, 36, 639-643.

Writing Committer Lancet Conference. (1996). The challenge of the atenentias. Lawet, 347, 1303-1307.

Yates, E. E. (1993). Biological perspectives on growing old. In J. J. F. Schroots (Ed.). Aging bealth ard compectence, (pp. 55-63). Amsterdam: Elsevier. 


\section{The Maastricht Aging Study (MAAS): Rationale, objectives, design, and methods ${ }^{1}$}

The research described in this thesis are part of a series of related projects in the realm of cognitive aging, called the Maastricht Aging Study (MAAS). This study is carried out at the University of Maastricht, the Netherlands. The present chapter describes the rationale, objectives, design and the methods used in MAAS and thus provides the scientific background and research infrastructure on which the research described in the experimental chapters of this thesis are based.

In 1991, MAAS started with research grants from the Dutch Government (Departments of Education and Science and the former deparment of Welfare, Health and Cultural Affairs) and the University of Maastricht. The core of the research program is a longitudinal study into cognitive aging, which investigates biomedical, psychological and sociodemographical factots in relation to neurocognitive functioning. With respect to biomedical factors, special attention is paid to experienced morbidity and to subclinical changes in physiological paraneters. MAAS involves almost 2,000 healthy individuals aged 24 through 81 years at baseline. Data are collected by means of questionnaires, medical screening and neuropsychological investigation. This chapter describes the rationale and research questions $(\$ 3.1)$, design $(\$ 3.2)$, methods used in postal surwey (\$3.3), and methods used in medical and neuropsychological assessment $(\$ 3.4)$. It is and abridged version of the first four chapters of a recent book entitled The Madstrich Aging Stady: Determinants of Cognitive Aging, by Jolles, Houx van Boxtel and Ponds (1995). Descriprions of procedures and methodology, as well as results from ten research projects related to cognitive aging can be found in this book in more detail. The next paragraph gives an overview of the objectives and design of MAAS.

\subsubsection{MAAS objectives and design: an overview}

MAAS is largely devoted to the age-related decline of memory and memory-related functions in normal people and the search for determinants of both successful and pathological cognitive aging. A major objective is to find determinants of cognitive deterioration with age, and to estimate the relative impact of these factors. What makes memory function decline?

\footnotetext{
1 Adapred from J. Jolles, P. J. Houm, M. P. J. van Boxtel, 8x R. W. H. M. Ponds (Eds,). (1995). Maatricht Agthy Study: Deterwinames of cognitive agrag. Maistricht: Neuropsych Publishers, Chaprers 1-4.
} 
Why do some individuals show a greater decline than others? Ower the past few years, a host of factors, including biological, medical, psychological and social. factors, have been studied in relation to cognive decline. The aim of MAAS is to evaluate these factors in an integrative study of cognitive aging. This can only be achieved if large numbers of nomal healthy adults of all ages are studied and if these subjects are monitored for some period of time. Pathological forms of aging (e.g. dementia or depression) are studied in the longitudinal follow-up program. It is expected that some subjects who were normal and healthy at the first measurement poine will show abnormalities in the long run. For this reason, MAAS intends to perform case-finding studies of pathological aging involving subjects with well-documented histories of premorbid functioning. The longitudinal phase of MAAS will enable the search for prodromes of dementia (more specifically, dementia of the Alzheimer type or vascular dementia), and other forms of psychoparhology (such as depression or anxiety disorder).

Different individuals may and do age in different ways. The decline may be sudden or gradual, invalidating or mild, and may occur at differene points in time. The main study of MAAS involves the collection of information about individual patterns of cognitive aging. Much of the research that preceded MAAS was dewoted to Biological Life Events (BLE, brain function-related health factors) as possible determinants of cognitive aging. Strong evidence from cross-sectional studies suggested that BLE accounted for much of the age-related decrease in cognitive performance and for the increase in the variance of performance.

In MAAS, additional information was obtained from nearly four thousand subjects by the use of postal surveys and questionnaires. The demographic, biomedical, psychological, and social information will be related to the results from extensive neuropsychological testing in almost half of this group. The test group is made up of the participants in four consecutive pancl studies (referred to as $A_{1}$ to $A_{4}$ ). Each panel includes 440 to 480 subjects who are stratified for age in 12 discrete age groups. The chapters 5 to 9 of this thesis pertain to data. derived from the first three panel studies $\left(A_{1}\right.$ to $A_{3}$ ).

Several parallel studies are related to the main study. These involve dedicared experiments with smaller numbers of subjects. Some of these studies include subjects who took part in the main study and use parts of the basic data (so-called adnex studies). Other projects require subject sampling independent of the main study, e.g. as part of PhD projects that are supported by grants from the University of Maastricht or from third parties. Most of these studies focus on questions which are central to the research question of the main study.

\subsubsection{MAAS research quetions}

MAAS intends to find answers to a number of questions about the normal (non-pathological) aging of cognitive functions, particularly memory. The emphasis on memory in MAAS is not because, as commonly thought, this function is affected most or even chiefly in the aging process, but because aging people invariably first complain about their memories. In fact, there is ample evidence that a number of other functions deteriorate earlier and to a greater extent than important aspects of memory. Psychomotor functions, atrencion, and reaction time have all been shown to deteriorate much earlier than the time when most individuals first experience a deterioration of memory. However, memory is one aspect of cognition that people can 
directly relate to. Memory problens often constitute the first phase of the most important form of pathological aging, dementia. The main research questions of MAAS are then the WX7hen, What, and especially Who, of the decline of memory and memory-related functions associated with aging and will be discussed below.

Question $I$ - The first and probably most basic question is: when in the course of a human liferime do changes in memory and memory-related functions appear? Is there a distinct point in an individual's life when cognitive changes first emerge? Very little is known about when cognitive changes appear or how rapidly they progress. Does the decline start early in life and gradually go on or accelerate with age, or does it manifest itself abruptly? A sudden decline in cognitive performance, leading to death within a limited time interval (terminal drop), may occur after a major event. This can be a physical event, such as an infective disease or head trauma, or a psychosocial ewent, such as the death of a spouse. "This sudden decline is of course more likelly to occur in the second half of the life span, but since life expectancy has incrensed over the last century, this period can extend over the fourth to the ninth decades of life.

Another intuitively appealing possibility is that most individuals do indeed show a gradual decline in cognitive function with age, perhaps as a result of the accumulation of effects of minor brain dysfunction. At first, these minor abnormalities may have little impact, but as they accumulate, or as age advances, their combined effects result in cognitive deficits that can be perceived by the individual or clinically observed. Terminal drop would then only occur as a result of major abnormality. The latter possibility is clearly the more optimistic one, as it paves the way to better cognitive functioning in later years. As yet, we do nor know which of the possibilities, or a combination of them, applies.

Unfortunately, the majority of experimental cognitive aging research performed up till now has focused on performance differences berween young adults (mostly srudents) and elderly subjects, making the information on cognitive deterioration in middle age scarce. Yer, it seems essential to study the ages between 30 and 60 to gain insight into functional development during adulthood and to learn about which functions decline when.

Most studies on cognitiwe aging are cross-sectional, i.e. they study two or several age groups at one point in time. There is a distinct possibility that gradual cognitive decline in the reported studies is an artefact of so-called period effects (see chapter 10), or of the fact that older age groups merely contain more poorly performing subjects. This is because the number of elderlly subjects in the period between the terminal drop and death within a given birth cohort increases as the age of the cohorr increases. Consequently this would cause the average performance of an older group to be poorer and would result in a higher variance in performance within older age groups - a phenomenon often encountered in cross-sectional research. Individual age-performance trajectories, as Rabbitt (1990) put it, may differ widely, and yet result in a steadily declining average trajectory.

Question 2-Do all functions deteriorate at the same rate or are specific aspects of cognitive functioning more affected than others? Does continuous decline or terminal drop exist to a comparable extent for the various domains of cognitive function? This is unlikely, because memory is not a unitary function and particular aspects of memory appear to remain relatively 
intact until late in life. The decline in sensory function and physical performance that occurs with age may have some effect on the performance on cognitive function tests, but there need not be any direct or causal relationship with cognitive performance itself. Any loss of memory may well lag wery much behind perceptual loss, or may not occur at all.

A well-known example of differential age trends in cognitive function is the dissociation between crystallized and fluid imtelligence, as originally proposed by Cattell (1963). In this dichotomy, the former denores those cognitive processes and skills that are more or less independent of age (such as retrieval of long-stored information), whereas the latter concerns processes that show age-related decline (such as attentional processes or spatial reasoning). White and Cunningham (1988) demonstrated that the terminal drop phenomenon mentioned above is probably limited to crystallized abilities. However, little is known about the fluidicy of cognirive functions. Whatever the hypothetical underlying cause of the observed functional decline, it is important not to ascribe the observed decline blindly to age per se, but to determine the underlying, more specific factors that may trigger a decline in cognitive abilities.

Question 3 - The third main research question is closely related to the first two. Do individuals differ with respect to the age of onset and the rate of progression of cognitive aging? Information is lacking about whether all aging people experience a general deterioration of their cognitive functions. In orher words, is cognitive aging an inherent aspect of physiological aging or are additional factors, such as biological or psychosocial factors, also responsible for cognitive aging? No systematic information is available in the literature about determinants of healthy and pathological cognitive aging. This makes it important to acquire more information on individual cognitive aging trajectories and the factors that mediate them (Rabbitt, 1990). Several studies have shown that some elderly subjects perform cognitive tasks just as well as young adults do, which raises the question about what determines successful cognirive aging or, conversely, what causes the majority of individual aging patterns to be less successful (Rowe \& Kahn, 1987).

Are there particular biological or psychosocial determinants, or risk factors of pathological cognitive aging in normal, healthy individuals? Do so-called Biological Life Events (BLE) play a role in this respect? BLE are health-related factors that are possibly associated with brain functioning (Houx, Vreeling \& Jolles, 1991). Examples of BLE are the use of psychoactive medication, use of alcohol, closed head injury, and general anaesthesia. Most individuals are exposed to one or more of these factors during their lifetime. Usually, however, the impact of BLE goes unnoticed by the individual, which is why their importance is rarely acknowledged by physicians. The MAAS study aims ro identify the determinants of successful or less-thansuccessful cognitive aging and to evaluate the BLE concept.

Question 4- What is the relationship between complaints about cognitive abilities (particularly memory) and cognitive test performance? Several studies have failed to find a clear relationship between complaints about memory function and performance memory tests. Older subjects who complain about memory may perform well on memory tests, and vice versa. Psychological and psychosocial variables (e.g. metamemory) seem to be related to the existence 
and maintenance of complaints about cognituve functioning. However, it should be reallaed that several psychometric tests that are used in clinical and experimentall setrings are not standardized, and that many tests have been developed or modified in recent years. Farmeaching conclusions are often drawn on the basis of a particular aspect of the test performance of a neuropsychological patient. For this reason one may expect that case-control studies and orher patient-related research inwolving cognitive testing can gain greatly from well-designed normative studies.

A related question inwolves the possibilities that patients with memory complaints or: dysfunctions may have to compensate for deteriorating functions and what can be done to overcome the handicap many elderly experience in acquiring, terrieving, and applying information in daily-life situations: This question pertains to the need for educational facilities for the elderly and the necessity to improve the use of information or information technology by the elderly.

The quesrions outlined above can only be addressed in a large-scale study such as MAAS that involves different age groups and that monitors the subjects for a considerable period of time. A cross-sequential design and a study population with a wide age range is essential to collect the necessary information about a substantial part of different aging trajectories. This approach appears to be the optimal combination of longitudinal. and cross-sectional methodology, dealing with the shortcomings of both in the best possible way (Williams \& Klug, 1996).

The relevance of MAAS to society is found in the difficulties that many individuals experience in the course of the aging process, difficulies which adversely affect their quality-of-life because of decreased mental abilities and increased forgetfulness. Furthermore; the memory problems of aging indiwiduals hawe a large impact on society because of the double aging caused by the rapidly growing number of elderly individuals. The impact is also reflected by the sharply increasing financial and organizational costs of health promotion and health care for the middle-aged and older population.

\subsubsection{General approach: the cross-sectional phase of $M A A S$}

The basis of MAAS (the so-called A-study) is founded by a cross-sectional study involving several thousands of healthy subjects aged 24 to 86 years. Data were collected in four consecutive panel studies that were identical in structure and organization. In the first study $A_{1}$ which took place in 1993, some 2,000 subjects received an extensive postal questionnaire. Of these 2,000 subjects, 480 were actually screened in the test laboratory. Based on the experience with the $A_{1}$ three additional experiments $\left(A_{2-4}\right)$ were scheduled, in which some indiviclual data were to be collected by means of postal questionnaire, and other data by in-deprh neuropsychological and medical examinations of 1,450 additional subjecrs, 440 to 480 subjects in each panel.

The next section describes the procedure, design and methods of MAAS. Briefly, MAAS now consists of four panel studies $A_{1-4}$ and an exrended postal survey study that was part of $A_{1}$. Each panel study was age-stratified in 12 or 11 discrete age groups $(n=40)$ between 24 and 81 years. All age groups were subdivided into four subgroups $(n=10)$ by the factor sex and the 
level of occuparional activity ( $L O A$, two levels). The subjects were recruited from the Registration Network Family Pracrices (Registratienet Huisutspraktjken, RNH), a data base managed by the Deparment of General Practice of the University of Maastricht. This project should prowide answers to most of the scientific questions underlying the research program. It should provide population norms for tests of memory and memory-related functions, for several medical tests, and for the prevalence of risk factors and maintenance factors for (un-) healthy cognitive aging. A basic batrery of psychometric instruments and medical tests was used for all subjects. Additional information was obtained with questionnaires.

The A-study was set up to meet the requirements for longitudinal follow-up. The results from the $A_{1}$ follow-up will be used to define the necessary characteristics of the longitudinal phase of the study, which is planned to follow a cross-sequential design.

\subsection{MAAS STUDY DESIGN}

\section{2 .1 Introduction}

Thils paragraph describes the logistic implementation of MAAS, its study design, rime schedule, and subject inclusion procedure. A description of the methods used (postal survey questionuaire and test program) can be found in the sections 3.3 and 3.4 .

The cross-sectional pariel studies of MAAS share the same methodology with respecr to sample frame, subject inclusion, stratification criteria, and basic measurement protocol. Each A-study includes an independent population sample and a ser of specific variables in addition to the set of variables that is constant for all A-studies. Each subject panel is sratified for age, sex, and a proxy measure of general ability (section 3.2.5). Four cross-sectional panell standies were executed between March 1993 through December 1995 of which the toral number of subjects that will proceed to the follow-up phase was 1,823. The frequency of follow-up assessment depends on actual age at baseline, i.e., three years for subjects aged 54 years and alder, and six years for subjects younger than 52 . The toral dutation of the follow-up program is at least 12 years, but may last longer if supplemental funding can be acquired. The first 3-yeat follow up of pand A was conducted fromoctober 1996 to January 1997. Figure 3. $\mathbb{1}$ displays a schemaric time schedule for the complete MAAS project. In the following sections, at description is given of the sample frame, inclusion and exclusion criteria, and procedure.

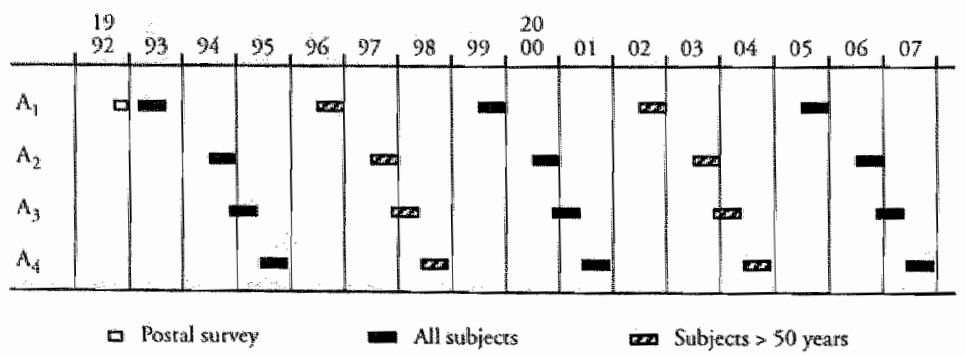

Figure 3,1. Timetable of the four MAAS panel studies and their successive follow-up measurements. 


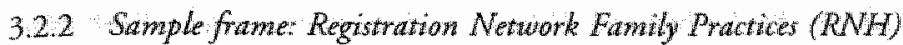

MAAS closely collaborates with the Registration Network Family Practices (Regismatienet Huisartspraktijken, RNH). This register intends to serve as a sample frame for research in primary care and related scientific fields (Metsemakers, Höppener, Knotnerus, Kocken 8 Limonard, 1992). The RNH will eventually concain a set of demographic and health characteristics of 80,000 patients from 15 general praccices and 42 practitioners in the province of Limburg, the Netherlands. This information is updated and stored every three month in a central data base. Patients included in the RNH register are considered to be representative for the Limburg and Dutch populations with respect to demographic characteristics (age, gender, educational level, and type of health insurance). The register contains background information such as socioeconomic status, level of formal education, and marital status. All relevant health problems are coded in a problem list. A health problem can be defined as awything that has reguired, does or may require bealth-care management and bas affected or could sigwifuantly affect a person 'physical or emotional well-being'. Problems are identified and recorded according to the International Classification of Healrh Problems in Primary Care (ICPC; Lambers and Wood, 1987). They are only recorded by the general praccitioner if they are permanent (no recovery expected), chronic (duration longer than six months) or recurrent (more than three recurrences within six months). An overview of the most common problems is given in chapter 9.

The use of RNH as a sample frame for MAAS subject panels has several advantages over sampling procedures in the general population, eng. the use of census registers. For example, the invitation to participate in the study is sent by the personal family doctor, which is expected to promote the compliance. Furthermore, a preselection of subjects based on the medical and demographical RNH information can be made beforehand. Subjects with known morbidity which may have severe consequences for cognitive ability are considered uneligible to participate. A major adwantage is that the effect of pre-inclusion attrition can be evaluated in the successive phases of each panel study by comparing the general characteristics of each subsample to those of the original sample. Finally, the continuously updated RNH data base can facilitate case-finding in the longitudinal phase of MAAS.

\subsubsection{Medical exclusion criteria}

Medical exclusion criteria for the subject sampling procedure at baseline were defined as those active or inactive medical conditions in the RNH problem list that maly seriously interfere with nomal cognitive function. This definition induded the following problems: coma (only acrive), cerebrovascular pathology, all tumors of the nervous system, congenital malformations of the nerwous system, multiple sclerosis, parkinsonism, epilepsy (all rypes), dementia, organic psychosis (other than dementia), schizophrenia, affective psychosis, and mental retardation. In addition, before participation in the test program all participants were screened in a semi-structured interview to update RNH exclusion criteria and to check for the following exclusion criteria that were not coded in the RNH data base: history of transient ischemic attacks (TLA), brain surgery, hemodialysis for renal failure electroconvulsiwe therapy, and 
regular use of psychotropic drugs. Transient conditions, such as intercurrent illness or hospitalization, was a reason to postpone participation. Finally, a score below 24 on the MMSE (Mini-Mental State Examination, Folstein, Folstein \& McHugh, 1975), a cognirive screening test for dementia, led to exclusion from the study.

\section{2 .4 Procidure $A_{1}:$ Postal survey}

MAAS study $A_{1}$ consisted of two complementary projects:" a postal survey, described in the present section, that was followed by a test progran described in section 3.2.5. This program involved extensive medical and neuropsychological screening of a subgroup that was recruited from the postal survey population. It should be noted that the postal survey distinguishes $A_{1}$ from other A-stidies. As discussed in section 3.1, the postal survey questionnaire was administered in studies $A_{2}$ to $A_{4}$ only to participants in the test program.

Subject inclusion in the postal survey $A_{1}$ was as follows: all subject panels of MAAS Astudies were stratified for age (13 discontinuous classes ranging from $25 \pm 1$ years $85 \pm 1$ years), and sex. As no information on compliance tates was available at the start of the program, the number of subjects drawn per cell was fixed.

Screening for medical exclusion criteria $(\$ 3.2 .3$ ) as coded by the RNH reduced the group of eligible participants in the data base with $4 \%$. Exclusion for medical reasons was age-dependent: for four aggregated age categories (25-35, 40-50, 55-65, and 70-85 years) the exclusion percencages were $2.3,3.3,4.4$, and 8.9 , respectively. From the resulting population, approximately 310 subjects were randomly selected for each discontinuous age class, balanced for sex. To meet the requirements for $A_{11}$, all subjects in the 85-year-age class present were drawn from the RNH register.

Subjects were invited to participare in the study according to a standard RNH procedure. First, the selected subjects were screened by the general practitioner for psychosocial reasons to participate (e.g. actual majot life events). Five percent $(n=197)$ of the original selected popularion of 3,941 was excluded for this reason. Each general practitioner personally invited the selected patients in his or her practice to take part in the study. A short introductory letter with an enclosed return postcard was sent to all subjects. Of this group, 62 percent $(n=2,340)$ agreed to take part in rhe postal survey. After four weeks a reminder was sent to all nonresponders. In total 2,043 subjects (54\%) completed and returned the questionnaire in good order. Of this group, 61 percent $(n=1,252)$ volunteered for the additional test program.

\section{2 .5 Procedure Al: Test program}

Subjects for the $A_{1}$ test program were randomly drawn from the pool of 1,252 individuals who wolunteered for the test program in the postal survey. The participants were stratified for age class, sex, level of occupational activity (LOA, 2 levels; see below), and health status (Biological Life Events, BLE, \$3.3.3). The number of age classes was limited to 12 , because only a very small percentage of subjects in the 85 year group was both available and eligible for furcher assessment. Stratification according to BLE status within each age by sex by LOA cell was performed in $A_{1}$ only. 
The subjects were assigned to two lewels of occupational activity (LOA). LOA was based on a split-half $(1-3$ Low, $4-7 \mathrm{high})$ of scones on a 7 -point scale which esrimates the highest level of professional achievement (DGA, 1989). This scale ranges from the lowest extreme of unskilled, very simple labor to highly specialized labor at academic level Classification was based on the reported occupation and a description of the professional labor. When the information was insufficient to classify LOA, subjects were contacted by telephone for furcher inquiry. Participants with no history of professional activity were assigned to the class of their professionally acrive partner. The choice for LOA as an estimate of general ability for intelligence), instead of the more widely used level of education is discussed in more detail in Jolles er al. (1995, pp. 69-71).

Subjects who agreed in the postal survey questionnaire to participate in further studies were contacted by telephone, to inform them about the purpose of the program, session length (approximately three hours), and test schedule. An appointment was made to wisit the subject at home within two weeks before the actual test session.

During the home visit the subjects were screened once more for specific medical conditions that may be associated with impaired cognitive performance (\$3.2.3). In particular, all RNH exclusion criteria used in the sampling procedure were checked again in more detail and the MMSE was administered. Finally, several tests were performed to screen for primitive reflexes $(\$ 3.4 .2)$.

In total 211 of 679 subjects who were contacted by telephone or who were visited at home eventually did not take part in the test program (Table 3.1). Eighty-five subjects (12.5\%) were excluded for medical reasons; particularly in the older age groups. A substantial group of 121 subjects $(18.1 \%)$ withdrew after being told about the study program in greater detail or after an appointment for the test program was made. The most reported reason for withdrawal was the expected personal investment in time and effort.

Written information about two different addirional. (adnex) studies was handed out at the end of the home visit. Participarion in the MAAS rest program was in no way made contingent on participation in an adnex study. The subjects in the age classes $30,40,50,60,70$, and 80 $( \pm 1)$ years were asked to take part in a collaborative study with the Department of Internal Medicine (24-hour ambulant blood pressure monitoring, see chapters 6 and 8 of this thesis). Intervening age groups in the age berween 25 and $75( \pm 1)$ years were encouraged to volunteer for additional physical fitness assessment at the Department of Movement Sciences (chapter 5 ). The additional studies cook place within four weeks after the $\mathbb{A}_{\|}$test program.

\subsubsection{Effect of inclusion procedure an subject characteristics in $A_{\perp}$}

It is important to identify systematic differences in potentially relevant background wariables of the compliance and noncompliance groups that were formed on the basis of the data from the postal survey. It is known that cognitive impaiment can be associated with a higher risk of morbidity and mortality and also with refusal of cognicive testing (Colsher $\$$. Wallace, 1989 ). Berween-group differences should be taken into account with respect to the external validity of 
findings in MAAS research. Particular variables of interest in this respect are age, sex, educational level, and general health status, which was operationalized as the tocal number of reconded healtin problems.

To study the relation between background characteristacs and participation in the $A_{1}$ study; age level was reduced to four groups: young 25-35 years, young middle-aged $40-50$ years, old middle-aged $55-65$ years, and old 70-85 years. Each group consisted of approximately the same number of people. Wirt respect to the effect of age on subject compliance, there was an increase in compliance with age in the first three age groups. A sharp decrease in the percentage of compliance was observed in the oldest age group compared to the other three groups (Jolles et al., 1995, pp. 32-35).

Participation rate was also influenced by sex, albeit only in the youngest and the oldest age group. In the youngest age group a significantly higher percentage of women were willing to participate. In the oldest age group the opposite was observed, although the difference was smaller.

The RNH educational level discerns three levels of education: low, meditm, or bigh. Patticipation was strongly affected by educational level. Subjects in all four age groups with a lower education were less willing to participate than other subjects. No clear differences in compliance rate were found between subjects with a medium or high level of education.

With respect to the mean numbers of recorded health problems for compliance and noncompliance groups, a small but significant difference was found in the oldest aged group (mean $\pm S D$ was $6.5 \pm 3.8$ in the compliance group, versus $6.0 \pm 3.6$ in the noncompliance group, $p<.05$, Mann-Whimey 0 -Test). Thus, assuming that the number of health problems is a valid proxy for general health status, it can be concluded that health stacus did not seem to have an important effect on compliance rate.

Health status of the participants of the $A_{1}$ test program was compared to that of the remainder of the group that was originally selected from the RNH data base. The inclusion procedure did not affect the total number of health problems. A small but significant overall selection effect was found on the total number of active problems, i.e. slightly more active problems were present in the not-sclected group $(p<.0 \%$, Mann-Whitney U-Test). However, in age-stratified analyses this difference could not be atributed to one of the four age groups. This finding is in accordance with our expectations, as some volunteering subjects were excluded on medical grounds (see Jolles et al. (1995) for a more elaborate discussion on this subject).

In general, selection did not have a substantial effect on health status, based on aggregated RNH morbidity.

\section{2 .7 Procedure of subject enrolment in $A_{2}, A_{3}$ and $A_{4}$}

There were some procedural differences between $A_{1}$ and orher panel studies. On the basis of logistic experience and preliminary data from the $A_{1}$ study, it was deemed necessary to adjust the subject inclusion procedure in some respects. The sample number of 3,941 subjects drawn from the register in $A_{1}$ was needed to get a sufficient number of subjects with and without specific BLE in each of the 48 age by sex by LOA strata. However, a valid escimation of the 
prevalence of $B L E$ was not available until the end of $A_{1}$. Desplte ample subject sampling; no adequate stratification of subjects on the basis of BLE status was possible in the youngest and oldest age cohorrs. Subjects free of BLE were over-represented in the younger age categories, whereas the opposite was true for the older age caregories. BLE status was therefore not maintained as a stratification criterion in $A_{2}$ to $A_{4}$. Next, as no additional advantage was expecred, no home visits were performed prior to resting in $A_{2}$ to $A_{4}$. The administration of the postal questionnaire in these panel studies was restricted to only those subjects who participated in the test program, as screening of a much larger popularion sample was no longer necessary. Therefore, postal questionnaire and test program were merged into one functional unity from $\mathrm{A}_{2}$ onward.

Participancs in the $A_{2-4}$ test programs were again randomly recruited from the RNH data base ( $\$ 3.2 .2)$. They were stracified for age and sex, using the same procedure and medical exclusion criteria as described for $A_{1}(\$ 3.2 .3$ to 3.2 .5$)$. On the basis of the compliance and exclusion rate data from $A_{1}$ and later studies, an estimate was made of the number of subjects needed to meet the age class by sex by LOA stratification criteria for each successive panel study. Generally, older subjects were oversampled, particularly older females. When for some strata the required number was not reached at finalization of one study, additional subjects were drawn in the sampling procedure for the next study. Redundant subjects in one study who were willing to participate and were still eligible with respect to age requirements were invited to take part in the next study. Interim analysis of the subjects available for $A_{3}$ and $A_{4}$ in the RNH data base revealed that specific age by sex strata had become prematurely exhausted as a result of the ample oversampling in these categories to meet the requirements for studies $A_{1}$ and $A_{2}$. At the start of MAAS, age and sex related non-compliance could not be estimated. After two studies it was concluded that non-compliance in the older age groups was a major concern. As expected, older subjects are excluded for medical reasons more often than young or middle-aged subjects. As a result, more than eightold oversampling rates appeared necessary to meet the required number of individuals for cerrain strata. The $80 \pm 1$ year age class was omitred from $A_{3}$ and $A_{4}$, as this category was exhausted by the time the frrst two panel srudies were completed. The option of subject recruitment from other population samples (e.g, non-RNH general practices) was considered unsatisfactory for both methodological and logistic reasons. Therefore, additional measures were taken in $A_{3}$ and $A_{4}$ to accommodate the specific needs of subjects aged 69 years and older, such as transportation to and from the test laboratory and (general) feedback of test tesults.

The subjects were informed about each study in a letter that was signed by the general pracritioner. Willingness to participate in the test program could be indicated on a returti postcard.

The response status and lost-to-follow-up status immediately after the completion of the panel studies $A_{1-4}$ are summarized in Table 3.1. Resulles for $A_{1}$ are displayed separately from other panel studies, because of the postal survey phase that preceded $A_{1}$ and the resulting two-stage sampling procedure for the test program. It can be readily observed that the compliance rate for the $A_{1}$ postal survey was twice as thigh compared to the compliance rate for questionnaire and test program in $A_{2.4}$ combined $(59.2 \%$ and $30.2 \%$, respectively). However, a much larger proportion of volunteers for the $A_{1}$ test program withdrew after telephone 
Table 3.1. Response status and lost-wo-follow-up status for each panel. One should nore that the response sraitus for panel $A_{1}$ periains to the postal survey. Row totals are given separately for $A_{2-4}$ and $A_{1-4}$, because of the procedural differences berween $A_{1}$ ard the later three panel seidies with respect to the inclusion procedure.

\begin{tabular}{|c|c|c|c|c|c|c|c|c|c|}
\hline & \multicolumn{5}{|c|}{ Pane study } & \multicolumn{4}{|c|}{ Row tolals } \\
\hline & \multicolumn{2}{|c|}{$\mathrm{A}_{1}$} & $\mathrm{~A}_{2}$ & $A_{3}$ & $\mathrm{~A}_{4}$ & \multicolumn{2}{|c|}{$\mathrm{A}_{2-6}$} & \multicolumn{2}{|c|}{$A_{1}-4$} \\
\hline 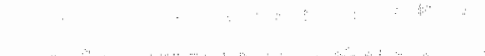 & $N$ & $\%$ & $N$ & $N$ & $N$ & $N$ & $\%$ & $N$ & $\%$ \\
\hline \multicolumn{10}{|l|}{ Response stathes ( = sample drawn from RNHD) } \\
\hline Noncormpliers (No') & 679 & 17.2 & 862 & 1.224 & 766 & 2,852 & 40.6 & 3,531 & 32.2 \\
\hline Compliers $(" \mathrm{es})$ a & 2.362 & 59.2 & 676 & 703 & 749 & 2,128 & 30.2 & 4,490 & 409 \\
\hline Nonpesponders (ro answer received) & 703 & 179 & 509 & 622 & 541 & 1,672 & 23.8 & 2.375 & 21.7 \\
\hline Removed by the GP from sellection & 197 & 5.0 & 89 & 201 & 89 & 379 & 5.4 & 576 & 5.2 \\
\hline Column notal & 3,941 & & 2,136 & 2,750 & 2,145 & 7,031 & & 10,972 & \\
\hline \multicolumn{10}{|l|}{ N Compliers } \\
\hline Total cested b & 471 & 69.4 & 498 & 459 & 446 & 1,403 & 65.9 & 1.874 & 66.8 \\
\hline Exclusion after telephone contact $c$ & 85 & 12.5 & 70 & 67 & 79 & 216 & 10.1 & 301 & 30.7 \\
\hline Exclusion due to exceeding the age limit & 0 & .0 & 28 & 70 & 117 & 215 & 10.1 & 215 & 7.7 \\
\hline Not interested afrer telephone contact & 117 & 17.2 & 63 & 71 & 78 & 212 & 10.0 & 329 & 11.7 \\
\hline Did not show up for cest program & 6 & 9 & 17 & 36 & 29 & 82 & 3.9 & 88 & 3.1 \\
\hline Columin total & $679 \mathrm{~d}$ & & 676 & 703 & 749 & 2,128 & & 2,807 & \\
\hline
\end{tabular}

jo Lost-to-follow-tip stanc $(=$ total tested $)$

\begin{tabular}{lrrrrrrrrr} 
Complete and reliable & 468 & 99.4 & 475 & 446 & 434 & 1,355 & 96.9 & 1,823 & 97.4 \\
Exclusion: MMSE < 24 & 0 & .0 & 13 & 5 & 9 & 27 & 1.9 & 27 & 1.4 \\
Untcliable test results & 1 & 2 & 7 & 8 & 1 & 16 & 1.1 & 17 & 9 \\
Exdlusion: other & 2 & .4 & 2 & 0 & 1 & 3 & .1 & 5 & .3 \\
Columin total & 471 & & 497 & 459 & 445 & 1.401 & & 1.872 & \\
\hline
\end{tabular}

ye Exchusian affer teleptrone connat

\begin{tabular}{|c|c|c|c|c|c|c|c|c|c|}
\hline Dailly use of psychoactive medication & 18 & 212 & 35 & 22 & 28 & 85 & 39.4 & 103 & 342 \\
\hline Status incompatible with testing & 27 & 31.7 & 12 & 18 & 10 & 40 & 18.5 & 67 & 22.3 \\
\hline Cerchrovascular disease (TIA/ CVA) & 8 & 9.4 & 8 & 10 & 11 & 29 & 13.4 & 37 & 12.3 \\
\hline Durch not nartiwe language & 0 & .0 & 4 & 4 & 13 & 21 & 9.7 & 21 & 7.0 \\
\hline Extremely poor wisual / auditory function & 11 & 13.0 & 2 & 7 & 5 & 14 & 6.5 & 25 & 83 \\
\hline Other neurological conditions & 9 & 10.6 & 9 & 1 & 4 & 14 & 6.5 & 23 & 7.6 \\
\hline Other /undocumented & 12 & 14.1 & 0 & 5 & 8 & 13 & 60 & 25 & 83 \\
\hline Column conal & 85 & & 70 & 67 & 79 & 216 & & 301 & \\
\hline
\end{tabular}

Note. Reference date for starus assessmenc was the day after complecion of the panel study. GP = general praciutioner MMSE $=$ Mini-Mental State Examinacion; $I L A=$ rransient ischemic actack; $C V A=$ cetebrovascular sccident. $d$ Number of subjects who volunteered for the $A_{1}$ test program in the postal survey that were conracted by
telephone. 
contact (17.2\% compared to $10.0 \%$ in other parnel studies). Loss of subjecrs as the result of exceeding the age limit did not take place in $A_{0}$ where a relative large pool of potential participants was available.

\subsection{METHODS I: Postal survey}

\subsubsection{Introduction}

In the first phase of the $A_{1}$ study, an extensive postal questionnatre was sent to approximately 2,350 subjecrs aged between 24 and 86 years. A postal survey was considered necessary for rwo reasons. Firstly, there was no information about the prevalence of BLE in a normal healthy population. This information was necessary for the stratification of participants in the $A_{1}$ test program $(\$ 3.2 .5)$. Secondly, epidemiological data were needed on memory complaints or experienced change in memory and memory related funccions in relacion to age, psychosocial funcrioning, mood, and health, with reference to research question $4(\$ 3.1 .3)$. The main topics of interest can be clustered as follows: demographic variables, BLE, physical health, psychological health, and subjecrive complaints about, or experienced changes in memory and memory-related functions, described in sections 3.3 .2 to 3.3 .6 , respectively). The questions used were derived mainly from existing and validated questionnaires. The quality of the questionnaire in terms of comprehensibility and length was evaluated in a pillot study with 80 subjects. The final version contained approximately 500 data fields in a 32 -page booklet. The following section provides more information about the five main topics in the postal survey questionnaire.

\subsubsection{Demagraphic variables}

Lewel of education was measured on an 8-point scale, ranging from primary education to higher vocational training and uniwersicy (De Bie, 1987). In addition, the number of years of full time education was recorded, to comply with the American and British scientific literature. Information was collected about marital status, siocioeconomic status (working position and responsibilities. living conditions, and housing. De Bie, 1987), and the sacial network of the respondents.

To arrive at the level of occupational activity (LOA) of the participants (see also \$3.2.5), the full description of occupational activities was given a 4-digit code (CBS, 1985). This score was then cransformed to the 7-point LOA score, based on a functional classification (Van den Brand et al., 1990). The LOA score incorporates the degrec of complexity of professional work, and the associated knowledge and experience required, ranging from low skilled to scientific labor. The LOA scale was originally developed as a guideline for employment and career counselling (DGA, 1989). 


\subsubsection{Biological Life Events (BLE)}

The concept of BLE and its relevance for MAAS was discussed earlier. In short, BLE can be regarded as health-related factors that are associated with brain dysfunction. Nine types of BLE could be identified on the basis of information from the questionnaire: treatment by a neurologist, systemic disease, brain trauma, general anaesthesia, psychoactive medication use, alcohol and drug abuse, neurotoxic factors, treatment by a psychiatrist (within the past five years), and perinatal or developmental complications (for a further description see Jolles et al., 1995. pp. 40-41).

\subsubsection{General bealth}

Questions regarding past and present morbidity that may have relevance for cognitive functioning were derived from a medical screening questionnaire commonly used in general practice (LHV, 1981). Several items were added about the type of medical consultation resulting from health complaints or illnesses. Medication use (including over-the-counter drugs) was recorded and coded according to a custom classification, based on the pharmacological characteristics and side-effecrs of drugs (Dukes, 1988; Dukes \& van Dijke, 1984).

The subjects were asked to rate their overall health on a 5-point scale in three ways: in general, compared to that of age mates, and compared to their overall health one year ago (ranging from very bad to very good). The VOEG-21 (inventory of subjective health) was included as an index of subjective health (Dirken, 1967) which probes health complaints of a somatic and psychosomatic nature. It was included because of the expected relationship between subjective measures of memory and memory-related functions, and subjective health. More specific questions cover the instrumental activities of daily living (IADL), functional status, and consumption of health services, including the use of alternative health care.

\subsubsection{Lifectyle and psychologiral bealth}

Detailed information was collected about alcohol, coffee, and tea consumption, and smoking habirs. Because of the expected relationship berween mood and memory complaints, three subscales of the Symptom Check List (SCL-90) were included (depression, anxiety, and sleep). The SCL-90 is a widely used multidimensional checklist for psychopathological complaints (Arrindell \& Etrema, 1986).

In addition to mood and health, several other psychosocial variables may play a mediating role in determining the presence or absence of complaints about cognitive functioning in later life. For this reason the questionnaire covered the following psychosocial domains: daily activities (expressed as hours devoted to, for example, watching television reading, and practicing sports), experienced life-events in the past year, the quality of life, and the lifesatisfaction. 


\subsubsection{Sibjective complaints abowt memory and mewory-related functions}

Most research on age-related (subjective) changes in cognitive functioning has focused solely on memory. To what extent age-related changes occur in other cognitive domains, eg. attentional functions, mental speed, and planning, is largely unknown. Therefore, the subjects were asked to rate their present cognitive functioning in three ways" by comparing it to that of people of their own age, by comparing it to their own level of cognitive funcrioning 5-10 years ago, and, finally, by comparing their present level of cognirive functioning with their functioning at the age of 25 years. The fact that subjects notice a change in their cognitive functioning does not necessary imply that they have complaints about cognitive functioning. 'Therefore, specific questions were included about memory complaints and perceived hindrance in other cognitive domains (e.g. attention, reading, motor performance) and about how people dealt with this.

Detaled information about subjective memory functioning is obtained with the Meramemory in Adulthood Questionnaire (Dixon, Hultsch \& Herzog, 1988). One is asked to rate, on a 5-point Likert scale, 108 statements describing one's memory funcrioning and the knowledge of general memory processes. The MIA is a multidimensional questionnaire consisting of seven dimensions, or subscales. Three of these scales (change, capacity and anxiety) can be combined to form one higher-order dimension of memory selfefficacy, reflecting the belliefs about one's capacity to use memory efficiently in different siruations (for further details, see Jolles et al, 1995 , pp. 85-94).

\subsubsection{The MAAS-questionnaire in $A_{2-4}$}

The contents of the questionnaire remained largely unmodified after the analysis of the $A_{1}$ postal survey data. The extensive MIA questionnaire was reduced wo abour half the length of the original questionnaire (Ponds \& Jolles, 1996). Furthermore, additional questions were included regarding health-related life styles, health-related locus of control, and about one's expectations of medical services when complaints with respect to cognitive functioning were reported. The final version of the questionnaire was used in the $A_{2}, A_{3}$ and $A_{4}$ panel studies and now serwes as the basic questionnaire for many other research projects.

\subsection{METHODS II: medical and neurocognitive assessment}

\subsubsection{Introduction}

This section describes the medical and neurocognitive measurements that were used in the $A_{1}-A_{4}$ studies.

Not all cognirive tests that are used in MAAS serve as dependent measures. Tests may be applied as screening instruments or even serve as exclusion criterion (e.g. the Mini-Mental State Examination (MMSE), as a sceening test for possible dementia) and some are used as independent subject variables (e.g. hand preference). The outcome of several subtests from the Groningen Intelligence Test (GIT; Luteijn \& wan der Ploeg, 1983) are combined to make an 
reliable estimation of formal 1Q. Finally, wariables derived from medical tests can be used as indicators of sensory function and health status and may serve as covariates in statistical analyges (e.g. wisual acuiry).

The majority of the dependent variables in MAAS are of course cognitive, as MAAS is essentially a cognitive gerontological project. The cognitive tests can be divided into three categories, based on the frequency of their use in the A-studies. The first is made up by those tests that are given at least once in every parallel study. They constitute a leitmotiv of domains of cognitive functioning probed in MAAS and, indeed, in clinical assessment. For each of these aspects of cognition, one or more variables are defined as being central to the domain. After staristical validation, these variables are used to arrive at standardized compound scores indexing specific cognicive domains (see $\$ 3.4 .4$ ). These rests are re-administered at all follow-up measurements (category 1 tests in Table 3.2). One typical example is the Verbal Learning Test, a widely used test of secondary memory.

A second category of tests is administered to subjects within several but not all A-studies. These tests are used to sudy specific research questions that are not central to the MAAS project, as a whole. They are administered to a sufficiently large sample population to arrive at age norms which are essentially needed if a test is to be used in a clinical setting (category 2 , Table 3.2 ).

The third category of tests (number 3 in Table 3.2) are under development and are administered only to a subsample of one or two $A_{x}$ studies. Based the experience gained in the study, the test can be modified, or provisional norms can be drawn up. This procedure has the additional advantage that more tests can be studied (see Jolles et al., 1995).

\subsubsection{Medical variables}

The antbropometric parameters length, weight, waist, and hip circumference, are determined to calculate the Body Mass Index (BMI), and waist-to-hip ratio. Both indices are used as independent risk factors for vascular damage (Egger, 1992; Mueller et al., 1991) and can therefore be directly or indirectly associated with cognitive function. From $\mathrm{A}_{2}$ onward, head. circumference was measured as an index of cranial wolume that may be used as estimate of brain reserve capacity (Graves et al, 1996).

Binocular wirual acuity is determined by means of the Landoll-C optotype chart, at a distance of fwe meters, under standard luminescence and with corrected vision.

Hedring acwity is assessed at four different frequencies that are important for adequate speech perception, with the aid of pure tone audiometry. Each ear is rested separately at frequencies of $.5,1.0,2.0$, and $4.0 \mathrm{kHz}$ in steps of $10 \mathrm{~dB}$ to determine pure tone detection thresholds. The rationale to assess sensory loss is the obserwation that hearing defects may moderate cognitive outcome measures (Rabbitt, 1991; Van Rooij \& Plomp, 1991).

Blood pressure is a well-recognized risk factor for vascular pathology. During each test session, blood pressure and pulse are measured five times in 20 minutes at fixed intervals, on the left arm and with the subject, seated, by means of an automatic recording device (Critikon Dinamap $\left(\right.$ 8100). In $A_{2}$, two additional blood pressure measurements were performed with 
the subject standing upright after 20 minutes to detect an orthostatic hypotensive reaction. Several studies have suggested that blood pressure status may be related to cognitive measures (e.g. Elias, Robbins, Schultz \& Pierce, 1990; Elias, Wolf, D'Agostino, Cobb \& White, 1993; Scherr, Hebert, Smith \& Evans, 1991).

In $A_{1}$ only, a set of nine primitive reflexes were scored for amplitude and persistence according to the standard protocol of Vreeling, Jolles, Verhey and Houx (1993). For example, the existence of the grasp reflex, palmomental reflex, and pollicomental reflex was determined on both sides of the body. The prevalence of primitive reflexes increases with age and a relationship with the presence of specific BLE (e.g. general anesthesia and the use of psychotropic medication) was demonstrated earlier (Vreeling et al., 1993).

\subsubsection{Cognitive wariables: description of core tests}

Mini Mental State Examination (MMSE). As MAAS is a study into cognitive aging, and a large number of elderly people are included, it was considered necessary to use an internationally accepted screening instrument for dementia: the Mini-Mental State Examination (Folstein et al., 1975). The MMSE is a test which broadly assesses several domains of cognitive functioning. It should be noted that the MMSE was included in MAAS because of its widespread use, not because of its psychomerric qualities. Conclusions about the cognitive functions studied will therefore not be based upon items from this test, but on more extensive, domain-specific tests. The instrument consists of the subscales orientation, registration, recall, attention, language, and construction.

Verbal Learning Test (VLT). The Groningen Fifteen Words Test (Brand \& Jolles, 1985; Deelman, Brouwer, van Zomeren \& Saan, 1980) is an improved version of a test originally devised by Rey (1964). Fifteen words are successively presented, separated by short time intervals. Nexr, the subject is asked to reproduce as many words as possible. This procedure is repeated five times. After 20 minutes, delayed recall and recognition are assessed. In its present form, the VLT makes it possible to assess separately learning capacity, memory storage and memory retrieval of newly learned verbal material.

The Letter-Digit Substitution Test (LDST) is a modification of the procedurally identical Symbol-Digits Modalities Test (SDMT, see Lezak, 1983, pp. 554-555; Smith, 1968). In neuropsychological assessment, this coding task yields a measure of the speed of processing of general information, i.e., the test is supposed to draw upon several (cognitive) processer simultaneously, without the intention of making inferences about specific processes, such as visual scanning and perception, visual memory, visuoconstruction, or motor functions.

The Memory Scanning Test - paper and pencil version (PorP-MST) is designed to study the speed of memory processes (Brand \& Jolles, 1987). The underlying principle is that the additional time needed to complete a test in which there is a stepwise increase in the amount of information to be kept in memory, reflects the ease at which information is processed in working memory (Sternberg, 1975). 
"The Movor Chore Reaction Test (MCRT) is a computerized rest, in which reaction times are studied as a function of the complexity of task requirements (Houx, Vreeling \& Jolles, 1993). In addition, the speed and accuracy of arm movements over short trajectoties are also studied.

Fluency is defined here as the abiliry to produce as many words as possible in a given caregory, within a fixed time span. It is regarded as a measure for the adequate, strategy-driven retrieval of information from semantic memory. If, for instance, the subject is requested to name as many animals as possible within one minute, performance is greatly enhanced when a limired number of categories (such as farm animals or aquarium fish) are systematically searched. The naming of animals and professions / trades for one minute each is a subtest of the GIT (see below). Another Duency task that is used is to name as many four-letter words starting with a given leter $(M$ and $S$ ) as possible.

Concept Shifting Test (CST). This is an adapted wersion of the Trail Making Test (TMT) that is used to mosure visual conceptual and visuomotor tracking. The TMT has been used for clinical diagnostic purposes, especially as part of the Halstead-Reitan Battery (Reitan, 1958). The CST was designed to avoid several methodological problems with the TMT. On each test sheet, 16 small circles $(\varnothing 15 \mathrm{~mm})$ are grouped in a larger circle $(\varnothing 8 \mathrm{~cm})$. In the smaller circles, the test items (numbers (A), letters (B), or both (C)) appear in a fixed random arder. Subjects are requested to cross out the items in the right order. The time needed to complete the tasks is recorded.

The Stroop Color-Word Test (SCWT) is often used to test selective attention (e.g. Houx, Jolles \&. Vreeling, 1993). It involves three cards which display a hundred stimuli each: color names, colored patches, and color names printed in incongruously colored ink (cards I-III, respectively). The amount of time needed to read (card I and III) or to name colors (card II) is recorded. Performance on card III is determined for a large part by the time needed to discard irrelevant but very salient information (verbal), in favor of a less obvious aspect (color naming), a process known as cognitive interference.

Four subtasks of the Croningen Intelligewce Test (GIT, Luteijn \& van der Ploeg, 1983) are administered to arrive at an estimation of the intelligence quotient, or IQ. The GIT tends to rely less on verbal abilities and is therefore deemed berter suited than the also broadly used Wechsler Adult Intelligence Scale (WAIS, Wochsler, 1981) which is more performance-based. These subtasks are:

Doing sums [in Dutch: 'Cifferen'] (GIT1) involves the correct completion of as many sums (addition) as possible in one minute. As this is a timed task, ir cant be considered a typical performance test, involving fluid abilities.

Vocabulary ['Woordenlijst'] (GIT2) is a multiple-choice rest for perhaps the most crystallized ability of all. The subject is asked to indicate which of five alternative words is exactly synonymous with a given word.

Mental rotation ['Legkaar"] (GIT3) requires the subject to indicate which two-dimensional shapes from a larger ser are needed to exactly fill up a given space on the test page. Subjects have to mentally rotate each of the shapes that are, as a rule, not presented in the proper orientation. Although there are cime constraints, it is not a speed test since the time allotred 
per item is seldom exceeded. Apart from mental rotation, this subrest also draws heavily upon constructional abilities.

Andogies ["Woordmatrijzen'] (GIT4) can be considered as a multiple choice version of the well-known Similarities subtest of the WAIS. The task is to indicate which of five alternarives is related in the same way to a given word as words in an example are related. This test calls upon werbal reasoning capacity, which is thought to be primarily a crystallized ability.

An overview of all cognitive tests that were used in MAAS- $A_{1-4}$ in one or more panel studies is given in Table 3.2: an elaborate description of each test is given in Jolles et al. (1995).

\subsubsection{Compound scores of cagnitive performance measures}

The ample cognitive data base of MAAS forces the individual researcher to make strategic choices with respect to the set of outcome measures of interest, depending on the question under study. For this purpose the use of composite cognitive scores is recommended in which taw test scores measuring performance in the same cognitive domain are combined to yield a more robust estimate of function within such domain. Three different domains are generally distinguished, memory, sensorimotor or basic speed, and cognitive or complex speed. The distinction in two discrete speed measures is based primarily on the assumption that some cognitive measures more closely reflect direct stimulus-response connections and only a low level of central processing (e.g. word reading or digit cancellation) while other tests draw heavily on resources and more closely reflect the time needed for higher order information processing (e.g. concept shifting, color-word interference; see Larue, 1992). This approach is employed in the chapters 4 , and 7 to 9 and is discussed in more detail in chapter 10 .

\subsubsection{Additional questionnaires}

Several questionnaires were added to the test battery in the course of the program.

Effort scales $\left(A_{1-4}\right)$. Visual analogue scales are used to assess subjective effort to complete the cognitive tests. These measures are taken to study the potential discrepancy berween performance and the amount of effort needed to complete a task, as is often observed in neuropsychological practice (Zijlstra \& Meijman, 1989).

Satisfaction with Life Scale (SWLS; $A_{1-4}$ ). A five-item questionnaire developed as a measure of overall subjective well-being (Pavot, Diener, Randall Colvin \& Sandvik, 1991).

Positive and Negative Affect Schedule (PANAS; $\mathrm{A}_{1}$ ). A 20-item mood scale that measures positive and negative affect (Watson, Clark \& T'ellegen, 1988).

Maustricht questionnaire $\left(A_{2}\right)$. This 23-item questionnaire is sensitive to psychological prodromes of cardiovascular morbidity (Appels, Höppener \& Mulder, 1987) and was administered in one panel study to arrive at normative walues for a non-clinical population.

Neuro-vegetative questionnaire $\left(\mathrm{A}_{2-4}\right)$. The questionnaire consists of a list of 28 neurovegetative symptoms that can be reduced to a single score. The outcome correlates with persisting complaints after mild head injury (Bohnen, Twijnstra \& Jolles, 1992). Reference values for this questionnaire are obtained from three different MAAS panels. 
Table 3.2. Neurocognirive test that were used in one or more A-scudies.

\begin{tabular}{|c|c|c|c|c|c|}
\hline \multirow[b]{2}{*}{ 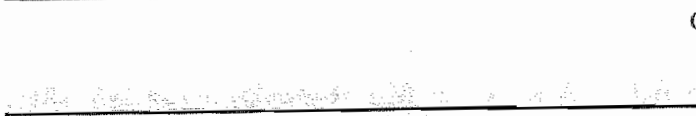 } & \multirow[t]{2}{*}{ Category } & \multicolumn{4}{|c|}{ Panel study } \\
\hline & & $\mathrm{A}_{1}$ & $A_{2}$ & $A_{3}$ & A4 \\
\hline Aurmerksamikeits-Beldstungstest (D2) & $2 *$ & & - & & \\
\hline Benton Visual Rerention test (BYRT) & 2 & . & & & \\
\hline Benton Revised Visual Rerention Test (BVRT-R) & $2^{*}$ & & & $\bullet$ & \\
\hline Boston Naming Test (BNT) & $2^{\text {*n }}$ & & & & - \\
\hline Dicycle Drawing Test (BDT) & 2 & $*$ & & & \\
\hline Catrell Culture Fair ( $\mathrm{CCF})$ & $2^{*}$ & & $\cdot$ & & \\
\hline Concept Shifuing Test (CST) & $\mathbb{1}$ & - & $\bullet$ & . & - \\
\hline Continuous Tapping (TAP) & 2 & - & & & \\
\hline Desugn Fluency (DF) & $3^{*}$ & & & & - \\
\hline Discturatue Arithmetic (DA) & $3^{*}$ & & & & $\cdot$ \\
\hline Dunch Adule Reading Test (NLV) & 2 & $*$ & & & \\
\hline Durch Adult Reading Test: contextual version (NIV-C) & $3^{*}$ & & & & 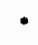 \\
\hline Edimburgh Handedness Inwentory (WHDb & 1 & $\cdot$ & - & $*$ & - \\
\hline Episodic Merrory (EM) & 2 & $\cdot$ & & & \\
\hline Four Choice Spatial Reacion Time Task (FCSRT) & 2 & & & & - \\
\hline Gromingen Arithmetic Memory Scamning Task (GAMST) & $2^{*}$ & & & & $\cdot$ \\
\hline Groningen Cartegory Task (GCT) & $2^{*}$ & & & & - \\
\hline Groningen Intelligence Test - abbreviated (GIT)b & 1 & * & $\cdot$ & - & - \\
\hline Letter-Digit Substitution Test (LDST) & 1 & $\cdot$ & $\cdot$ & $\cdot$ & - \\
\hline Letrer-Digit Substutution Test - rotated (LDST-R) & 2 & & & & 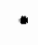 \\
\hline Lexical Decision "Task (LOT) & $3^{*}$ & & & & 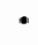 \\
\hline (Hypersensitivity to) Light and Sound & $2^{\text {** }}$ & & & & - \\
\hline Line Bisecrion Test (LBT) & $2^{*}$ & & & $\cdot$ & \\
\hline Logical Memory (LM) & $2^{*}$ & & - & & \\
\hline Memory Scanning Test (P\&P-MST) & $\mathbb{1}$ & $\cdot$ & $\cdot$ & - & - \\
\hline Memory Scanming test Shadowrs and Cubes (S\&C P\&P-MST) & $2 *$ & & & - & \\
\hline Mini Mental State Examination (MMSE) & 1 & $\cdot$ & $\cdot$ & $\bullet$ & - \\
\hline Motor Choice Roaction Test (MCRT) & $\|$ & $*$ & $*$ & - & $*$ \\
\hline Prospective Mcumory (PM) & 3 & & $\cdot$ & & \\
\hline RAKIT Hidder Figures (RAK-HF) & $2 *$ & & & & * \\
\hline Raven's Standard Progressive Martiones (RSPM) & 2 & $\cdot$ & & & \\
\hline Recognicion Memory (RM) & $2^{*}$ & & - & & \\
\hline Sell-Paced Audinory Serial Addicion Test (SPASAT) & $2 *$ & & $\bullet$ & & \\
\hline Signal Detection Test (SDT) & 2 & $\cdot$ & $*$ & $\cdot$ & \\
\hline Stroop Color-Word Test (SCWT) & 1 & $\cdot$ & * & $\cdot$ & • \\
\hline Siroop Color Word Test Plus (SCWT+*) & 2 & & * & & \\
\hline Tower of London "iest (TOL) & 2 & $\cdot$ & & & \\
\hline Verbal Learning Test (VL.T) & 1 & $\cdot$ & $\cdot$ & $\cdot$ & - \\
\hline Verbal Learning Test: LSI manipularion $(V L T \cdot E)$ & 3 & & & $\bullet$ & \\
\hline Verbal Learring Test: with interference (VLT-D) & $3 *$ & & & & - \\
\hline Warrington :s Facial Recognition Test (WFRT) & $2^{*}$ & & - & & \\
\hline Word Span Tear (WST) & 2 & $\bullet$ & & & \\
\hline
\end{tabular}

Note. aragory: 1 a core test included in all follow-up measurements; 2 = included for normative or validation purposes; 3 = tests under development; * $=$ administered to a subgroup of a panel scudy.

bxception: core rest not inchuded in all follownup measturements. 
The RAND-36 is a general health questionnaire $\left(A_{3-4}\right)$. This scale has recently been adapted for the Dutch language and is identical to the Anerican MOS SF-36 (Van der Zee \& Sanderman, 1993). The scale defines health in terms of funcrional capacity and includes subscales for physical function, social function, role limitations induced by physical problems, mental health, energy, pain, and general health perception.

COOP / WONCA functional health assessment charts $\left(\mathrm{A}_{2-4}\right)$. The original charts probe seven aspects of functional status, physical condition, emotional condition, daily activities, social activities, overall health, change in health and pain (Nelson, Wasson, Kirk \& al., 1987; Scholten \& Weel, 1992). An additional chart was added regarding the cognitive status (memory and concentration). The eight charts contain simple pictograms to help respondents choose the appropriate answer. Chart scores can be used as potential predictors of cognitive outcome and to define reference values in a mon-clinical population.

Loneliness questionnaire $\left(A_{3-4}\right)$. The scale is used as a correlate of subjective outcone measures in MAAS (De Jong-Gierveld \& Kamphuis, 1986). Perceived loneliness may well be a strong determinant of happiness or unhappiness and of low scores on, for instance, the Satisfaction With Life Scale (SWLS).

\subsubsection{Data management}

All MAAS questionnaires and test forms were structured in such a way that all data could be stored readily in numerical fields. Final versions of data files were transferred to MEMIC (Center for Data and Information Management, University of Maastricht), where all data are stored in a relational database (Register of Cognitive Aging and Dementia, RCAD). RCAD is implemented on a DEC-Alpha mini-computer, using a dient-server concept. Data security is safeguarded by the use of username and password protection. Researchers who want to consult data in RCAD require permission from the register team. After approval is obtained, the data blocks are delivered by the coordinator of the register as computer files that can be readily used in standard statistical packages (e.g. SPSS). Data dictionaries can be consulted by researchers via the internet, or are made available as hard copy.

Data from the RNH register can be linked to data in RCAD for specific purposes. For example, information about past and actual morbidity can be coupled to test performance data. The key code for matching procedures is kept by MEMIC, the university service that also manages RNH. Personal identification codes are stripped from files that contain matched RNH and RCAD data by MEMIC before delivery to the requesting research deparment to guarantee confidentiality. RCAD complies to governmental regulations regarding registration of personal data (Wet Persoonsregistraties, 1988).

MAAS can be visited on the internet (WWW) at: http:l/mpo011.rulimburg.nLMAAS/ 


\section{REFERENCES}

Appets, A., Hoppener, 1 ., 8 Malder, P. A (1987). A questionmaire to assess premonitory symproms of myocandial

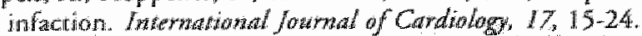

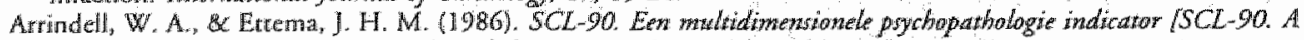

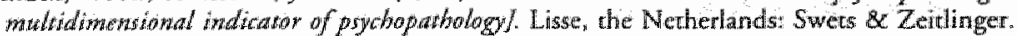

Bohnen, $W_{, 3}$ Twinstia, A. \& Jolles, J. (1992). Post-raumatic and emorional symproms in different subgroups of

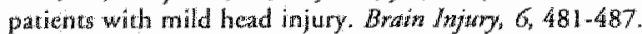

Brand, N., \& Jolles, J. (1985). Learning and retrieval rire of words presented anditory and wisually. Jourmat of Geineral Psychalogy, $112,201-210$.

Brand, W., \& Jolles, J. (1987). Fiformation processing in depression and anxiety. Prychological Medicine, 17, 145153.

Catcell, R. B. (1963). Thegry of flud and crystallized incelligence: A critical experimenr fowmat of Educational Pychologit, 54, 1-22.

Centrabl Bureatu voor de Staristick. (1985). Beropenclassificatie 1984 (Clasification of Occupations 1984). Voorburg: CBS.

Colsher, P. L. \& Wallace, R. B. (1989). Data qualiry and age: Healch and psychobehawioural correlates of item nonicesponse and inconsistent responses. Jownal of Gerowology, 44, $\mathrm{P} 45.52$.

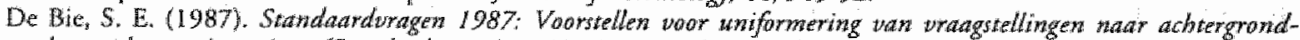

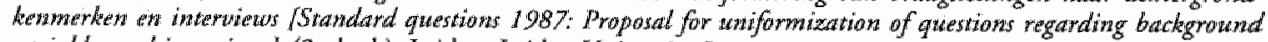
watrables and interwieus. (2nd ed.). Lexiden: Leiden Uniwersity Press.

De Jonge-Gierveld, J., \& Kamphuis, F. H. (1986). The development of a Rasch-type Londiness scalc. Applied Psydologich Meaturement 9, 289-299.

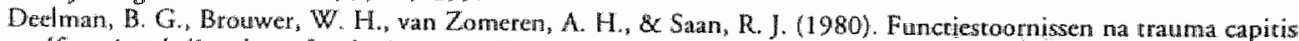
[functional disordets after brain tratuma], In A. Jennekens-Schinkel, J. J. Diamant, H. F. A. Diesfelde, \& $\mathbb{R}$. Hatama (Eds.), Newropsychologie in Nederland. Devencer. The Netherlands: Var Loghum Slaterus.

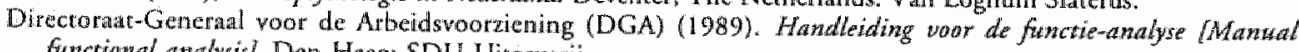
functional atwolysisy. Den Haag; SDU Uitgewerij

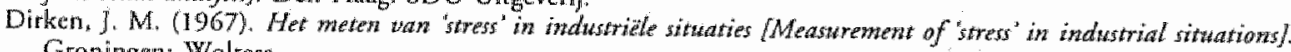
Groningen: Wolters.

Dixon, R. A. Hultech, D. P, \& Herzog, C. (1988). The Mecamemory in Adulthood (MIA) questionnaire. Psychophatmacalogy Bullerin, 24,671-688. Dukes, M. N. G. (1988). Meyler's side effects of drugs: An encyclopedia of adwerse reacrions and interactions (11 ed.).
Amsterdam. Elsevier.

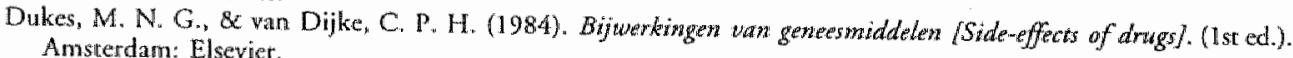
Amstherdam: Elsevier.

Egger, G. (1992). "The case for using waist-to-hip ratio measurements in routine medical checks. The Medical journal of Anatatia, $156,280-285$.

Elias, M. F., Robbins, M. A., Schuln, ]. N. R. Be Pierce, T. W. (1990). Is blood prassure an important variable in

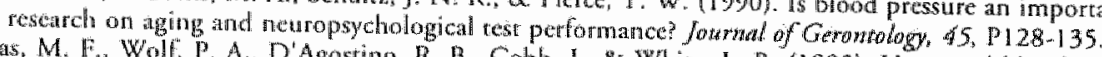

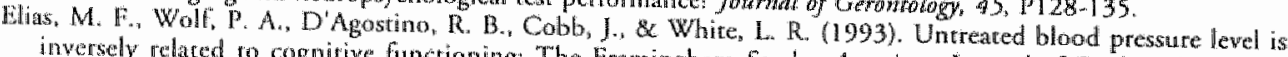

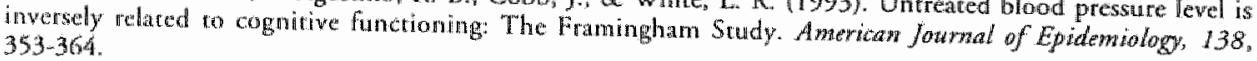

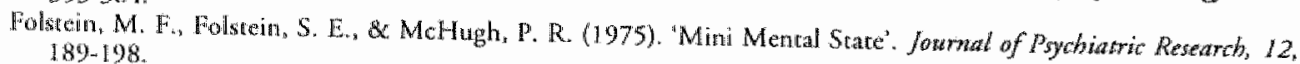

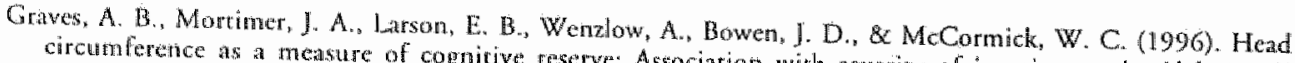

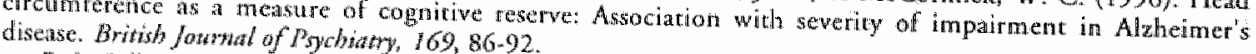

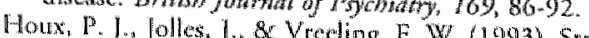

Word test. Experimewat Agring Rertwh. 10,200-22

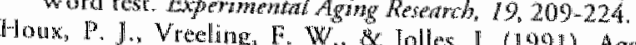

avents. In K. lgbal, D. R. C McLach

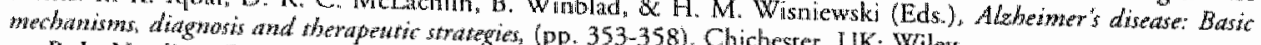

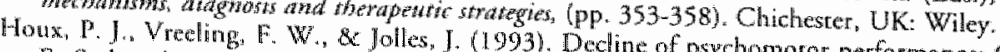

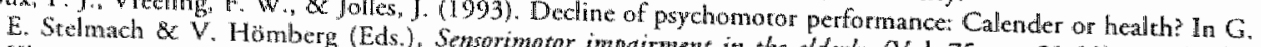
K! luwer.

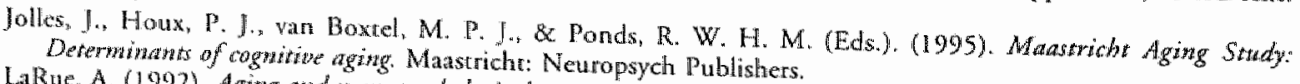

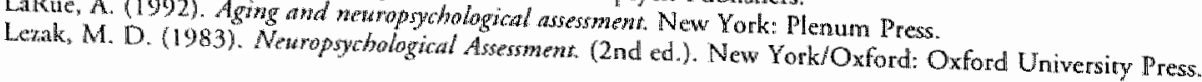




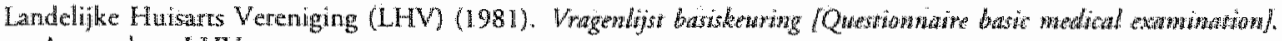
Amsterdam: LHV.

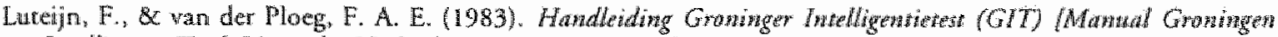
Hatelligence Test. Lisse, the Netherlands: Swers and Zeitlinger.

Metsemakers, J. F. M.. Höppener, P.s Knotmenus J. A., Kocken, R. J. J.2 \& Limonard, C. B. G. (1992). Computerized health information in the Netherlands: A registration network of family pracrices. Brinish foumal of Geneval Pratcice, 42, 102-106.

Mueller, W. H., Wear, M. L., Hanis, C. L., Emerson, J. B., Barton, S. A., Hewent-Emment, D. \& Schull, W. I. (1991). Which measure of body fac discriburion is best for epidemiologic researcla? American Jourmal of Epidemiology, 133, 858-886.

Nelson, E. C., Wasson, J., Kirk, J., er al. (1987). Assessment of function ith routine elinical pracrice. Description of

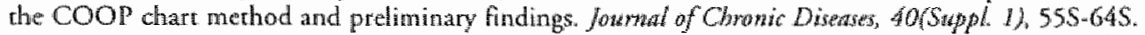

Pawot, W., Diener, E, Randall Colwin, C. R, \& Sandwik, E. (1991). Further validation of the Sutisfaction Wirh Life Scale: Evidence for the cross-method convergence of well-being measures. Jow of pal personaticy Assessment, 57, 149-161.

Ponds, R. W. H. M., \& Jolles, J. (1996). The abridged Dutch Metamemory in Adulthood (MIA) Questionmaire: Structure and effects of age, sex, and educarion. Pyychology and Aging, 11, 324.332.

Rabbirt, P. (1990). Applied cognitive gerontology: Some problems, methodology and data. Applied Cogzitive Psychology, 4, 143-149.

Rabbirt, P. (1991). Mild hearing loss can cause apparent memory failures which increase wirth age and reduce with 1Q. Acta Otolaryngolagia Stockbolm, 476 (Suppli), 167-176.

Reitan, R. M. (1958). Validity of the Trail Making Test as an indication of organic brain damage. Percepratal atwa Moror Skills, $8,271-276$.

Rey, A. (1964). Lexamen psychologigae dans des cas d'encephalopatbie manmatique (Psychatogical assessment in cases of trawamatic bratin injuryl. Paris, France: Presses Universitaires de France.

Rowe, J. W. \& Kahr, R. L. (1987). Human aging: Usual and successful. Science, 237, 143-149.

Scherr, P. A., Hebert, L. E., Smith, L. A., \& Evans, D. A. (1991). Relation of blood pressure to cognitive function in the elderly. American Journal of Epidemialogy, 134, 1303-1315.

Scholten, J. H. G., \& Weel, C. v. (1992). Functional status assessment in family practice: The Dartmore COOP functional health assessment chare IWONCA. Lelystad: Meditekst.

Smith, A. (1968). The Symbol Digit Modalicies Test: A neuropsychological test for economic screening of learning and orther cerebral disorders. Learning Disorders, 36, 83-91.

Sternberg, S. (1975). Memory scanning: New findings and current controversies. Quarterly Journat of Experimental Psychology. 27, 1-32.

Van den Brand, P. A., Goldbohm, R. A., van 't Veer, P., Volovics, A., Hermus, R. J. J., \&e Surmans, F. (1990). A largescale prospective cohorr study on diet and cancer in the Netherlands. Joumat of Clinsical Epidemiolory, 43, 285 295.

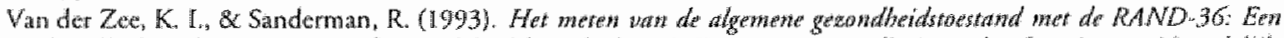

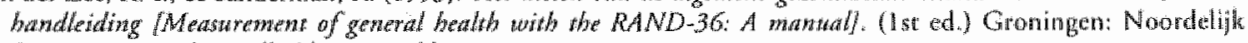
Cestrum woor Gezondheidswragagrukken.

Van Rooij, J. C. G. M. \& Plomp, R. (1991). Auditive and cognitive factors in spech perception by eldarly listeners. Acta Otolarymgologia Stockholon, $476,177 / 181$.

Vreeling, F. W., Jolles, J. Verhey, F. R. J., \&. Houx, P. J. (1993). Primitive reftexes in healthy, ad ule wolunteers and: neurological parients: Merhodological issues. Jourhal of Neurology, 240, 495-504.

Watson, D. Clark, L. A., \& Tellegen, A. (1988). Dewelopment and walidation of brief measures of positive and negariwe affect: The PANAS scales. Joumal of Personality and Social Psychology. 54, 1063-1070.

Wechsier. D. (1981). Manual of the Wecther Adult Intelligence Scale-Rerused. Now York: Psychological Corporation.

Whice, N., \& Cinningham, W. R. (1988). Is rerminal drop pervasive or specifics Jonowat of Gerountology, 13, P141144 .

Williarns, J. D., \& Klug, M. G. (1996). Aging and cognition: Methodological differences in outcome: Experimental Aging Resaarch, 22, 219-244.

Zijlstra, F., \& Meijman, T. (1989). Het meten van mentale inspanning met behulp warn een subjectieve methode [Measurement of mental efort wsing a subjecrive merhod]. In T. Meijman (Ed.). Mentale belasting en werkstress, (pp. 42-61). Assen/Mastriche: Van Gorcum. 



\section{Self-reported physical activity, subjective health, and cognitive performance in older adults ${ }^{2}$}

\section{ABSTRACT}

The literature to date suggests a positive relationship between physiological indicators of physical fitness (such as aerobic capacity) and indices of cognitive performance. However, the complexity and cost of methods to measure physical fitness prohibits their use in large population studies in cognitive aging research. In this study a questionnaire measuring habitual physical activity was used as an indirect estimate of physical fitness, to predict performance in several cognitive domains in an age and sex stratified sample of 80 healthy older adults ( 55 years and over). Age effects were found on several measures of cognitive speed and fluency, but not on memory performance. Women were slower in sensorimotor speed than men but scored higher on memory tasks. No main effects of activity on cognitive measures were found, but two measures which assess cognitive speed were sensitive to the age by activity interaction term. Subjective health also appeared to contribute to the explained variance in the same two indices of cognitive speed. Limitations of the use of activity questionnaires in cognitive aging research are discussed.

\section{INTRODUCTION}

Evidence from population studies suggests that several basic cognitive abilities are affected by chronological age (Poon, 1985). In particular, tasks that involve some form of fluid intelligence, secondary memory, abstract reasoning or visuospatial abilities show an agerelated decline (for a comprehensive review, see LaRue, 1992). Recently, it was demonstrated that factors which could potentially influence brain funcrioning may have a substantial effect on the cognitive performance of healthy elderly subjecrs (Houx \& Jolles, 1993; Houx "Vreeling \& Jolles, 1991). Habitual physical activity has received much attention in this respect as a potential protective factor for neurocognitive functioning (Chodzko-Zajko, 1991).

Physical activity may improwe the aerobic capacity, defined as the maximal oxygen consumption of the body, and may be positively related to brain function in several ways. Improvement of cerebral blood flow through physical activity can play an important role in the maintenance of adequate brain function in old age (Rogers, Meyer \& Mortei, 1990). Physical exercise may increase the oxidative capacity of the brain and is presumed to exert a trophic effect on brain centers involved in sensorimotor function (Spirduso, 1980).

2 M. P. J. van Boxtel, K. Langerak, P. J. Houx, and J. Jolles (1996). Experimental Aging Research, 22, 363-379. 
Several cross-sectional studies suggest a positive relarionship in older adults berween aerobic capacity or acrobic ckercise lewel and, e.g, reaction time, working memory abstract reasoning (Clatkson-Smith \& Hartley, 1989; Clakson-Smith \& Hardcy, 1990), psychomotor speed (Baylor \& Spirduso; 1988; Spirduso, 1975), symbol-igit subsritution (Stones K Kozma, 1989), and visuospatial processing (Shay \& Roth, 1992). However, longitudinal studies that have directly manipulated aerobic capacity in an exercise incervention program have yielded mixed results. Elsayed, Ismail and Young (1980) found that a 4-month aerobic training program improved the performance of a relatively young sample (24-68 year) on subtests of Auid intelligence, but not on crystallized intelligence. In another study, a 55-70 year old group was investigated before and after a 4 -month exercise program (Dustman er al, 1984). The performance in this group showed an exercise related improvement of simple reaction cime, digit-symbol substitution and Stroop interference, but not of nonverbal reasoning or choice reaction time. In another sample of older adults (60-83 year) no exercise-mediated improvement was found on reaction time tests of attention and memory retrieval after 16 weeks of aerobic exercise training (Madden, Blumenthal, Allen \& Emery, 1989). Blumenthal and Madden (1988) found that the memory search performance of middleaged subjects (30-58 years) was positively related to aerobic capacity only at the start of a 12-week fitness program but was unrelared to the increased finess achieved in this period. Finally, in another study no improwement on a broad range of cognitive performance measures was found after a 1-year training program in sedentary older subjects between 60 and 73 years of age (Hill, Storandr \& Malley, 1993). In summary, older subjects with an active lifestyle ofren perform better than their sedentary contemporaries on performance tasks that are typically sensitive to the effects of age. "The effects of short-term exercise intervention programs on performance are, however, equiwocal (Hawkins, Kramer \& Capaldi, 1992).

Population-based research aimed at the complex relationship between physical activity and cognitive function is frustrated by a lack of practical and valid instruments to estimate the level of physical activity. In general, there is a strong need for comprehensive methods to measure energy expenditure directly or indirectly (LaPorte, Montoye \& Caspersen, 1985). The most valid and reliable methods to date are based on physiological monitoring, e.g. by deremining the maximal oxygen consumprion $\left(\mathrm{VO}_{2}\right.$-max). Such techniques are laborious, expensive, and may even interfere with the actual behavior under study. In addition, performance-based measures may be unsuitable for older individuals or may imply a serious health hazard. Survey methods using questionnaires are pracrical in larger studies but must be validated for specific usage (Montoye \& Taylor, 1984: Washburn \& Montoye, 1986).

In the present study, the level of habitual physical activity was measured by using a questionnaire that has recently become available for use in gerontological populations to assess. activity-based caloric expenditure (Voorrips, Ravelli, Dongelmans, Deurenberg \& van Staveren, 1991). On the assumption that energy expenditure can be estimated indirectly by using a questionnaire that measures habitual physical activity, this scudy evaluates the predictive value of habitual activity on cognitive performance, as measured by objective tests. It is hypothesized that speeded tasks that require effortful processing of new information are most sensitive to the level of physical activity (Chodzko-Zajko, 1991). In addition, a measure of subjective hatal th was used as copredictor of cognitive performance in view of the fact that 
physical activity and health status are related phenomena, especially in older study groups (Clarkson-Smith \& Hartley, 1990). Moreover, self-reported physical health has been related to performance in tests for crystallized and fluid intelligence (Perlmutter \& Nyquist, 1990).

\section{METHODS}

\section{Subjects}

Eighty subjects were included in the study, stratified for sex and age in five continuous age classes (55-59 years, 60-64 years, 65-69 years, 70-74 years, and 75 years and older). To reach this number, healthy community dwelling subjects were recruired through newspaper advertisements and direct mailing of organizations for older people in the region of Maastricht, the Netherlands. To assure participation of sufficiently physically active subjects, local organizations which provide aerobic sports for older adults were included in the mailing. A total of 228 subjects volunteered for the study, of whom 107 were screened by telephone for exclusion criteria to yield sufficient subjects in each stratum, i.c. actual medical conditions with a possible impact on brain function; a history of cerebrovascular disease (stroke, transient ischemic attacks), epilepsy, parkinsonism, neurosurgery, other chronic neurological stares, psychiatric disorders or actual daily use of psychotropic drugs. Twenty-seven subjects in this group did not meet the health criteria, the use of sedatives or hypnotics being the most prominent reason for exclusion. All 80 participants were professionally inactive, which is a prerequisite for the use of the actual physical activity questionnaire (APAQ; see next section). Table 4.1 presents demographic information about the study population.

\section{Procedure}

All participanrs completed a postal questionnaire that serwed as the basis for the interview within two weeks after the health screen by telephone. A semi-structured interview of 1.5 hours was conducted by two trained senior medical students. It consisted of a check of the postal questionnaire for completeness and administration of the Mini-Mental State Examination (MMSE), physical activity questionnaire and a cognitive test battery that lasted 45 minutes. Subjects were paid HAl. 20. = for their participation.

\section{Measurements}

Demographic variables and bealth status. Socioeconomic background and detailed medical information were obtained with the postal questionnaire. The questionnaire consists of standard rating scales to assess level of education, ranging from primary education to higher vocational training and university on an 8-point scale (De Bie, 1987), demographic parameters, medical history, and subjective health. The latter is expressed as the total of affirmative answers on a 21 -item health complaint rating scale (inventory of subjective health, ISH, Dirken, 1967). The Mini-Mental State Examination (MMSE, Folstein, Folstein \& McHugh, 1975) was used to 
screen for dementia. It was decided ro exclude individuals with a MMSE score below 24 , but all screened subjecrs scored well above this limit (Table 4.1).

Actual Physical Actwity Questionnatre (APAQ). This semi-structured questionnaire probes three domains of physical acrivity in the preceding year that are relevant for older people: household work, sport, and leisure-time physical activity. The caloric work load of household activities was scored as total outcome on ten rating scales. Sport and leisure-time activity scones were the sums of the products of estimated caloric intensity (expressed in an intensity code with no unit, derived from estimated energy costs) and reported frequency, for each sport or activity. The overall index of the datly caloric expenditure is expressed as the total of scores in the three acrivity domains. The APAQ score correlates reasonably well with pedometer data and measures of dietary caloric intake (Spearman's $\%$ of 72 and .78 . respectively, Voorrips et $\mathrm{al}, 1991)$ but has to date not been validated with direct measures of calloric expenditure, such as $\mathrm{VO}_{2}-\mathrm{max}$.

Short Cognitive Screening Battery (SCSB). A set of standard neuropsychological tests was used to assess different aspeces of cognitive function (SCSB, Jolles, Houx, van Boxtel \& Ponds, 1995). The test battery includes tasks to assess the neuropsychological core constructs immediate and delayed recall, attentional capacity, planning, verbal intelligence, and sensorimotor speed (Jolles, 1985). A short description of each test is given below.

Word Learning Task (WLT). This test is based upon the Auditory Verbal Learning Test (Brand \& Jolles, 1985 ) and evaluates the ability to acquire and retain new verbal information. Fifteen frequently used monosyllabic words are presented, in three trials, on cards at a rate of one every two seconds. The subject is instructed to memorize the words. Each trial ends with a free recall of the words. This procedure is repeated two times, using the same word set in fixed order. After 20 minutes the subject is asked to reproduce the set of words. The total number of correctly reproduced words on the three immediate recall trials is recorded, together with the maximum score in three trials and the number of correctly reproduced words after 20 minutes (Houx et al. 1991).

Concept Shiffing Task (CST). Based on the trail making task of the Army Individual Test Battery, this test evaluates behavioral planning and evaluation (Houx et al., 1991). "The subject's ability ro alternate two psychological concepts during rask performance is measured, i.e., number and letrer cancellation in correct order. A test sheet contains 16 small diameter circles (O) $15 \mathrm{~mm}$ ) arranged in a larger circle $(016 \mathrm{~cm}$ ). Two null versions (pat 0 ) contain no symbols in the circles, the number version (part A) presents figures 1 to 16 in random order in the circles, a letter version (part B) depicts random letters, and finally a number / letter version (part $C$ ) alternates the numbers 1 to 8 and letters $A$ to 1 . The subject is instructed to cross out the circles in correct order, as fast as possible without making errors. The time required to complete each task is recorded.

Letter Digit Substitution Tent (LDST). This paper-and-pencil test is a modified version of the Symbol. Digit Modalities Test (SDMT, Smith, 1968) and measures fundamental information processing speed. The subject is requested to copy numbers in cells that are indexed by a lerter. The letter refers to nine letter / number combinations ar the rop of the form. The total number of correctly copied corresponding numbers in 60 seconds is recorded as test outcome. 
Stroop Color-Word Test (SCWT). The abbreviated version of this perceptual interference test consists of three subtasks. Each subtask consists of a test sheet containing four rows of ten columns of color names or colored spots. The test examines the speed at which color names are read (subtask D) and the speed at which color spots are named (subtask II). Subtask III involves color names again but the printing ink is different from the color name. The speed at which the color of the printing ink of the words is named is recorded. This test shows robust effects of chronological age (Howx, Jolles \& Vreeling, 1993).

Word Fluency. The total number of animal names correctly reproduced in 60 seconds is recorded (Luteijn \& van der Ploeg, 1983). The test reflects the level of organizarion among dusters of meaningful related words.

Dutch Adult Reading Test (DART). This is the Dutch version of the National Adult Reading Test, NART (Nelson, 1982). A series of 50 words with an irregular pronunciation has to be reproduced correctly by the subject. The DART score is calcutated from the number of words pronounced correctly multiplied by two, raised with the number of doubrfully correctly reproduced words. Scores can be converted to WAIS-IQ (Schmand, Lindeboom \& van Harskamp, 1992) but we preferred to use the more elementary raw score. In patients suffering from brain damage this test reflects the premorbid level of verbal intelligence (Schmand, Bakker, Saan \& Louman, 1991). The DART score was used in this study to control for intelligence level as a known predictor of cognitive performance.

Continuows tapping (TAP). Though not part of the SCSB, this test was included to assess peripheral motor speed more specifically (Houx, 1991). The subject is required to press the button of an electronic counting device with the index finger at maximum frequency for 20 seconds. Dominant and non dominant hands are tested alternately twice. The average number of taps over these four trials is recorded.

\section{Data reduction and analysis}

Selected raw test scores for specific performance tasks were clustered in the three domains memory, cognitive flexibility, and sensorimotor speed, to yield compound cognitive performance indices. This was done to reduce the number of dependent variables whille improving the robustness of the underlying cognitive construct. Raw rest scores were transformed to $Z$-scores in the total population. Next, the average was calculated of the $Z$-transformed scores that were included in a compound performance index. Thus a memory score was derived from the $Z$-transformed toral, maximal and delayed recall scores of the WLT. The cognitive flexibility score included the $\mathrm{C}$ version of the CST and subtask III of the SCWT (LaRue, 1992, pp. 114115) and sensorimotor speed was calculated from the $0, A$ and B wersions of the CST, the continuous tapping score, and subcask I of the SCWT. In formula:

Memory $($ MEMORY $)=(Z$ WLTTOT $+Z$ WLTMAX $+Z$ WLTDEL $/ 3$

Cognitive flexibility (FLEX) $=-\left(Z_{\mathrm{CST}-C}+Z_{\mathrm{SCWT}-\mathrm{HII}}\right) / 2$

Sensorimotor speed $($ SPED-S $)=-\left(Z_{\mathrm{CST}-0}+Z_{\mathrm{CST}-\mathrm{A}}+Z_{\mathrm{CST}-\mathrm{B}}-Z_{\mathrm{TAP}}+Z_{\mathrm{SCWT}-1}\right) / 5$ 
The sign of the speed and flexibility score was inverted to make them reflect above average performance when positive and below average performance when negative. LDST and Auency test outcomes were treated as separate variables as performance in these tests draws on virtually ewery aspect of cognitive function.

In the first step of data analysis, multivariate analysis of variance (MANOVA) and separate univariare ANOVA's were performed on subjecrive heath (ISH), physical activiry level (APAQ), and cognitiwe scores to detect effects of age and sex. Next, hierarchical regression analysis was performed on five cognitive performance scores with age, sex, DART intelligence, $A P A Q$ and $I S H$ as potential predictors of cognitive test outcome. In addition, the APAQ by age and the ISH by age interaction terms were entered in the model to study the possibility that age moderates the effects of APAQ and ISH. Residual scores were screened for systematic crends, but were not identiffed in the five final models. Error probabilities of .05 or less were considered as statistically significant. All analyses were performed with the SPSS statistical software series.

\section{RESULTS}

Physical activity level, subjective health, and cognitive test outcome by age class and sex are listed in Table 4.1. The average score on education (3.5) was equivalent to secondary level education (De Bie, 1987). A multivariate analysis of variance test revealed a significant age (Wilks $F(32,234)=2.19, p<.001), \operatorname{sex}(F(8,63)=2.51, p<.05)$, but no age by sex interaction effect $(F(32,234)=1.06$, n.s.) for a combination of main independent and dependent variables that were included in the regression models. In separate univariate ANOVA's (Table 4.2) no main or inceraction effect of age and sex was found on measures of intelligence, activity level, or subjecrive health, suggesting a homogeneous distribution of these predictor variables in the study population. However, the compound speed and flexibility measures, LDST and fluency; showed strong age effects that indicated lower scores with increasing age. No age effect was found on the memory score. A sex difference was found on compound scores for memory and sensorimotor speed: women were slower than men but had higher scores for memory. Sex did not moderate the age effects on cognitive performance: no significant age by sex interaction effects were demonstrated.

In Table 4.3 the zero-order correlarions are shown berween predictor variables and dependent variables. Apart from a weak but significant negative correlation between APAQ and ISH scores $(r=-.28 ; p \leq .05$, two-tailed), no significant relationship becween predictor variables appeared to exist in the study population. All five cognitive ontcome measures were highly correlaced $(r=.33$ to 77$)$, with age as an intermediate wariable that was also strongly predictive for all these cognirive measures $(r=-.29$ to -.66$)$. The negative correlation between the memory score and age was significant $(r=-29, p<.01)$, in contrast to the absence of an age effect on memory in the univariate ANOVA.

A series of hierarchical regression analyses were performed to predict cognitive measures from the background variables age, sex, and intelligence (DART) and the experimental variables physical activity level (APAQ), subjective health (ISH), and the interaction terms of 
Table 4.I. Mean ( + SD) levels of background characteristics, physical activity, subjective health, and cogniwe performance measures by age chass and sex.

\begin{tabular}{|c|c|c|c|c|c|c|c|}
\hline & \multicolumn{5}{|c|}{ Age dass (years) } & \multicolumn{2}{|c|}{$5 \mathrm{ex}$} \\
\hline & $55-59$ & $60-64$ & $65-69$ & $70-74$ & $\geq 75$ & Male & Fenale \\
\hline$n$ & 16 & 16 & 16 & 16 & 16 & 40 & 40 \\
\hline Age & $\begin{array}{l}57.4 \\
(1.5)\end{array}$ & $\begin{array}{r}61.8 \\
(1.2)\end{array}$ & $\begin{array}{l}67.0 \\
(1.5)\end{array}$ & $\begin{array}{l}71.2 \\
(1.1)\end{array}$ & $\begin{array}{l}78.3 \\
(3.0)\end{array}$ & $\begin{array}{l}67.5 \\
(7.9)\end{array}$ & $\begin{array}{l}66.8 \\
(7.3)\end{array}$ \\
\hline Education & $\begin{array}{r}4.4 \\
(1.6)\end{array}$ & $\begin{array}{r}4.3 \\
(1.7)\end{array}$ & $\begin{array}{r}2.8 \\
(2.1)\end{array}$ & $\begin{array}{r}2.9 \\
(2.0)\end{array}$ & $\begin{array}{r}2.9 \\
(2.2)\end{array}$ & $\begin{array}{r}3.6 \\
(2.3)\end{array}$ & $\begin{array}{r}3.4 \\
(1.9)\end{array}$ \\
\hline MMSE & $\begin{array}{r}29.6 \\
(.7)\end{array}$ & $\begin{array}{l}29.3 \\
(1.0)\end{array}$ & $\begin{array}{l}29.1 \\
(1.4)\end{array}$ & $\begin{array}{r}29.2 \\
(.8)\end{array}$ & $\begin{array}{l}28.9 \\
(1.2)\end{array}$ & $\begin{array}{l}29.2 \\
(1.1)\end{array}$ & $\begin{array}{l}29.2 \\
(1.1)\end{array}$ \\
\hline DART & $\begin{array}{r}85.5 \\
(16.3)\end{array}$ & $\begin{array}{r}82.8 \\
(20.5)\end{array}$ & $\begin{array}{r}80.6 \\
(18.5)\end{array}$ & $\begin{array}{r}81.8 \\
(115.8)\end{array}$ & $\begin{array}{r}75.8 \\
(17.3)\end{array}$ & $\begin{array}{r}81.8 \\
(15.0)\end{array}$ & $\begin{array}{r}80.8 \\
(20.1)\end{array}$ \\
\hline$A B A Q$ & $\begin{array}{l}10.8 \\
(4.9)\end{array}$ & $\begin{array}{r}7.6 \\
(3.7)\end{array}$ & $\begin{array}{r}9.0 \\
(3.6)\end{array}$ & $\begin{array}{r}9.3 \\
(4.6)\end{array}$ & $\begin{array}{r}7.4 \\
(4.2)\end{array}$ & $\begin{array}{r}9.2 \\
(4.5)\end{array}$ & $\begin{array}{r}8.4 \\
(4.2)\end{array}$ \\
\hline ISH & $\begin{array}{r}3.8 \\
(3.8)\end{array}$ & $\begin{array}{r}4.7 \\
(3.6)\end{array}$ & $\begin{array}{r}3.2 \\
(2.4)\end{array}$ & $\begin{array}{r}4.4 \\
(4.8)\end{array}$ & $\begin{array}{r}4.9 \\
(3.7)\end{array}$ & $\begin{array}{r}40 \\
(3.7)\end{array}$ & $\begin{array}{r}4.5 \\
(3.7)\end{array}$ \\
\hline MEMORYb & $\begin{array}{r}.52 \\
(.81)\end{array}$ & $\begin{array}{r}-.06 \\
(.73)\end{array}$ & $\begin{array}{r}.00 \\
(92)\end{array}$ & $\begin{array}{r}-.2 \\
(86)\end{array}$ & $\begin{array}{r}-30 \\
(1.13)\end{array}$ & $\begin{array}{r}.25 \\
(.99)\end{array}$ & $\begin{array}{r}.25 \\
(.79)\end{array}$ \\
\hline SPEED-Sb & $\begin{array}{r}.57 \\
(.37)\end{array}$ & $\begin{array}{r}.24 \\
(.53)\end{array}$ & $\begin{array}{r}.09 \\
(.54)\end{array}$ & $\begin{array}{r}.29 \\
(.47)\end{array}$ & $\begin{array}{r}.62 \\
(1.04)\end{array}$ & $\begin{array}{r}.15 \\
(.80)\end{array}$ & $\begin{array}{r}-15 \\
(.66)\end{array}$ \\
\hline FLEX & $\begin{array}{r}.61 \\
(.46)\end{array}$ & $\begin{array}{r}.42 \\
(54)\end{array}$ & $\begin{array}{r}.21 \\
(.56)\end{array}$ & $\begin{array}{r}-.24 \\
(.57)\end{array}$ & $\begin{array}{r}-.99 \\
(1.16)\end{array}$ & $\begin{array}{r}.05 \\
(.98)\end{array}$ & $\begin{array}{r}.05 \\
(.81)\end{array}$ \\
\hline LDST & $\begin{array}{l}35.1 \\
(5.3)\end{array}$ & $\begin{array}{l}30.3 \\
(5.3)\end{array}$ & $\begin{array}{l}31.1 \\
(6.2)\end{array}$ & $\begin{array}{l}25.5 \\
(4.6)\end{array}$ & $\begin{array}{l}23.1 \\
(6.6)\end{array}$ & $\begin{array}{l}28.8 \\
(7.0)\end{array}$ & $\begin{array}{l}29.3 \\
(7.0)\end{array}$ \\
\hline Fluency & $\begin{array}{l}28.1 \\
(5.1)\end{array}$ & $\begin{array}{l}25.1 \\
(5.0)\end{array}$ & $\begin{array}{l}23.0 \\
(6.11)\end{array}$ & $\begin{array}{l}22.3 \\
(6.1)\end{array}$ & $\begin{array}{l}20.7 \\
(6.9)\end{array}$ & $\begin{array}{l}24.3 \\
(6.5)\end{array}$ & $\begin{array}{l}23.3 \\
(6.1)\end{array}$ \\
\hline $\begin{array}{l}\text { Nole. MMSE } \\
\text { score, APAQ } \\
\text { score, MEMO } \\
\text { FLEX = comp } \\
\text { a Mean DART } \\
\text { respecrively (S }\end{array}$ & $\begin{array}{l}\text { mal } \\
\text { sical } \\
\text { jund } \\
\text { live } \\
\text { men }\end{array}$ & $\begin{array}{l}\text { Exan } \\
y \text { que } \\
\text { ory sc } \\
\text { ligy sc } \\
\text { vomer } \\
\text { Popul }\end{array}$ & $\begin{array}{l}\text { On so } \\
\text { iatre } \\
\text { PEE } \\
\text { DST } \\
\text { equiv }\end{array}$ & $\begin{array}{l}\text { DAR } \\
=1 S \mathrm{SH} \\
=\text { corr } \\
\text { teter } \\
\text { to }\end{array}$ & $\begin{array}{l}\text { Du } \\
\text { inwen } \\
\text { and } \\
\text { gir Su } \\
\text { IS IQ }\end{array}$ & $\begin{array}{l}\text { ult Rez } \\
\text { subjec } \\
\text { iotor } \\
\text { ion " } \\
\text { of } 102\end{array}$ & $\begin{array}{l}\text { nig Test } \\
\text { e health } \\
\text { d score, } \\
\text { core. } \\
\text { nd } 103\end{array}$ \\
\hline
\end{tabular}

age with each of the latter two variables. In the first step of the analysis the background variables were entered in the equation (Table 4.4). In separate steps thereafter, APAQ, APAQ by age, ISH, and ISH by age were entered.

The background variables age, sex, and intelligence explained the largest amount of variance in cognitive measures. The proportion of explained variance in cognitive measure ranged from .17 for memory and fluency scores to .54 for the cognitive flexibility score. Beta coefficients that range from -.24 (MEMORY) to -.57 (LDST) indicate the predominant load of 
Table 42. Effects of age and sex and their interaction in univariate ANOVA's on DART intelligence, pliysical activity, subjective health and cognivive performance.

\begin{tabular}{|c|c|c|c|}
\hline & $\begin{array}{l}\text { Age } \\
44,70) \\
\end{array}$ & $\begin{array}{c}5 e x \\
A(1,70)\end{array}$ & $\begin{array}{c}\text { Age } x \text { Sex } \\
F(4,70)\end{array}$ \\
\hline DART & $\alpha$ & $<1$ & 1,04 \\
\hline APAQ & 177 & $<1$ & 1.17 \\
\hline $1 \mathrm{SH}$ & $<\mathbb{I}$ & \&ll & $<1$ \\
\hline MEMORY & 2.20 & $6.49^{*}$ & $\ll 1$ \\
\hline SPEED-S & 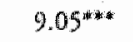 & $475 *$ & 1.15 \\
\hline JLEX & $12.54^{2 *}$ & al & $<1$ \\
\hline LDST & $11.1 .4^{m * x}$ & $<1$ & $<\mathrm{I}$ \\
\hline Fluency & $3.68^{*}$ & $<1$ & $<1$ \\
\hline
\end{tabular}

Note. DART = Dutch Adult Reading Test seore, APAQ = acrual physical activity questionnaire score, ISH $=$ inwentory of subjective health score, MEMORY = memory score, SPEED-S = sensorimotor speed score, FLEX $=$ cognitive Rexibility score, LDST = Letter Digit Substiturion Test score.

$* p \leq .05, * * \leq \leq 01, * * * * \leq 001$

Table 4.3. Zero-order correlations between predictor variables ( $N=80$ for all coefficients).

\begin{tabular}{lllllllll}
1 & 2 & 3 & 4 & 5 & 6 & 7 & 8 & 9 \\
\hline
\end{tabular}

1. Age

2. Sex

.05

3. DART

$-.17 \quad-.03$

4. $A P A Q$

5. $I S H$

6. MEMORY

7. SPEED.S

8. FLEX

9. LDST

$\begin{array}{lll}-.15 & -.09 & .02\end{array}$

$\begin{array}{rrr}.08 & .07 & -.07\end{array}$

$\begin{array}{llll}.08 & .07 & -.07 & -.28 \\ -.29^{* *} & .27^{* *} & .18 & .05\end{array}$

$\begin{array}{rrrr}.58 * * & -.20 & .23^{*} \quad .16\end{array}$

$.66^{* *}-.06 \quad .42^{* *} \quad .15$

10. Fluency

$-.61 \% .03$

$.26 * \quad 10$

$-.39 * * \quad-.08 \quad .20 \quad .17$

$-.07 \quad$.

$-.24^{*} \quad .38 * *$

$-24^{*} \quad .36 * *$

$-25 * \quad .47^{* *} \quad .71^{* *} \quad .72^{* * 1 *}$

Note. DART $=$ Durch Adult Reading Test score, APAQ = actual physical acriviry questionnaire score, ISH = inventory of subjective healh score MEMORY = memory score, SPEED-S = sensorimotor speed score, FLEX = cognitive thexibility score, LDST = Letter Digit Substicution. Test score. $* p \leq .05, * * \leq .01$.

chronological age on all cognitive measures. 'The habitual physical activity score did not add significantly to the explaned variance in step two: $R^{2}$ remained virtually unchanged after step rwo in all five models. Cognitive flexibility and LDST, however, were positively correlated with the APAQ by age interaction term in step three. This may be interpreted as higher performance scores, when a Jigh APAQ is associated with a relatively old age, ar vice versa. In step four subjective health increased the explanatory power of two of the models further, again for cognivive flexibility (2\%) and LDST (4\%). In step five the ISH by age interaction term did not alter one of the models significantly, thus indicating no differential effect of subjective health with age on performance. In addition, as APAQ score and subjective health score were significantly correlated $(r=-.28)$, ir was investigated post hoc if the effect of health on cognitive variables was moderated by the activity level: no activity by thealth interaction effects could be demonstrated when the APAQ by ISH interaction term was added to the models after step 5 (results nor shown). 
Table 4.4. Hierarchical regression analysis on cognürive measures: standardized regression coefficients (Bema) in the final model, $R^{2}$ and significance of $R^{2}$ change after teach step.

\begin{tabular}{|c|c|c|c|c|c|c|c|c|c|c|}
\hline \multirow[b]{2}{*}{ Predictors } & \multicolumn{2}{|c|}{ MEMORY } & \multicolumn{2}{|c|}{ SPEED-S } & \multicolumn{2}{|c|}{ FLEX } & \multicolumn{2}{|c|}{ LDST } & \multicolumn{2}{|c|}{ Fluency } \\
\hline & Betat & $R^{2}$ & Beta & $R^{2}$ & Berata & $B 2$ & Betat & $p^{2}$ & Berat & $\overrightarrow{R^{2}}$ \\
\hline 1. Age & -.22 & $.17^{* *}$ & -.57 & $.41^{* * * *}$ & -.62 & $54^{* * * * * *}$ & -.57 & $.39 * *$ & -.35 & $.17 *$ \\
\hline Sexa & .28 & & -.22 & & .08 & & .01 & & .08 & \\
\hline DART & .14 & &, $\mathbb{1} 1$ & & 30 & & .15 & & .12 & \\
\hline 2 APAQ & .03 & .17 & .01 & .41 & .01 & .55 & -.03 & .39 & .07 & 19 \\
\hline 3. APAQ x Age & -.04 & .17 & .14 & .43 & .23 & $.59^{* * *}$ & .20 & $.44^{*}$ & .17 & .22 \\
\hline 4. ISH & -.04 & .17 & -.117 & 46 & .17 & $.61^{*}$ & -.21 & $.48^{*}$ & -18 & 25 \\
\hline 5. ISH $\times$ Age & -.21 & .21 & .05 & .46 & .11 & .62 & .04 & .48 & -.03 & .25 \\
\hline
\end{tabular}

Note. DART $=$ Durch Adult Reading Test score, $\mathrm{APAQ}=$ accual physical accivity quescionnaire score, $15 \mathrm{SH}=$ inventory of subjective health score, MEMORY = memory score, SPEED-S = sensorimotor speed score, FLEX = cognitive flexibility score, LDST $=$ Letrer Digir Substiturion "Test score.

asex: $1=$ male, $2=$ female

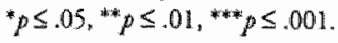

Finally, to test the possibility that age was masking the effects of variables introduced after step one, age was also entered last instead of in the first step. This procedure yielded essentially the same pattern of effects and the results are therefore not presented here.

\section{DISCUSSION}

In this study the predictive value of a habitual activity questionnaire score for cognitive performance was tested in a population of healthy older adults. Strong effects of age were found on several measures of cognitive flexibility and fluency, but not on memory. Women performed worse on sensorimotor tasks but better on memory related tasks than men. The activity score measured with the physical activity questionnaire (APAQ) did not appear to contribute significantly to explaining variance in the three cognitive domains of memory, sensorimotor and cognitive flexibility, or the word fluency or LDST performance, when the effects of chronological age, sex and intelligence were controlled for. However, the small but significant contribution of the age by activity interaction term on cognitive flexibility and LDST performance may indicate a differential effect of activity with age on basic information processing speed. These findings are in agreement with other recent studies showing age by activity interaction effects on complex cognitive tasks, although these studies used less specific activity measures (Christensen \& Mackinnon, 1993; Hultsch, Hammer \& Small, 1993). Still, the absence of a main effect of activity on performance does raise several questions that have to be dealt with.

\section{Activity}

Given that the APAQ score and cognitive performance do not seem to be related, it can be argued that the distribution of APAQ scores in the present study is not representarive for an 
active older population, in part due to self-selecrion of participants. However, mean APAQ scores in the study of Voorrips et al. (1991), who used a comparable subject inclusion procedure and population age range (63-80 year), were comparable to the present results $(M=$ 1. $1.0(S D 4.6)$, vs. $M=8.8(S D 4.3)$ in this study). Still, is remarkable that the APAQ scores were independent of age in the present study, in contrast to carlier findings that the habitual activity level tends to be lower in older age groups (e.g. Kannel \& Sorlie, 1979). This might be because relatively active older adults were recruited as the result of the inclusion procedure, to achicve an adequate represerntation of acriwe subjects in the older age classes. Random recrutment from the general population, irrespective of activity level, would have been an aternative inclusion strategy, but for a population based study larger samples are needed to attain adequate variance of activity level in all age groups.

It seems inevitable that some degree of inacruracy remains when dally caloric expenditure is estimated from an activity questionnaire. Subjects may, whether or not deliberately, be inaccurate in their report of daily activities, thereby affecting the validity of the questionnaire. A particular problem with the use of activity scales in aging research based on self report is that the outcome largely relies upon the ability of subjects to recall recent experiences, a cognitive skill that is known to decline with age (Poon, 1985). The free recall capability may have a particular impact on the APAQ cluster 'leisure-rime activities', where the meticulous reporring of relatively minor activities may add up to a substantial cluster score. In addition, it is not clear if the intensity of these relatively low aerobic activities is substantial enough to contribute to the overall acrobic capacity. This suggests the need for further validation of the APAQ score with other physiologically based indices of caloric expenditure, parricularly the maximal oxygen uptake ( $\mathrm{VO}_{2}$-max).

The present findings and the discussion above raise another important issue. It thas been suggested that the physical activity history should be taken into account when the relationship between aerobic capacity and cognitive funcrion is studied (Paas, Adam, Janssen, Vrencken \& Bovens, 1994). If the assumption holds that the maintenance of an adequate level of physical activity throughou life provides a cognitive reserve capacity in old age - equivalent to a reduced risk of osteopotosis - then the actual level may grossly under-or overestimate the lifetime effect of physical acrivity. This notion accentuates the need of a valid instrument to estimate lifetime physical accivity. Several attempts have been made to measure this construct (Kriska ex al., 1988; Voorrips, et al., 1992), but the methodological difficulties are obvious.

Taken together, the present findings suggest that the more widespread use of a questionnairebased index of habitual physical activity as a predictor of cognitive performance cannot be advocated until the relationship becween habitual physical activity and physiological indices of physical finess is further elucidated. It may, however, still be of some interest to test the external validity of our conclusions and to replicate the above results in a larger, population based study, as in this study active clderly are potencially over-represented.

\section{Healsh}

Subject selecrion based on health criteria was deemed necessary to control for the potential modification of the effect of activity on cognitive performance (Christensen, Moye, Armson \& 
Kern, 1992). It cannot be ruled our, however, that a more rigoraus health screening procedure would have attenuated several of the effects found in this study, in particular that of age on speeded performance tasks. The issue of adequate subject selection is difficult to resolve, as rigorous health screening will inevitably result in study groups that are no longer representarive for age-matched population samples, as they may differ in more respects than the factor health alone, such as personality characteristics or nutritional factors (Spirduso \& MacRac, 1990).

In our study, subjective health was positively related to cognitive flexibility and LDST but, in contrast to activity, no interactions with age were observed. This would be in partial agreement with recent findings that older subjects who are regarded as healthy according gerontological criteria can be divided into two groups on the basis of the absence or presence of mild health-related factors (Houx, 1991; Houx \& Jolles, 1993). Houx et al. (1991) found that very old subjects ( 80 years) without these factors and who judged their subjective health as 'good' were not characterized by the usual age-relared cognitive decline. Health as a construct obviously includes more than health perception alone, and although some authors suggest a close relationship between subjective health and more objective health assessments (e.g. physician rated health, LaRue, Bank, Jarvik \& Hetland, 1979) it is preferable to define health as a multidimensional characteristic of subjects (and to measure it accordingly). In doing this, one may arrive at more specific conclusions about which aspect of health is rellevant for cognitive function throughout life.

\section{REFERENCES}

Baylor, A. M., \& Spirduso, W. W. (1988). Systematic aerobic exercise and components of reaction time in older women. Journal of Gerontology, $43,12121-126$.

Blumenthal, J. A., \& Madden, D. J. (1988), Effects of aerobic exercise training, age, and physical fieness on menory-search performance. Pyobology and Aging, 3, 280-285.

Band, N., \& Jolles, I. (1985). Learning and retrieval rate of words presented auditory and visually. foumal of Geveral Psycholog, $112,201-210$.

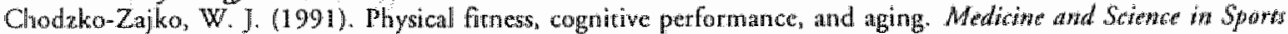
and Everise, $23,868-872$.

Christensen, H, \& Mackinnon, A. (1993). The association berween mental, social and physical aterivity and cognituve performance in young and old subjects. Age and Ageing, 22, $175-182$.

Christensen, K. J., Moye, J. Armson, R. R, \& Kern, T. M. (1992). Healdh screening and random recrutoment for cognituive aging research. Pychology and Aging, $7,204-208$.

Clarkson-Smith, L., 8. Hartley, A. A. (1989). Rellationships berween physical excercise and cognitive abiliries in older adulta. Pycbology and Aging, 4, 183:189.

Clarkson-Smith, L., \& Hartley, A. A. (1990). Structural equacion models of relationsthips between exoctise and cognitive abilicies. Pycholoys and Aging, 5, $437-446$.

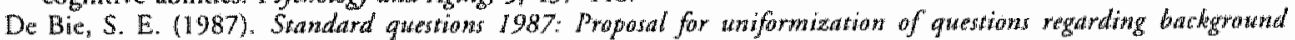
varables and interwews. (2nd ed.). Leiden: Leiden Universicy Press.

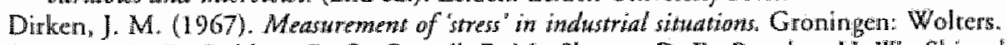

Dustman, R. E., Ruhling, R. O., Russell, E. M. Shearee, D. E, Boneknt, H. W, Slygeoka, J. W., Wood, J. S, \& Bradford, D. C. (1984). Aerobic exercise craining and improwed neuropsychological fanction of alcter individuals. Neurobialagy of Aging $5,35-42$.

Elsayed. M., Ismail, A. H., \& Young, R. J. (1980). Intellectual differences of adult men related to age and physical finess before and after an exencise program. Joumal of Gerontology, 35, 383-387.

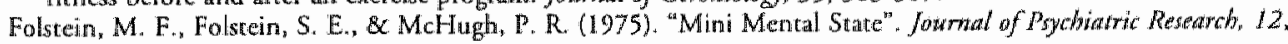
$189 \cdot 198$.

Hawkins, H.L. Kramer,H.F, \& Capaldi, D, (1992).Aging, exercise and antention. Psychology and Aging, 7,643-653.

Hill, R. D., Storand, M., \& Malloy, M. (1993). The impact of long-term exercise training on psychological function in older adults. Jourtat of Gerontology, 48, P12-17.

Houx, P. I. (1991). Cogrwivie aging and health related factors. Doctoral Thesis, University of Magstrich 


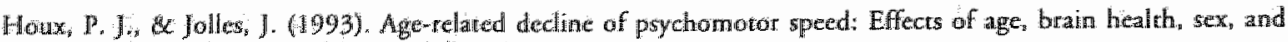
education Percephas and Motor Skills, 76, 195-211.

Houx, P. J., Jolles, J., \& Vreeling, F. W. (1993). Stroop interference: aging effects assessed with the Stroop ColorWord test. Experimental Aging Reseateh. 19, 209-224.

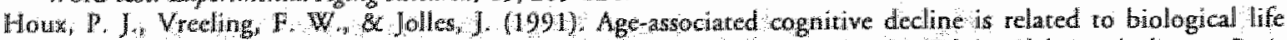

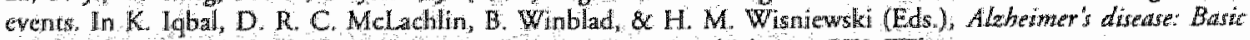
methanism, diagrosis and theratentic shrategies, (pp. 353-358). Chichester, UK. Whiley.

Fuliseth, D. F, Hanmer, D. \& Small, B. J. (1993). Age differences in cognirive performance in later life: Relationships to self-reported health and activicy life style. Jotornal of Gerontology, 48, Pl-11.

Jolles. J. (1985). Early dagnosis of dementia: possible contributions from neuropsychology. In W. H. Gispen \& J. Traber (Eds), Aging of the brath, (pp. 84-100). Berlin: Springer.

Jolles, J., Houx, P. J. van Boxtel, M. P. J. \& Ponds, R. W. H. M. (Eds.). (1995). Matastricht Aging Study: determinants of cognitive aging Maastriche Neupopsych Publishers.

Kannel, W. B, \& Sorlie, P. (1979). Some health benefirs of physical activity: The Framingham study. Archives of Internal Medichis; $139,857-861$.

Kriskka, A. M., Sandler, R. B., Cauley, J. A, L,al'orte, R. E., Hom, D. L., \& Pambianco, G. (1988). The assessment of histofical physical activity and its relation to adult bone parameters. Ameritan Journal of Epidemiology. 127, $1053-1063$.

LaPorte, R. E, Montoye, H. J., \& Caspersen, C. J. (1985). Assessment of physical acrivity in epidemiologic research: Problems and prospects. Public Health Reparts, 100, 131-146.

LaRue, A. (1992). Aging and neuropsychological assessment. New York: Plenum Press.

LaRue, A. Bank, L. Jarvik, L., \& Hetland, M. (1979). Health in old age: How do physician's ratings and selfratings compare? foumal of Geransalogy, 34, 687-691.

Lateijn, F. \& van der Plocg, F. A. E. (1983). Handleiding Groninger Intelligentietest (GIT) Manual Groningen Intelligence" Testy. Lisse, the Netherlands: Swets \& Zeitlinger.

Madden, D. J. Blumenthal, J. A., Alien, P. A. \& Enery, C. E. (1989). Improving aerobic capacity ün heallhy older adtults does not necessarily lead to improved cognitive performance. Psychology and Aging, 3, 307-320.

Montoye, H. J., \& Taylor, H. L. (1984). Measurement of physical activity in population studies: A review. Human Biology, 56, 195-216.

Nelson, H. E. (1982). National Adtult Reading Test Mamual. London: National Hospital.

Paas, F. G. W. C. Adarm, J. J. Janssen, G. M. E., Wirencken, J. G. P. M., \& Bowens, A. M. P. M. (1994), Effects of a 10month endurance-training program on performance of speeded perceptual-motor tasks. Perceprual and Motor Skills, 78, $1267-1273$.

Perlmutter, M., \& Nyquist, L. (1990). Relationships berween self-reported physical and mental health and intelligence performance across adulthood. Jon roual of Gerontology, 45, P145-155.

Poon, L. W. (1985). Differences in human memory with aging: nature, causes and clinical implications, In J. E. Birren B K. W. Schaie (Eds.), Handbook of the pryphology of nging. New York: Van Nostrand Reinhold.

Rogers, R. L., Meyer, I. S., \& Morrel, K. F. (1990). Afrer reaching retirement age physical activity sustains cerebral perfusion and cognition, Journal of the Ameritan Geriatrias Society, 38, 123-128.

Schmand, B., Bakker, D., Satn, R., \& Louman, J. (1991). The Duch Adult Reading Test: A measure of premorbid intelligence. Tijdsclorift wow Gerontologie en Geriatwie, $22,15-19$.

Schmand, B., Lindeboom, J., \& wan Harskamp, T. (1992). Manwal Dutch Adult Reading Test. Lisse, The Netherlands: Swets \& Zeitinger.

Shas, K. A. \&. Roth, D. L. (1992). Association berween acrobic fitness and visuosparial performance in healthy older adults. Psychology and Aging, $7,15-24$. Smith, A. (1968). The Symbol Digit Modalitics Test: A neuropsychological test for economic screening of
learning and other cerebral disorders. Letwrning Disorders, 36, 83-91. Spirduso, W. W. (1975). Reaction and movement rime as a function of age and physical activity lewel. Journal of
Gerontology, 30,435-440.

Spirduss, W. (1980). Maysicall fitness, agging, and psychomotor speed. Jotomal of Gerontology, 35, 850-865.

Spirduso, W. W. \& MacRae, P. G. (1990). Moror performance and aging. In J. E. Birren \& K. W. Schaie (Eds.), Mandlowk of the pisylology of aging (3 ed., pp. 183-200). San Diego: Academic Press.

Srones, M. I., \& Kooma, A. (1989). Age, exercise and coding performance. Psycholog and Aging, 4. 190-194.

Voorrips, L. A., Meijers, J. H. H., Sol, P., Seidell, J. C. \& van Staveren, W. A. (1992). History of body weight and physical activity of elderly women differing in current physical activity. International journat of 0 besity, 16 ,
$199-205$.

Voorrips, L. E., Ravelli, A. C. J., Dongetmans, P. C. A., Deurenberg, P, \& van Staveren, W. A. (1991). A physical activity questionnaire for the elderly. Medicine and Science in Sparts and Exercie, 23; 974-979. Washburn, R. A, \& Montoye, H. J. (1986). The ansessment of physical activity by questionnaire. Amerizan Journat
of Epidemialogy, 123,563-576. 


\section{Aerobic capacity and cognitive performance in a cross-sectional aging study ${ }^{3}$}

\section{ABSTRACT}

In a population unselected for aerobic fitness status, the aerobic fitness and its interaction with age were used to predict performance on several cognitive outcome measures that are known to be sensitive to effecs of chronological age. It was hypothesized that in particular cognitively demanding tasks would be sensitive to aerobic capacity, as measured in a submaximal bicycle ergometer protocol. Healthy subjects between 24 and 76 years of age were recruiced from a larger cognitive aging study $(N=132)$. The participants were more hours per week engaged in aerobic sports and felt healthier than non-participants of the same age. No group differences were found on anxiety and depression symptomatology, or basic anthropometrical variables. Two out of four subtasks that reflect complex cognitive speed (Stroop interference and Concept Shifting Test) showed main and interaction effects with age of aerobic capacity in a hierarchical regression analysis, accounting for up to $5 \%$ of variance in parameter score, after correction for age, sex, and intelligence main effects. These findings add to the notion that aerobic fitness may selectively and age-dependently act on cognitive processes, in particular those that require relatively large attentional resources.

\section{INTRODUCTION}

It becomes increasingly clear that the aging process is accompanied by deterioration of cognitive functions such as memory, attention, reaction rime, and the speed of information processing (e.g. Jolles, Houx, van Boxtel \& Ponds, 1995; Poom" 1985; Salthouse, 1989). Also, differences in cognitive performance whin groups of individuals of the same age rend to increase as a function of calendar age (Morse, 1993). It is recognized that age-extrinsic factors that are related to physical health may play a role in explaining the increase with age in variability of cognirive performance within birth cohorts (Houx \& Jolles, 1993; Houx 8 Jolles, 1994; Nolan \& Blass, 1992).

Physical fitness is one of the potential interwening factors that may be tesponsible for the larger variance in cognitive performance measures with increasing age. The most important functional aspect of physical fitness is the cardiorespiratory component, known as the actobic capacity $\left(\mathrm{VO}_{2-m a x}\right)$, which can be defined as the oxygen uptake capacity of the body during

\footnotetext{
3 M. P. J. wan Boxtel, F. G. W. C. Paas, P. J. Houx, J. J. Adam, J. C. Teeken, and J. Jolles (1997). Medicine and Science in Sporss and Exercise, in press.
} 
maximal physhical exercise (LaPorte, Montoye $\$$ Caspersen, 1985). Although conclusive evidence is still lacking, there are two basic mechanisms which have been suggested to explain we eftect of aerobic fitness on cognitiwe processes; the cerebral circulation bypothesis (induction regional cerebral blood Aow, also known as the axygen bypothesis, Rogers, Meyer \& Mortel, 1990) and the netwotropbic sitimulation bypowesis which predicts a beneficial effect of netromuscular activity on higher brain centers (Spirduso, 1980), or a combination of both (newral effiency bypothesis). Experinental evidence in support of either mechanism in humans is however largely circumstantial (Chodzko-Zajko \& Moore, 1994).

The positive relation between physical fitness and cognitive performance has not been consistent for specific cognivive domains (Chodzko-Zajko, 1991), with the exception of performance in timed rask paradigms, where differences between high and low fit elderly subjects have been demonstrated repeatedly (Spirduso \& Mackae, 1990). Intervention studies that employed exercise programs to improve aerobic capacity, in order to test the effect of this manipulation on cognitive performance, have shown mixed results (Buchner, Beresford, Larson, LaCroix \& Wagner, 1992). Dustrnan et al. (1984) found improvement in a group of 55-70 year old sedentary subjects afrer an aerobic training program of four months on the critical flicker fusion threshold (CFF), digit symbol substiturion test (DSST), simple reaction time, and Stroop interference, but did not employ a non-exercise control group. Other controlled longitudinal community studies of middle-aged subjects (Blumenthal \& Madden, 1988), and healthy elderly (Emery \& Gatz, 1990; Madden, Blumenthal, Allen \& Emery, 1989; Panton, Graves, Pallock, Hagberg \& Chen, 1990) found no beneficial effect of aerobic training. A recent study using a twelwe month aerobic intervention program in a group of 87 sedentary older adults found no improvement in cognitive task performance associated with the increase in $\mathrm{VO}_{2-\text { max }}$ compared to a non-exercising control group (Hill, Storandt \& Malley, 1993). In contrast, Rikkli and Edwards (1991) reported a decrease in reaction time in older women between 57 and 85 year of age after a three year exercise program, compared to inactive controls. They suggest that duration of the intervention may be a critical factor in establishing th benificial effect of acebic training on brain function.

A common design in cross-sectional studies to rest the effect of physical firness on cognitive processes is to randomise discrete age cohorts in different subgroups on the basis of selfreported physical activity level (e.g. Clarkson-Smith \& Hartley, 1989; Rikli \& Busch, 1986; Sparrow \& Wright, 1993), based on the notion that acrobic capacity is in part derermined by regular engagement in vigorous physical activity (LaPorte et $1 ., 1985$ ). However, relations berween self-reports of physical activity and measures of cardiorespiratory fitness are weak, as many factors (such as genetic constitution or inaccuracy of recall) nay contribute to the error variance (LaPorte et al. 1985). Next, apart from the potential subjective bias in activity classification based on self-report one can argue that selection of highly active or fit subjects neglects other personal background characteristics that may confound the effect of activity on cognition, like mood, life style, motivational drive, or educational level (Spirduso, 1975; Stones \& Kozma, 1988).

No clear conclusion can be drawn from earlier studies about what can be expected from the cognitive effect of aerobic fitness in a normal aging population. We therefore studied aerobic capaciry as a potential predictor of performance in different cognitive task paradigms. A 
bealthy population sample, aged between 24 and 76 years was recruited from a larger group of participants in a cognitive aging study, independent of the aerobic capacity status. This pocedure enabled a comparison berween the participating and non-participating groups on several background characteristics and thereby some evaluation is possible of the effect of the inclusion procedure on study outcome. It was hypothesized that after removal of effects of age, sex and intelligence level some additional variance in cognitive performance could be explained by aerobic capacity or the age by aerobic capacity interaction term. The latter effect would express the age-dependency of the relation between aerobic capacity and cognition. These effects were expected to be most prominent in tasks that require some form of effortful processing, as performance tasks in this category have shown the largest degree in consistency in demonstrating activity or aerobic capacity effects (Chodzko-Zajko \& Moore, 1994).

\section{METHODS}

\section{Subjects}

The study program was part of a larger cross-sequential study into the determinants of cognitive aging (Maastricht Memory Study, MAAS, Jolles et al., 1995). Subjects in MAAS were randomly drawn - stratified for age and sex - from a register of family practices in the region of the city of Mastricht, the Netherlands (Metsemakers, Höppener, Knottnerus, Kocken \& Limonard, 1992). The sample register contains all relevant past and present health problems of all subscribed patients. Eligible subjects from the register were excluded for the MAAS study when specific morbidity was present that can be related to brain health (Houx \& Jolles, 1994): cerebrovascular disease, chronic neurological pathology (such as dementia "epilepsy and parkinsonism), mental retardation, or psychotropic drug use. Participants in the MAAS study took part in an extensive neuropsychological rest program of three hours. All 245 subjects in the six discrete age groups of $25 \pm 1$ year, $35 \pm 1$ year, ...,75 \pm 1 year were invited to take part in an additional firness test session. Of this group, 55 subjects did not want to participate on beforchand. In the remaining group there was evidence in 30 subjects of some degree of cardiovascular morbidity (e.g. angina pectoris, prior myocardial infarction, cardiac insufficiency, or arrhythmias) and in 22 subjects of other medical conditions (in particular pulmonary and musculoskeletal morbidiry) that resulted in exclusion. Finally, strict criteria were used to control for homogenous distribution of IQ within age group: six subjects with extreme IQ scores (five below 90 and one above 140) were not included in the study group. resulting in a total group of 132 subjects. Sociodemographic and anthropometric descriptors of the study sample are presented in Table 5.1.

\section{Test procedure}

The addirional firness protocol was administered within three weeks after the neuropsychollogical test session. On this occasion additional anthropometric measurements were performed and $\mathrm{VO}_{2-\max }$ was determined in a submaximal ergometer protocol. All tests 
were administered under medical surveillance and informed consent in writing was obtained from all participants. As part of MAAS, all participants filled out an extensive questionnaire pertaining sociodemographic characteristics and physical and mental health. The Symptom Check List (Arrindell \& Etrema, 1986) was used to measure symptomatology related to anxiety and depression and subjects were asked to rate their general health on a five point scale (1: wery bad, to 5: wery good). Finally, one was asked to rate in hours the average weekly engagement in aerobic sports, such as jogging, swimming; or racket sports.

\section{Physical fituess measurements}

Antbropometry. Body height and weight was measured to the nearest $\mathrm{cm}$ and $\mathrm{kg}$ in all MAAS subjects. The method of Durnin and Womersley (Durnin \& Womersley, 1974) was employed to calculate the fat-free body mass from body weight and the biceps and triceps skinfold thickness on the left arm in the participants of the fitness study.

Submaximal cycle ergometer test. Maximal aerobic capacity $\left(\mathrm{VO}_{2}\right.$-max $)$ was estimated in a submaximal endurance protocol (Siconolfi, Cullinane, Carleton \& Thompson, 1982), to maximize compliance to the study while keeping health hazards in some untrained individuals in the sample while at an acceptable lewel. Subject were instructed to maintain a constant cycling rate of 50 rotations per minute on a cycle ergometer (Erich Jaeger ER800). Heart rate (HR) was monitored using a standard chest lead connected to a digital pulse transmitter (Polar Sporttester PE3000). A wristwatch-type receiver on the arm of the subject displayed the on-line HR. For each subject the HR at $70 \%$ of maximal aerobic capacity was estimated using the formula: $\mathrm{HR}_{70}=.7 \times(220$ - age [years]), in beats-per-minute $(\mathrm{BPM})$. The initial work load of the cycle test was set off at 25 W. Work load was increased every cwo minutes in 25 W steps until HR was at or above the target HR70\%. The subject was to maintain this final work load $\left(W_{s s}\right)$ for at least another two minutes to reach a steady-state HR (HR ss $_{\text {s }}$ ). For male subjects under 35 years the protocol was different. Initial work load was set at $50 \mathrm{~W}$ and increase in 50 W sups every two minutes, until HR was between 60 and $70 \%$ of the estimated maximal HR. Next, work load was increased after every two minutes in $25 \mathrm{~W}$ steps until the $70 \%$ limit was reached. Again $H_{\mathrm{s}}$ was recorded after at least two minutes cycling. The average duration of the endurance protocol was eight minutes.

$\mathrm{VO}_{2 \cdot \mathrm{max}}$ was calculated for males and females differently, using the following regression equations (age in years, HR in $\mathrm{BPM}_{3} \mathrm{VO}_{2-\max }$ in I. min-1: Astrand \& Ryhming, 1954; Siconolfi et al., 1982):

Mriles $\quad V_{2-\max }=0.348 * \mathrm{X}-0.035 *$ age +3.011 [where $\left.\mathrm{X}=\left(174.2 * \mathrm{~W}_{\mathrm{ss}}+4,020\right) /\left(103.2 * \mathrm{HR}_{\mathrm{ss}}\right)-6,299\right)$ ]

Femalas: $\quad \mathrm{VO}_{2 \text {-17ax }}=0.302 * \mathrm{X}-0.019 *$ age +1.593 [where $\left.\mathrm{X}=\left(163.8 * \mathrm{~W}_{\mathrm{sc}}+3.780\right) /\left(104.4 * \mathrm{HR}_{\mathrm{sg}}\right)-7.514\right)$ ]

Validation of the endurance protocol was done in a healthy population sample in the age between 20 and 70 years. The outcome can be considered as a safe and reliable measure of cardiovasular fitness that correlated .24 with direct measurements of $\mathrm{VO}_{2 \text {-max }}$ (Siconolfi er al., 1982). To compensare for the systemaric decrease in fat free mass with age (Jackson et al, 
1990), and because body fat must be regarded as metabolic relatively inert tissue, $\mathrm{VO}_{2}$ max was corrected for weight and percentage body far using the fat free mass (ffrm). This procedure yielded a $\mathrm{VO}_{2-\max }$ in $\mathrm{ml} \cdot \mathrm{min}^{-1} \mathrm{~kg}-\mathrm{ffm}^{-1}$.

\section{Cogntive assessment}

A set of neuropsychological tests was used to tap the cognitive domains of memory and memory related functions, simple psychomotor speed and information processing speed. These teses were selected for their robustness in detecting aging effects in normal aging populations (Jolles et al., 1995). A short description of each test is given belowt.

\section{General intelligence}

Groningen Intelligence Test (GIT). The GIT is the commonly used Dutch estimate of formal IQ which was used in its abbreviated form (Luteijn \& van der Ploeg, 1983).

\section{Mernory}

Visual verbal learning test (VVLT). This test evaluates the ability to aquire and retrieve new verbal information (Brand \& Jolles, 1985). A fixed sequence of fifteen frequently used monosyllabic words were presented on a computer screen. Subjects were asked to reproduce the words after each of five subsequent trials. The total of correctly reproduced words in five trials was recorded (immediate recall), together with the number of correctly reproduced words 20 minutes after the last trial (delayed recall).

Verbal fluency (VF). Outcome of this test reflects the level of organization in memory berween clusters of meaningful related words. The number of animal names correctly produced in 60 seconds was recorded (Luteijn 8 van der Ploeg, 1983).

\section{Simple prychomotor speed}

Continuous tapping (CT). The continwous tapping task required the subject to press the button of an electronic counting device at maximum frequency during 30 seconds, using the index finger of the dominant hand. The total tap count was recorded as index of peripheral motor speed (Lexak, 1995, pp. 672-673).

\section{Information processing speed}

Concept Shifing Test (CST). This test evaluates behavioral planning and evaluation (Houx, Vreeling \& Jolles, 1991). The subject's ability to alternate two psychological concepts during task performance is measured, i.e., number and letter cancellation in correct order. A test sheet contains 16 mall diameter circles $(\varnothing 15 \mathrm{~mm})$ arranged in a larger circle $(\varnothing 16 \mathrm{~cm})$. The digit version (Part $A$ ) presents figures 1 to 16 in random order in the circles, a letter version. (Part B) depicts random letrers, and finally a digit / letter version (Part C) alternates the numbers 1 to 8 and letters $A$ to $\mathbb{H}$. The subject is instructed to cross out the circles in correcr order, as fast as possible without making errors. Outcome is the time required to complete each separate task. 
Motor Choice Reatron Test (MCRT). A computer test was used that evaluates reacrion times as a funcrion of the complexity of task requirements (Houx \& Jolles, 1993). It consists of a simple and a complex choice reaction subtask. In the simple task the subject is required to push a central button on a switch panel with the index finger of the dominant hand. When a white butron $5 \mathrm{~cm}$ above the central butron lights up, one is instructed to push this button and then to return the finger on the central butron. The complex task introduces a decision component: ane of three adjacent white buttons, positioned on a 90 degree arc $5 \mathrm{~cm}$ above the central red bution, may light up in a random order, again requiring the subject to push the button that is lit as fast as possible. Target parameters are median initiation time (decision making and motor preparation) and actual mowement time, calculated after 30 rrials for both subtasks.

Lenter Digit Substitution Test (LDST). This paper-and-pencil test is a modification of the Symbol Digit Modalities Test and intends to measure fundamental processing speed (Smith, 1968). Subjects were instructed to copy numbers in cells indexed by a letter. The letter refers to nine letrer / number combinations at the top of the form. The number of correctly copied corresponding numbers in 90 seconds is recorded.

Stroop Color Word Test (SCWT). This perceptual interference test consists of three subtasks. Each subtask consists of a test sheet containing four rows of ten columns of color names or colored spots. The test measures the speed at which color names are read (subtask $I$ ) and the speed at which color spots are named (subtask II). Subtask. III involves color mames again but the printing ink is different from the color name. The speed at which the collor of the printing ink of the words is named is recorded. The time to complete this subrask reflects the ability to inhibit overlearned responses and has shown robust effects of chronological age (Houx, Jolles \& Vreeling, 1993).

In particular, the complex subtask of the MCRT, the letter / digit version (Part C) of the CST and Stroop subtask III can be regarded as being on the effortul extreme of the effortful versus automatic cognirive processing demand continum (Chodzko-Zajko \& Moore, 1994).

\section{Statistical andlysis}

Differences between participaring and non-participating groups on several measures of mood and physical acrivity were studied using analysis of covariance (ANCOWA), with age and sex as covariates. All cognitive outcome measures were rested for age, sex and age by sex interaction effects with ANCOVA, after correction for differences in general intelligence. The effects of aerobic capacity $\left(\mathrm{VO}_{2-\max }\right)$ and $\mathrm{VO}_{2-\max }$ by age interaction on cognitive performance were tested in several multiple hierarchical regression models, where age, sex and $1 Q$ were entered together in the first step of the analysis. In effect, this means that the effecrs were tested of acrobic capacity on residual scores of the cognitive parameters. 'Goodness-of-fit' of the model was cescribed in terms of variance explained by the variables in the equation, expressed. as (adjusted) $R 2$. Increase of explained variance by the model was tested for significance after each step. Residual scores were screened for systematic trends, but these were nor identified in
the fitred models. 


\section{RESULTS}

When participating and non-participating groups were compared it was found that included subjects were more engaged in aerobic sport activities $(2.0$ vs. 9 hours $/$ week, $F(1,241)=7.77$, $p=.006)$ and rated themselves higher on the general health dimension $(4.0$ ws. $3.6, F(1,239)=$ 7.94. $p=.005)$. No group differences were observed on years of formal education $(11,0$ vs. 11.3 years for non-participants and participants, respectively, $F(1,241)=1.81$ ), general inteligence (GIT-IQ 113.2 vs. $112.0, F(1,241)<1)$ or the mood subscales depression and anxiety of the SCL questionnaire (SCL depression 21.7 vs. 20.3, $F(1,224)<1$; SCL anxiery 12.9 vs. $12.3, F(1,224)<1)$. Furthermore, the anthropometric measures body height $(1.68$ vs.

Table 5.1. Mean (+SD) anchropometric measures in the participant group by age and sex $(N=132)$.

\begin{tabular}{|c|c|c|c|c|c|c|c|c|}
\hline & \multicolumn{6}{|c|}{ Age Class (years) } & \multicolumn{2}{|c|}{ Sex } \\
\hline & $25 \pm 1$ & $35 \pm 1$ & $45 \pm 1$ & $55 \pm 1$ & $65 \pm 1$ & $75 \pm 1$ & M & Fi \\
\hline$n$ & 23 & 24 & 28 & 25 & 21 & 11 & 77 & 55 \\
\hline$M / F$ ratio & $15 / 8$ & $16 / 8$ & $13 / 15$ & $15 / 10$ & $13 / 8$ & 516 & & \\
\hline Body height $(\mathrm{cm})$ & $\begin{array}{r}173.2 \\
(8.0)\end{array}$ & $\begin{array}{r}176.2 \\
(8.3)\end{array}$ & $\begin{array}{r}172.8 \\
(7.1)\end{array}$ & $\begin{array}{r}170.9 \\
(8.2)\end{array}$ & $\begin{array}{r}167.4 \\
(7.2)\end{array}$ & $\begin{array}{r}163.0 \\
(8.8)\end{array}$ & $\begin{array}{r}176.3 \\
(6.1)\end{array}$ & $\begin{array}{r}165.0 \\
(6.8)\end{array}$ \\
\hline Body weight $(\mathrm{kg})$ & $\begin{array}{r}70.3 \\
(11.3)\end{array}$ & $\begin{array}{r}78.5 \\
(14.8)\end{array}$ & $\begin{array}{r}75.2 \\
(10.2)\end{array}$ & $\begin{array}{l}76.9 \\
(9.5)\end{array}$ & $\begin{array}{r}73.5 \\
(10.1)\end{array}$ & $\begin{array}{r}69.8 \\
(12.2)\end{array}$ & $\begin{array}{r}79.7 \\
(10.0)\end{array}$ & $\begin{array}{l}67.5 \\
(9.5)\end{array}$ \\
\hline Body Mass Index $\left(\mathrm{kg} \cdot \mathrm{m}^{-2}\right)$ & $\begin{array}{l}23.4 \\
(3.3)\end{array}$ & $\begin{array}{l}25.2 \\
(3.9)\end{array}$ & $\begin{array}{l}25.2 \\
(3.2)\end{array}$ & $\begin{array}{l}26.3 \\
(2.9)\end{array}$ & $\begin{array}{l}26.2 \\
(3.2)\end{array}$ & $\begin{array}{l}26.1 \\
(2.7)\end{array}$ & $\begin{array}{l}25.6 \\
(2.9)\end{array}$ & $\begin{array}{l}24.9 \\
(3.9)\end{array}$ \\
\hline$\%$ Body fat & $\begin{array}{l}23.8 \\
(9.0)\end{array}$ & $\begin{array}{l}28.4 \\
(6.0)\end{array}$ & $\begin{array}{l}34.0 \\
(7.4)\end{array}$ & $\begin{array}{l}38.4 \\
(7.9)\end{array}$ & $\begin{array}{l}34.7 \\
(7.5)\end{array}$ & $\begin{array}{l}35.7 \\
(4.4)\end{array}$ & $\begin{array}{l}28.0 \\
(7.9)\end{array}$ & $\begin{array}{l}38.2 \\
(6.3)\end{array}$ \\
\hline Fat-free weight $(\mathrm{kg})$ & $\begin{array}{r}53.5 \\
(10.2)\end{array}$ & $\begin{array}{r}56.2 \\
(11.3)\end{array}$ & $\begin{array}{l}49.5 \\
(8.0)\end{array}$ & $\begin{array}{l}47.5 \\
(9.1)\end{array}$ & $\begin{array}{l}47.9 \\
(8.0)\end{array}$ & $\begin{array}{l}44.9 \\
(9.1)\end{array}$ & $\begin{array}{l}57.0 \\
(6.9)\end{array}$ & $\begin{array}{l}41.4 \\
(4.7)\end{array}$ \\
\hline $\mathrm{VO}_{2 \cdot \max }\left(\mathrm{ml} \cdot \mathrm{min}^{-1} \cdot \mathrm{kg}^{-1}\right)$ & $\begin{array}{l}41.1 \\
(9.3)\end{array}$ & $\begin{array}{l}33.0 \\
(7.0)\end{array}$ & $\begin{array}{l}27.7 \\
(7.3)\end{array}$ & $\begin{array}{l}25.3 \\
(6,0)\end{array}$ & $\begin{array}{l}23.5 \\
(7.1)\end{array}$ & $\begin{array}{l}14.5 \\
(3.2)\end{array}$ & $\begin{array}{l}33.7 \\
(9.5)\end{array}$ & $\begin{array}{l}22.3 \\
(6.6)\end{array}$ \\
\hline $\mathrm{VO}_{2-\max }-\mathrm{frm}\left(\mathrm{ml} \cdot \mathrm{min}^{-1} \cdot \mathrm{kg}^{-1}\right)$ & $\begin{array}{l}53.5 \\
(7.6)\end{array}$ & $\begin{array}{l}45.7 \\
(7.1)\end{array}$ & $\begin{array}{l}41.6 \\
(8.1)\end{array}$ & $\begin{array}{l}41.0 \\
(9.0)\end{array}$ & $\begin{array}{l}35.6 \\
(8.9)\end{array}$ & $\begin{array}{l}22.5 \\
(4.2)\end{array}$ & $\begin{array}{r}46.3 \\
(10.6)\end{array}$ & $\begin{array}{l}35.8 \\
(8.7)\end{array}$ \\
\hline
\end{tabular}

Note. $\mathrm{VO}_{2-\max }=$ estimated maximal aerobic capacity: $\mathrm{VO}_{2-\text { max }}-\mathrm{fm}=$ maximal acrobic capacity, corrected for body far.

$1.71 \mathrm{~m})$, weight $\left(72.9 \mathrm{vs} .74 .4 \mathrm{~kg}\right.$ ), or body mass index (BMI; 25.6 vs. $25.3 \mathrm{~kg} \cdot \mathrm{m}^{2}$ ) were not distributed differently in participant and nomparticipant groups $(F(1,238)<1)$. Table 5.1 displays the mean scores of anthropometric variables by levels of age class and sex in the participants group. Descriptives of the cognitive dependent parameters used are presented in Table 5.2 .

Aerobic capacity, both corrected and uncorrected for body composition, showed lower values for women and older age groups (Table 5.3). An age by sex interaction effect was found 
Table 5.2. Mean ( $+5 D)$ cognitive outcome measures, by lewels of age and $\operatorname{sex}(N=132)$.

\begin{tabular}{|c|c|c|c|c|c|c|c|c|}
\hline & \multicolumn{6}{|c|}{ Age class (years) } & \multicolumn{2}{|c|}{ Sex } \\
\hline & $25 \pm 1$ & $35 \pm 1$ & $45 \pm 1$ & $55 \pm 1$ & $65 \pm 1$ & $75 \pm 1$ & $\mathrm{M}$ & $\mathrm{F}$ \\
\hline $\mathrm{MQ}$ & $\begin{array}{l}1100 \\
(11.0)\end{array}$ & $\begin{array}{l}117.3 \\
(10.2)\end{array}$ & $\begin{array}{l}115.3 \\
(13.1)\end{array}$ & $\begin{array}{r}113.4 \\
(13.2)\end{array}$ & $\begin{array}{l}113.3 \\
10.11\end{array}$ & $\begin{array}{r}119.5 \\
(13.2)\end{array}$ & $\begin{array}{r}116.3 \\
(12.4)\end{array}$ & $\begin{array}{l}111.7 \\
(10.8)\end{array}$ \\
\hline VVLT: recall toal & $\begin{array}{r}47.3 \\
(10.3)\end{array}$ & $\begin{array}{l}49.4 \\
(6.4)\end{array}$ & $\begin{array}{l}44.3 \\
(6.8)\end{array}$ & $\begin{array}{l}45.0 \\
(8.4)\end{array}$ & $\begin{array}{l}37.5 \\
9.9)\end{array}$ & $\begin{array}{r}34.9 \\
(10.5)\end{array}$ & $\begin{array}{r}42.2 \\
(10.3)\end{array}$ & $\begin{array}{l}46.5 \\
(7.9)\end{array}$ \\
\hline WVLT: delayed recill & $\begin{array}{l}10.4 \\
(2.7)\end{array}$ & $\begin{array}{l}10.2 \\
(2.9)\end{array}$ & $\begin{array}{r}9.5 \\
(2.4)\end{array}$ & $\begin{array}{r}9.8 \\
(2.4)\end{array}$ & $\begin{array}{r}7.7 \\
(3.0)\end{array}$ & $\begin{array}{r}79 \\
(4.0)\end{array}$ & $\begin{array}{r}8.9 \\
(3.0)\end{array}$ & $\begin{array}{l}10.3 \\
(2.5)\end{array}$ \\
\hline SRT: indration (ms) & $\begin{array}{l}316.9 \\
(48.3)\end{array}$ & $\begin{array}{l}311.0 \\
(34.0)\end{array}$ & $\begin{array}{l}326.4 \\
(57.6)\end{array}$ & $\begin{array}{l}341.5 \\
(55.5)\end{array}$ & $\begin{array}{l}367.1 \\
(72.1)\end{array}$ & $\begin{array}{l}376.3 \\
(84.9)\end{array}$ & $\begin{array}{l}332.5 \\
(61.8)\end{array}$ & $\begin{array}{l}339.5 \\
(59.4)\end{array}$ \\
\hline $\mathrm{SRT}_{\mathrm{T}}$ mowemert (ms) & $\begin{array}{l}104.2 \\
(22.5)\end{array}$ & $\begin{array}{r}114.1 \\
(32.8)\end{array}$ & $\begin{array}{r}121.8 \\
(27.0)\end{array}$ & $\begin{array}{l}134.1 \\
(36.8)\end{array}$ & $\begin{array}{l}150.0 \\
(36.0\end{array}$ & $\begin{array}{r}154.5 \\
(36.3)\end{array}$ & $\begin{array}{r}116.1 \\
(29.2)\end{array}$ & $\begin{array}{r}142.0 \\
(38.1)\end{array}$ \\
\hline CRT: iniciation (ms) & $\begin{array}{l}349.3 \\
(38.2)\end{array}$ & $\begin{array}{l}357.4 \\
(37.4)\end{array}$ & $\begin{array}{l}350.7 \\
(27.2)\end{array}$ & $\begin{array}{l}367.2 \\
(50.6)\end{array}$ & $\begin{array}{l}398.0 \\
(43.4)\end{array}$ & $\begin{array}{l}391.8 \\
(72.6)\end{array}$ & $\begin{array}{l}363.9 \\
(50.1)\end{array}$ & $\begin{array}{l}368.3 \\
(40.6)\end{array}$ \\
\hline CRT: movement (ms) & $\begin{array}{l}110.4 \\
(23.8)\end{array}$ & $\begin{array}{l}120.7 \\
(27.4)\end{array}$ & $\begin{array}{l}123.6 \\
(24.7)\end{array}$ & $\begin{array}{l}137.0 \\
(36.0)\end{array}$ & $\begin{array}{r}147.4 \\
(30.8)\end{array}$ & $\begin{array}{r}168.6 \\
(46.3)\end{array}$ & $\begin{array}{r}119.8 \\
(27.3)\end{array}$ & $\begin{array}{r}146.4 \\
(37.1)\end{array}$ \\
\hline Stroop l: words (s) & $\begin{array}{l}41.6 \\
(6.3)\end{array}$ & $\begin{array}{l}43.6 \\
(6.7)\end{array}$ & $\begin{array}{l}45.5 \\
(6.2)\end{array}$ & $\begin{array}{l}47.3 \\
(6.5)\end{array}$ & $\begin{array}{l}49.9 \\
(9.3)\end{array}$ & $\begin{array}{l}50.4 \\
(7.5)\end{array}$ & $\begin{array}{l}44.6 \\
(7.4)\end{array}$ & $\begin{array}{l}47.8 \\
(7.4)\end{array}$ \\
\hline Stroop II: colors (s) & $\begin{array}{r}55.3 \\
(8.2)\end{array}$ & $\begin{array}{l}55.4 \\
(8.4)\end{array}$ & $\begin{array}{l}55.2 \\
(8.0)\end{array}$ & $\begin{array}{l}60.8 \\
(7.8)\end{array}$ & $\begin{array}{r}62.2 \\
(11.8)\end{array}$ & $\begin{array}{r}64.0 \\
(16.0)\end{array}$ & $\begin{array}{r}57.6 \\
(10.2)\end{array}$ & $\begin{array}{l}58.9 \\
(9.8)\end{array}$ \\
\hline Stroop III: color / words $(s)$ & $\begin{array}{r}83.1 \\
(14.3)\end{array}$ & $\begin{array}{r}81.6 \\
(12.6)\end{array}$ & $\begin{array}{r}88.0 \\
(18.9)\end{array}$ & $\begin{array}{l}103.5 \\
(16.1)\end{array}$ & $\begin{array}{l}104.3 \\
(21.5)\end{array}$ & $\begin{array}{r}127.5 \\
(37.1)\end{array}$ & $\begin{array}{r}94.0 \\
(23.1)\end{array}$ & $\begin{array}{r}96.0 \\
(23.8)\end{array}$ \\
\hline CST: digits (s) & $\begin{array}{l}15.8 \\
(3.6)\end{array}$ & $\begin{array}{r}18.3 \\
(4.3)\end{array}$ & $\begin{array}{l}18.4 \\
(4.1)\end{array}$ & $\begin{array}{l}21.2 \\
(3.7)\end{array}$ & $\begin{array}{l}23.9 \\
(5.2)\end{array}$ & $\begin{array}{l}24.6 \\
(7.2)\end{array}$ & $\begin{array}{l}19.7 \\
(5.1)\end{array}$ & $\begin{array}{r}19.9 \\
(5.6)\end{array}$ \\
\hline CST: Ietrers $(5)$ & $\begin{array}{l}21.7 \\
(8.1)\end{array}$ & $\begin{array}{l}23.2 \\
(6.3)\end{array}$ & $\begin{array}{l}22.5 \\
(6.1)\end{array}$ & $\begin{array}{l}27.7 \\
(7.6)\end{array}$ & $\begin{array}{l}29.4 \\
(7.9)\end{array}$ & $\begin{array}{l}29.2 \\
(6.1)\end{array}$ & $\begin{array}{l}25.8 \\
(8.5)\end{array}$ & $\begin{array}{l}24.2 \\
(6.2)\end{array}$ \\
\hline CST: digit / letrers $(s)$ & $\begin{array}{l}25.4 \\
(6.2)\end{array}$ & $\begin{array}{l}27.9 \\
(6.6)\end{array}$ & $\begin{array}{l}29.9 \\
(9.6)\end{array}$ & $\begin{array}{l}34.1 \\
(6.2)\end{array}$ & $\begin{array}{l}39,2 \\
(8.9)\end{array}$ & $\begin{array}{r}50.6 \\
(19.2)\end{array}$ & $\begin{array}{r}32.9 \\
(10.3)\end{array}$ & $\begin{array}{r}32.3 \\
(12.5)\end{array}$ \\
\hline $\operatorname{LDST}$ & $\begin{array}{r}65.5 \\
(10.3)\end{array}$ & $\begin{array}{l}61.4 \\
(8.5)\end{array}$ & $\begin{array}{r}61.5 \\
(10.0)\end{array}$ & $\begin{array}{l}54.4 \\
(9.4)\end{array}$ & $\begin{array}{l}52.3 \\
(8.9)\end{array}$ & $\begin{array}{r}48.0 \\
(12.9)\end{array}$ & $\begin{array}{r}58.4 \\
(10.7)\end{array}$ & $\begin{array}{r}58.0 \\
(11.6)\end{array}$ \\
\hline Tapping & $\begin{array}{l}203.6 \\
(19.1)\end{array}$ & $\begin{array}{r}193.6 \\
(22.1)\end{array}$ & $\begin{array}{r}188.7 \\
(15.8)\end{array}$ & $\begin{array}{l}176.0 \\
(27.3)\end{array}$ & $\begin{array}{r}171.6 \\
(17.5)\end{array}$ & $\begin{array}{r}146.4 \\
(30.2)\end{array}$ & $\begin{array}{l}191.8 \\
(21.9)\end{array}$ & $\begin{array}{l}172.1 \\
(27.9)\end{array}$ \\
\hline filuency & $\begin{array}{l}25.4 \\
(6.6)\end{array}$ & $\begin{array}{l}24.3 \\
(6.2)\end{array}$ & $\begin{array}{l}23.1 \\
(4.9)\end{array}$ & $\begin{array}{l}21.9 \\
(5.5\}\end{array}$ & $\begin{array}{l}22.9 \\
(7.1)\end{array}$ & $\begin{array}{l}19.6 \\
(5.0)\end{array}$ & $\begin{array}{l}22.9 \\
(6.1)\end{array}$ & $\begin{array}{r}23.5 \\
(6.0)\end{array}$ \\
\hline
\end{tabular}

Note. $1 \mathrm{Q}=$ Groningen Intelligence Test $(\mathrm{GTT})-1 \mathrm{Q}_{i}$ VVLT $=$ Visual Verbal Learning Tesi; SRT = simple reaction time; CRT = complex reaction time; CST - Concept Shifting Test; 1 .DST $=$ Letter Digit Subatitution Test.

only for aerobic capacity, uncorrected for body fat, indicating lower values of $\mathrm{VO}_{2 \text {-max }}$ with increasing age in men, when compared to women. No effect of age was observed on the general abiliny measure GIT-1Q, indicating a homogeneous distribution of $\mathrm{IQ}$ - after the exclusion of six subjects with extreme values. Female IQ scores tended to be somewhat lower. All 
Table 5.3. Results of analysis of covariance (ANCOVA) on aerobic capacity and cognitive outcome measures; tests for main and interaction effects of age and sex, with $1 \mathrm{Q}$ as covariate $(N=132)$.

\begin{tabular}{|c|c|c|c|c|}
\hline & $\begin{array}{c}\text { Age } \\
R(5,119)=\end{array}$ & $\begin{array}{c}\text { Sex } \\
F(1,119)=\end{array}$ & $\begin{array}{l}\text { Age x Sex } \\
(75,119)=\end{array}$ & $\begin{array}{c}\mathrm{TQ} \\
F(1,119)=\end{array}$ \\
\hline $\mathrm{VO}_{2 \mathrm{man}}\left(\mathrm{ml} \cdot \mathrm{min}^{-1} \cdot \mathrm{kg}^{-1}\right)$ & $4.7 .99^{\text {nikik }}$ & $113.89^{* * *}$ & $3.03^{*}$ & 1.49 \\
\hline$V \mathrm{O}_{2-\max }\left(\mathrm{mil} \min ^{-1} \cdot \mathrm{kg}-\mathrm{ffm}^{-1}\right)$ & $34.41^{1+\infty \ldots}$ & $50.14^{* * * *}$ & 1.79 & 1.25 \\
\hline GIT-IQR & 1.69 & $6.18 *$ & $<1$ & - \\
\hline VVLT: recall total & 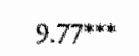 & $17.60 * *$ & 1.11 & $4.20^{*}$ \\
\hline VLT: delayed recall & $5.09^{* * * *}$ & $16.23^{* * *}$ & $\ll 1$ & $4.36 *$ \\
\hline SRT: initiation time & $5.38^{* * *}$ & $<1$ & $<1$ & $23.55^{* * * *}$ \\
\hline SRT: movement time & $8.63^{* * * *}$ & $16.79 * * *$ & $\ll$ & $5.72 *$ \\
\hline CRT: initiation time & $5.74^{* * * *}$ & $<1$ & $<1$ & $12.94^{* * *}$ \\
\hline CRT: movement time & $9.21^{* * * *}$ & $19.88^{* * *}$ & 1.74 & $5.11^{*}$ \\
\hline Stroop 1: word naming & $5.93^{* * * * *}$ & $2: 20$ & 1.01 & $14.79^{* * * * *}$ \\
\hline Stroop II: color naming & $4.06 * *$ & $<1$ & 1.14 & $13.73^{\text {*anate }}$ \\
\hline Stroop III: color/words & $18.51^{* * 2 * * *}$ & 1.70 & $<1$ & $28.69^{* * * * *}$ \\
\hline CST: digit cancellation & $13.80^{* * * *}$ & $<1$ & $2.38^{*}$ & $7.40^{* *}$ \\
\hline CST: letter cancellation & $6.81^{* * * * *}$ & $7.32^{* *}$ & $<1$ & $19.51^{* *}$ \\
\hline CST: digit / letter cancellation & $23.07^{* * * *}$ & $5.08^{*}$ & 2.14 & $21.60^{* * * *}$ \\
\hline LDST & $10.72^{* * *}$ & 1.00 & $<1$ & $12.32^{* * *}$ \\
\hline Tapping & $18.98^{* * *}$ & $19.77^{* * *}$ & 2.23 & $13.31^{* * *}$ \\
\hline Fluency & $2.72^{*}$ & 2.68 & 1.46 & $5.16^{*}$ \\
\hline
\end{tabular}

Note. $\mathrm{VO}_{2-\mathrm{max}}=$ maximal aerobic capacicy (in ml-min-1. $\left.\mathrm{kg}^{-1}\right) ; \mathrm{VO}_{2-\max }-\mathrm{fm}=$ maximal aerobic capacicy - corrected for body fat (in ml. $\mathrm{min}^{-1} \cdot \mathrm{kg}^{-1}$ fat free mass); $\mathbb{l Q}=$ Groningen Intelligence Test $-I Q ; V V L T=$ Visual Verbal Learning Test; $S R T=$ simple reaction time; CRT $T^{2}$ complex reaction time; CST $=$ Concept Shifting Test; $L D S T=$ Letter Digit Substitution Test.

a Result of ANOVA witli only age and sex as independent wariables.

${ }^{*} p \leq .05, * * p \leq .01, * * * * ; \leq .001$

cognitive outcome measures were more or less strongly age and IQ sensitive, showing lower average performance values for older age groups and lower IQ scores. Men outperformed women on movement times of the simple and choice reaction time tasks (SRT" and CRT, respectively), on the concepe shifting test (CST) subtasks letter and digit / letter cancellation, and on finger tapping speed. However, the opposite was crue for the immediate and delayed recall of learned words (VVLT) where women scored higher. Age interacted with sex on CST digit cancellation, where the time required to complete the task tended to increase more with age in women, when compared to men.

Before the regression models were fitted, zero-order correlations were computed between independent and dependent variables as used in the subsequent analysis (Table 5.4). All cognitive measures (excepr CRT movement time) were correlated with chronological age and incelligence level in the expected direction, lower performance being associated with lower IQ levels or higher age. $\mathrm{VO}_{2-\max }$ was strongly correlated with cognitive measures, except in word 
Auency. This may be in part due to the intermediate factor age which is associated with both cognitive and phystcal performance measures. Higher lewels of the age by aerobic capacity interaction term were associated with higher total VVLT recall scores and faster CRT initiation, Stroop III performance, and CST digit/ letter cancellation, indicating that the effect of aerobic capacity was age-dependent.

In the final phase of the analysis, hierarchical regression models were firted for all cognitive outcome measures, in order to test the predictive value of $\mathrm{VO}_{2 \text {-max }}$ (in step 2) and of the $\mathrm{VO}_{2 \text {-max }}$ by age interaction term (in step 3), after linear correction for main effects of age, sex and IQ in step 1 (Table 5.5). By far the largest proportion of $R^{2}$ increase was observed in scep 1 in all cognitive measures, which confirms the effects already present in the ANCOVA's. When $\mathrm{VO}_{2-\text { miax }}$ was entered there was an increase in $R^{2}$ of $1 \%$ and $2 \%$, for the interference version (III) of the Stroop and concept shifting - digit / letter cancellation - respectively. Again, $R^{2}$ increased significantly for both tests on introduction of the interaction term age by $\mathrm{VO}_{2-\max }$ in step 3 , with $2 \%$ and $5 \%$, respectively. In addition, $R^{2}$ of the choice reaction time task - movement time - increased with $2 \%$ in step 3 . All other outcome measures remained unaffected by the aerobic capacity measures in the final two steps of the analysis.

Table 5,4. Correlations berween predicrors chronological age, sex, $1 \mathrm{Q}, \mathrm{VO}_{2 \text { max }}$, age $\mathrm{x} \mathrm{VO}_{2-\max }$ and cogninive dependent wariables (Pearson's $r$ ).

\begin{tabular}{|c|c|c|c|c|c|}
\hline & Age & Sex & GIT-1Q & $\mathrm{VO}_{2 \text { max }}$ & Age $x \vee O_{2-\max }$ \\
\hline Age & - & & & & \\
\hline Sex & .07 & - & & & \\
\hline GIT.IQ & .07 & -.17 & - & & \\
\hline $\mathrm{VO}_{2-\max }$ & $-.67^{* *}$ & $-.47^{* * *}$ & .05 & - & \\
\hline$A g e \mathrm{VO}_{2-\max }$ &. .12 & .07 & -.06 & .17 & - \\
\hline VVLT: recall total & $-.42^{\text {*ik }}$ & $.22^{*}$ & $.23^{* *}$ & $.25^{* * *}$ & $.17 *$ \\
\hline VVLT: delayed recall & $-30^{* * *}$ & $.24 *$ & $.23^{* *}$ & $.18^{*}$ & .12 \\
\hline SRT: iniriation time & $.34^{* *}$ & .06 & $-.35 * *$ & $-32^{* *}$ & -.11 \\
\hline SRT: movement nime & $47 *$ & $36^{* *}$ & $.117^{*}$ & $-.49 * *$ & -.10 \\
\hline CRT: invitiation time & $34^{* * *}$ & .05 & $-.28^{* * *}$ & $-32^{i *}$ &., 11 \\
\hline CRT: movement time & $.46^{* *}$ & $38^{* *}$ & .15 & $-.49^{\text {kik }}$ & $-.19^{*}$ \\
\hline Stroop I: word naming & $39^{* * *}$ & $.21^{*}$ & $-31 * k$ & $-40^{* *}$ & -.09 \\
\hline Srroop II: color naming & $30^{* *}$ & .07 & $-.33^{* * *}$ & $-.24^{* * 1 *}$ & ${ }_{0} 07$ \\
\hline Stroop III: colar / word & $53^{* *}$ & .04 & $-.37^{\text {事 }}$ & $-46^{* *}$ & $-.24^{* *}$ \\
\hline CST digit concellation & $54^{* * *}$ & .02 & $-.23^{* *}$ & $-.35^{* *}$ & -.16 \\
\hline CST: levier cancellation & $.38^{*}$ & -.11 & $-35^{* *}$ & $.27^{\text {intat }}$ & -.14 \\
\hline CST: kligic / letrer & $.58^{* * *}$ & -.03 & $-.33^{* * *}$ &. $.47^{* *}$ & $-.31^{* * *}$ \\
\hline LDST & $-48^{* * *}$ & -.02 & $.29^{* *}$ & $.35^{* * *}$ & .15 \\
\hline Tapping & $-.56^{* *}$ & $-.37^{* *}$ & $.24^{* * *}$ & $.56 * *$ & .16 \\
\hline Fluency & $-23^{* *}$ & .06 & $.43^{* * *}$ & .10 & .06 \\
\hline
\end{tabular}

Note. GIT-IQ = Groningen Intelligence Test $-\mathrm{MQ}_{i} \mathrm{VO}_{2 \text {-max }}=$ maximal aerobic capacity - corrected for body far (in ml min-1, $\mathrm{kg}^{-1}$ far free mass); VVLT $=$ Visual Verbal Learning Test; $\mathrm{SRT}=$ simple teaction time; $\mathrm{CRT}=$ complex reaction titne; $\mathrm{CST}=$ Concept Shifring Test; $\mathrm{LDST}=\mathrm{L}$ Letrer Digit
Sulbstiturion Test.

*p $p .05, * * j \leq .01$ (two-railed) 
Table 5.5. Results of multiple hierarchical regression analysis age, sex and GIT IQ were entered in step II of the analysis, $\mathrm{VO}_{2 \text { - wax }}$ and age $x V_{2 \text { max }}$ interaction in step 2 and 3 , respectively. Displayed atre standardized regression coefficients (Beta) in the final model, $R^{2}$ (equavalent to the proportion of exptained wariance) and significance of $R^{2}$ change after each step.

\begin{tabular}{|c|c|c|c|c|c|c|c|c|}
\hline & \multicolumn{5}{|c|}{ Betutit } & \multicolumn{3}{|c|}{$R^{z}$ after step } \\
\hline & Age & Sex & $\mathrm{IQ}$ & $\mathrm{VO}_{2 \mathrm{~m}}$ & Age $\times \mathrm{VO}_{2 \mathrm{~m}}$ & 1 & 2 & 3 \\
\hline VVLT: recall total & -37 & 37 & .26 & .14 & .09 & $.29 * *{ }^{*}$ & .29 & 30 \\
\hline VVLT: delayed recall & -.22 & .42 & .26 & .19 & .03 & $.21^{* * *}$ & .22 & .22 \\
\hline SRT: initiation rime & .25 & .09 & -.41 & .15 & .06 & $23 * * *$ & 23 & .23 \\
\hline SRT: movemene rime & .42 & .25 & -17 & -.08 & .07 & $.33^{* * *}$ & .33 & .33 \\
\hline CRT: initiation rime & .23 & -.08 & -.31 & -.17 & -.06 & $.17^{* 1 *}$ & .17 & .17 \\
\hline $\mathrm{CRT}$ : movement time & .44 & .29 & -.17 & -.03 & -.16 & $33^{* * * *}$ & .33 & $.35^{*}$ \\
\hline Stroop li word naming & .30 & .07 & 31 & -.14 & -.05 & 24 & .24 & 24 \\
\hline Stroop II: color naming & .26 & -.07 & -.37 & -.05 & -.01 & .17 *aid & .16 & .16 \\
\hline Stroop III: collor/word & .46 & $\sim 08$ & $\cdot 42$ & -.15 &. .18 & $42^{* * * *}$ & $43 *$ & $.46^{* *}$ \\
\hline CST: digit cancellation & 61 & -.04 & -.28 & .06 & -.10 & $.35^{* * * * *}$ & .35 & .35 \\
\hline CST: letter cancellation & .33 & -.28 & -41 & -.13 & -.07 & $.29^{*+1 \times k}$ & 30 & .29 \\
\hline CST: digit / letter & .48 & 4.18 & -.37 & -.18 & -23 & $.44^{* * * * * *}$ & $.46^{*}$ & $.51 * * *$ \\
\hline LDST & -.47 & .08 & .34 & .02 & .10 & $28^{* * *}$ & .28 & .28 \\
\hline Tapping &. .52 & -.27 & .25 & .05 & .11 & $.45^{* * *}$ & .44 & .45 \\
\hline Fluency & -31 & .06 & .24 & -.09 & .05 & $.08^{* * *}$ & .07 & .07 \\
\hline
\end{tabular}

Note. $\mathrm{IQ}=$ Groningen Incelligence $\mathrm{Test}-\mathrm{IQ}, \mathrm{VO}_{2 \text { max }}$ = estimated maximal aerobic capacity - corrected for body fat (in $\mathrm{ml} \cdot \mathrm{min}^{-1} \cdot \mathrm{kg}^{-1}$ (at free mass); WVLT = Visual Verbal Learning Test; SRT = simple reaction time; $\mathrm{CRT}=$ complex reaccion time; $\mathrm{CST}=$ Concept Shifting Test; $\mathrm{LDST}=$ Letter Digit Substiturion Test. ${ }^{*} p \leq .05, * * p \leq .011^{* * * *} p \leq .001$

\section{DISCUSSION}

Our chief aim in this study was to assess the relationship between aerobic capacity $\left(\mathrm{VO}_{2-\max }\right)$ and cognitive test performance, in a healthy, normal aging population, in particular without a priori stratification on physical fitness parameters. After evaluation and control for relevant background characteristics, a positive association was found between $\mathrm{VO}_{2 \text { max }}$ and the age by $\mathrm{VO}_{2-\max }$ interaction on the one hand, and two measures of information processing speed (Stroop III and CST - digit / letter cancellation) on the other. Test outcome related to memory and simple psychomotor speed was relatively unaffected by aerobic capacity measures, except for an isolated association between CRT-movement rime and the age by $\mathrm{VO}_{2-\text { max }}$ interaction term. We have to evaluate these findings in the light of earlier research.

\section{Strudy population thatracteristics}

No clear effect of the inclusion procedure was present on mood parameters, years of formal education or general intelligence. However, differences in hours per week spent in aerobic 
activities and perceived general health berween participant and nonparticipant groups suggest that some selection bias may have been present, in part due to the health exclusion criteria that were employed. The reason for our strict scrutiny with respect to health status was to forestall any potential bias due to cardiopulmonary pathology on study ourcome (see Herzog, Schaie $8 \mathrm{c}$ Gribbin, 1978) and to prevent any health hazard for participants due to the firness protocol. It cannot be ruled out entirely that because levels of aerobic actiwity and functional health may be directly related to actual aerobic capacity (Dehn \& Bruce, 1972; LaPorte et al., 1985) this bias may have resulted in a restriction of range of $\mathrm{VO}_{2-\max }$ in the study group, thereby attenuating the effects of $\mathrm{VO}_{2 \text {-max }}$ on cognitive outcome. This is a well-known methodological problem in developmental research where the utrimate goal is to obrain unbiased estimates of change (Hayslip \& Panek, 1989). Furthermore, although differences in overall IQ berween participant and non-participant groups were absent (112.0 ws. 113.2 , respectively) it is obvious that the averages are in the high-normal range (Luteijn \& wan der Ploeg, 1983). A higher level of IQ has been shown to protect against age-related memory performance deficits (Huppert, 1991). As all measures of cognitive test performance in this study were positively related to IQ, it cannot be ruled out that the study population is less inclined to benefit from higher aerobic capacity levels. Higher IQ and restriction of range may therefore have attenuated the observed effects of aerobic capacity.

The values for $\mathrm{VO}_{2 \text {-max }}$, uncorrected for body fat, that were obtained in this study are somewhat higher compared those in the Siconolfi et al. (1982) validation study, who employed a comparable inclusion procedure and used approximately the same age groups that were balanced for sex. Their averages ranged from $37.2 \mathrm{ml} \cdot \mathrm{min}^{-1} \cdot \mathrm{kg}^{-1}$ body weight $(S D=7.9)$ in the 20-29 year group to $20.6(S D=6.1)$ in subjects between 60 and 70 years. The difference may be attributable to a relative underrepresentation of women in this study.

\section{Speed of information processing and aging}

It has been suggested that cognitively demanding tasks are most sensitive to aspects of physical fitness, in particular tasks where processing speed is the target variable, and tasks of high complexity and low S-R compatibility (Chodzko-Zajko, 1991; Chodzko-Zajko \& Moore, 1994). Both the Stroop task III (interference) and the complex concept shifting task which showed effects of aerobic capacity in this study can be classified as tasks that require effortfull cognitive processing. Both task variables combined in a compound score were sensitive to habitual physical activity measured by questionnaire in a healthy group of older adults (Van Boxtel, Langerak, Houx \& Jolles, 1996). Furthermore, the age by finess interactions that were found fit in with the moderator model proposed by Stones and Kozma (Stones \& Kozma, 1988). This model predicts an augmentation of fitness effects with age, as the result of a decrease in attentional resources. Within a theoretical framework that defines cognitive aging in terms of resource limitation, it can indeed be understood that tasks that draw heavily on the central information processing capacity generally have shown the largest effects of calendar age (Satthouse, 1988). Additional support for this notion has been found in several studies that demonstrated an association between complex reaction time (CRT) and physical activity level (Spirduso, 1980) or CRT and improvement in $\mathrm{VO}_{2-\max }$ after an aerobic training intervention 
(Rikli \& Edwards, 1991). Our results, however, indicated that CRT initiation time - which is known to represent the time needed for stimulus evaluation and response formation - did not covary with aerobic capacity or its interaction with age. Of course, this may in part be the result of procedural differences in the employed task compared to earlier studies. Absence of aerobic fitness effect on digit copying (LDST) is more readily understood, as the central processing contribution to the outcome of this task is to some extent confounded by basic sensorimotor speed.

In summary, small proportions of variance explained by aerobic capacity and the aerobic capacity by age interaction term could be demonstrated in two out of four tasks that measure speed of information processing. These findings add to the notion that aerobic capacity, measured as a continuous variable in a healthy adult population sample, may act selectively in task paradigms that require cognitive effort. Our findings suggest that aerobic fitness per se is a factor of moderate importance in cognitive aging research. However, the authors feel that any evidence for the existence of a factor that may prevent or postpone age-related cognitive decline and that is amenable to intervention should be fully explored and justifies further research that uncovers the underlying mechanism of action in more detail.

\section{REFERENCES}

Arrindell, W. A., \& Errema, J. H. M. (1986). SCL-90. Een multidimentionele psychoparthologie indicator (SCL-90. A multidimensiomal indicator of psychopathology. Lisse, the Necherlands: Swets \& Zeitlinger.

Astrand, $\mathbb{P} .0$., \& Ryhming, I. (1954). A nomogram for calculation of aerobic capacity (physical fitness) from pulse rate during submaximal work. Joumal of Applied Physiology, 7, 218-221.

Blumenthal, J. A.s \& Madden, D. J. (1988). Effects of aerobic exercise training, age, and physical fitness on memory-search performance. Pyychology and Aging, 3, 280-285.

Brand, $N_{0}$, \& Jolles ${ }_{0}$ J. (1985). Learning and retrieval rate of words presented auditory and visually. Journat of General Psychology, 112, 201-210.

Buchner, D. M., Beresford, S. A. A., Larson, E. B., LaCroix, A. Z., \& Wagner, E. H. (1992). Effects of physical activity on health status in older adults II: Intervention studies. Annwal Review of Public Health, 13, 169.488.

Chodzko-Zajko, W. J. (1991). Physical fitness, cognitive performance, and aging. Medicine and Science in Sports and Exercise, 23, 868-872.

Chodzko-Zajko, W. J., \& Moore, K. A. (1994). Physical fitness and cognirive functioning in aging. In J. O. Hollosty (Ed), Exercise and sport sciersers reviews, (Vol. 22, pp. 195-220). Baltimore: Williams \& Wilkins.

Clarkson-Smith, L, \& Hartley, A. A. (1989). Relationships between physical exercise and cognitive abilities in older adults. Psychology and Aging, 4, 183.189.

Delhn, M. M., \& Bruce, R. A. (1972), Longitudinal variations in maximal oxygen intake with age and activity. Joumal of applied Physiology, 33, 805-807.

Dumin, ]. V. G. A., \& Womersley, J. (1974). Body fat assessed from total body density and its estimation from skinfold thickness: Measurements on 481 men and women aged from 16 to 72 years. British fournat of Nutrition, 32,77-97.

Dustman, R. E., Ruhling, R. O., Russell, E. M., Shearer, D. E., Bonekar, H. W., Shigeoka, J. W., Wood, J. S., \&c Bradford, D. C. (1984). Aerobic exercise training and improved neuropsychological function of older individuals. Neurobiology of Aging, 5, 35-42.

Emery, C. F., \& Gatz, M. (1990). Psychological and cognitive effects of an exercise program for communityresiding older adults. Geronzologist, 30, 184-188.

Hayslip, B. \& Panek, P. E. (1989). Adult developement and aging. New York: Harper \& Row.

Herzog, C. Schaie, K. W. \& Gribbin, K. (1978). Cardiovascular disease and changes in intellectual functioning from middle to old age. Journal of Gerontalogy, 33, 872-883.

Hill, R. D., Storandr. M., \& Malley, M. (1993). The impact of long-term exercise trainirig on psychological function in older adults. Journal of Gerontology, 48, P 12-17.

Houx, P. J., \& Jolles, J. (1993). Age-related decline of psychomotor speed: Effecrs of age, brain health, sex, and education. Perceptual and Motor Skills, 76, 195-211. 
How, P. I., \& Joller, (1994). Vuhnerabiliry factors for agc-nelated cognitive decline. In R. L. Isaacson \& K. F Jensen (Eds, Towins in air and water, (Vol. 3, pp. 25-41). New York: Plenum Press.

Houx, P. J., Jolles, I, \& Veeling, F. W. (1993). Stroop interference: Aging effects assessed with the Stroop Color. Word test. Exparmental Agrats Reseachs 19,209-224.

Houx, P. J. Vreling, F. W, \& Jolles, 1 (1991). Age-associated cognitive decline is related to biological life

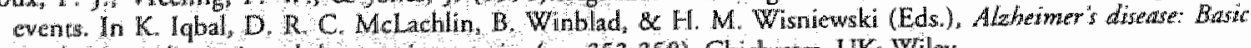

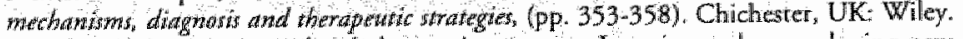

Huppert. F. A. (1991). Age-related changes in memony: Learning and remenbering new informarion. In F. Boller \& J. Grafman (Eds.), Handbot of Nouropsychology, (Vol. 5, pp. 123-147). Amsterdam: Elsevier.

Jackson, A. S. Blair, S. N. Mahar, M. T., Wier, L. T. Ross, R. M. \& Stureville, ). E (1990). Predicuon of Functional aerobic capaciry whont exercise tesurige Medicine and Science in Sports and Exercise $22,863-870$.

Jolles, J., Houx, P. J., van Bexrel, M. P. J., \& Ponds, R. W. H. M. (Eds.) (1995). Maanstricht Aging Study: Determanawn of cegnitive aging. Maastrichte Neuropsych Publishers.

LaPorte, R. E. Montoye, H. J. \& Caspersen, C. J. (1985). Assessment of physical activity in epidemiologic research: Problems and prospeess. Pablic Health Reports, 100, 131-146.

Lexak, M. D. (1995). Newropsychological Assessment. (3rd ed.). New York: Oxford Universiry Press.

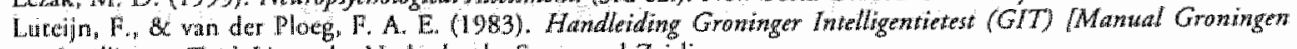
Intelligence Test/. Lisse, the Netherlands: Swets and Zeitlinger.

Madden, D. I., Blumenthal, J. A., Allen, P. A. \& Emery, C. F. (1989). Improving aerobic capacity in healthy older adults does not necessarily lead to improved cognitive performance. Psychology and Aging, 3 , 307-320.

Mersenakers, J. F. M. Hoppener, P., Knotnerus, J. A., Kocken, R. J. J., \& Limonard, C. B. G. (1992). Computerized health information in the Netherlands: A registration nerwork of family practices. British fournal of General Practice, $42,102-106$.

Morse C. K. (1993). Does variability increase with agex An archival study of cognitive measures. Plychology and Aging, $8,156-164$.

Nolan, K A., \& Blass, J. P. (1992) "Preventing cognitive decline. Clinics in Geriatric Medicine, 8, 19-34.

Panton, L. B., Graves, J. E. Pollock, M. L., Hagberg, J. M., \& Chen, W. (1990). Effect of acrobic and resistance training on fracrionated teaction time and speed of mowement. Jowrnal of Gerontolog, 45, M26-31.

poon, L. W. (1985). Differences in human memory with aging: Nature, causes and clinical implications. In J. E. Birren \& K. W. Schaie (Eds.). Handbook of the prychology of aging. New York: Van Nostrand Reinhold.

Rikli, R. \& Busch, 5. (1986). Motor performance of women as a function of age and physical activity level. Journal of Gerontology, 41, 645-649.

Riklli $i_{2}$ R. E. \& Edwards, D. J. (1991). Effects of a three-year exercise program on motor function and cognitive: processing speed in older wonen. Reseatch Quatterly for Exercise and Spart, 62, 61-67.

Rogers, R, I. Meyer, J. S., \& Mortel, K. F. (1990). After reaching retirement age physical acrivity susfains cerebral perfusion and cognicion. Joumal of the American Geriatrics Society, 38, 123-128.

Salthouse, T. A. (1988). Resource-reduction interpretarions of cognitive aging. Developmental Reviere, 8, 238-272.

Salthouse, T. A. (1989). Age-related changes in basic cognitive processes. In M. Srorandt \& G. R. Vandenbos (Eds.),

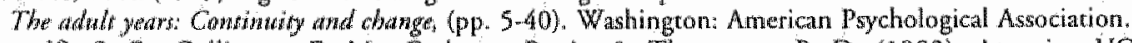

Siconolfi, S, F., Cullinane, E. M. Carleton, R. A., Thompson, P. D. (1982). Assessing VO2-max in epidemiologic srtudies: Modificarion of the Astrand-Rybming test. Medicine and Sctence in Sports and Exercise, $14,335.338$.

Smith. A. (1968). The Symbol Digit Modalities Test: A neuropsychological rest for economic screening of learring and other cercbral disorders. Leaming Disoiders, 36, 83-91.

Sparrow, W. A., \& Wright, B. J. (1993). Effect of physical exercise on the performance of cogritive tasks. Pereptual and Motor Skils, 77,675-679.

Spirduso, W. (1975). Reaction and movement rime as a function of age and physical actiwity level. fournal of Gerontology, 30, 435-4.40.

Spindusa, W. W. (1980). Physical firness, aging, and psychomotor speed: A review. Jowmal of Gerontology, 35, P850865.

Spirduso, W. W., \& Mackac, P. G. (1990). Motor performance and aging. In J. E. Birren \&C K. W. Schaie (Eds.), Handlbok of the piychology of aging (3 ed., pp. 183-200). San Diego: Academic Press.

Stones, M, J., \& Korma, A. (1988). Physical activity, age and cognitive / motor performance. In M. Howe \& C. Brainard (Eds.). Cogninitue dexplepement in adulthood' (pp. 273-322). New York: Springer.

Var Boxtel, M. P. I. Langerak, K., Houx, P. I. \& Jolles, J. (1996). Self-reported physical activity, perceived health. and cognitive performance in older adults. Experimental Aging Research, 22, 363-379. 


\section{Repeated automatic versus ambulatory blood pressure measurement: the effects of age and sex in a normal aging population 4}

\section{ABSTRACT}

Blood pressure adaptation was studied in relation to age and sex in 469 healthy volunteers, aged between 23 and 82 years, who were stratified for age, sex and educational level. In a subsample, laboratory blood pressure measurements were compared with ambulatory day-time blood pressure measurements to determine the degree of agreement between both methods. The night-time blood pressure reduction was analyzed as a function of blood pressure status, age, and sex. These preliminary analyses were performed prior to several studies on the relationship berween blood pressure and cognitive performance.

Laboratory blood pressure was measured automatically five times during a $20 \mathrm{~min}$ recording session (Dinamap ${ }^{\circledR} 8100$ ). Cardiovascular events in the medical history were identified in order to analyse the cardiovascular event-free group separately. Within three weeks after laboratory blood pressure measurement, ambulatory blood pressure was monitored for 24 hours in 135 volunteers from the main study.

Both diastolic and systolic blood pressure changed markedly in a single measurement session as a function of age, independent of mean pressure level. No further lowering of blood pressure was observed after 15 minutes. Based on the average of the final two blood pressure measurements, $18.8 \%$ of the subjects were in the hypertensive range (WHO / ISH guidelines). Ambulatory blood pressure measurements were in accord with earlier findings and correlated .74 and .73 with laboratory diastolic and systolic blood pressure, respectively, albeit weighted. Kappa values indicated only moderate agreement (.42 and .51). Women showed a more profound reduction in night-time blood pressure than did men.

In conclusion, there is a substantial change in blood pressure during a single measurement session which is greater in older age groups. The moderate agreement between both methods of blood pressure measurement indicates that blood pressure measured in a single session has only limited generalizability to the average day-time level in a population sample and that the outcome of both measurements should be treated as separate entities.

4 M. P. J. van Boxtel, C. Gaillard, P. N. van Es, J. Jolles, and P. W. de Leeuw (1996). fourmat of Hiypertension, $14,31-40$. 


\section{INTRODUCTION}

Hypertension has an important role in the pathogenesis of cardiovascular and cerebrovascular disease. Although it is recognized that repeated blood pressure measurements on separate occasions are necessary to reach a definite diagnosis of hypertension (WHO/ISH, 1993), this may not always be achieved in large population-based studies. It is common practice in epidemiological studies to define blood pressure status based on measurements taken during a single visit. This procedure may produce a less accurate estimate of the average habirual blood pressure as a result of uncontrolled environmental conditions, in addition to the normal physiological variability in blood pressure (Llabre et al., 1988). In particular, the alerting reaction to blood pressure measurement, resulting in a transient pressor response, is a well-described elinical phenomenon which is for a large part determined by the presence of a medical professional (Mancia, Casadei, Groppelli, Parati \& Zanchetti, 1991; Mancia et al., 1987). Besides the average blood pressure level, short-term changes in blood pressure and diurnal variation are potential factors that may mediate the detrimental effects of hypertension (Pickering, 1994). The variability of circadian blood pressure is known to increase with age (Pickering, 1991) and the exrent to which this may interfere with blood pressure adaptation during a measurement session is not clear.

The main focus of this study was to determine age- and sex-related changes in blood pressure measured in a laboratory setring, on the basis of repeated oscillometric measurements during a single session. These analyses were performed in order to define an optimal. estimate of the habitual blood pressure after adaptation. In addition, laboratory blood pressure values were compared with day-time averages, obtained by $24 \mathrm{~h}$ ambulatory blood pressure monitoring, for a subgroup of subjects. Because the extent to which single session blood pressure measurements in a non-clinical population can be generalized to average blood pressure on the basis of repeated measurements over a longer period of time is not clear, we further analyzed the agreement berween single session blood pressure and average blood pressure during normal dailly activities. Finally, the effects of age and sex on the circadian blood pressure rhythm were evaluated.

In this study, which is a part of the Maastricht Aging Study (MAAS; Jolles, Houx, van Boxtel \& Ponds, 1995), blood pressure was measured in a healthy population sample aged between 23 and 82 years. The panel was stratified for age and sex, and thus the data allow the analysis of the effect of these variables on blood pressure and its variability. The rationale for introducing blood pressure into the MAAS study and to perform these preliminary analyses is the accumulating evidence that hypertension may play a role in age-relared cognitive decline (for a review, see Waldstein, Manuck, Ryan \& Muldoon, 1991). In this respect, there is special interest in ambulatory blood pressure monitoring because the blood pressure measurements obtained with this technique are superior to single blood pressure measurements in predicting latent cerebrovascular disease in elderly subjects (Shimada, Kawamoto, Matsubayashi \& Ozawa, 1990).

The specific questions addressed in this study can be summarized as follows: how is age related to the adaptation of blood pressure in a laboratory setring and what are the effects of age, sex, and cardiovascular status on diastolic and systolic pressure? How is blood pressure 
measured in the laboratory related to comparable ambulant measures in terms of averages and variability, and, finally, what effect do chronological age and sex have on the differences in day-time and night-time blood pressure?

\section{METHODS}

\section{Subjects}

A rotal of 469 community-dwelling subjects were recruited from a register of family practices (Metsemakers et al., 1992). Exclusion criteria were previous or current medical conditions with known impact on cognitive function, namely overc cerebrovascular disease (including stroke), chronic neurological pathology (e.g. dementia, epilepsy, and Parkinson"s disease), mental retardation, or chronic psychotropic drug use. The sample was stratified for age (12 classes; ranging from $25 \pm 1,30 \pm 1,35 \pm 1, \ldots, 80 \pm 1$ years, mean age 51.4 (SD 16.8) years), sex and two levels of occupational activity, to control for the effect of relevant cognicive performance predictors. For the purpose of data presentation in this study two successive pairs of age groups were combined to form new age classes $(25-30,35-40$, to $75-80$ years $)$.

\section{Procedure}

All of the 469 subjects completed a postal questionnaire and were visited at home by a research nurse who trook a semistructured medical interview. Detailed information about the medical history and use of medication was obtained during this session. Next, all of the participants were tested within two weeks after the home wisit in a neuropsychological test laboratory. A broad range of cognitive tests was administered in two test clusters of one hour each, during a morning $(09.00-12.00 \mathrm{~h})$ or afternoon session $(13.30-16.30 \mathrm{~h})$. During a 25 min internission blood pressure was measured five times at the left arm, with the subject in seated position, using an oscillometric technique. A Dinamap 8100 monitor (Critikon, Tampa FL, USA) with the appropriate cuff size (small, medium, or large adult) was programined for automaric blood pressure measurement at 5 min intervals. During the measurement interval the subject was left unatrended and was instructed to refrain from smoking, to relax, and to remain seated until the research assistant returned. A subgroup of 135 subjects in the six age classes $30,40,50,60$, 70 , and 80 ( \pm 1 ) years agreed to participate in 24 h ambulatory blood pressure monitoring, scheduled 1-4 weeks later at a convenient moment for the subject. The subjects visited the hypertension laboratory of the university hospital between 08.00 and $09.00 \mathrm{~h}$ where an ambulatory blood pressure monitor (Spacelabs@ 90207, Spacelabs Inc., Redmond WA. USA) was applied. The apparatus was programmed to measure blood pressure four times every hour during the day $(07.00-22.59 \mathrm{~h})$ and twice every hour at night $(23.00-06.59 \mathrm{~h})$. All participants were asked to refrain from unusual physical activities and to adhere to their regular sleeping hours.

The prevalence of cardiowascular morbidity was expressed as the presence of one of the following disorders or events reported in the medical interview: angina pectoris, cardiac 
arrhythmia, myocardial infarction, cardiac insufficiency, valvular lesions, heart surgery, peripheral atherosclerosis or cardiac reanimation. A subjective report of hypertension or the use of antihypertensive medication was recorded separately. On the basis of this information the subjects were divided inno a group with and without cardiovascular events in their history. The cardiovascular event group was defined by the reported occurrence of current or past cardiovascular disorders or events - hypertension excluded - or the current use of antihypertensive drugg, or both. The subjective report of a diagnosis of hypertension was not considered sufficient unless the subject was also receiving antihypertensive drugs. These medical population characteristics are summarized in Table 6.1. There was no clinical evidence for renal or renovascular abnormalities in the study group.

All of the subjects were classified into two categories of blood pressure status, based on the average of the fourth and fifth blood pressure measurements, namely normal blood pressure when systolic blood pressure was $<140 \mathrm{mmHg}$ and diastolic blood pressure was $<90 \mathrm{mmHg}$, and byperiension when systolic blood pressure was $\geq 140 \mathrm{mmHg}$ or diastolic blood pressure was $\geq$ $90 \mathrm{mmHg}$. Isolated systolic hypertension (ISH) was defined as a systolic blood pressure of $140 \mathrm{mmHg}$ or higher with diastolic pressure remaining below $90 \mathrm{mmHg}$. These criteria are currently being proposed by the WHO for classification of hypertension based on standard office readings on repeated occasions (WHO/ISH, 1993).

Ambulatory blood pressure values were classified using the regression equations that described in this study the relation between mean laboratory blood pressure and mean daytime ambulatory blood pressure. The WHO/ISH cut-off points for normotension (140/90 $\mathrm{mmHg}$ ) were entered into these equations for systolic and diastolic blood pressure separately to compute the corresponding ambulatory blood pressure monitoring values; day-time mean blood pressure above $135.2 / 88.6 \mathrm{mmHg}$ was considered to be in the laypertensive range. This procedure was employed as no definite reference values for ambullatory blood pressure monitoring are as yet available for clinical purposes.

\section{Statistical analysis}

Diastolic and systolic blood pressure were treated separately in all subsequent analyses. Linear and non-linear effects of age on blood pressure change within 20 min were tested in a one-way analysis of variance procedure. For this analysis the difference between blood pressure at the first and last measurement was expressed as the absolute difference and as a percentage of the average blood pressure over five measurements. This average was corrected for the effect of mean absolute blood pressure level on blood pressure variability (Pickering, 1991), using the formula:

$$
\left(M_{1}-M_{5}\right) \cdot 100 /\left[\left(M_{1}+M_{2}+M_{3}+M_{4}+M_{5}\right) / 5\right]
$$

were $M_{1}$ indicates blood pressure at the time of first measurement, and so forth. The end of blood pressure adaptation was defined as the absence of a significant decrease in systolic and diastolic blood pressure berween two consecutive measurements, using paired $t$-tests with an acijusted $p=.01$ (Bonferroni correction for multiple comparisons). Multiple hierarchical regression analysis was used to test the independent variables cardiovascular event-group 
membership, age, sex and the age by sex interaction term on laboratory blood pressure outcome, and to evaluate the effect of blood pressure status, age, sex, and age by sex interaction on day-night blood pressure differences, in terms of the overall proportion of variance explained in the outcome measure. In case of a significant contribution of a variable to the explained overall wariance, its associated partial regression coefficient $(B)$ and the $95 \%$ confidence interval $(\mathrm{Cl})$ was presented. Compatisons between estimates of mean and variability in blood pressure based on laboratory measurement or ambulatory blood pressure monitoring were presented as Pearson's r and as weighed Kappa ( $\left.K_{w}\right)$. $K_{w j}$ is commonly used as a measure of agreement (concordance) because it expresses the degree of interchangeability between two measurements that are intended to assess the same concept, whereas $r$ is only an index of general relatedness, or trend (Kramer \& Feinstein, 1981). For this purpose all ambulant day-time parameters were ranked in quartiles. Next, laboratory parameters were ranked according to the same ambulatory day-time classification criteria. From the resulting 4 $\times 4$ cross-tabulation table $K_{t b}$ was compured.

Deviation from normality of day-night blood pressure differences was tested using the Kolmogorov-Smirnov test statistic $(K-S) . P<.05$ was considered statistically significant. All analyses were performed with the SPSS program series (Norusis, 1990).

\section{RESULTS}

\section{Relation between age and blood pressure adaptation during repeated laboratory measurement}

The average systolic and diastolic pressures during the laboratory session were calculated for every consecurive measurement $\left(\mathrm{M}_{\mathrm{x}}\right)$ and age class (Figure 6.1). A steady overall increase in systolic pressure was observed with age. The increase in diastolic pressure was less outspoken and diastolic pressure remained relatively constant after $45-50$ years of age. Furthermore, a gradual mean decrease in systolic and (again less extreme) diastolic blood pressures over consecutive measurements was apparent.

A linear increase in diastolic and systolic blood pressure difference with age was found, for both the absolute blood pressure differences and the differences in terms of percentage (one-way analysis of variance, $F(1,456)=14.8$ and 15.2 (both $p<.001$ ), respectively, for diastolic blood pressure; $F(1,456)=26.4$ and 16.0 (both $p<.001$ ), for systolic blood pressure). The mean absolute difference between the first and the last diastolic blood pressure measurements ranged from 0 in the youngest to $5 \mathrm{mmHg}$ in the oldest group. For systolic pressure these values were 6 and $12 \mathrm{mmHg}$, respecrively. The same pattern was observed when the subjects of the cardiowascular event group were excluded from the analysis. No evidence was found for a significant non-linear trend in pressure differences with age. Thus, the decrease in diastolic and systolic blood pressure during the measurement interval was more profound with increasing age, even after correction for the mean pressure level.

In the next step it was determined when this decrease in blood pressure was completed. Differences in blood pressure of four successive pairs of measurements $(1-2,2-3,3-4$ and $4-5$, respectively) computed for the total group were $1.3(t=2.9, p<.01), 1.1(t=3.0, p<.01)$, 


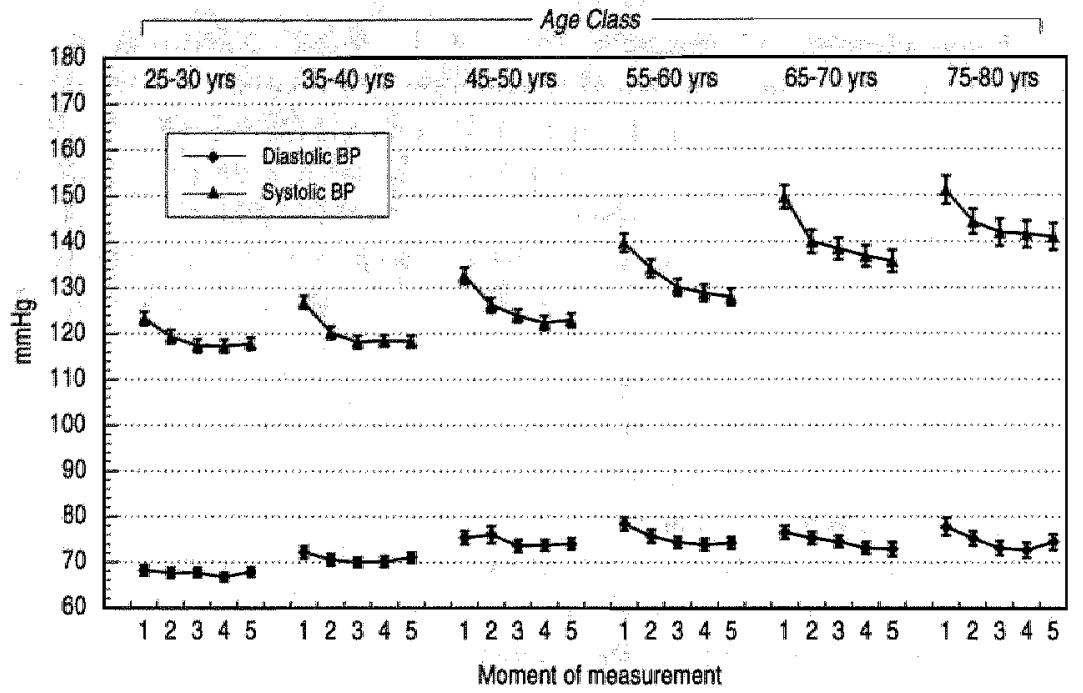

Figure 6.1. Mean systolic and diastolic blood pressures (BP) on five consecutive measurements. within $20 \mathrm{~min}$. Separate plots are shown for different age classes. Error bars indicate the standard error of the mean; total group, $n=469$.

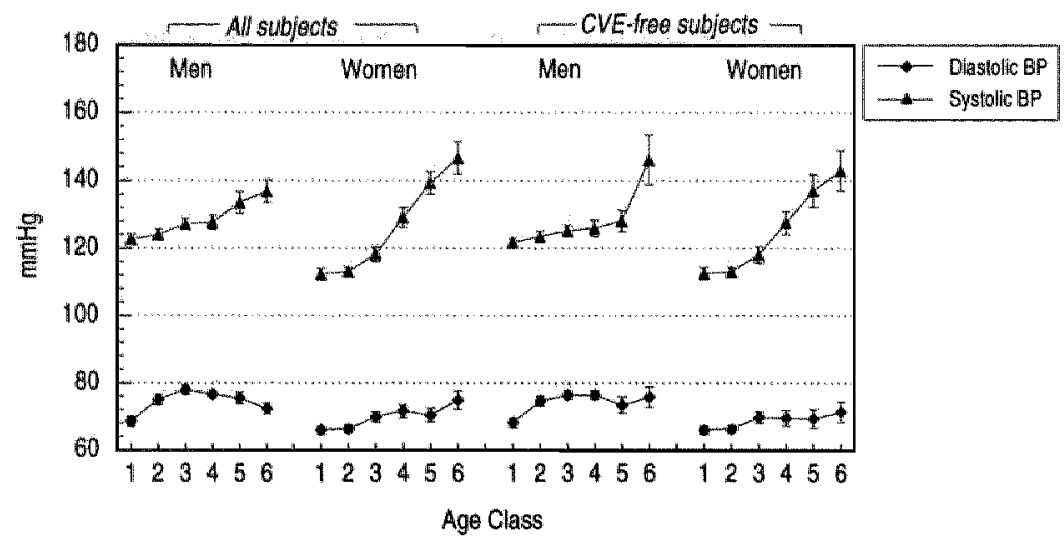

Figure 6.2. Average laboratory systolic and diastolic pressures by age class $(1,25-30$ years, to 6 , $75-80$ years) ard sex, for the toral group $(n=469)$ and for the group free of cardiovascular events $(n=$ 349), separately. Error bars indicate the standard error of the mean. 
Table 6.1. Presence of reported hypertension, use of antihypertensive medicarion, and cardiovascular morbidity by age class and sex.

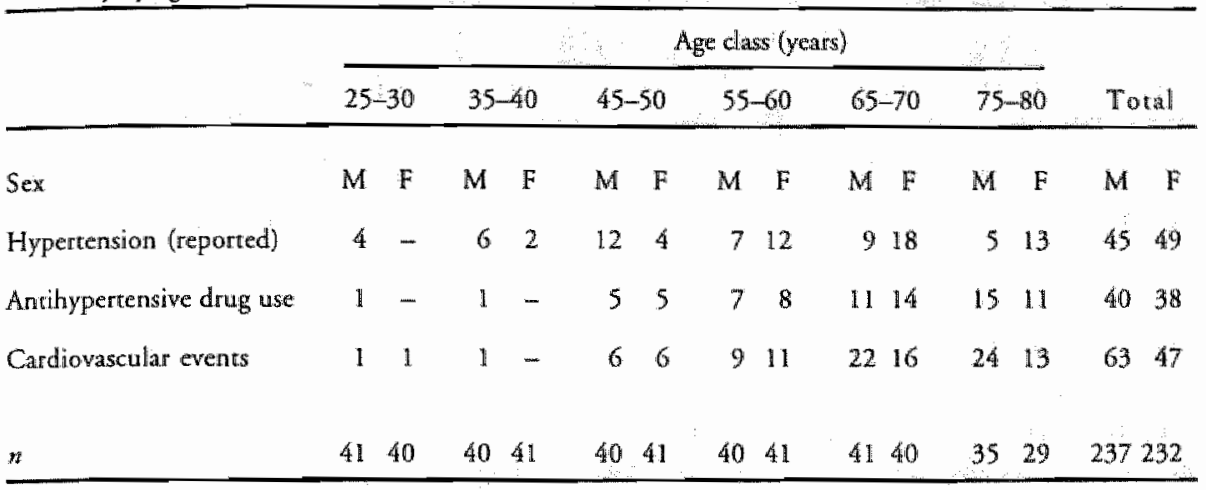

Note. Cardiovascular events included angina pectoris, cardiac arrhythmia, myocardial infarction, cardiac insufficiency, valvular lesions, heart surgery, peripheral atherosclerosis, reanimation, or antihypertensive drug use.

$.7(t=2.6, p<.05)$, and $-.7 \mathrm{mmHg}(t=-2.3, \mathrm{n} . \mathrm{s})$ for diastolic blood pressure, and $6.5(t=$ $15.0, p<.001), 2.4(t=5.9, p<.001), 1.0(t=3.0, p<.01)$, and $3 \mathrm{mmHg}(t=.8, \mathrm{n.s})$ for systolic blood pressure (all analyses $d f=461$ ). This indicates that, at least on a group level, no major adaptation of blood pressure is to be expected afrer measurement 4 . On the basis of these results it was chosen to average the diastolic and systolic pressure level of measurement 4 and 5 as the optimal estimates of habitual blood pressure after adaptation. These averages were used in further analyses.

Table 6.2. Percentage of hypertensive subjects (WHO/ISH criteria) and percentage of subjects with isolated systolic hypertension in different subgroups.

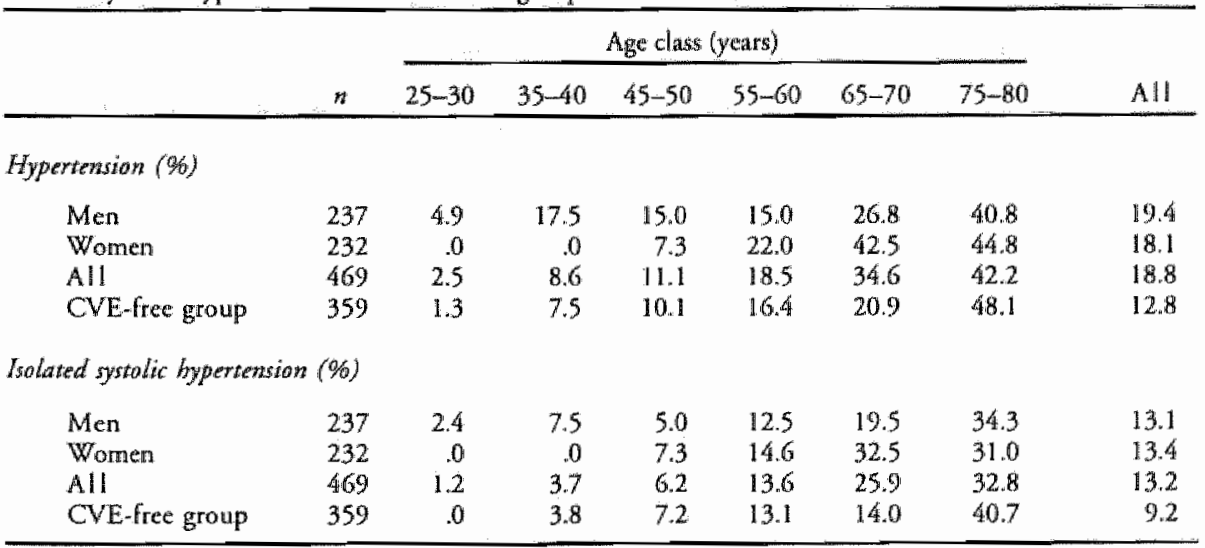

Note. $\mathrm{CVE}=$ Cardiovascular event. 
Effects of alge sex, and cardionascular status on adapred diastolic and systolic prestare

Figure 6.2 illustrates the relarion berwen age dass and diastolic or systolic pressure, for male and female participants separately. Additional plots are shown for the group with no reported cardiovascular events in then medical history.

The effects of membership of the cardiowascular event-group, calendar age, sex, and age by sex interaction on diastolic and systolic pressures were analyzed in two hierarchical multiple regression analyses. In both regression models, cardiowascular event membership (coded as $0 / 1$ for no/yes) was entered in the first step, and sex (coded as 1/2 for male/female), chronological age and the age by sex interaction term in the second step. The overall proportion of the variance explained in the final models by these varubles was .09 and 27 . for diastolic and systolic blood pressure respectiwely, both $p<.001$. The presence of cardiovascular events was associared with higher diastolic blood pressure (partial regnession coefficient $B=2.7,95 \%$ confidence interval $(C D)$ for $B=.2$ to $5.3 ; p<.05)$ and systolic blood pressure $(B=5.3,95 \%$ $C I=1.5$ ro $9.2 ; p<.01)$. Women showed lower mean diasrolic blood pressure levels $(B=-4.6$, $95 \% C D=-6.5$ to $-2.7 ; p<.001$ ) but the same trend in systolic blood pressure was not significant. Only in systolic blood pressure a substantial age by sex interaccion was found $(B=$ $3.7 .95 \% C I=2.3$ to $5.1 ; p<.001)$, indicating a more prominent increase in mean systolic blood pressure with age in women than in men (Figure 6.2). Chronological age was associated with higher diastolic blood pressure $(B=.1,95 \% C I=.0$ to $.1 ; p<.05)$ and systolic blood pressure $(B=4,95 \% C I=.3$ to .5 i $p<.001)$.

Table 6.2 summarizes the hypertensive status for each age class, based on the WHO/ISH classification criteria. The prevalence of hypertension gradually increased with age (both uncorrected and corrected for cardiovascular event status) but was lower in the cardiovascular eventufree group, except for the 75-80 year ald subjects (48.1\% versus $42.2 \%$ ). The proportional contribution of ISH tose with age, from. 48 and .00 in the 25 ro 30 year group, up to 78 and .85 in the 75-80 year group, for the cardiovascular event uncorrected and correcred groups, respectively:

\section{Laboratory blood pressure and its wariability in relation to ambulant blood pressure}

Of 135 subjects who participated in the additional 24 blood pressure measurements within 4 weeks of the labotatory tests, 28 reported one or nore cardiovascular events in their medical history, or used anthypertensive medication. In addition, eight ambulant recordings yielded incomplete data during the night-time period because some subjects felt uncomfortable wearing the arm cuff while sleeping, leaving 99 subjects for the $24 \mathrm{~h}$ ambulant blood pressure data presented in Table 6.3. No subjects reported unusual sleeping episodes or abnormal events during the night.

Seweral aspects of laboratory and ambulant day-rime measurements were analyzed for all 135 subjects. The averages of the laboratory diastolic and systolic pressures at measurements 4 and 5 were used as the mean habitual blood pressure. The standard deviation of five repeated measurements and differences in diastolic and systolic pressures at measurements 1 and 5 were analysed as estimares of pressure variability. These parameters of laboratory blood pressure 
Table 6.3. The $24 \mathrm{~h}$ ambulatery blood pressure for each age class and sex. Only subjects with no cardiowascular ewents in the medical history and with complete $24 \mathrm{~h}$ blood pressure readings are included $(n=29)$.

\begin{tabular}{|c|c|c|c|c|c|c|c|c|c|}
\hline \multirow[b]{2}{*}{$\therefore$} & \multicolumn{6}{|c|}{ Age dass (years) } & \multicolumn{2}{|r|}{ Sex } & \multirow[b]{2}{*}{ All } \\
\hline & 30 & 40 & 50 & 60 & 70 & 80 & $\mathrm{M}$ & $\mathrm{F}$ & \\
\hline Total $w$ & 16 & 18 & 25 & 18 & 14 & 8 & 55 & 44 & 99 \\
\hline M/F ratio & $10 / 6$ & 7111 & $14 / 11$ & $11 / 7$ & $7 / 7$ & $6 / 2$ & & & \\
\hline \multicolumn{10}{|l|}{ Laboratory mean } \\
\hline Syscolic & $121(11)$ & $116(11)$ & $124(14)$ & $125(11)$ & $134(11)$ & $135(23)$ & $129(13)$ & $119(14)$ & $125(4)$ \\
\hline Diastolic & $70(7)$ & $70(11)$ & $75(12)$ & $76(8)$ & $69(12)$ & $70(13)$ & $76(10)$ & $67(10)$ & $72(11)$ \\
\hline \multicolumn{10}{|c|}{ Ambudatory day-sime mean } \\
\hline Systolic. & $1249)$ & $1.23(10)$ & $127(9)$ & $125(9)$ & $130(14)$ & $133(16)$ & $129(10)$ & $124(11)$ & $126(11)$ \\
\hline Diastolic & $76(5)$ & $79(9)$ & $83(7)$ & $80(7)$ & $78(8)$ & $77(10)$ & $81(8)$ & $77(8)$ & $79(8)$ \\
\hline \multicolumn{10}{|c|}{ Ambulatory night-sime mean } \\
\hline Systolic & $110(8)$ & $107(10)$ & $113(11)$ & $111(10)$ & $116(15)$ & $120(20)$ & $115(11)$ & $109(13)$ & $112(12)$ \\
\hline Diastolic & $61(4)$ & $64(10)$ & $69(8)$ & $67(9)$ & $63(10)$ & $64(12)$ & $68(9)$ & $62(8)$ & $65(9)$ \\
\hline \multicolumn{10}{|c|}{ Ambulatary 24 b mean } \\
\hline Systolic & $12 \pi(9)$ & $120(11)$ & $124(9)$ & $121(9)$ & $127(14)$ & $130(17)$ & $126(10)$ & $120(11)$ & $123(11)$ \\
\hline Diastolic & $72(5)$ & $76(9)$ & $80(7)$ & $77(7)$ & $75(8)$ & $73(10)$ & $78(8)$ & $74(7)$ & $76(8)$ \\
\hline
\end{tabular}

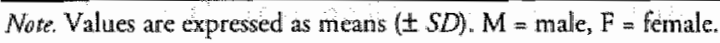

Table 6.4. Relation between mean blood pressure and estimates of variability (difference in highese and lowest recording (DHiL) and the standard deviation (SD)] of laboratory and ambulatory day-time blood pressure measurement.

\begin{tabular}{|c|c|c|c|c|}
\hline \multirow{2}{*}{$\begin{array}{c}\cdots \\
\vdots \\
\end{array}$} & \multicolumn{2}{|c|}{$\begin{array}{c}\text { Total group } \\
(n=135)\end{array}$} & \multicolumn{2}{|c|}{$\begin{array}{c}\text { Cardiovascular } \\
\text { event-free group } \\
(n=106)\end{array}$} \\
\hline & $r$ & $K_{u}$ & $r$ & $K_{n w}$ \\
\hline Diastolic blood pressure & $.74^{4 *}$ & .42 & $.74^{m+n}$ & .56 \\
\hline Mean arcerial pressure & $.71^{\text {w*** }}$ & .49 & $.69^{* *}$ & .55 \\
\hline Systolic bload presstre & $.73^{* * *}$ & .51 & $.73^{* *}$ & .56 \\
\hline DHI diastolic & .13 & .00 & .10 & .00 \\
\hline DHL mean arterial & $.23^{* * *}$ & .01 & .17 & .07 \\
\hline DHL systolic & $.23^{* *}$ & .02 & $.25^{*}$ & 00 \\
\hline SD diastolic & $.24^{* * *}$ & .06 & $.21^{*}$ & .07 \\
\hline$S D$ mean arterial & $36^{*}$ & .15 & $.24^{*}$ & .13 \\
\hline$S D$ systalic & $.28^{* *}$ & .11 & $.32^{* *}$ & .08 \\
\hline
\end{tabular}

Note. The relationship is expressed in terms of correlation (Pearson's $y$ and agreement (weighed Kappa, $K_{\text {we }}$ ), the latter based on classification of ambulatory day-time values in quartiles. The total group and cardiovaseular event-free group are described separately. Strength of agreement measured by $K_{w^{*}}<.20$ is poor; .21 to .40 is fair; .41 to .60 is moderate: .61 to .80 is good; > 80 is very good (Alman, 1991).

"p $\leq$.05," $p \leq 01$. 
wete compared with the mean diastolic and systolic ambulant day-time pressure. Variabiliry in ambulant day-time pressure was defined as the difference berween the highest and the lowest diastolic or systolic day-time pressure and as the day-time standard deviation of these pressures. Correllations (Pearson's $x$ ) were computed between continuous scalled laboratory and ambulant parameters as indices of general relatedness. In addition, weighted Kappa's $\left(K_{w}\right)$ were computed to formed for the rotal group and for the cardiovascular event-free group separately (Table 6.4). For both groups there was a moderate correlation and concordance for mean pressure parameters but low correlations and extremely poor concordance for estimates of variability.

The relation between ambulant day-time blood pressure and laboratory blood pressure was studied in more derail. Using the scatrerplots for diastolic and systolic pressures presented in Figure 6.3, the regression equations were determined that predicted day-time blood pressure From laboratory means for all subjects. These were $40.9+.53 x(r=.74, p<.01)$ and $59.6+.54 x(r=.73, p<.01)$ for diastolic and systolic pressures, respectively. Laboratory measurement clearly underestimates mean day-time pressures in the lower pressure range but overestimates in the high pressure range (regtession line and line of identity intersect at 130 and $87 \mathrm{mmHg}$ for systolic and diastolic pressure, respectively). This can be illustrated even more clearly when the differences between laboratory and ambulant day-time means for diastolic and systolic blood pressures are plotted against their means (Figure 6.4). This method is commonly used to compare two clinical assessments when systematic measurement bias is suspected (Bland \& Altman. 1986). Diastolic pressure measured in the laboratory tended to be systematically lower than ambulant day-time diastolic pressure, but the difference became smaller and eventually disappeared with higher levels of diastolic blood pressure. In approximately $95 \%$ of the present subjects the difference ranged between 6.9 and -21.6 $\mathrm{mmHg}$. The difference in systolic pressures tended to change from a negative to a positive value with increasing mean pressure. Furthermore, a slight increase in variability was observed with increasing mean pressure, suggesting an increase in error bias. For systolic pressure the $95 \%$ limirs of agteement ranged from -22.1 to 19.3 .

In order to pur the relationship berween the rwo methods of measurement in a more clinical perspective, we classified the blood pressure status of all ambulatory blood pressure montitoring participants based on both their laboratory value (using the WHO/ISH criteria) and of their mean day-rime blood pressure, according to the predicted ambulatory blood pressure monitoring values $(135.2 / 88.6 \mathrm{mmHg}$ ) that were calculated by entering the WHO/ISH cur-off points $(140 / 90 \mathrm{mmHg})$ in the regression equations presented above. A total of 19 out of 39 subjects in the ambulatory blood pressure monitoring group who were classified as hypertensive on the basis of either ambulatory or of laboratory measurement, were classified as hypertensive using both methods, four subjects were in the hypertensive range in the laboratory only, and 16 subjects were hypertensive based on ambulatory blood pressure monitoring values only. These results indicate that the agreement berween both methods is poot when clinical criteria for grouping are used. 

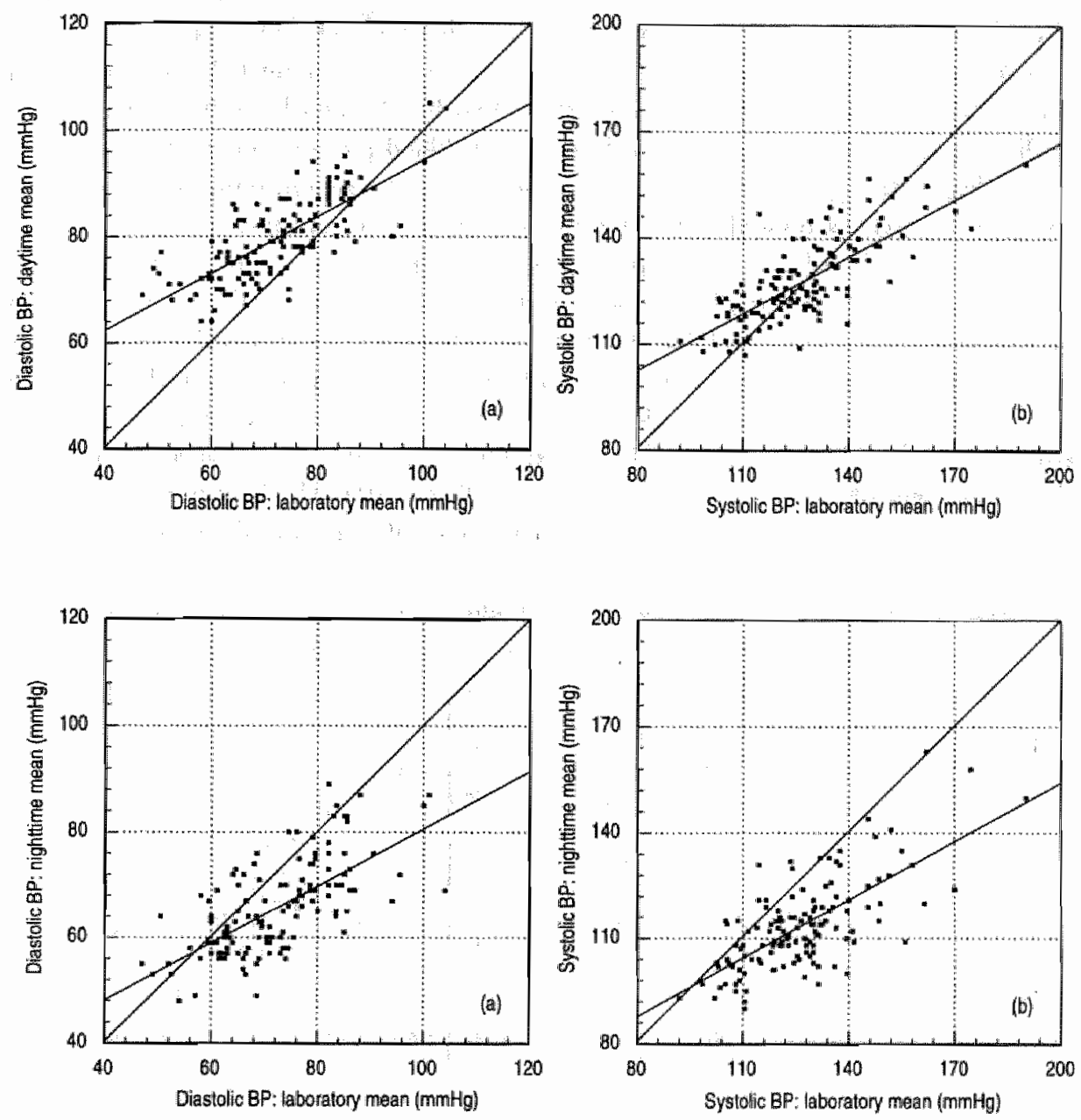

Figure 6.3. Scatrer plots of diastolic and systolic blood pressures measured in the test laboratory and with day-time ambulatory recording (upper plots, total group $n=135$ ) and night-time ambulatory recording (liower plots, total group $n=127$ ). The line of idenvity and regression line are also displayed.

Age- and sex-related effects on day-time and night-time blood pressure differences

Ninery-nine antihypertensive drug-free subjects with no cardiovascular event in their medical history were included in the analysis. Twelve subjects in this group could be elassified as non-dippers, showing overall night-time reductions in systolic and diastolic blood pressure of less than 10\%, compared with day-time values (Verdecchia, Schillaci \& Porcelatti, 1991). 
Both differences in day-nighe diastolic and systolic blood pressure were normally distributed: tests to detect dewiation from normality (Kolmogorov-Smirnov) were not significant for the distribution of both pressure differences $(K-S=.04$ and $.07(d f=99)$, for diastolic and systolic blood pressure, respectively). This dearly demionstrates that the night-time reduction in blood pressure (dipping) is a gradual phenomenon that follows a unimodal distribution. As a consequence, any classification rule for dipper status may be considered largely arbitrary.

Finally, the extent to which day-night differences in blood pressure could be explained by the factors hypertensiwe starus, age, sex, and the age by sex interaction term, was analysed in two separate hierarchical multiple regression models for diastolic and systolic blood pressure. Hypertensive status, based on the day-time average blood pressure and predicted WHO/ISH cut-off points, was entered as the first variable in the model, all other variables were entered in step 2. Day-night blood pressure differences were not influenced by hypertensive status, age or the age by sex interaction term. Only sex contributed significantly to explained variance in diastolic day-night blood pressure difference: the night-time decrease in diastolic blood pressure was predicted to be $3.0 \mathrm{mmHg}$ greater for women than for men when all other variables were controlled for $(B=3.0,95 \% \quad C I=9-5.0 ; p<.01)$. The final models predicted $12 \%(p<.05)$ and $2 \%$ (n.s.) of the variance in day-night differences of diastolic and systolic blood pressure, respectively.
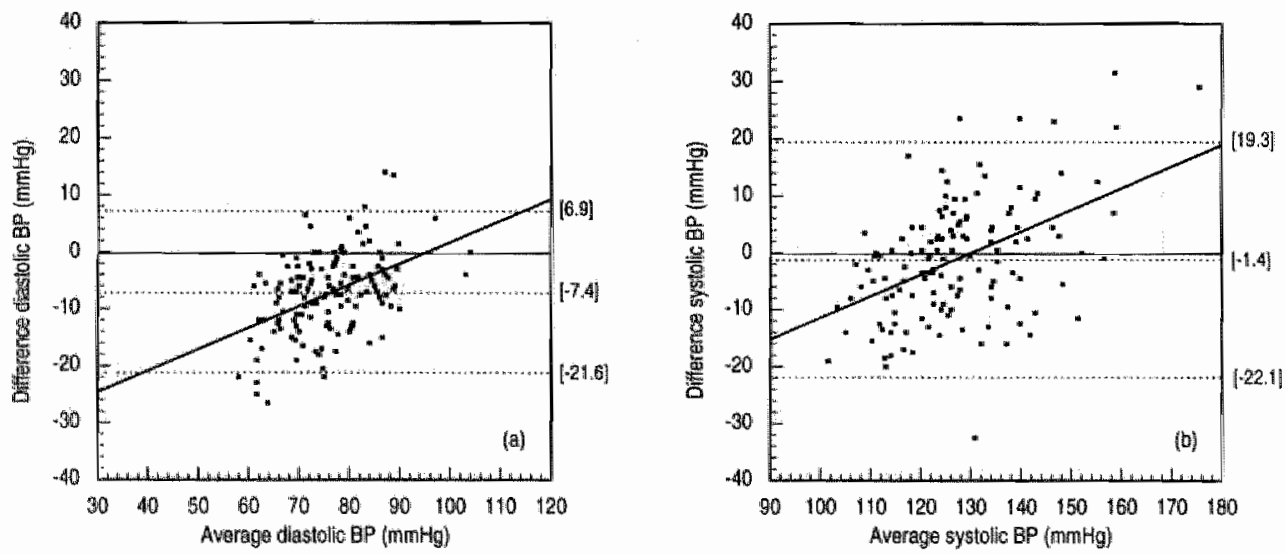

Figure 6.4. Bland-Altman plots for diastolic and systolic blood pressures (BP); differences in pressure (laboratory minus mean day-time values) are plotted against the average of the two meassures. Thin doted lines indicate the mean difference and the distance of 2 SD from the mean: $95 \%$ of cases tend to fall wirhin these limits (95 go limits of agrement, skewed lines indicate regression lines. 


\section{DISCUSSION}

\section{Blood pressure adaptation and age}

One of the main features of our scudy is that the reduction in systolic and diastolic blood pressure, measured automatically over a $20 \mathrm{~min}$ period, increased with age, 'This effect was still present when blood pressure differences over rime were corrected for mean blood pressure levels. Using a different approach, Mancia et all. (1987) found no direct relation between age and adaptation to an intra-arterial measured blood pressure response that was induced by the presence of a medical professional. However, they studied a smaller $(N=46)$ and younger group (age range 16-64 year) of hospitalized inpatients of mixed hypercensive starus in an less standardized measurement environment. It may even be argued that the observed effects of age on blood pressure adaptation will be even greater in a clinical setting, in particular in hypertensive patients. For instance, all our measurements were performed in the absence of an observer, thereby minimizing a possible pressor response (wbite coat effect, Haegholm, Kristensen, Madsen \& Svendsen, 1992) and measurement bias. Furthermore, the pressure response in ou" experimental setting may be less extreme because the individuals were less stressed because the blood pressure measurement had no direct implications for medical intervention (Mancia et al., 1991). Finally, blood pressure variability is greater in hypertensive subjects (Mancia et al., 1983). Until these studies are repeated in a clinical setting it seems reasonable not to underestimate the effect of age on blood pressure adaptation during a measurement session.

The trend analysis of five consecutive measurements in 20 min indicated that adaptation of blood pressure took place within 10-15 min on the average, and, furthermore, that the blood pressure measured after this episode reflects the basal blood pressure more accurately than the average of all five measurements taken together. Although risk estimates for blood pressure in the pachogenesis of vascular disease are based on unavoidably biased casual measurements in a doctor's office, we adhere to the use of an approximated basal blood pressure because there is evidence that blood-pressure-mediated target organ damage is more closely related to $24 \mathrm{th}$ ambulatory blood pressure than to office values (Devereux \& Pickering, 1991; Omboni, Frattola, Parati, Ravogli \& Mancia, 1992). We chose to use an adaptation period of $15 \mathrm{~min}$ before basal blood pressure recordings were made. Fifteen min of adaptation is in any case longer than the 'several minutes' advised by the WHO/ISH guidelines for office measurement (WHO/ISH, 1993). However, some authors have shown that increasing the number of blood pressure measurements by means of (semi-) automatic devices may enhance the reproducibility of blood pressure estimates, expressed as the reciprocal value of the standard deviation of the differences between measurements (1/SD; Mancia, Ulian, Parati \& Trazzi, 1994; Trazzi et al,, 1991). Although these observations were made in hypertensive subjects in whom, as mentioned above, blood pressure variability is known to be higher (in contrast to our largely normotensive population) it can not be ruled out that prolongation of the laboratory measurement interval on increasing the number of measurements after $15 \mathrm{~min}$ might have improved the prediction of day-time blood pressure in this study. 
Blood pressure status and age

Laboratory blood pressure measurements showed a general increase in systolic and diastolic blood pressure with age, the former increase being more extreme in women than in men. These result are in accord with earlier findings of large population surveys in which classical sphygmomanometric measurements were made (e.g. the National Health and Nutrition Examination Survey 1976-1980 (NHANES II), see Kaplan, 1990). The same patterns for age and sex were found in the prevalence of hypertension when criteria proposed for office readings were used. It must be taken into account, however, that prevalence of hypertension in this study may be slightly underestimated by the generally lower blood pressure values obtained by automatic measurement when compared to office blood pressure readings. In contrast, the fact that blood pressure was measured on only one occasion may have produced the opposite effect, because in clinical settings blood pressure tends to decrease on repeated visits. The percentage of men with blood pressure in the hypertensive range gradually increased from $4.9 \%$ in the $25-30$ year group to $40.8 \%$ in the group aged $75-80$ years. Women with hypertension were first found in the group aged $45-50$ years $(7.3 \%)$, after which the percentage rose steeply towards $44.8 \%$ in the $75-80$ year group. Even in the cardiovascular event-free group the prevalence of untreated hypertension was substantial $(12.8 \%)$. It is not clear whether this indicates a selective undertreatment in this group. The prevalence of isolated systolic hypertension in our population is in accord with earlier findings that isolated systolic hypertension is largely restricted to the older age groups (Amery, Fagard, Guo, Staessen \& Lutgarde, 1991).

\section{Comparison between parameters of laboratory and ambulatory blood pressure measurement}

The mean values for $24 \mathrm{~h}$ ambulatory blood pressure measurements were similar to earlier published reference data (O'Brien et al., 1990; Staessen et al., 1991). Day-time and night-time values for women were slightly higher in this study than the values reported by $\mathrm{O}^{\prime} B$ rien et al. (124/77 $\mathrm{mmHg}$ day-time and $109 / 62 \mathrm{mmHg}$ night-time in our study, versus $118 / 75 \mathrm{mmHg}$ and $102 / 58 \mathrm{mmHg}$ in their study).

"The blood pressure measured in the doctor"s office is systematically higher than values derived from ambulatory measurements (O'Brien et al., 1990). Our laboratory diastolic pressure levels were lower than the ambulatory day-time values whereas systolic pressures did not differ $(7.2 \mathrm{mmHg}, p<.001$, versu $1.2 \mathrm{mmHg}$, n.s., respectively). We expect this to be, at least partly, to be a result of a lower pressor response (or white coat effect) in our study.

Correlations between laboratory blood pressure and ambulatory day-time blood pressure walues for systolic and diastolic measurements were .73 and .74 , respectively, and are comparable to those of other studies. Enström (1991) found correlations of .81 systolic and .61 diastolic berween ambulatory day-time blood pressure and blood pressure measured repeatedly in a doctor's office in a group of 48 middle-aged normotensive men, and lower correlations between the same measures in 81 borderline hypertensive middle-aged men $(.62$ and .54 for systolic and diastolic pressure, respectively). Staessen et al. (1991) found correlations of .72 and .60 for systolic and diastolic pressures between blood pressure measured. repeatedly by a trained observer at home and mean ambulatory day-time blood pressure, in a 
population sample aged 20-81 years $(N=328)$. Correlations between measures of variability in this study were significant, but low. However, the extremely poor agreement between the measures of variability indicates that the blood pressure variability of repeated measurements on a single occasion is not comparable in magnitude to the spontaneous fuctuation of ambulatory day-time blood pressure. This may not be surprising because the circumstances under which variability was assessed were essentially different for both measurements. The laboratory indicators of variance ( $S D$ and highestilowest blood pressure difference) are more related to standardized blood pressure adaptation in a resting position, whereas $S D$ in ambulatory day-time recordings is more determined by less controllable environmental factors like physical activity or posture.

Notwithstanding the reasonable correlations between day-time mean and laboratory pressures, the difference between both pressures varied with the average diastolic and systolic blood pressure level in an almost linear fashion. The systematic discrepancies between both measurement procedures are reflected in only moderate weighted Kappa values when the values measured by both methods for systolic; mean arterial and diastolic pressure are classified uniformly. In addition, classification of hypertensive status may lead to different results depending on the chosen type of measurement. If the laboratory blood pressure measurements were to be used to predict ambulatory day-time values a linear transformation of the data would seem to be appropriate. However, the fit of such a model may be rendered poor by an increase in error bias with increasing mean blood pressure level, as can be observed for systolic pressure in Figure $6.4 \mathrm{~b}$. One has to realize therefore that estimation of habitual day-time blood pressure from laboratory blood pressure levels during a single session is more error-prone with increasing blood pressure level.

Another factor that may have atrenuated the accuracy of prediction in ambulatory blood pressure values is that the time of laboratory session within the day was not fixed. Di Rienzo et al. (1985) have shown that differences between mean $24 \mathrm{~h}$ blood pressure and subsequent $30 \mathrm{~min}$ intervals of such recordings shows considerable diurnal variation. It can be argued that fixed day-time measurement interwals will reduce this type of inaccuracy.

\section{Daynnight blood pressure difference}

Gender was the only factor that contributed significantly to the variance in day-night diastolic blood pressure difference, with women tending to have a larger blood pressure difference than had men. Age and hypertensive status did not have a significant effect. The classification according to dipper status (Verdecchia et al., 1991) may suggest a bimodal distribution of pressure level difference, where a sharp distinction can be made between dippers and non-dippers according to a dichoromous criterion. Our data clearly demonstrate the continuous, normal distribution of day-night blood pressure differences and that any classification for dipper status is essentially arbitrary in this largely normotensive population sample. It needs to be confirmed in future research whether the day-night difference in blood pressure shows a normal distribution in hypertensive groups also, but at this point we prefer to include the absolute decrease in day-night blood pressure instead of dipper status in any risk analysis that pertains to the relation between day-night blood pressure differences and target organ damage. 


\section{Canclusion}

In summary, these findings demonstrate that the importance of an adequate adaptation phase for single blood pressure neasurement increases with age. We chose to average blood pressure measurements after 15 and 20 min of relaxation because no further decrease in blood pressure was obserwed after $15 \mathrm{~min}$ on a group level. Furthermote, it was confirmed that, at least for day time ambulatory blood pressure, a clear Jinear relation with laboratory blood pressure can be demonstrated in this largely normotensive population sample. However, defining the hypertensive status on the basis of both measurements separately may lead to unequivocal conclusions, because the error bias in predicting ambulatory systolic pressure from laboratory measurements of systolic pressure is likely to increase as the absolute pressure level increases. As stated earlicer, parameters of ambulatory blood pressure may reflect the blood pressure load that leads to target organ damage more accurately than do pressure levels derived from single measurements alone. Current knowledge about the relation between blood pressure and target organ disease is largely based on studies where repeated casual blood pressure measurements are made and there is scill much debare about the use of parameters related to ambulatory blood pressure as more sophisticated risk factors for vascular morbidity and mortality (White, 1991). We therefore suggest that vascular risk estimates based on ambulatory blood pressure and repeated single measurements should be treated as different entities until the relation between blood pressure, measured with combined techniques, and vascular damage has been elucidated in more detail.

\section{REFERENCES}

Altman, D. G. (1991). Practical statistics for medical research. (1st. ed.). London: Chapman \& Hall.

Amery, A., Fagard, F., Guo, C., Staessen, I., \& Lutgarde, T. (1991). Isolated Systolic Hyperrension in the elderlyn an epidemiological review. American Jothrnd of Medicine, 90 (suppl 3A), 64S-70S.

Bland, J. M. \& Altman, D. G. (1986): Statistical methods for assessing agreement between two methods of clinical neasurement, Lather, is Feb \& $307-310$.

Dewereux, R. B., \& Dickering, T. G. (1991). Relationship between the lewel, patern and variability of ambulant blood pressure and target organ damage in hypertension. Jowral of Hypertension, 9, \$34-538.

Di Rienzo, M., Parati, G., Pomidossi, G., Veniani, M., Pedorti, A.s \&x Mancia, G. (1985). Blood pressure monitoring over short day and nigh times cannot predict 24 -hour average blood pressure. Journal of Hyportention, 3,34343\%.

Enarröm, L. Thulin, T., \& Londholm, L. (1991). How good are standardized blood pressure recordings for diagnosing hypertension? A comparison between office and ambulatory blood pressnure. Journal of Hypertension, $2,561-566$.

Hereghólm, A., Kristensen, K. S., Madsen, N. H., \& Swendsen, T. L. (1992). White coar hypertensian diagnosed by 24-h umbulatory monitoring: Examination of 159 newly diagnosed hypertensive parients. American journal of Hypertension, 5,6470 .

Jolles, J., Houx, P. J. wan Boxtel, M. P. J., 8x Ponds, R. W. H. M. (Eds.). (1995). Marastriebs Aging Study:

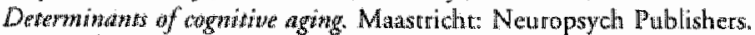

Kaplan, N. M. 1990 . Clinsical Hypertension, (5 ed). Baltimore: Williams \& Wilkins.

Kiamer, M. \$. \& Feinstein, A. R. (1981). Clinical biostatistics. LIV. The biostatistics of concordance. Clivical Pharwacelogy and Therapentics, $29,111-123$.

Luabre, M. M. Ironson, G. H., Spitzer, S. B., Gellman, M. D., Weidler, D. I. \& Schneidermann, N. (1988). How many blood pressire measurements are enough? An application of generalisability theory to the study of blood pressure reliability. Psychopbysiolog, 25,97-105.

Mancia, $G_{n}$, Casadei, R., Groppelli, A., Parati, G., \& Zancheri, A. (1991). Effect of stress on diagnosis of typertension. Hypertemsion, I7 (Suppl III), 56-62. 
Mancia, G., Ferrari, A., Gregorini, L., Parati, G., Pornidossi, G., Bercinieri, G., Grassi, G., Rienzo, M. d. Pedotii A., \& Zanchetri, A. (1983). Blood pressure and heart rate wariabilities in normotensive and hypertensive human beings. Circulation Researd, 53, 96-104.

Mancia, G., Parati, G., Pomidossi, G., Grassi, G., Casadei, R, \& Zanchetri, A. (1987). Alerting reaction and rise in blood pressure during measurement by physician and nurse. Hypertevision, 9, 209-215.

Mancia, G. Ulian, L., Parati, G., \& Trazzi, S. (1994). Increase in blood pressure reproducibility by repeared

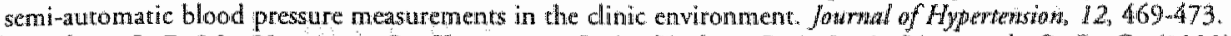

Mersemakers, J. F. M., Höppener, P., Knotnerus, J. A., Kocken, R. J. J. \& Limonard, C. B. G. (1992). Compaterized health information in the Netherlands: A registration necwork of family practices. Briash Journal of General Practice, 42, 102-106.

Norusis, M. J. (1990). SPSS/PC+Advanted Statistics 4.0. Chicago: SPSS Inc.

O'Brien, E., Murphy, J., Tyndall, A, Arkins, N., Mee, F., McCarthy, G., Sraessen, J., Cox, J., \& O'Malley, K. (1990). Twenty-four-hour ambulatory blood pressure in men and women aged 17 to 80 years: The Allied Irish Bank Study. Jowrnal of Hypertension, 9, 355-360.

Omboni, S., Frattola, A., Parati, G., Ravogli, A., \& Mancia, G. (1992). Clinical value of blood pressure measurements: Focus on ambulatory blood pressures. American formal of Cardivlogy. 70, 4D-8D.

Pickering. T. G. (1991). Ambulatory mositoring and blood pressure warriabilaty. London: Science Press.

Pickering, T. G. (1994). Blood pressure measuremenr and derecrion of hypertension. Lances, 344,31-35.

Shimada, K., Kawamoto, A., Marsubayashi, K., \& Ozawa, T. (1990). Silent cerebrowascular disease in the elderly: Correlation with ambulane pressure. Hypertersion, 16, 692-699.

Staessen, J. Bulpitt, C. J., Fagard, R., Mancia, G., O'Brien, E. T., Thijs, L., Vyncke, G., \& Amery, A. (199l). Reference values for the ambulatory blood pressure and the blood pressure measured at home: $A$ population study. Journal of Humatn Hypertension, 5, 355-361.

Trazzi, S., Mutti, E., Frattola, A., Imholz, B., Parati, G., \& Mancia, G. (1991). Reproducibilicy of non-invasive and incra-arterial blood pressure manitoring: Implicarions for studies on ancihypertensive treatment. Journal of Hypertension, 9, 115 119 .

Verdecchia, P., Schillaci, G., \& Porcelatu, C. (1991). Dippers versus non-dippers. Journal of Hypertension, 9 (Suppl 8), $\$ 42-\$ 44$.

Waldstein, S. R., Manuck, S. B., Ryan, C. M., \& Muldoon, M. F. (1991). Neuropsychological correlates of hypertension: Review and methodological considerations. Psychological Bulletin. 110, 451-469.

White, W. B. (1991). Blood pressure load and karget organ effects in patients with esservial hypertension. Journal of Hypertension, 9, S39-541.

WHO/ISH. (1993). 1993 Guidelines for the management of mild hypertension: memotandum from a World Health Organization/International Society of Hypertension meeting. Journal of Hypertension, 7, 689-693. 


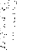




\section{Can blood pressure predict cognitive task performance in a healthy population sample? 5}

\section{ABSTRACT}

Hypertension increases the risk of cerebrovascular disease and has been consistently associated with reduced performance on cognitive tasks. It remains unclear to what extent blood pressure status contributes to age-related cognitive decline in the population. We studied the relation of blood pressure and other vascular risk factors (smoking, alcohol, body mass index, body fat distribution) with five measures of cognitive ability, including verbal memory and speed of information processing. A group of 936 healthy adults was recruited from a register of family practices, stratified for age (24-81 years), sex, and occupational level, and took part in a medical and neurocognitive test program. Blood pressure was measured five times using an automatic recording technique (Dynamap $\$$ 8100). After adjustment for age, sex and educational level in a hierarchical regression analysis, no straightforward association was found between mean systolic and diastolic blood pressure (or other vascular risk factors) and cognitive test performance in the total group, nor in the subgroup of subjects free of antihypertensive medication or cardiovascular events in their medical history. Stratified analysis within four age levels did not reveal any age-specific associations between blood pressure and cognitive function. Subjects whose blood pressure was in the hypertensive range did not perform worse than matched controls. We conclude therefore that in a community sample in which there is a high standard of hypertension treatment the relation between blood pressure status and cognitive performance is not of clinical importance.

\section{INTRODUCTION}

The integrity of cognitive abilities is vital to maintain independence in the aged, and any potential risk factor for cognitive decline that is open to intervention warrants careful evaluation. In recent years it has been a matter of debate wherher blood pressure status contributes incependently to the impairment of cognitive function that comes with age. Hypertension has been associated with atherosclerotic changes in large and small cerebral blood vessels and a reduced autoregulation of cerebral blood flow (Launer, Masaki, Petrovitch, Foley \& Havlik, 1995; Starr \& Whalley, 1992) and is a major risk factor for stroke and vascular dementia. Clinically silent white matter lesions in hypertensive subjects have been observed on neuroimaging and may in turn be associated with decrements in cognitive functioning (Breteler

\footnotetext{
5 M. P. J. yan Boxrel, C. Gaillard, P. J. Houx, F. Buntinx, P. W. de Leeuw, and J. Jolles (Subm.)
} 
et al, 1994; Van 5 wieten et a1, 1991). The majority of case-control studies have reported a functional impaiment of the central nerwous system in hypertensive subjects, as assessed with neuropsychological tests (Battersby et al, 1993; Boller, Vrtunski, Mack \& Kim, 1977; Goldman, Klenman, Snow, Bidus \& Korol, 1974; Herzog, Schaie \& Gribbin, 1978; Madden 8. Blumenthal, 1989; Shapiro, Miller, King, Ginchereau \& Firzibbon, 1982; Spieth, 1964; Waldstein, Manuck, Ryan \& Muldoon, 1991; Wilkie \& Eisdorfer, 1971), but several studies did not demonstrate different cognitive profiles between hypertensives and normotensive control subjecrs (e.g. Light, 1975; Perez Stable, Coates, Halliday, Gardiner \& Hauck, 1992). The deficiencies that werte most consistenty associated with hypertension were found in memory function, attentional capacity, abstract reasoning and response speed (King \& Miller, 1990; Waldstein, 1995; Waldstein et al., 1991). Longitudinal data suggest that cognitive decline over time is more outspoken in hypertensives compared to normotensive control subjects (Wilkie \& Eisdorfer, 1971), although other investigators did not find a differential tate of change in cognitive scores related to hypertensive status (Elias, Schultz, Robbins $8 x$ Elias, 1989; Schultz Jr, Elias, Robbins, Streeten \& Blakeman, 1989). However, from a clinical perspective the between-group differences are small and not very specific.

Population based studies on this issue have shown mixed results. In the Framingham Heart Study, 2,123 subjects between 55 and 89 years were tested with a short cognitive screening battery (Farmer et al., 1987). After adjustment for the effects of age, sex, education, vascular risk factors (smoking, alcohol intake), and antihypertensive medication use, no relation was found between diastolic or systolic blood pressure (measured once of twice) and cognitive performance scores. However, when information from the past biennial, control visits on blood pressure status and antihypertensive medication use was taken into consideration, an inverse relation was found berween the cognitive compound score on the one hand, and the proportion of blood pressure measurements in the hypertensive range and overall meari systolic and diastolic blood pressure on the other in subjects who had not been treated with antihypertensive medicarion (Farmer et al., 1990). Re-analysis of these data revealed an inverse relation berween historical mean blood pressure levels and overall cognitive performance (Elias, Wolf, D'Agostino, Cobb \& White, 1993). Finally, in the 4,678 surviwing male members of the Honolulu-Asia Aging Study (mean age 78 years), the level of midlife systolic blood pressure but not diastolic $\mathrm{BP}^{-}$- was negarively related to the score on a cognitive screening instrument 25 years later, independent of age. education, cardiovascular disease, or subclinical atherosclerosis (Launer et al, 1995).

The issue becomes more complex when the factor age is taken into account. It was suggested that blood pressure may account for variance in measures of cognitive performance that otherwise would be ascribed to primary or 'intrinsic' aging (Elias, Robbins, Schultz \& Pierce, 1990). The prevalence of both hypertension and cognitive impairment rises with age. Conversely, cerebral blood flow is known to decline markedly with age and the structural changes in the brain associated with hypertension may induce cerebral ischemia (Starr \& Whalley, 1992), a process that indirectly may aggravate the age-related cognitive decline (Boller et al., 1977; Van Swieten et al., 1991). Remarkably, some evidence from cross-sectional studies suggests that elevated blood pressure may exactly be beneficial for the cognitive starus in older subjects by promoting cerebral blood flow (Elias et al., 1990; Farmer 
et al., 1987, Lawner, Drinkgreve, Jonker, Hooijer \& Lindeboom, 1993, Launer et al, 1995), Thus, as the prevalence of vascular risk factors (including blood pressure in the hypertensive range) and the development of vascular pathology and end organ damage are intricately related with age and sex, it is important to control these variables the telation is studied berween vascular risk factors and cognitive function. This study intends to examine the relation between repeatedly measured blood pressure and performance on tests of global and specific cognitive functioning in a large adult population sample, with rigorous adjustment for factors age, sex, and general ability. Other vascular risk factors (smoking behavior, alcohol intake, body mass index, and fat distribution) were included in the analysis as potentially confounding variables (Swan, Carmelli \& LaRue, 1996).

\section{METHODS}

\section{Subjects}

The study population consisted of the first panel of 936 participants in the Maastricht Aging Study (MAAS; Jolles, Houx, wan Boxtel \& Ponds, 1995). This communiry-dwelling adult cohort was randomly drawn from a register of family practices in the region of Maastricht (Metsemakers, Höppener, Knotmerus, Kocken \& Limonard, 1992). Inclusion was stratified for age (12 classes, ranging from $25 \pm 1$ years, $30 \pm 1$ years, up to $80 \pm 1$ years), sex, and rwo levels of occupational achievement, the latter to control beforehand for the factor general ability (Jolles et al., 1995). The subjects were invited to take part in the study in an introductory letter from their general practicioners. The overall compliance rate was $32 \%$. Participating and non-parriciparing groups did not differ on the number of medical problems or on the presence of a number of specific chronic diseases, as recorded by their general practitioners. Non-complying subjects were more often in the youngest or oldest age classes, were less well educated, and were more often female (Jolles et al., 1995).

Subjects with past or present morbidity gencrally associated with brain dysfunction, namely, overt cerebrovascular disease (including stroke), chronic neurological diseases (such as dementia, epilepsy, and Parkinson's disease), mental retardation, or psychotropic drug use, were not included. Subject characteristics are summarized in Table 7.1.

The study protocol was approved by the local ethics committee and all participants gave their informed consent.

\section{Measurements}

\section{Background characteristics}

A postal questionnaire filled in by all participants covered background characteristics, including education (8-point scale, ranging from primary education to university degree (De Bie, 1987) and an extensive health history. A structured medical interview was administered to all participants prior to the actual tests, to check eligibility for inclusion and to screen all 
information in the questionnaire for completeness. Tobacco use and alcohol intake were scored as dichotomous variables: present or past smoking yes / no, alcohol intake of less / more than 21 standard consumptions per week for females, or 35 for males (WHO, 1980). Subjects with medically confirmed previous or actual cardiovascular morbidity (cardiovascular event; or CVE, including angina pectoris, cardiac arrhychmia, myocardial infarction, cardiac insufficiency, valvular lesions, heart surgery, cardiac reanimation, or evidence of peripheral atherosclerosis) and subjects currently on antihypertensive medication were identified, to enable separate analyses to be done on data from subjects without these factors. The prevalence of these characteristics is displayed in Table 7.1. Subjects were then thoroughly screened in a medical and neuropsychological test battery, to obtain objective information abour their physical and cognitive status.

\section{Pbysical meatsurements}

Body height and weighe were measured to calculate the body mass index (BMI, in $\mathrm{kg} \cdot \mathrm{m} \cdot 2$ ). In addition, waist and hip circumference was measured, the waist-to-hip ratio being used as an independent wascular risk factor (Despres et al., 1990). Blood pressure was automatically recorded five times, with fixed intervals of five minutes, during the 30-minute intermission between two test blocks. Measurements were made at the left arm with a Critikon Dinamap ${ }^{\left({ }^{(}\right)}$ 8100 monitor (Critikon, Tampa FL, USA) that was equipped with the appropriately sized arm cuff. During blood pressure measurements the subjects were seated, did not smoke or drink caffeine containing beverages and were left unattended by the researcher after they had been given careful instructions. The five consecutive measurements were averaged to yield mean systolic and diastolic blood pressure values.

\section{Cognitive assessment}

Standard neuropsychological tests were used to assess the cognitive domains general intelligence, memory, sensorimotor speed, and information processing speed / cognitive flexibility (Jolles et al., 1995), which are described briefly here.

Four subtests of the Groningen Intelligence Test (GIT) were used to arrive at a measure of formal IQ (Luteijn \& van der Ploeg, 1983).

The Word Learning Task (WLT) is based upon the Auditory Verbal Learning Test (Brand \& Jolles, 1985) and evaluates the ability to acquire and retain new verbal information. A set of fifteen frequently used monosyllabic words is presented in fixed order at a rate of one every two seconds in each of five trials. After every trial the subject is asked to reproduce the memorized words (immediate recall). Twenty minutes after the last trial the subject is asked again to reproduce the set of words (delayed recall). The total of correctly reproduced words on five trials, the maximum score in five trials, and the number of correctly reproduced words after 20 minutes are recorded.

The Concept Shifring Task (CST) is a test of behavioral planning and is analogous to the Trail-Making-Test of the Army Individual Test Battery (Houx, Vreeling \& Jolles, 1991). The subject's ability to alternate two psychological concepts during task performance is measured, i.e., number and letter cancelllation in correct order. A test sheet contains 16 small diameter circles $(\varnothing 15 \mathrm{~mm})$ arranged in a larger circle $(\emptyset 16 \mathrm{~cm})$. Two null versions (part 0 ) 
Table 7.1. Mean (SD) levels of main independent and dependenc variables used in this spady, by levels of age (regrouped in six classes) and sex. Note that the cognitive outcome measures presented hete atre population based, Z-transformed scores (population mean $=0, S D=1$ ).

\begin{tabular}{|c|c|c|c|c|c|c|c|c|}
\hline \multirow[b]{2}{*}{. } & \multicolumn{6}{|c|}{ Age class } & \multicolumn{2}{|c|}{ Sex } \\
\hline & $25 / 30$ & $35 / 40$ & $45 / 50$ & $55 / 60$ & $65 / 70$ & 75180 & M & F \\
\hline Total $n$ & 161 & 162 & 162 & 159 & 162 & 130 & 475 & 461 \\
\hline Men / women ratio & $811 / 80$ & $81 / 81$ & $80 / 82$ & $81 / 78$ & $81 / 81$ & 71159 & - & $a$ \\
\hline \multirow[t]{2}{*}{ Diastolic blood pressure (mmHg) } & 67 & 71 & 75 & 76 & 76 & 76 & 76 & 71 \\
\hline & (8) & (10) & $(10)$ & (11) & (i1) & $(12)$ & (10) & (11) \\
\hline \multirow[t]{2}{*}{ Systolic blood pressure ( $\mathrm{mmHg}$ ) } & 119 & 120 & 126 & 133 & 142 & 147 & 133 & 128 \\
\hline & (11) & (11) & (14) & $(17)$ & (19) & (2:1) & (17) & (20) \\
\hline Hypertension ab & 5 & 11 & 23 & 39 & 67 & 62 & 118 & 89 \\
\hline \multirow[t]{2}{*}{ Waist-to-hip ratio } & .81 & .84 & .86 & .88 & 90 & .90 & .91 & .81 \\
\hline & $(.08)$ & $(.09)$ & $(.10)$ & $(.08)$ & $(08)$ & $(.07)$ & $(.07)$ & $(.08)$ \\
\hline \multirow[t]{2}{*}{ Bady Mass Index (kg.m²) } & 24.8 & 25.6 & 27.0 & 27.1 & 27.9 & 27.6 & 26.7 & 26.5 \\
\hline & $(399)$ & (3.8) & (5.5) & $(3.6)$ & $(4.1)$ & $(3.5)$ & $(4.0)$ & $(4,6)$ \\
\hline Smokers (past/actual)b & 87 & 24 & 123 & 102 & 98 & 88 & 365 & 257 \\
\hline High alcohol inake (actual) ${ }^{b}$ & 3 & 7 & 9 & 8 & 1 & 4 & 14 & 18 \\
\hline Antihypertensive drug use b & 1 & 1 & 16 & 26 & 51 & 59 & 76 & 78 \\
\hline Cardiovascular event (CVE)b & 1 & 6 & 7 & 25 & 48 & 57 & 92 & 52 \\
\hline CVE / antihypercensive drug use b. & 2 & 7 & 18 & 39 & 74 & 76 & 119 & 97 \\
\hline \multirow[t]{2}{*}{ Memory } & .56 & 47 & .10 & .01 & -40 & -.91 & -.26 & .27 \\
\hline & $(.76)$ & $(76)$ & $(.78)$ & $(84)$ & $(.91)$ & $(87)$ & $(.95)$ & $(.87)$ \\
\hline \multirow[t]{2}{*}{ Sensorimotor speed } & .65 & .47 & .25 & -.08 & -47 & -1.00 &. .01 & .03 \\
\hline & $(.43)$ & $(.45)$ & $(.54)$ & $(.64)$ & $(.69)$ & $(.81)$ & $(.79)$ & $(.82)$ \\
\hline \multirow[t]{2}{*}{ Cognitive thexibulity } & .67 & .51 & .28 & .09 & -.89 & $-1,13$ &. .04 & 07 \\
\hline & $(.45)$ & (.53) & (.65) & $(.67)$ & $(76)$ & $(.89)$ & $(87)$ & $(89)$ \\
\hline \multirow[t]{2}{*}{ Letter / Digit Substirurion Test } & 90 & .56 & .25 & -.19 & -63 & .112 & -.08 & .08 \\
\hline & $(70)$ & $(.74)$ & $(.78)$ & $(.71)$ & $(.78)$ & $(72)$ & $(96)$ & $(1.03)$ \\
\hline \multirow[t]{2}{*}{ Word Aluency } & .42 & .31 & .18 & -.15 & -31 & -.57 & -.03 & .03 \\
\hline & $(94)$ & (94) & $(.97)$ & $(.97)$ & $(97)$ & $(.82)$ & $(1.01)$ & $(99)$ \\
\hline
\end{tabular}

Note. "Diastolic blood pressure $\geq 90 \mathrm{mmHg}$ or systollic blood pressure $\geq 140 \mathrm{mmHg}$ (WHO/SH, 1993 ).

b Displayed are cell counrs.

contain no symbols in the circles, the number version (part A) presents figures 1 to 16 in random order in the circles, a letter version (part B) depicts randomly the letters $A$ to $P$, and finally a number/letter version (part C) alternates the numbers 1 to 8 and letters $A$ to $H$. The subject is instructed to cross out the circles in correct order, as fast as possible without making errors. Outcome is the time needed to complete each task.

Susceptibility to perceptual interference was measured in the Stroop Color Word Test (SCWT), consisting of three subtasks; color word maming (I), color naming (II) and naming of 
color words printed in a different color (interference task III). This test shows robust effects of chronological age (Houx ${ }_{n}$ Jolles \&e Vreeling, 1993).

The Letter Digit Substitution Test (LDST) is a modified version of the paper-and-pencil Symbol Digit Modalities Test (Smith, 1968) and measures basic information processing speed. The subject is requested to copy numbers in cells that are indexed by at letter. The letter refers to nine letter / number pairs in a key at the top of the form. The total number of corresponding numbers correctly copied in 90 seconds is recorded.

Finally, Word Fluency was scored as the total number of animal names correctly reproduced in 60 seconds (Luteijn \& wan der Ploeg, 1983). The test reflects the organizational level among clusters of meaningful related words.

\section{Data reduction and analysis}

To limit the number of dependent variables and to improve the robustness of the underlying cognitive construct (Houx \& Jolles, 1994; Van Boxtel, Langerak, Houx \& Jolles, 1996), the relevant raw test scores were clustered in three compound performance indices, labelled memory cognitive flexibility, and sensorimotor speed. Raw scores were transformed to standardized $Z$-scores for the total group $(z=[\mathrm{x}-\overline{\mathrm{x}}] / S D)$. Next, the average was taken of $Z$-scores from tests that were included in the compound performance index: the memory score was derived from the total, maximal and delayed recall scores of the WLT; the cognitive flexibility score included the C version of the CST and subtask III of the SCWT (LaRue, 1992); sensorimotor speed was calculated from the $0, A$, and B versions of the CST, and subtask I of the SCWT. Thus, in formula: Memory $=\left(Z_{\text {WLTTOT }}+Z_{\text {WLTMAX }}+Z_{\text {WLTDEL }}\right) / 3$, cognitive flexibility $=-\left(Z_{\text {CST-C }}+Z_{\text {SCWT-1II }}\right) / 2$, and sensorimotor speed $=-\left(Z_{\text {CST-0 }}+\right.$ $\left.Z_{C S T-A}+Z_{C S T-B}+Z_{S C W T-D}\right) / 4$. Signs of the speed and flexibility scores were inverted to make them reflect above average performance when positive and below average performance when negative. LDST and fluency rest outcomes were also transformed to $Z$-scores but not included in compound scores as the performance on these tests is less domain specific.

Performance on cognitive outcome variables was predicted using multiple hierarchical regression analysis, where chronological age, sex, and education were entered in the first step. Then all vascular risk factors and their interaction with age were tested pairwise in separate steps to detect an association with cognitive outcome measures. Predictor variables under study were systolic and diasrolic blood pressure, BMI, WHR, alcohol intake, smoking behavior, antihypertensive drug use, and presence of cardiovascular events (CVE) in the medical history. Separate models were fitted for all subjects and for subjects free of CVE and antihypertensive medication use $(n=720)$.

Next, subjects were classified according to clinical criteria as hypertensive when the diastolic was blood pressure was $\geq 90 \mathrm{mmHg}$, or systolic blood pressure was $\geq 140 \mathrm{mmHg}$ (WHO/ISH, 1993). All hypertensive subjects were matched, for age in years, sex, and educational level, with normotensive controls, and between-group differences were tested with paired $t$-tests. $P$-values of .01 or lower were considered statistically significant, unless indicated otherwise. 


\section{RESULTS}

Table 7.1 summarizes mean levels (or prevalence) of predictor variables and cognitive outcome measures by age class and sex.

Zero-order correlations between predictor variables and cognitive outcome measures are presented in Table 7.2. All cognitive parameters were highly negatively correlated with age (-.34 up to -.68$)$, and, to a lesser extent, with educational lewel (.35-.48) and general intelligence $(.11-36)$. Relarively high correlations of cognitive parameters with educational level may in part be explained by the -.39 correlation berween age and education. Systolic blood pressure, diastolic blood pressure, BMI, WHR, antihypertensive medication use, and cardiovascular events in the medical history were also negatively correlated with cognitive outcome scores, but again a large part of the common variance was shared with age.

Table 7.2. Zero-order correlations berween age, sex, educational level, vascular risk factors and cognitive paramevers.

\begin{tabular}{|c|c|c|c|c|c|c|c|c|c|}
\hline & Age & $\operatorname{Sex} b$ & $1 Q^{\mathrm{a}}$ & Educ. & Mermuty & S5ia & CFi a & LDST & Fluency \\
\hline Age & - & - & - & - & $-.50^{*}$ &. $.67^{*}$ & $-.65^{*}$ & $-68^{*}$ & $-34^{*}$ \\
\hline Siex & -.02 & - & - & - & $.28^{*}$ & .03 & .06 & .08 & .03 \\
\hline $\mathbb{I Q}$ & $.12 *$ & $-.21^{*}$ & - & - & $\|^{*}$ & $244^{*}$ & $.27^{*}$ & $.27^{*}$ & $.36^{*}$ \\
\hline Education & $-39 *$ & .07 & $48 *$ & - & $.35^{*}$ & $.46^{*}$ & $.47^{*}$ & $.48^{*}$ & $.36^{*}$ \\
\hline Diastolic BP & $.26^{*}$ & $-.25^{*}$ & .07 & $-.10^{*}$ & $-.17^{*}$ & $-.17^{*}$ & $-.16^{*}$ & $-.21^{*}$ & $-.111^{*}$ \\
\hline Systolic BP & $.55^{*}$ & $-.13^{*}$ & .07 & $-.24 *$ & $-30^{*}$ & $.40^{*}$ & $.38^{*}$ & $-.41^{*}$ & $-.21 *$ \\
\hline Pulse Pressure & $.5 \mathbb{1}^{*}$ & .02 & .05 & $-.21^{*}$ & $-.26^{*}$ & $-.38^{*}$ & $-.37^{*}$ & $-.37^{*}$ & $-.18^{*}$ \\
\hline Body Mass Index & $.24^{*}$ & -.03 & -.05 & $-.20^{*}$ & $-17^{*}$ & $-.16^{*}$ & $-.18 *$ & $.18^{*}$ & $-.10 *$ \\
\hline Waist-co-hip Ratio & $.36^{*}$ &. $.55^{*}$ & $.10^{*}$ & $-.18^{*}$ & $-.35 *$ & $-.26 *$ & $-.27^{*}$ & $-.30^{*}$ & $-.18 *$ \\
\hline Alcohol intake: & .01 & .03 & .04 & .04 & .03 & .02 & .03 & .03 & .04 \\
\hline Smoking behavior: & .01 & $-.22 *$ & $.10^{*}$ & -.02 &., $09^{\circ}$ & .03 & .01 & .01 & .05 \\
\hline Antihyp medication $c$ & $4 \|^{*}$ & .01 & .03 & $-144^{*}$ & $-.22^{*}$ & $-28^{i *}$ & -.27 & $-30^{*}$ & $-.17 *$ \\
\hline Cardiovascular events c & $.40^{*}$ & $-11^{*}$ & $.11^{*}$ & $-.10^{4}$ & $-26^{*}$ & $-23^{*}$ & $-25^{n}$ & $-.26^{*}$ & $-.10^{*}$ \\
\hline
\end{tabular}

Note, Abbrewiations: $1 Q$ intelligence Quotient; SS Sensorimotor Sped; CF = Congritive Flexibility; LDST $=$ Letker Digir Subsrirarion Test.

bo $0=$ nale, $1=$ female, $c 0=$ no, $1=$ yes.

$* p \leq .01$ (two-tailed test)

The associations berween vascular risk factors, the risk factor by age interaction, and the five cognitive scores (memory, sensorimotor speed, cognitive flexibility, letter digit copying, and fluency) were tested in separate multiple hierarchical regression analyses, after adjusting for age, sex, and educarional level. No contribution to the prediction of cognitive outcome measures was observed when the variables BMI, WHR, smoking, alcohol inrake, antihypertensive medication use, cardiovascular events (CVE), and their respective interaction with age, were entered in pairs in the regression models ( $p$ associated with $R^{2}$ increase $>05$ ). These variables were not included as control variables in the final models in which blood pressure and the blood pressure by age product term were tested as predictors of cognitive outcome, in order to minimize the number of redundant variables. 
Separate models that were fitted for diastolic and systolic blood pressure showed that predictors in step 1 explained between $17 \%$ (word fluency) and $50 \%$ (letter / digit copying) of the variance in cognitive scores, which was for the largest part due to the factor age. No main effect of blood pressure on any cogritive parameter was observed in step 2. However, for systolic blood pressure the age by blood pressure interaction term was negatively associated with two speed indices; sensorimotor speed and cognitive flexibility. There was no noticeable change in the size or direction of the observed effects when the entry of blocks was reversed and age was entered in the last block of variables, or when the analyses were iterated on the subgroup with no history of cardiovascular events or antihypertensive drug use. Table 7.3 summarizes the regression results for systolic blood pressure on the toral group and on the group free of cardiovascular events (CVE) and antihypertensive drug use $(n=720)$. Results for diastolic blood pressure are not shown, but were virtually identical up to step 1 .

In terms of explained variance, the contribution of blood pressure to the models was small (up to $1.0 \%$ in the cognitive flexibility score for systolic blood pressure in the unmedicated and CVE-free group). However, the observed age by systolic blood pressure interactions suggested that the blood pressure / cognitive performance relation was age-dependent. Identical regression analyses were therefore performed post-hoc on the data, in four age strata: 25-35 years, 40-50 years, 55-65 years, and 70-80 years. No association between systolic blood pressure and any of five cognitive variables was observed within any age stratum at the $p=.05$ level, or lower, using the same adjustments for background variables as in earlier analyses. Moreover, no systematic trend was observed in the Beta weights over the four age classes, to account for the significant interaction effects in the overall analyses.

In an attempt to replicate carlier findings of cognitive deficits in patient groups with dinical hypertension, subjects whose blood pressure was in the hypertensive range, based on the mean of laboratory values, were matched with normotensive controls with respect to age ( \pm 1 year), sex, and educational Jevel. Of 207 thus identified hypertensive subjects (diastolic blood pressure $\geq 90 \mathrm{mmHg}$ or systolic blood pressure $\geq 140 \mathrm{mmHg}$ ), 195 could be matched in this way. The raw cognitive scores of this subgroup were again transformed to individual $Z$-scores and compound scores, using the above described formulae. Both groups are contrasted in Table 7.4. Paired trests revealed a higher mean BMI in the hypertensive group, but the groups did noe differ on cognitive outcome measures.

\section{DISCUSSION}

In this study the relation between vascular risk factors - in particular blood pressure status - and seweral aspects of cognitive performance was evaluated in an adult population that was stratified for age, sex, and general ability. This was done in an attempt to discriminate the effects on cognirive processes of factors related to cerebrovascular pathology, and of primary aging. Apart from the weak inverse associations between the age by systolic blood pressure interaction term and two measures of information processing speed (sensorimotor speed and cognitive flexibility), it was found that blood pressure status nor any other vascular risk factor did have a main effect on cognitive performance, after the variance explained by age, sex, and educational level was accounted for. The same conclusion was reached when the sample was 
Table 7.3. Results of mulriple hierarchical regression analyses of cognitive ourcome wariabies. Shown are standardized regression coefficients (Bera) and the significance level of the unstandardized regression coefficient $(B)$ in the final model and $R^{2}$ (proportion of explained variance) and significance of $R^{2}$ change after each step. Separate models were fitted for all subjects $(N=936)$, and for subjects free of cardiovascular events or antihyperrensive drug use $(n:=720)$.

$\frac{\text { Seep } 1}{\text { Age Sex Education }} \frac{\text { Step 2 }}{\text { SBPa Age X SBP }} \frac{R^{2} \text { after step }}{1}$

All sitbjects

Memory

Sernsorimotor speed

Cagnirive flexibility

Letter I digit copying

Word Auency

$\begin{array}{lllllll}. .40^{* *} & .30^{* *} & .21^{* *} & .05 & -.08 & .331^{* *} & .336 \\ -.57^{* *} & .05 & .24^{* *} & .03 & -.11^{* *} & .478^{* *} & .487^{* *} \\ -.54^{* *} & .10^{* *} & .28^{* *} & .03 & -.10^{* *} & .485^{* *} & .493^{* *} \\ -.55^{* *} & .09^{* *} & .26^{* *} & -.01 & -.02 & .498^{* * *} & .499 \\ -.22^{* *} & .06 & .28^{* *} & .00 & -.03 & .173^{* *} & .174\end{array}$

CVE- and medication free subjects is

$\begin{array}{llllllll}\text { Memory } & -.35^{* *} & .29^{* *} & .25^{* * *} & .02 & -.07 & .302^{* *} & .306 \\ \text { Sensorimotor speed } & -.54^{* *} & .05 & .25^{* *} & .00 & -.11^{* *} & .456^{* *} & .467^{* *} \\ \text { Cognitive flexibility } & -.51^{* *} & .11^{* *} & .31^{* *} & -.02 & -.10^{* *} & .489^{* *} & .499^{* *} \\ \text { Letter / digit copying } & -.50^{* *} & .09^{*} & .26^{* *} & -.05 & -.03 & .466^{* *} & .469 \\ \text { Word fluency } & -.21^{* *} & .08^{*} & .28^{* *} & .03 & -.02 & .157^{* *} & .158\end{array}$

Note: SBP $=$ Systolic blood pressure; ${ }^{b}$ CVE $=$ Cardiovascular event.

${ }^{*} p \leq .01 ; * * 0.001$

Table 7.4. Characteristics of subjects whose blood pressure was in the hypertensive range (diastolic blood pressure $\geq 90 \mathrm{mmHg}$ or sysrolic blood pressure $\geq 140 \mathrm{mmHg}$ (WHO/ISH, 1993); $N=195$ ) compared to normorensive controls from this sample, marched for age, sex and educarional level. In borh groups 80 subjects were female.

\begin{tabular}{|c|c|c|c|c|}
\hline & \multicolumn{2}{|c|}{ Control group } & \multicolumn{2}{|c|}{ Hypertensive group } \\
\hline 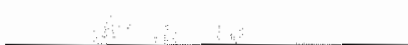 & $M$ & (SD) & $M$ & $(50)$ \\
\hline Age (years) & 63.3 & $(12.5)$ & 63.3 & $(12.5)$ \\
\hline Education & 2.8 & $(1.6)$ & 2.8 & (1.6) \\
\hline IQ & 114,1 & $(13.1)$ & 114.0 & $(13.0)$ \\
\hline Body Mass Index $\left(\mathrm{kg} \cdot \mathrm{m}^{-2}\right)$ & 27,3 & $(3.7)$ & 28.2 & $(3.9)^{*}$ \\
\hline Waise-rowip racio & .90 & $(.08)$ & .90 & (.07) \\
\hline Diastolic blood pressure $(\mathrm{mmHg})$ & 69.4 & $0.5)$ & 83.9 & $(10.1)^{* * *}$ \\
\hline Systolic blood pressure (mmHg) & 125.3 & (8.3) & 154.1 & $(14.8)^{* \cdots *}$ \\
\hline Memory & .01 & $(.89)$ & -.02 & $(1.00)$ \\
\hline Sensorimotor speed & .07 & $(78)$ & .03 & $(.78)$ \\
\hline Cognicive flexibility & .09 & $(.85)$ & .03 & $(86)$ \\
\hline Letter / Digir substitutionz & .06 & $(1.02)$ & .06 & $(98)$ \\
\hline Word fluency & .04 & (291) & -.04 & $(1.08)$ \\
\hline
\end{tabular}

Note. a $1 \mathrm{Q}=$ intelligence quorient.

$* p \leq .05, * * 0.01, * * * * 10.001$ 
broken down into four, equally sized age strata that were balanced for sex and general ability: again blood pressure status faled to explain unique variance, which indicates that there was no age-speeific internelation between blood pressure and performance. Finally, subjects in this sample who were idenefied as being hypertensive had similar performance scores than age-, sex-, and education-matched normotensive control subjects.

Several methodological issues need to be addressed before a final conclusion can be drawn. Blood pressure was measured under standarlized condicions because it was measured on one occasion only and because blood pressure can be temporarily affected by factors such as posture, speech, and physicall or mental activity (Pickering, 1991). Furthermore, blood pressure was measured in the absence of an observer to minimize the pressure response in some individuals, as the result of an alerting reaction (Mancia, Casadei, Groppelli, Parati \& Zanchetti, 1991). In this tespect, single or duplicate blood pressure measurement with classical sphygmomanometry is particularly errormprone, because an observer is present to record blood pressure. Nevertheless, classical single or duplicate measurement of blood pressure has been used in most studies that were reviewed here (e.g. Breteler et al., 1994; Elias et al., 1993; Farmer et al., 1987: Star, Whalley, Inch \& Shering, 1993) - with one exception in which repeated measurements were made using an oscillometric technique (Elias et al, 1990) - which may have resulted in somewhat biased estimates of habitual blood pressure.

Our findings do not corroborate those of Elias et al. (Elias et al., 1990). From a study in 301 healthy subjects, aged 20 to 72 years, they reported negative correlations between systolic and diastolic blood pressure (in the normal to hypertensive range) and performance on relatively complex cognitive tests, after the effects of age, sex, and educarional level were controlled for. The number of subjects in their study was much smaller and, more importantly, more hypertensive participants were included who were encouraged by their physician to take part in the cognitive test program. This inclusion procedure may have biased their sample in that a priori knowledge of the study participants with respect to their blood pressure status was unviodable and inclusion of a larger proportion of hypertensive patients may have resulted in a higher prevalence of vascular morbidity in this sample.

A potential - but as yet speculative - mechanism that could explain the negative association between blood pressure and cognition found in some studies is that the same factors which induce an alerting reaction and an increase in blood pressure may also induce a temporary lapse in performance on some cognitive tasks. Indeed, in a subgroup of this sample we also found a tendency towards lower blood pressure at the end of the 20-minute measurement session that was more pronounced in the older age groups (Van Boxtel. Gaillard, van Es, Jolles \& de Lecuw, 1996). This may indicate that some adaptation of blood pressure had raken place during the measurement interval.It was therefore decided to perform additional post hoc analyses, using the averages of the first two and of the last two systolic and diastolic blood pressure measurements as predictors of performance, intending to reflect blood pressure before and after adaptation, respectively. The resulting regression models were however not substantially different from those that were fitted using the average of all five measurements.

It can be argued that the cross-sectional nature of this study may threaten in some respects the external validity of our negative findings with respect to the blood pressure / cognition relationship. Blood pressure status was based on repeated blood pressure measurement during a 
single session. Reliable informarion about the subjects' blood pressure status in the past; to reconstruct the systemic blood pressure load over time, was not avallable. The importance of such additional data was supported by two large population studies in which blood pressure over time was demonstrated to predict cognitive decline (Framingham study, Elias et al., 1993; Honolulu-Asia study, see Launer er all, 1995). In addition, bias due to cohort effects may in part counteract potential negative associations between blood pressure status and performance, such as selective survival of individuals whose vascular system is less compromised and who may therefore be at lower risk for cognitive impaiment. Apart from overt cerebrovasicular disease, which was reason for exclusion, our population was unselected with respect to vascular health status. Self-selection bias can, however, not be ruled out entirely, even though participants did not differ in morbidity (as recorded by the family physician) when compared to non-compliers (Jolles et al., 1995). Limitations of this kind, however, pertain to any cross-sectional study on this subject and to any other predictor of age related cognitive dysfunctions. They can only be circumvented by follow-up measurements in the same cohort.

Even though antihypertensive medication use or experienced CVE covers a heterogeneous cluster of different drugs and types of morbidity, it is clear that excluding subjects from the analysis who had one or more of these characteristics reduces the prevalence of vascular pathology in the remaining group, including subclinical cerebrovascular damage. The presence of cardiovascular disease has earlier been associated with cognitive deficits (e.g. Herzog et al., 1978; Spieth, 1964). However, neither ancihypertensive medication use nor CVE was associated with performance in this study. The most convincing population-based studies to date that demonstrated hypertension-related cognivive impaiment used a blood pressure exposure index within a time frame when no effective drug therapy was available on a large scale (Elias et al, 1993; Launer et al., 1995). It is likely that any population study in Western socicties will be confounded by the widespread use - and heterogeneity - of drug treatment, which may partially cover up the true extent of subclinical brain damage, caused by high blood pressure. It can therefore not be concluded from these data that chronically elevated blood pressure in susceptible individuals does not contribute to cognirive decline with age, but our findings do suggest that in a communiry dwelling healthy population where there is a high standard of antihypertensive drug treatment, the relation between blood pressure status and cognitive function is at least too weak to be of clinical importance.

\section{REFERENCES}

Batersby, C. Hartley, K., Fletcher, A. E., Markowe, H. I. L, Brown, R. G., Styles, W., Carnes, S, Jamieson, T, Koppel, I., Fraser., S., Sapper, H., \&. Bulpir, C. J. (1993). Cognitive funcrion Un hypercension: A communily based study. Joumbl of Human Hyperiewsion, $7,117-123$.

Boller, F., Vrunski, P. B., Mack, J. L., 2. Kum, Y. (1977). Neuropsychological contelates of hypertension. Archiver of Newrology. 34,701-705.

Brand, N., \& Jolles, I. (1985). Lewrning and retrieval rate of words presented atudirory and wisually. fownal of Geraeral Pycholog, $112,201-210$.

Breteler, M. B. B., Wan Swieren, J. C., Bots, M. L., Grobbec, D. E. Clats: J. Ja, Van den Hout, H. H. W., Var Harskamp, F., Tanghe, H. L. J, de Jong, P. T.V.M., van Gija, J., \& Hofman, A. (1994). Cerebral white matrer lesions, wascular risk facrors, and cogrintwe function in a poputation-based study: The Rotrerdant Study, Neurolog, 44, 1246-1252. 


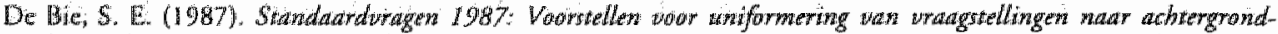

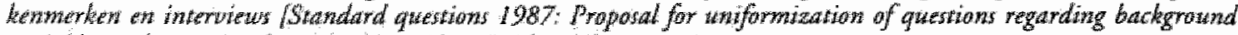

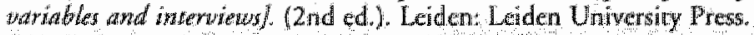

Despres, J. P. Moorjani, S, Lupien, P. I. Tremblay, A., Nadeau, A, \& Bouchard, C. (1990). Regional distribution of body fax, plasma lipoproteins, and cardiovascular disease. Arteriosclerosis, $10,497.511$.

Elias, M. If , Robbins, M. A, Schuln, IN, R, \& Piere, T, W. (1990). Is blood pressure an important variable in reseaten on aging and neuropsychological resi performance journal of Gerontology, 45. P128-135.

Elitis, M. F, Scluultw, J. N. R, Robbins, M. A. \& Elias, P. K. (1989). A longirudinal study of neuropsychological performance by hypertensives and normotensives; thind measurement point. Journal of Gerontology, 44, $\$ 25$ 28.

Elias, M. F, Wolf, P. A, D Agostino, R. B, Cabb, I, \& White, L. R, (1993). Untreated blood pressure level is inwersely related to cognitive functioning: The Framingham Study. American Journal of Epidemiology, 138, $353-364$

Farmer, M, E, Kinner, S. J., Abbort, R. D., Wol, M. M; Wolf, P. A., \& White, L. R. (1990), Longirudinally measured blood pressure, anithypertensive medication use, and cognivive performance: The Framingham Study. Journal of Clinical Epidemiology $43,475-480$.

Farmer, M. E. White, L. R, Abbott, R. D., Kitner, S. J., Kaplan, E., Wolz, M. M., Brody, J. A., \& Wolf, P. A. (1987). Blood pressure and cognitive performance: The Framingham study. American Journal of Epidemiology. $126.1103-1114$.

Goldman, H., Keinman, K. M., Snow, M. Y., Bidus, D. R., \& Korol, B. (1974). Correlation of diastolic blood pressure and sigres of cognitive dysfunction in essential hypertension. Diseases of the Nerwous System, 35, 571 572.

Herzog, $\mathrm{C}, 5 \mathrm{chaie}, \mathrm{K} . \mathrm{W}_{,}$\& Gribbin, $\mathrm{K},(1978)$. Cardiovascular disease and changes in intellectual functioning from middle to old age. fournal of Gerontology. 33, 872-883.

Houx, P. J., \& Jolles, J. (1994), Vulnerability factors for age-related cognitive decline. In R. L. Isaacson \& K. F. Jensen (Eds.), Toxims in air and water, (Vol. 3, pp. 25-41). New York: Plenum Press.

Houx, P. J., Jolles, ], \& Vreeling, F, W. (1993). Stroop interference: Aging effects assessed with the Stroop ColorWord rest. Experimental Aging Research, 19, 209-224.

Houx, P. J., Vreeling, F. W., \& Jolles, J. (1991). Age-associated cognitive decline is related to biological life events, In K. Iqball, D. R. C. McLachlin, B. Winblad, \& H. M. Wisniewski (Eds.), Alzheimer's disease: Basic mechamisms, diagrosis and therapetutic strategies, (pp. 353-358). Chichester, UK: Wiley.

Jalles, J.; Houx, P. J., van Boxtel, M. P. J., \& Ponds, R. W. H. M. (Eds.). (1995). Maastricht Aging Study: Dexerminatuts of cognitive aginge. Maastricht: Neuropsych Iublishers.

King, H. E, \& Miller, R, E. (1990). Hypertension: cognitive and behavional considerations. Netropsychology Rewiew, $1,31-73$.

LaRue, A. (1992). Aging and newropsychological assessmemt. New York: Plenum Press.

Launer, L. J., Dinkgreve, M. A., Jonker, C., Hooijer, C., \& Lindeboom, J. (1993). Are age and education independent corrdates of the Mini-Mental State Exam performance of communicy dwelling elderly? Joumal of Gerowtologis, 48 ; $271-277$.

Launer, L. J, Masalki, K., Petrovitch, H. Foley, D., \& Havlik, R. J. (1995). The association between midlife blood pressure lewels and late-life cognitive function: the Honoluh-Asia Aging Study. Journal of the American Medical Association, 274, 1846-1851.

Light, $K$. C (1975). Slowing of response time in young and middle-aged hypertensive patients. Experimental Aging Research, 1, 209-227.

Luteijn, $\mathrm{F}$, wan der Ploeg, F. A. E. (1983). Hawdeuding Groninger Intelligentietest (GIT) [Manual Groningen Intelligence Test/. Lisse, whe Netherlands: Swers and Zeitlinger.

Madden, D. J., \& Blumenthat, J. A. (1989). Slowing of memory-search performance in men with mild hypertension. Heath Psychology, 8, 1.31-142.

Mancian, G. Casadei, R., Groppelli, A., Parati, G. \& Zanchetri, A. (1991). Effect of stress on diagnosis of hypertension. Hypertemsionn, I7 (Suppl IIL), 56-62.

Mersemakers, J. F. M. Höppener, P., Knottnerus, J. A., Kocken, R. J. J., \& Limonard, C. B. G. (1992). Compucerized health information an the Netherlands: A registration nerwork of family practices. British fow of Genteral Pratice, $42,102-106$.

Perez Stable, E. 1., Coates, T. J., Halliday, R., Gardiner, P. S., \& Hauck, W. W. (1992). The effects of mild diascolic hypertension on the results of tests of cogna rive function in adults 22 to 59 years of age. Jowrnal of Gesteral buterat Medicine, 7. 19-25.

Pickering, T. G. (1991). Ambulatony monitoring and blood pressure variability, London: Science Press.

Schulkz Ir, N. R., Elias, M. F., Robbins, M. A., Streeren, D. H. P.. \& Blakeman, N. (1989). A longirudinal study of the performance of hypertensive and normotensive subjects on the Wechisler Adult Intelligence Scale. Prychology and Aging, 4, 496-499. 
Shapiro, A. Po, Miller, R. E., King, H. E., Ginchereau, E. H. \& Firzgibbon, K. (1982). Behavional consequences of mild hypertension. Hypertersion, 355-360.

Smith, A. (1968). The Symbol Digit Modalities Test: A neuropsychological test for economic sereening of learning and other cerebral disorders. Learying Disorderts 36, 83-91.

Spiech, W. (1964). Cardiovascular healch status, age and psychological performance. Journat of Gerontology" 19. $277-284$

Starn. J. M., \& Whalley, L. J. (1992). Senile hypertension and cognicive impairment: An overview. Joumal of Hypertenssion (Suppl), 10, S31-S42.

Starr, J. M., Whalley, L. J., Inch, S., \& Shering, P. A. (1993). Blood pressure and cognitive furccion in healthy old people. Journal of the American Getiatries Society, 1.753-756.

Swan, G. E., Carmelli, D., \& LaRue, A. (1996, February). CHD risk facton and neuropsychological performuance inz the elderly. Paper presented at the Annulal Meeting of the International Neuropsychological Society. Chicago, III.

Van Boxtel, M. P. J., Gaillard, C., van Es, P. N., Jollex, J., \& de Leeuw, P. W. (1996). Repeated automatic versus ambulatory blood pressure measurement: The effecrs of age and sex in a normal ageing population. Joumal of Hypertension, 14, $31-40$.

Van Boxtel, M. P. J., Langerak, K. Houx, P. J. \& Jolles, J. (1996). Self-reported physical activity, perceived heallh, and cognirive performance in older adults. Experimental Aging Researeh, 22, 363-379.

Van Swieten, J. C., Geyskes, G. G., Derix, M. M. A., Peek, B. M., Ramos, L. M. P., van Latum, Jn C., \& van Gijn, J. (1991). Hypertension in the elderly is associated with white matter lesions and with cognuive dectine. Anmals of Neurology 30, 825-830.

Waldsteir, S. R. (1995). Hypertension and neuropsfchological function: A lifetime perspective. Experimentral Aging Research, 21, 321-352.

Waldstein, S. R., Manuck, S. B., Ryan, C. M., \& Muldoon, M. F. (1991). Neuropsychological correlates of hypercension: review and methodological considerations. Pyychological Bralletin. $110,451-469$.

WHO. (1980). Problems related to alcohol consumprion: Repart of a WHO expert cominuittee. Genewa: World Health Organisation.

WHO/ISH. (1993). 1993 Guidelines for the management of mikl bypertension: memorandum from a World Health Organization/International Sociery of Hypertension meeting. Journal of Hypertension. 7, 689-693.

Wilkie, F. L., \& Eisdorfer, C. (1971). Intelligence and blood pressure in the aged. Science, 172, 959-462. 



\section{Is cognitive impairment related to a reduced nocturnal blood pressure drop? ${ }^{6}$}

\section{ABSTRACT}

The outcome of 24-hour ambulatory blood presure monitoring was used to predict cognitive performance, in order to evaluate the potential relevance of blood pressure status for cognitive function in healthy individuals. Furthermore, the hypothesis was tested that a reduction in the physiological blood pressure drop during sleep (dipping) is associated with a cognitive performance deficit, in line with studies in hypertensives that suggest associations between non-dipping and target organ damage.

For this purpose, a group of 115 largely normotensive community residents in the age between 28 and 82 years were recruited from a larger study on cognitive aging. All participants were screened for past or present cardiovascular events and medication use and underwent standard 24-hour blood pressure monitoring within three weeks after the administration of a cognitive battery of tests, including verbal memory, attention, simple speed, and information processing speed. Raw test scores were $Z$-transformed and combined in compound measures of memory performance, sensorimotor speed and cognitive flexibility.

Mean levels of systolic or diastolic blood pressure during the day or the night were nor predictive for cognitive outcome, after control for age, sex and educational level. However, the absolute and relative difference between mean day-time and night-time blood pressure was positively associated with performance on verbal memory (8-9\% of additional variance explained), but not with speed-related cognitive measures. The relation found for memory was independent of both antihypertensive medication use and evidence of cardiovascular events in the medical history. Non-dippers $(n=15)$ showed lower levels of both the memory and sensorimotor speed scores compared to dippers $(n=100)$.

In conclusion, mean ambulatory blood pressure was not predictive for cognitive performance. However, blunting or absence of the nocturnal blood pressure drop may be associared with quite specific cognitive deficits. The underlying mechanism remains as yet unclear.

6 M. P. J. wan Boxtel, C. Galllard, P. J. Hoax, F. Buntinx, P. W. de Leeuw, and J. Jolles (Subnm) 


\section{INTRODUCTION}

Blood pressure is considered to be a key factor in the development of cerebrovascular disease, in particular stroke and vascular dementia (Gorelick, 1995, Skoog, 1994). Hypertension may cause a teduction in regional cerebral blood flow (Rodriguez et ali, 1987) and subclinical brain damage on structural imaging, such as white matter hypodensities (Breteler et al, 1994; Shimada, Kawamoto, Matsubayashi \& Ozawa, 1990; Van Swieten et al, 1991) or signs of local brain atrophy (Salerno et al, 1992). Elevated blood pressure hevels concribute to functional cerebral impairment in susceptible individuals, in particular when other vascular risk factors leading to cerebral ischemia are present (Starr \& Whalley, 1992). Individuals diagnosed as being hypertensive consistently perform worse on cognitive performance tasks of learning and memory, attention and information processing speed when compared to normotensive controls (King \& Miller, 1990; Waldstein, 1995; Waldstein, Manuck, Ryan \& Muldoon, 1991). Population studies on the relation between blood pressure and cognitive status have shown mixed results. Results from the Framingham Heart Study indicated that longitudinally measured untreated blood pressure in the hypertensive range is negatively associated with cognitive performance, in particular in the domains of memory and attention (Elias, Wolf, D'Agostino, Cobb \& White, 1993; Farmer et al., 1990). In a large cohort of older Asilan men (mean age 78 years) the syscolic blood pressire, but not diastolic blood pressure, was inversely related to performance on a broad cognitive screening test that was administered approximately 25 years later (Launer, Masaki, Petrovitch, Foley \& Havlik, 1995). A study in 301 largely normotensive to borderline hypertensive adult subjects showed inverse associacions between systolic and diastolic blood pressure status and speeded performance tasks, suggesting that even small blood pressure elevations may result in functional decline (Elias, Robbins, Schultz \& Pierce, 1990). However, a recent large age-stratified study in 936 subjects of mixed bload pressure starus did not corrobotate the findings of Elias et al. (Van Boxiel, Gaillard, Houx, de Leeuw \& Jolles, 1996).

An important merhodological pitfall in studies on the blood pressure / cognition relationship is the mensurement of blood pressure itself. Blood pressure can be highly variable over the due to endogenous or exogenous stimuli. Furthermore, a substantial proportion of individuals is prone to a alerting reaction during blood pressure measurement that persists over successive measurements (white coat effect, Mancia et al, 1987). This may result in higher blood pressure readings in a medical than values obtained under daily living conditions. The measurement bias in studies that use on only a small number of blood pressure readings may thereby reduce the chance of picking up an associarion between blood pressure status and functional cerebral decline, if such association exists.

Non-invasive ambulatory blood pressure monitoring (ABPM) enables one to obtain repeated measurements of blood pressure under normal living conditions, thereby providing a more reliable estimation of blood pressure status and potentially a more valid predicrion of hypertension-related complications (Pickering, 1994). Although prognostic studies to substantiate this notion are as yer not available, there is some support that ABPM is superior to casual blood pressure (assessed with classical auscullatory measurement) in predicring hypertension-related target organ damage, such as retinopathy or left ventricular hypertrophy 
(Devereux \& Pickering, 1991). As evidenced by a study of 73 healthy elderly subjects of mixed blood pressure status, clinically silent cerebral lesions on magnetic resonance imaging can be predicted by ambulant blood pressure, but not by the blood pressure level measured in the doctor's office (Shimada et al., 1990). Moreover, the circadian blood pressure rhythm provides additional information on the condition of the vascular system, as blunting of the physiological blood pressure reduction during the night (non-dipping) is sugested to be linked with more cardiovascular complications of essential hypertension (Verdecchia, Schillaci \& Porcelatti, 1991). Comparable observations have been made with respect to cerebrovascular pathology as the incidence of stroke may be higher in non-dippers (O'Brien, Sheridan \& O'Malley, 1988). In a recent case-control study that contrasted patients with vascular dementia of the Binswanger type with non-demented age-matched controls, the day-night differences in ambulant blood pressure were smaller in the patient group (Toghi, Chiba \& Kimura, 1991). Finally, a study in elderly hypertensives reported a higher prevalence of cerebrovascular damage on magnetic resonance imaging in subjects with a reduced nocturnal blood pressure fall (Shimada et al., 1992).

In this study the potential was tested of parameters derived from 24-hour ambulatory blood pressure monitoring in predicting cognirive test performance, thereby ruling out measurement bias that would have resulted from fewer blood pressure readings. Moreover, the hypothesis was investigated that a reduction in the circadian variation in blood pressure is associated with a cognitive performance decrement.

\section{METHODS}

\section{Subjects}

Participants in this study were recruited from a larger subject sample that rook part in a cross-sectional cognitive aging study (Maastricht Aging Study, Jolles, Houx, van Boxtel \& Ponds, 1995). Subjects for this cross-sectional study were randomly drawn from a tegister of general practices (Registration Network Family Practices, Metsemakers, Höppener, Knottnerus, Kocken \& Limonard, 1992). Clinical evidence of past or present morbidity or drug use that could compromise brain function rendered a subject not eligible for the study: cerebrovascular disease, chronic neurological pathology - including dementia, epilepsy, and parkinsonism - and mental retardation or psychotropic medication use. Subjects were stratified for age (12 discontinuous groups; $25 \pm 1$ year, $30 \pm 1$ year, $35 \pm 1$ year, ..., $80 \pm 1$ year), sex, and two levels of occupational activity, used here as a proxy measure of general ability. In total 126 subjects in six age groups ( $30 \pm 1$ year, $40 \pm 1$ year, up to $80 \pm 1$ years) with complete cognitive data were invited and agreed to participate in addirional ABPM, within 3-4 weeks after completion of a comprehensive neuropsychological test battery. Elever subjects were dropped from the analysis because of incomplete ABPM recordings, defined as a proportion of valid measurements during the 24-hour meastrement interval of less than two-thirds of the maximal number of readings. Thus, data from 115 subjects were available. 
The study protocol was approved by the local ethics committee and informed consent in writing was obtained from all participants.

\section{Measurewents}

All subjects filled in a questionnaire pertaining socioecomomic background variables and medical history. Edtucational level was measured on an 8-point scale, ranging from primary school to higher vocational training and university degree (De Bie, 1987). In addition, a more specific medical interwiew was taken to screen for past or present cardiovascular morbidity: angina pectoris, myocardial infarction, cardiac insufficiency, cardiac arrhythmia, heart valve defects, Heart surgery or peripheral atherosclerosis, and the use of antihypertensive medication. Reported evidence of past or present hypertension was recorded separately.

\section{Cogntive assessment}

All participants were screened on several aspects of cognitive function, including memory, attention, simple speed and cognitive processing speed, of which the procedure is described in detail elsewhere (Jolles et al., 1995). The tests that were used are describe here in short.

The Word Leanning Task (WLT) is based upon the Auditory Verbal Learning Test (Brand \& Jolles, 1985) and evaluates the ability to acquire and retain new verbal information. A set of fifteen frequently used monosyllabic words is presenced in fixed order at a rate of one every two seconds in each of five trials. After every trial the subject is asked to reproduce the memorized words (immediate recall). Twenty minutes after the last trial the subject is asked again to reproduce the set of words (delayed recall). The total number of correctly reproduced words on five trials is recorded, in addition to the maximum score in five trials and the number of correctly reproduced words after 20 minutes.

Tho Concept Shifting Task (CST) evaluates behavioral planning and evaluation (Houx, Vrecling \& Jolles, 1991). The subject's ability to alternate two psychological concepts during cask performance is measured, here number and letter cancellation in correct order. The test sheet contains 16 small diameter circles $(015 \mathrm{~mm}$ ) arranged in a larger circle $(016 \mathrm{~cm}$ ). Two wull wersions (part 0) contain no symbols in the circles, the number version (part $A$ ) presents figures 1 to $16 \mathrm{in}$ random order in the circles, a letter version (part $B$ ) depicts random letters, and finally a number / letter vetsion (part C) alternates the numbers 1 to 8 and letters $A$ to $\mathrm{H}$. The subject is instructed to cross out the circles as fast as possible in correct order. Outcome is the time required to complete each task.

Suscepribility to language interference was measured in the Stroop Color Word Test (SCWT), consisting of three subtasks; color word naming (I), color naming (II) and naming of color words printed in a different color (interference task III). The SCWT task III is often considered a test of selective attention and shows robust effects of chronological age (Houx, Jolles \& Vreeling, 1993).

\section{Ambulant blood pressure monitoring}

ABPM was scheduled to start in the morning between $08.00-09.00 \mathrm{~h}$ with a total duration of 24 h. A Spacelabs 90207 monicor (Spacelabs Inc. Redmond WA, USA) was attached to the 
non-dominant arm of the subject at the hypertension laboratory of the University Hospital. It was programmed to measure blood pressure at $15 \mathrm{~min}$ intervals during the day $(07.00-22.59 \mathrm{~h})$ and every 30 min during the night $(23.00-06.59 \mathrm{~h})$. Subjects were instrueted to adhere to normal daily activities and regular sleeping hours and to report any unusual event during the recording interval. No evidence of sleep disturbance during the night was reported by the participants.

\section{Data reduction and analysis}

Three domains of cognirive performance were defined: memory, sensorimotor speed, and cognitive flexibility. Compound domain scores were computed for each individual, based on $Z$-ransformed raw scores in the total sample, where $z=(x-\bar{x}) / S D$. In this way, a reduction of performance outcome parameters can be achieved while the robustness of the underlying cognirive construct is improved (Salthouse, 1992). Next, the average was taken of Z-scores from tests that were included in the compound performance index: the memory score was derived from the cotal, maximal and delayed recall scores of the WLT, the cognitive flexibiity score included the C version of the CST and subtask III of the SCWT (LaRue, 1992, PP. 114115), and sensorimotor speed was calculated from the $0, A$ and B versions of the CST, and subtask $I$ of the SCWT. In formula: memory $=\left(Z_{\text {WLTOT }}+Z_{\text {WLTMAX }}+Z_{\text {WLTDEL }}\right) / 3$, cognitive flexibility $=-\left(Z_{\mathrm{CST}-\mathrm{C}}+Z_{\mathrm{SCWT}-1 \mathrm{n}}\right) / 2$, and sensorimotor speed $=-\left(Z_{\mathrm{CS}-0}+Z_{\mathrm{CST}-\mathrm{A}}\right.$ $\left.+Z_{C S T-B}+Z_{S C W T-1}\right) / 4$. Signs of the speed and flexibility scores were inverted to make them reflect performance better than average when positive and performance below average when negative.

Separate day-time and night-time averages of blood pressure and heart rate were calculated using the custom software provided by the manufacturer of the ABPM recorder. From these averages the absolute and relatiwe differences were computed (expressed as a percentage of the day-time average) between day-time and night-time blood pressure. Subjects were classified as non-dippers when the nocturnal lowering of both systolic and diastolic blood pressure was less than $10 \%$ of the mean day-time level (Verdecchia et al., 1991). In all other cases participants were assigned to the dipper category.

Associations between $A B P M$-related variables and cognitive outcome measures were analyzed with multiple hierarchical regression analysis, using adjustments for chronological age, sex, and educational level. Separate models were fitted for the total group, and the group of subjects free of cardiovascular events (CVE) or antihypertensive medication use. Finally, dippers and non-dippers were contrasted on background variables, ABPM parameters and cognitive measures using a Student's t-test for groups, or a Cht ${ }^{2}$ test in case of $2 \times 2$ tables.

\section{RESULTS}

No differences in age, education, day time mean blood pressure or cognitive performance were apparent between the group that was excluded for missing ABPM data $(n=11)$ and the final sample of 115 ( $t$-test for groups, all $p>05$ ). Table 8.1 displays the number of participants, mean $\mathbb{I Q}$ educational level, and cognitive outcome scores, by levels of age and sex. 
Table 8.1. Mean ( 4 50) levels of background characheristics and cognitive dependent variables, by levels of age class and sex $(N=115)$.

\begin{tabular}{|c|c|c|c|c|c|c|c|c|}
\hline & \multicolumn{6}{|c|}{ Age class } & \multicolumn{2}{|c|}{$\operatorname{Sex}$} \\
\hline & $30 \pm 1$ & $40 \pm 1$ & $50 \pm 1$ & $60 \pm 1$ & $70 \pm 1$ & $80 \# 1$ & $M$ & $F$ \\
\hline Total $n$ percel & 16 & 15 & 33 & 22 & 20 & 9 & 68 & 47 \\
\hline$M / F$ ratio & 917 & $5 / 10$ & $17 / 16$ & $14 / 8$ & $15 / 5$ & $8 / \mathbb{1}$ & - & - \\
\hline Educational lewel & $\begin{array}{r}4.3 \\
(1.5)\end{array}$ & $\begin{array}{r}3.5 \\
(1.9)\end{array}$ & $\begin{array}{r}3.7 \\
(1.6)\end{array}$ & $\begin{array}{r}3.5 \\
(1.6)\end{array}$ & $\begin{array}{r}2.7 \\
(1.7)\end{array}$ & $\begin{array}{r}2.9 \\
(2.5)\end{array}$ & $\begin{array}{r}3.6 \\
(1.9)\end{array}$ & $\begin{array}{r}3.4 \\
(1.5)\end{array}$ \\
\hline Memory & $\begin{array}{r}56 \\
(.64)\end{array}$ & $\begin{array}{r}.47 \\
(.68)\end{array}$ & $\begin{array}{r}.19 \\
(.83)\end{array}$ & $\begin{array}{r}. .02 \\
(.63)\end{array}$ & $\begin{array}{r}-.21 \\
(.90)\end{array}$ & $\begin{array}{r}-1.26 \\
(.92)\end{array}$ & $\begin{array}{r}-.16 \\
(.92)\end{array}$ & $\begin{array}{r}.36 \\
(.78)\end{array}$ \\
\hline Sensorimoror speed & $\begin{array}{r}.73 \\
(35)\end{array}$ & $\begin{array}{r}46 \\
(37)\end{array}$ & $\begin{array}{r}.22 \\
(.58)\end{array}$ & $\begin{array}{r}.02 \\
(.66)\end{array}$ & $\begin{array}{r}-.53 \\
(.42)\end{array}$ & $\begin{array}{r}.55 \\
(.57)\end{array}$ & $\begin{array}{r}-.01 \\
(.67)\end{array}$ & $\begin{array}{r}.24 \\
(.64)\end{array}$ \\
\hline Cogritive flexibility & $\begin{array}{r}.57 \\
(33)\end{array}$ & $\begin{array}{r}33 \\
.60)\end{array}$ & $\begin{array}{r}.33 \\
(.60)\end{array}$ & $\begin{array}{r}13 \\
(.59)\end{array}$ & $\begin{array}{r}. .58 \\
(.77)\end{array}$ & $\begin{array}{r}-1.25 \\
(.87)\end{array}$ & $\begin{array}{r}-.05 \\
(.80)\end{array}$ & $\begin{array}{r}.18 \\
(.80)\end{array}$ \\
\hline
\end{tabular}

Note. Presented cognitiwe outcome measures are population based, $Z$ transformed scores (population $m e s t n=0, S D=1$ ).

Table 8.2 summarizes for the same strata the mean values of ABPM parameters and the prevalence of antihypertensive medication use, presence of cardiovascular events (CVE) in the medical history, and the distribution of non-dipper status. In total, 26 subjects (23\%) took antihypertensive medication or reported evidence of CVE. Fifteen subjects (13\%) were classified as non-dipper.

Lower values for heart rate are expected during normal, uninterrupred sleep, irrespective of dipper status (Pickering, 1991, p. 5.9). No differences were found in day-time or night-time mean heart rate between dipper and non-dipper groups that could have been caused by between-group differences in sleeping pattern (day-time $\mathrm{HR}=77 \pm 10 \mathrm{BPM}$ and $78 \pm 11 \mathrm{BPM}$ (p s .05), night-time $\mathrm{HR}=64 \pm 9 \mathrm{BPM}$ and $67 \pm 12 \mathrm{BPM}$, for dippers and non-dippers, respectively, for both differences $p>.05)$.

Next, age, sex and educational level were entered first in regression models that were intended to predict the three cognitive outcome scores (Table 8.3). The standardized regression coefficients (Beta) indicate that age was by far the strongest predictor of performance, followed by educational level: older age and lower education were consistently predictive for lower test outcome. Being of the fernale sex was associated with higher scores on the memory tests. Together these variables explained $29 \%, 45 \%$ and $44 \%$ of the variance in memory performance, sensorimotor speed, and cognitive flexibility, respectively.

To test the predictive value of mean blood pressure levels and day-time / might-time blood pressure differences we entered the ABPM variables separately in step 2 . In a comparable fashion it was checked if a relation was present between performance and antihypertensive drug use or CVE in the medical history. Table 8.3 displays the Beta"s for these variables in the respecrive models. Mean day-time or night-time averages of diastolic or systolic blood 
Table 8.2. Mean (* SD) leviels of diastolic and systolic ambulatory blood pressure, day / night blood pressure differences and prewalence of ancihypertensive medication use, cardiowascular events and dipper stanus, by levelis of age and sex $(N=115)$.

\begin{tabular}{|c|c|c|c|c|c|c|c|c|}
\hline & \multicolumn{6}{|c|}{ Age class } & \multicolumn{2}{|c|}{ Sex } \\
\hline & $30 \pm 1$ & $40 \pm 1$ & $50 \pm 1$ & $60 \pm 1$ & $70 \pm 1$ & $80 \pm 1$ & $M$ & $\mathbb{*}$ \\
\hline \multirow[t]{2}{*}{$\mathrm{DBP}$ day $(\mathrm{mmHg})$} & 76 & 79 & 83 & 81 & 78 & 83 & 81 & 78 \\
\hline & (5) & (9) & (7) & (8) & (6) & (9) & (8) & (7) \\
\hline \multirow[t]{2}{*}{ DBP nighe (mmHg) } & 61 & 63 & 69 & 68 & 63 & 72 & 68 & 63 \\
\hline & (4) & (10) & (7) & (9) & (9) & (10) & (9) & (8) \\
\hline \multirow[t]{2}{*}{ DBP 24-hour $\left(\mathrm{mmH}_{\mathrm{H}}\right)$} & 72 & 76 & 80 & 78 & 74 & 80 & 78 & 75 \\
\hline & (5) & (10) & (7) & (8) & (6) & (9) & (8) & (7) \\
\hline \multirow[t]{2}{*}{ SBP day $(\mathrm{mmHg})$} & 123 & 123 & 128 & 127 & 129 & 141 & 130 & 124 \\
\hline & (9) & (10) & $(10)$ & (11) & (10) & (18) & (12) & (10) \\
\hline \multirow[t]{2}{*}{ SBP night $(\mathrm{mm} H \mathrm{Hg})$} & 110 & 106 & 113 & 114 & 114 & 129 & 116 & 109 \\
\hline & (8) & (10) & (11) & (11) & (14) & $(20)$ & $(13)$ & (12) \\
\hline \multirow[t]{2}{*}{ SBP 24-hour $(\mathrm{mmHg})$} & 120 & 119 & 124 & 124 & 125 & 139 & 127 & 120 \\
\hline & (8) & (10) & (10) & (III) & (10) & $(18)$ & (11) & $(10)$ \\
\hline \multirow[t]{2}{*}{ DBP day-night $(\mathrm{mmHg})$} & 15 & 16 & 15 & 13 & 15 & $\Pi$ & 13 & 16 \\
\hline & (3) & (5) & (7) & (5) & (9) & (5) & (6) & (6) \\
\hline \multirow[t]{2}{*}{ SBP day-night (muHg) } & 13 & 17 & 15 & 13 & 15 & 12 & 14 & 15 \\
\hline & $(5)$ & (5) & (9) & (7) & (11) & $(10)$ & (9) & (7) \\
\hline Dippersa (\#) & 0 & 1 & 6 & 4 & 2 & 2 & 8 & 7 \\
\hline Antihypertensive drug use ( & 0 & 0 & 6 & 3 & 4 & 2 & 11 & 4 \\
\hline $\mathrm{CVE}(H)$ & 1 & 0 & 3 & 4 & 7 & 4 & 15 & 4 \\
\hline CVE or antihypert, drug use (\#) & 1 & 0 & 8 & 5 & 8 & 4 & 18 & 8 \\
\hline Total & 16 & 15 & 33 & 22 & 20 & 9 & 65 & 47 \\
\hline
\end{tabular}

Note. DBP $=$ Diastolic blood pressure; $S B P=$ Systrolic blood pressure; CVE $=$ prevalence of cartio vascullar events, a Classified according to the criter ia of Verdecthia cr al. (1991).

pressure were not related to cognitive performance measures when the effects of background variables were controlled for. However, both the absolute and relative difference in day-time / night-time systolic or diastolic blood pressure were positively correllated to memory performance, albeit no such association was found for the two compound speed measures. In terms of additional explained variance these variables increased the prediction of memory performance with 8 to $9 \%$ ( $R^{2}$-change, equivalent to partial $r$-squared). When the nocturnal blood pressure drop was defined as dipper status according to Verdecchia et al. (1991) the prediction of memory performance was improved with $3 \%$. Interestingly, dipper status now additionally explained $5 \%$ in the sensorimotor speed score, which had remained unaffected by the day-time / night-time differences. In statistical terms the effect of dipper status was comparable with being 22.4 years older with respect to memory performance, and with being 14.7 years older regarding sensorimotor speed performance. This estimation was computed as 
Table 3. Regresion of age, sex, educational lewel, and ABPM parameters on cognitive performanec outeone: displayed are standardited regression coefficients (Bera) and partial corrdation coeffecients $\left(P_{p}\right)$, adjusring for age, sex and educational level in step 1 . The variables entered in step explained $29 \%, 45 \%$ and $44 \%$ of the yariance in memory performance, sensorimotor speed, and cognitive fexibility, respectively. Wore that bets's for drug use, CVE and ABPM paramerers epresent the watues when the respective variables are entered separately in the rnosdel in step 2

\begin{tabular}{|c|c|c|c|c|c|c|}
\hline & \multicolumn{2}{|c|}{ Memory } & \multicolumn{2}{|c|}{$\begin{array}{l}\text { Serisonimotor } \\
\text { speed }\end{array}$} & \multicolumn{2}{|c|}{$\begin{array}{l}\text { Cognitive } \\
\text { Mexibility }\end{array}$} \\
\hline & Beta & $r_{p}$ & Betta & $r_{p}$ & Beta & $r_{p}$ \\
\hline Age (years) & 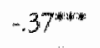 & - & $-.55^{* * * * *}$ & - & $-49^{* * *}$ & - \\
\hline Sext & $.21^{*}$ & - & .06 & - & .04 & $\sim$ \\
\hline Educational level & $.20^{*}$ & - & $.25^{* * * *}$ & - & $32^{* * *}$ & - \\
\hline Antilypertensive drug use & -.03 & .02 & .02 & .04 & .05 & .08 \\
\hline $\mathrm{CVE}^{2}$ & -.04 & .06 & .08 & -.10 & .10 & .10 \\
\hline DBP dayyime (nnm $/ \mathrm{Hg})$ & .15 & .14 & .11 & .14 & .10 & .13 \\
\hline SBP daycime (nom $\mathrm{Hg}$ ) & .05 & .04 & .02 & .03 & .00 & .02 \\
\hline DBP nightetime (mml & -.07 & .08 & .02 & .03 & .07 & .10 \\
\hline SBP nighrime $\left(\mathrm{mm} \mathrm{Hg}_{\mathrm{g}}\right)$ & -1.14 & -.14 & -.05 & -.05 & -.05 & -.03 \\
\hline DBP dip $(\mathrm{mmHg})$ & $.29 * * *$ & $30^{* * * *}$ & .12 & .14 & .03 & .02 \\
\hline DBP dip $(\%)$ & $.24 *$ & $.28^{* * * *}$ & .09 & .10 & .00 & -.01 \\
\hline SBP dip (mm Hg) & $.28^{* * *}$ & $.28 * * * *$ & .09 & .11 & .06 & .08 \\
\hline SBP dip $(\%)$ & $26^{* *}$ & $.29^{* * * * *}$ & .09 & .12 & .07 & .09 \\
\hline Dipper starusc & $.17 *$ & $.17^{*}$ & $.18^{*}$ & $.22^{* *}$ &. .01 & .04 \\
\hline
\end{tabular}

Note. $\mathrm{CVE}=$ Cardiovascular events: $\mathrm{DBP}=$ diasrolic blood pressure; $\mathrm{SBP}=$ systolic blood pressure. a Sex: $0=$ male, $1=$ ferrale; $b$ Ancihypertensive drug use $/ C V E: 0=$ no, $1=$ yes; CDipper status: $0=$ non-dipper, $1=$ dipper.

${ }^{*} p \leq 05 ; * * 0 \leq .01 \xi^{* * *} p \leq 001$.

$B_{\text {dipperatutur }} / B_{\text {age }}$ (yetris) or $.448 /-.020$ and $354 /-.024$, respectively). The observed associations were age-independent, as separate models. fitted for age by ABPM parameter interactions indicared no significant contriburions of these factors to the compound cognirive scores (results not shown).

Although no relations of CVE or antihypertensive drug use with cognitive variables were observed, the analyses were repeated on the group of $89 \mathrm{CVE}$-free and unmedicated subjects. A sniall atrenuation was found of the strength of observed relations (results not presented here), bur the pattern of effects remained essentially unchanged.

The background variables (Table 8.4) and cognitive scores (Figure 8.1) of non-dippers were contrasted with those of subjects who showed a normal circadian blood pressure pattern. No betweet group differences were found with respect to age, educational level, sex, prevalence of cardiowscular events or antihypertensive drug use. The difference in reported evidence of hypertension ( $12 \%$ in non-dippers, versus $27 \%$ in the dipper group) did not reach staristical 
Table 8.4. Background characteristics and mean ambulant blood pressure values of dippers and non-dippers: displayed are means $(+S D)$ or counts $(\%)$ and the significance level of
groupwise comparison

\begin{tabular}{cc} 
Dippers & Non-dippers \\
$(N=100)$ & $(N=15)$ \\
\hline
\end{tabular}

\begin{tabular}{|c|c|c|}
\hline Age (years) & $52.9(15.0)$ & $58.7(11.8)$ \\
\hline Educational level & $3.6(1.8)$ & $2.9(1.4)$ \\
\hline IQ & $117.3(12.9 \mathrm{j}$ & $113.1(11.0)$ \\
\hline Fernales (th) & $40(40 \%)$ & $7(47 \%)$ \\
\hline History of hypertension ( & $12(12 \%)$ & $4(27 \%)$ \\
\hline Antihypertensive drug use ( & $13(13 \%)$ & $2(13 \%)$ \\
\hline CVE (H) & $15(15 \%)$ & $4(27 \%)$ \\
\hline Ancihypertensive drug use / CVE ( & $21(21 \%)$ & $5(33 \%)$ \\
\hline DBP daycime (mmHg) & $80(8)$ & $83,(8)$ \\
\hline SBP daytime $(\mathrm{mmHg})$ & $127(11)$ & $132(14)$ \\
\hline DBP nightime (mmHg) & $64(8)$ & $78(8)^{* * *}$ \\
\hline SBP nightrime $\left(\mathrm{mmHg}^{2}\right)$ & $111(10)$ & $129(18)^{* * *}$ \\
\hline DBP dip (mm $\mathrm{mg})$ & $15(5)$ & $6(4)^{*+\cdots}$ \\
\hline DBP dip (\%) & $19(6)$ & $7(5)^{* * * *}$ \\
\hline $\mathrm{SBP}$ dip $\left(\mathrm{mm} \mathrm{Hg}_{\mathrm{g}}\right)$ & $16(7)$ & $4(7)^{* * * *}$ \\
\hline SBP dip $(\%)$ & $13(5)$ & $3(5)^{* * * *}$ \\
\hline
\end{tabular}

Note. $2 \times 2$ Tables were tested using the Chi starisric, with conturuiry correction (Yates); means were compared with Student's t-test for groups. CVE $=$ cardiovascular event.

${ }^{*} p \leq .05 ; * * 0.01 ; * * * 0.001$.

significance. The differences in blood pressure levels were limited to the night-time walues and, obviously, the nocturnal blood pressure drop. Non-dippers performed worse on memory and on sensorimotor speed. No difference was observed on cognitive flexibility.

\section{DISCUSSION}

In this study, blood pressure estimates from 24 -hour ambulant monitoring were used to arrive at a more accurate description of blood pressure related factors that may add to - or mediate - the age-related decline in cognitive function. After adjustment for effects of age, sex and educational level, it was found that mean day-time and night-time blood pressure levels were unrelated to the composite cognitive scores, with or without control for antihypertensive drug use or cardiovascular events in the medical history. These observacions comply with our earlier findings regarding the effect of habitual blood pressure status on comparable cognitive measures in a larger population ( $N=936$; Van Boxtel et al., 1996). However, artenuation or absence of the physiological lowering of blood pressure at night, a phenomenon that repeatedly 


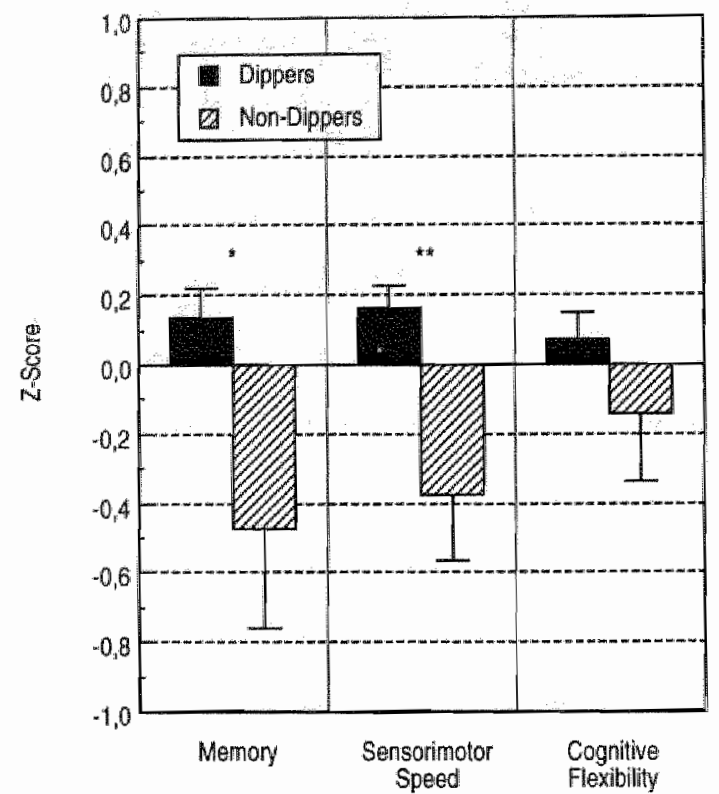

Figure 8.1. Mean cognitive performance scores ( $+5 E M)$ as a function of dipper status (* $p \leq 05 ; * * \leq .01$ ).

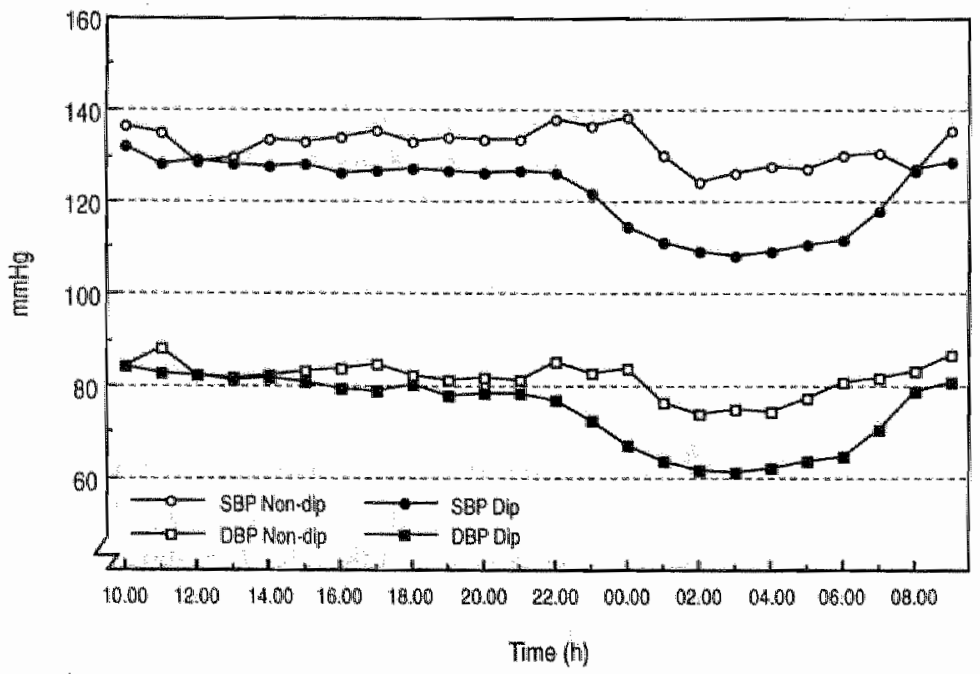

Figure 8.2.24-Hour systolic and diastolic blood pressure in dippers $(n=100)$ and non-dippers $(n=15)$. 
has been associated with evidence of cardiovascular and cerebrovascular damage in hypertensives, was related to a substantial lower performance on werbal memory. When dipper starus was classified according to the criteria commonly used in clinical practice, additional evidence was found for lower sensorimoror speed in non-dippers.

Apart from a small but significant association between dipper status and sensorimotor speed, there were no relations of nocturnal blood pressure reduction and speeded cognitive performance. Global cognitive decline associated with aging generally shows a pattern in which speed-related cognitive parameters are more affected by chronological age than non-speeded tasks, like word learning (Salthouse, 1989). This pattern can also be observed in our data, were Beta levels associated with age are much higher for both speed related compound scores $(-55$ and -.49$)$ than for the memory score $(-.37)$. The association berween nocturnal blood pressure reduction - a variable that was relatively unaffected by age in this sample (Van Boxtel et al.., 1996) - and cognitive performance is indeed largely testricted to the domain of learning and memory, which may suggest a selective decline in brain function. Multiple brain systems are involved in human memory processes (Markowitsch, 1995), but some, in particular older brain structures like specific areas in the hippocampus, are exeptionally vulnerable to hypoxia (Cervốs-Navarro \& Diemer, 1991). If non-dipping is indeed related to focal damage to specific brain strucrures it may be identified with brain-imaging techniques in future research.

To date, associations between absence of nocturnal dipping and target organ damage have only been described in hypertensive populations, as ABPM is seldom used in healthy population studies. It seems, however, that absence of the nocturnal blood pressure drop is not restricted to hypertensive individuals, as the mean day-time blood pressure of subjects in the dipper category was not different from mean day-time blood pressure in non-dippers. Typically it was the mean night-time blood pressure that differed in both groups (Figure 8.2). Airthough no such evidence came forward from our subjects, a reason for non-dipping may have been a shallow or interrupted sleep due to the measurement of blood pressure irself (Pickering, 1991). The appararus that was used is generally well tolerated by patients and performs virtually noiseless (O'Brien, Mee, Arkins \&. O'Malley, 1991). In addition, no differences were found in day-time or night-rime mean heart rate between dipper and non-dipper groups. It seems therefore unlikely that an abnormal sleeping patrern is responsible for the observed relations.

The mechanism of nocturnal dipping of blood pressure is still largely unknown, but reduced sympathetic nerwous activity during the night probably plays a role (Pickering. 1991). A blunted reduction of blood pressure during the night may have an adaptive funcrion in maintaining the night-time blood flow in vital organs at acceptable levels - including the blood supply to the brain - in advanced stages of vascular insufficiency, especially when autoregularory function fails (Imai \& Abe, 1993). Furthermore, in contrast to the blood flow in other organs, cerebral blood flow increases during the night as a result of an increased oxygen demand (Townsend 8c. Prinz, 1973). Although it is unlikely that substantial cerebrovascular insufficiency was present in our largely normotensive subjects it still may be possible that brain hypoxia at night is related to the observed functional decline in memory performance.

Causal inferences from correlational studies such as these must be made with caution. The present findings need to be replicated in an independent sample before definite conclusions can 
be drawn. If the relation bewwen night-time reduction in blood pressure and memory related function proves to be robust, the next step is to relate these findings to the morphological and functional diaracteristics of brain structures that are cngaged in memory function, using brain imaging techniques, such as MRI and SPECT.

\section{REFERENCES}

Brand, N. \& Jolles, J. (1985). Learning and retrieval rate of words presented auditory and visually. Journat of General Psybologe 112, 201-210.

Breteler, M. B. B., wan Swieren, J. C., Bots, M. L., Grobbee, D. E., Claus, J. J., Van den Hout, J. H. W., Van Harskarnp, F, Tanghe, H. L. J., de Jong, P. T. V. M., van Gijn, I., \& Hofman, A. (1994). Cerebral white matter lesions, yascular risk factors, and cognitive function in a population-based study: The Rotterdam Study. Newrology, 44, 1266-1252.

Cerrós Nawaro, J., \& Diemer, N. H. (1991). Selective vulnerabilicy in brain hypoxia. Crincal Reviews in Netrobiolog, 6, 149.182.

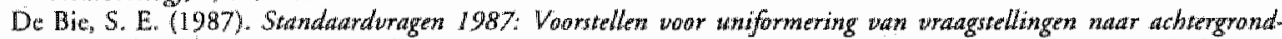
kenwerken en interviews IStandard guestions 1987: Proposal for wniformization of questions regarding backgromod warinbles and intervietusl. (2nd ed.). Leiden: Leiden University Press.

Devereux, R. B., \& Pickering, T. G. (1991). Relationship berween the level, pattern and variability of ambulan: blond pressure and target organ damage in hypertension. Jownal of Hypertension (Supph), 9, 534-538.

Elias, M. F., Robbins, M. A. Sctiulcz, J. N. R. \& Pierce, T. W. (1990), Is blood pressure an important variable in rescarch on aging and neuropsychological test performance? Journal of Gerontology, 45, P128-135.

Eltas, M. F. Wolf, P. A., D'Agostino, R. B., Cobb, J., \& White, L. R. (1993). Untreated blood pressure level is inversely related to cognirive functioning: The Framingham Study. American Joumal of Epridemiology, 138, $353-364$.

Farmer, M. E, Kitner, S. J., Abbort, R. D., Wola, M. M., Wolf, P. A. \& White, L. R. (1990). Langirudinally measured blood pressture, antilupertensive medication use, and cognitive performance: The Framingham Study. Journal of Clinical Epiderniology, 43, 475-480.

Gorelick, P. B. (1995). Stroke prevention. Archives of Neurology, 52, 347-355.

Honk, P. J., Jolles, J., \& Vreeling, F. W. (1993). Stroop interference: Aging effects assessed with the Stroop ColorWord rest. Experimental Aging Research, 19, 209-224.

Houx, P. J., Vreeling, F. W, \& Jalles, J. (1991). Age-associated cognirive decline is related to biological life events, In K. Iqbal, D. R. C. McLachlin, B. Winblad, \& H. M. Wisniewski (Eds.), Alzheimer"s disease: Basic

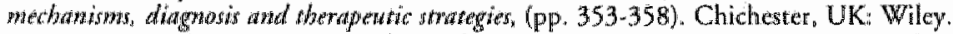

Imai $Y_{\text {., \& }}$ Abe, $K$. (1993). Clinical significance of nocrurnal blood pressure in the elderly. Cardiology in the Liderly, $1,483-489$.

Jolles, J., Houx, F. J. van Boxtel, M. P. J. \& Ponds, R. W. H. M. (Eds.). (1995). Marastricht Aging Skady. Destrmintanis of cognintwe aging. Manstricht: Neuropsych Publishers.

King, H. E., \& Miller, R. E. (1990). Hypertension: cognirive and behavioral considerations. Neturopsychology Review. $1,31-73$.

LaRne, A. (1992). Aging and nearopsychological assessment. New York: 'Plenum Press.

Launer, L. J., Masaki, K., Perrovich, H., Foley, D., \& Havlik, R. 1. (1995). The association berween midlife blood pressure levels and latc-wife cognitive funccion: The Honolulu-Asia Aging Study. Jowrnal of the American Medical Association, 274, 1846-1851.

Mancia, G., Parati, G., Pomidossi, G., Grassi, G., Casadei, R., \& Zanchetri, A. (1987). Alerting reacrion and rise in blood pressure during measurement by physician and murse. Hypertension, 9, 209-215.

Markowirsch, H. J. (1995). Anatomical basis of memory disorders. In M. S. Gazzaniga (Ed.). The cognitive neturosciences, (pp. 765-779). Cambridge Massachusetrs: MIT Press.

Metsemakers, J. F. M., Höppener, P., Knotmertis, I. A., Kocken, R. J. J., \& Limonard, C. B. G. (1992). Computerized health information in the Netherlands: A registration nerwork of family practices. Britisto Journat of Generial Practict, 42, 102-106.

OBBien, E., Mee, F., Atkins, N., \& O'Malley, K. (1991). Accuracy of the Spacelabs 90207 determined by the Bricish Hyperytension Saciecy Pratocol. Journal of Hypertension, 9, 573-57th.

O'Brien, E., Sheridan, J., \& O'Malley, K. (1988). Dippers and non-dippers [letter to the ediror]. Lancet, 2(8607), 397.

Pickering, T. G. (1991). Ambbulatory monitoring and blood pressure variability. London: Science Press.

Pickering, T, G. (1994). Blood pressure measurement and detection of hypertension. Lawcer, 344, 31-35. 
Rodriguez, G., Arigo, F., Marenco, S., Nobili, F., Sandini, G., \& Rosandini, G. (1987). Regional blood How in essencial hypertension: Dara evaluation by a mapping system. Siroke, 18, 13-20.

Salerno, J. A., Murphy, D. G. M., Horwitz, B., DeCarli, C., Haxby, J. V., Rapopart, S. I., Sc Schapiro, M. B. (1992). Brain atrophy in hypertension: A volumetric megnetic resonance inaging study. Hypertension, 20,340-348.

Salthouse, T. A. (1989). Age-relared changes in basic cognirive processes. In M. Srorandr \&* G. RE Vandenbos (Eds.). The adult years: Continuity and change, (pp. 5-40). Washingron: American Psychological Association.

Salihouse. T. A. (1992). Mechanisms of age-cognition relations in adulhood. Hillsdale, NJ: Lawrence Enlbaum Associares.

Shimada, K., Kawamoto, A. Marsubayashi, K., Nishinaga, M., Kimura, S., \& Ozawa, T. (1992). Dinurnal blood pressure wariations and silent cerebrowascular damage in elderly patients with hypertension. Joumal of Hypertension, $10,875-878$.

Shimada, K., Kawamoto, A., Matsubayashi, K., \& Ozawa, T. (1990). Silent cerebrowascular disease in the elderly: Correlarion with ambulant pressure. Hyperension, $16,692-699$.

Skoog, I. (1994). Risk factors for wascular dementia: A review. Dementia, 5, 137-144.

Starr, J. M., \& Whalley, L. J. (1992). Senile hypertension and cognitive impairment: An overvicw. foumal of Hypertersian (Suppl), 10, $531-542$.

Toghi, H., Chiba, K., \& Kimura, M. (1991). Twenty-four hour wariarion of blood pressure in vascular dementia of the Binswanger type. Stroke, 22,603-608.

Townsend, R. E. \& Prinz, P. N. (1973). Human cerebral blood flow during sleep and waking. fournat of Applied Pbysiolagy, 35, 620-625.

Van Boxtel, M. P. J., Gaillard, C., Houx, P. J., de Leeuw, P. W. \& Jolles, J. (Submitred), Can blood pressure predict cognirive task performance in a heal hy population sample?

Van Boxrel, M. P. J., Gaillard, C., wan Es, P. N., Jolles, 1., \& de Leeuw, P. W. (1996). Repeated automaric versus ambularory blood pressure measurement: The effects of age and sex in a nomal ageing popratation. Jow rnat of Hyperiension, $14,31 \times 40$.

Van Swieren, J. C. Geyskes, G. G., Derix, M. M. A., Peek, B. M., Ramos, L. M. P., van Latum, J. C., \& vain Gijp, J. (1991). Hypercension in the elderly is associated with white matter lesions and with cognitive decline. Annals of Nenrologe, 30, 825-830.

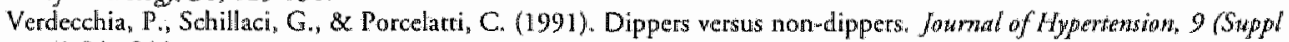
8), $\$ 42-\$ 44$.

Waldstein, S. R. (1995). Hypertension and neuropsychological function: A lifetime perspective. Experimental Aging Research, 21, 321-352.

Waldstein, S. R., Manuck, S. B., Ryan, C. M., Muldoon, M. F. (1991). Neuropsychological correlates of hypertension: review and methodological considerations. Psychologicial Bufletin, 110, 451-469. 



\section{Chapter 9}

\section{The relation between morbidity and cognitive performance in a normal aging population ${ }^{7}$}

\section{ABSTRACT}

Factors related to physical health have been proposed to account for both the normal and the pathological aging of cognitive abilities. To substanciate this notion, we sudied existing morbidity, as diagnosed by the general practitioner, as a potential predictor of cognitive test performance in a cross-sectional study. A population of 1,360 individuals living in the community, aged 24 to 81 years, was stratified for age, sex, and level of general ability. Active and total morbidity were classiffed according to the International Classification of Primary Care (ICPC). Neurocognitive rests were used to probe the domains of verbal memory, sensorimotor speed, and cognitive flexibility. Multiple regression analyses with adjustment for age, sex and educational level showed both insulin-dependent and non-insulin dependent diabetes to be negatively associated with all cognitive measures. More selective effects were found for for chronic bronchitis (on performance speed) and presbyacusia (on memory). Notably, single or aggregated cardiovascular morbidity clusters (including hypertension) were unrelated to test performance. It is concluded that the total sum of existing morbidity contributes only modestly (up to 3.5\%) to the total variance in cognitive outcome measures. However, some specific, relatively common diseases in older individuals, such as diabetes and chronic bronchitis, may aggravate the age-related decline in cognirive ability.

\section{INTRODUCTION}

On a population level, most cognitive abilities such as memory function information processing speed and attentional capacity tend to decline with advancing age (Poon, 1985 ; Salthouse, 1989). Adequate preservation of cognitive abilities is of primary importance to older people, as cognitive decline in the aged can result in a loss of independence and autonomy (McSweeny, Grant, Heaton, Prigatano \& Adams, 1985). Interindividual differences exist, however, in the rate of decline of specifie cognitive functions that can, at least in part, be mediated by individual differences in physical health (Elias, Elias \& Elias, 1990; Salthouse, 1992). Several studies have suggested that health-related factors, such as closed head injuries, general anesthesia, and chronic psychotropic medication use (e.g. Houx \&x Jolles, 1993: Houx \& Jolles, 1994) may be inwolved in the enhanced cognitive decline seen with increasing age. In addition, several disease entities have been associated with a reduced cognitive capacity in

7 M. P. J. van Boxtel, F. Buntinx, P. J. Houx, J. F. M. Metsemakers, and J. Jolles (Subm.) 
epidemiological surveys and clinical case-control studies (Colsher \& Wallace, 1991). For cxample, disorders such as thytoid disease renal or hepatic failure, cardiac insufficiency or chronic obstructive pulmonary disease may be accompanied by relatively non-specific neuropsychological deficits (Tarter, van Thiel 80 Edwards, 1988), and may aggravate a dementia syndrome in geriatric populations (Nolan \& Blass, 1992).

Mild cognitive impaiment with no frank dementia (CIND) has recently been recognized as a rellevant clinical enticy which must be identified in an early stage of its development (Writing Commitree Lancet Conference, 1996). The family physician may play a crucial role in recognizing parients who are at risk of cognitive deterioration that is mediated by physical disease or disability, as he is pre-eminently confronted with early stages of disease. It is unclear, however, if the findings on cognition-related morbidity in clinical populations can be readily transposed to the general practice setting. Clinical studies most often refer to advanced stages of disease and are therefore inclined to overestimate the potential effect of specific morbidicy categories on cognitiwe function in earlier stages. A cross-sectional design was used in this study to ascertain the potential relevance of well-described morbidity categories as possible determinants of cognitive function in a large sample of community living adult individuals, using established classification criteria for existing morbidity in general practice. More specifically, it was hypothesized that existing morbidity relaced to the vascular system is particularly prone to produce deficits in cognitive function.

\section{METHODS}

\section{Sample frame}

The study was part of a larger research program on determinants of normal cognitive aging, the Maastricht Aging Study (MAAS, Jolles, Hotux, van Boxtel $8 x$ Ponds, 1995). Participants were recruited from the Registration Nerwork Family Practices (RNH, Mersemakers, Höppener, Knottnerus, Kocken \& Limonard, 1992). The Registration Network was once established as a sample frame for research in primary care. It consists of the background characteristics and health problems of 60,000 patients in 15 general practices that are updated on a continuous basis via a computerized system. Health problems are classified according to the International Classificarion of Primary Care (ICPC, Lamberts \& Wood, 1987), along with the dates of becoming active and - for some problems - of becoming inactive. A health problem is diagnosed when it affects the functional status of the individual at present or in the future. Therefore, as a rule, only permanent, chronic ot tecurrent problems are included (Metsemakers et al. 1992). The randomely drawn individuals were personally invited by their family doctor to take part in the cognitive test program.

The a priori knowledge on the medical status of patients in the register enabled exclusion of individuals with evidence of stroke, chronic neurological pathology (e.g. dementia, epilepsy, parkinsonism and malignancies relared to the nervous system), mental retardation or chronic psychotropic drug use.

Participants were stratified for age (12 age classes, ranging from $25 \pm 1$ year, $30 \pm 1$ year, to 
$80 \pm 1$ year), sex, and level of general ability (two lewels, based on the achuevernent in professional life; Wan Berkel \& Tax, 1990), to control these background variables that in itself may affect cognitive performance (Jolles et al., 1995). The study populations of the first three MAAS panel studies, executed between april 1993 and december 1995, were combined in the current population of 1,373 participants. Of this group, thirteen individuals were not induded in the present analysis due to one or more missing walues in the cognitive dataset.

\section{Measurements}

All participants filled in a questionnaire pertaining to socioeconomic background and medical history. Educational level was measured on an 8-point scale, ranging from primary school to higher vocational training and university degree (Jolles et al., 1995).

\section{Cognitive assessment}

Standard neuropsychological tests were used to assess the cognitive domains of memory, sensorimotor speed and information processing speed/ cognitive flexibility (see Jolles et al., 1995, for a full description).

The Word Learning Task (WLT) evaluates the abilicy to acquire and retain new verbal. information. A sec of fifteen frequently used monosyllabic words is presented in fixed order at a rate of one every two seconds in each of five trials. After every trial the participant is to reproduce the memorized words (immediate recall). Twenty minutes after the last trial the participant is asked again to reproduce the set of words (delayed recall). Recorded are the total of correctly reproduced words on five trials, the maximum score in five trials and the number of correctly reproduced words after 20 minutes.

The Concept Shifting Task (CST) evaluates behavioral plamning and evaluation. It measures one's ability to alternate two psychological concepts during task performance, i.e. number, letter, and number / letter cancellation in correct order. Outcome is the time required to complete each task.

Selective attention and susceptibility to perceptual interference was measured in the Stroop Color Word Test (SCWT), consisting of three subtasks; color word naming (I), color naming (II) and naming of colot words printed in a different color (interference task III).

The Letter Digit Substitution Test (LDST) is a paper-and pencil task, measuring basic information processing speed.

Word Fluency was scored as the total number of unique animal names correctly reproduced in 60 seconds. The test reflects the organizational level among clusters of meaningful related words.

\section{Morbidity status}

The active and total morbidity status of all participants at the time of cogmitiwe testing was retrieved from the Registration Network database. ICPC morbidity categories with a sample prevalence of $13(=1 \%)$ or more were determined to be used in the analyses, including several 
with potential direct or indirect impact on brain funcrioning: cardiovascular diseases, obstructive pumonary disease, atherosclerotic disease, hypertension, endocrine disorders (such as diabetes and thyroid disease), malignancies, hepatic or renal disease, neurological disturbances, and hearing loss (Colsher \& Wallace, 1991; Tarter et al., 1988). The same procedure was used for total (active + inactive) morbidity, in order to test the potential effecr of relevant health events that in the ICPC coding system may only temporarily be coded as an active problem, e.g. acute myocardial infarction, or brain concussion. The list of all codes that were retained for further analysis is presented in Table 9.1 .

\section{Datad reduction}

To limir the number of dependent variables and to improve the robustness of the underlying cognitive construct, most of the raw test scores were clustered in three compound performance indices, Jabeled memory, cognitive flexibility, and sensorimotor speed. For all participants the raw scores were transformed to standardized $Z$-scores $(z=[x-\bar{x}] / S D) . Z$-scores from tests that were included in each compound performance index were averaged. Thus, the memory score was derived from the total, maximal and delayed recall scores of the WLT, the cognitive flexibility score included the C-version of the CST and subtask III of the SCWT, and sensorimotor speed was calculated from the $0, A$ and B versions of the CST, and subtask I of the SCWTI. Signs of the speed and flexibility scores were inverted to make them reflect above average performance when positive and below average performance when negative. LDST and flutency rest outcones were not included in compound scores as the performance on these tests is fat less dependent on the integrity of one specific cognitive domain.

Several single morbidity codes were uniquely combined in more broad morbidity clusters, including chronic diseases and malignancies (according to Knottnerus, Metsernakers, Höppener \& Limonard, 1992), hearing loss, cardiovascular diseases, cardiac rhythm disturbances, and obstructive pulmonary disease (see aggregated codes in Table 9.1).

\section{Statistical analysis}

Separate linear regression models were fitted for cognitive paramerers, adjusting for age, sex and educational level, using active or total ICPC morbidity codes that were present in at least $1 \%$ of all participanes, using a backward elimination procedure. This procedure was followed for both the active and total aggregated morbidity clusters. All analyses were performed with the SPSS statistical program series. $P$-values of .01 or less were considered to be statistically significant unless indicated otherwise.

\section{RESULTS}

Table 9.1 shows the single and aggregated morbidity categories with an associated prevalence of .01 or higher. It can be readily concluded from these data that discrepancies berween active and total morbidity status depend for a large part on the impace of the disease or complaint on 
Table 9.1. Number of single active (and atal) health problems, by levels of age and sex (total $N=1.360$ ). Only those total morbidiry categories are shown that were present in ar lease $\mathbb{l}$ os of this population and that were used in the regression analyses. Categories of acive morbidity used in the regression analyses (woth an associared $n \geq 13$ ) are marked with an asterisk (3). Aggregated motbidity caregories are displayed in the second half of the rable. Letter digit codes refer to the respective caregory in the ICPC.

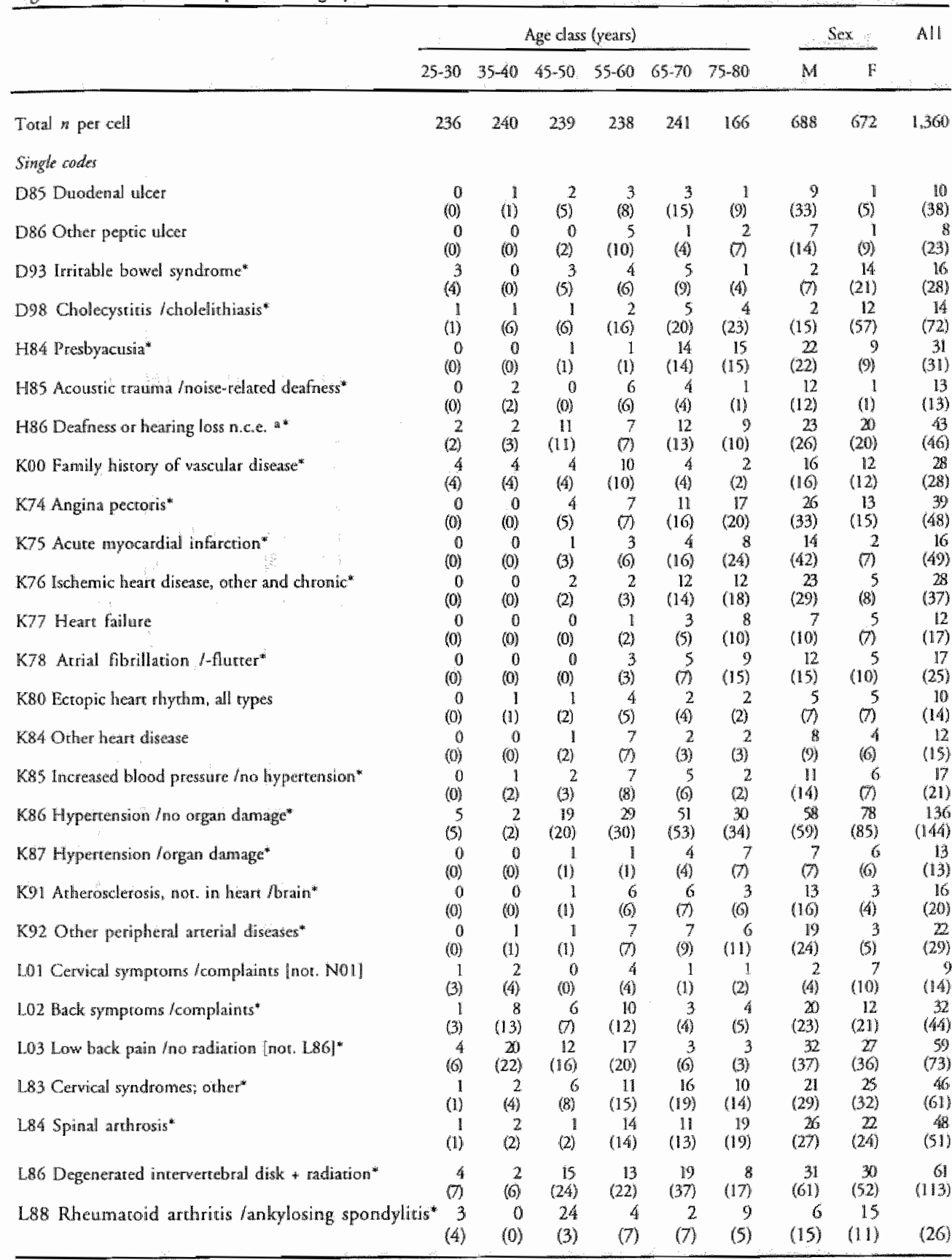

Note. This table is continued on the next page. 


$\frac{\text { Age class }(\text { years })}{25-30 \quad 35-40 \quad 45-50 \quad 55-60 \quad 65-70 \quad 75-80} \quad \frac{\text { Sex }}{\mathrm{M} \quad \mathrm{F}}$ All

\begin{tabular}{|c|c|c|c|c|c|c|c|c|c|}
\hline \multirow[t]{2}{*}{ Not Headache [not. No9/N89/No2/N03] } & 2 & 2 & 0 & 1 & 1 & 2 & 4 & 4 & 8 \\
\hline & $(4)$ & (3) & (2) & (2) & $\begin{array}{l}(4) \\
2\end{array}$ & $(2)$ & (9) & $(8)$ & $(17)$ \\
\hline M02 Tenston hedache & $(5)$ & (8) & $(7)$ & (5) & $(3)$ & $(2)$ & $(15)$ & $(15)$ & $\begin{array}{r}23 \\
(30)\end{array}$ \\
\hline \multirow[t]{2}{*}{ N79 Concussion } & 0 & 0 & 0 & 0 & 0 & 0 & 0 & 0 & 0 \\
\hline & (5) & (4) & (2) & (3) & (4) & (1) & (9) & (10) & (19) \\
\hline \multirow[t]{2}{*}{ N89 Migraine* } & 5 & 8 & 6 & 3 & 4 & 4 & 11 & 19 & 30 \\
\hline & (5) & (10) & (6) & (3) & (6) & (4) & (11) & (23) & (34) \\
\hline \multirow[t]{2}{*}{ P01 Anxious feelings finervousness } & 1 & 9 & 4 & 8 & 9 & 3 & 16 & 18 & 34 \\
\hline & (5) & (10) & (9) & $(10)$ & (11) & (4) & (23) & (26) & (69) \\
\hline \multirow[t]{2}{*}{ P03 Depressive feelings: } & 1 & 1 & 1 & 2 & 3 & 2 & 0 & 10 & 10 \\
\hline & (1) & (5) & (2) & (4) & (5) & (3) & (5) & (15) & (20) \\
\hline \multirow[t]{2}{*}{ P15 Chronic alcohol abuse } & 0 & 3 & $i$ & 1 & 0 & 1 & 6 & 0 & 6 \\
\hline & $(0)$ & (3) & $(5)$ & (4) & (0) & (4) & $(10)$ & (6) & (16) \\
\hline \multirow[t]{2}{*}{ P76 Depressive neurosis* } & 1 & 4 & 2 & 4 & $\mathbb{1}$ & 1 & 4 & 9 & 13 \\
\hline & (3) & (8) & (9) & (12) & (6) & (4) & $(19)$ & (23) & (42) \\
\hline \multirow[t]{2}{*}{ R70 I'ulmonary tuberculosis } & 0 & 0 & 0 & 1 & 1 & 1 & 3 & 0 & 3 \\
\hline & $(0)$ & $(0)$ & (1) & (8) & (7) & (8) & $(20)$ & (4) & (24) \\
\hline \multirow[t]{2}{*}{ R91 Chronic bronchinis /brondhiectisis ${ }^{*}$} & 4 & 3 & 1 & 7 & 8 & 12 & 25 & 10 & 35 \\
\hline & $(5)$ & (7) & (2) & (7) & (8) & (12) & (27) & (14) & $41)$ \\
\hline \multirow[t]{2}{*}{ R95 Emphysema* } & 0 & 1 & 2 & 2 & 6 & 13 & 18 & 6 & 24 \\
\hline & (0) & (1) & (2) & (2) & (6) & (13) & (18) & (6) & (24) \\
\hline \multirow[t]{2}{*}{ R96 Asthma* } & il & 9 & 6 & 10 & 8 & 4 & 33 & 15 & 48 \\
\hline & (12) & $(10)$ & (8) & $(10)$ & (10) & (4) & $(38)$ & (16) & (54) \\
\hline \multirow[t]{2}{*}{ T83 Obesicy* } & 6 & 3 & 5 & 9 & 9 & 8 & 18 & 22 & 40 \\
\hline & (7) & (3) & (6) & (9) & (9) & (8) & (20) & (22) & (42) \\
\hline \multirow[t]{2}{*}{ T85 Hyperthyroidism } & 1 & 1 & i & 2 & 1 & 0 & 1 & 5 & 6 \\
\hline & (1) & (2) & (2) & (5) & (3) & (2) & (2) & (13) & (15) \\
\hline \multirow[t]{2}{*}{ T90 Diaberes mellitus* } & 1 & 2 & 3 & 11 & 12 & 21 & 27 & 23 & 50 \\
\hline & (1) & (4) & (6) & (12) & (12) & (23) & (27) & (31) & $(58)$ \\
\hline \multirow[t]{2}{*}{ T93 Disorder of lipid metabolism } & 0 & 2 & 12 & 22 & 12 & 8 & 28 & 28 & 56 \\
\hline & $(0)$ & $(2)$ & (12) & (24) & (12) & (9) & $(28)$ & (31) & (59) \\
\hline
\end{tabular}

Aggregated cades

Anacmia $[\mathrm{B} 78 / \mathrm{B} 80 / \mathrm{B} 81 / \mathrm{B} 82]$

Pepric ulcers [D85/D86]

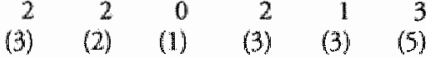

$\begin{array}{lll}0 & 1 & 2\end{array}$

(0) (1) (7)

Hearing loss [H83/H84/H85/H86]

$\begin{array}{lll}2 & 4 & 14\end{array}$

$\begin{array}{rrr}8 & 4 & 3 \\ (16) & (19) & (16)\end{array}$

$\begin{array}{lll}5 & 5 & 10\end{array}$

(2) (5) (14)

$\begin{array}{lll}15 & 30 & 26\end{array}$

$16-(12)$

(17)

Cardiac insuffeciency $[K 77 / K 82]$

$\begin{array}{rrr}0 & 0 & 0 \\ (0) & (0) & (0)\end{array}$

(15) (32) (27)

(45) $(14)$

(59)

Cardiac rhythm disturbances $[K 78 / K 79 / K 80]$

(0) (0) (0)

$\begin{array}{rrr}1 & 3 & 8 \\ (2) & (5) & (10)\end{array}$

$57 \quad 34$

91

(60) (35)

(95)

$\begin{array}{llllll}0 & 1 & 1 & 8 & 9 & 12\end{array}$

75

12

(0) (2) (2)

Cervical syndromes [L01/L83/L84]

36

(5) $(10) \quad(10)$

(10)

(12) (19)

(10) (7)

Lumbar syndrotnes/lumbar hernia [L02/L03/L86]

8

$30 \quad 32$

$27 \quad 20$

(22) (23)

$47 \quad 53$

(56) (65)

(121)

Chronic disease b

$\begin{array}{rrr}52 & 59 & (39) \\ 52 & (14)\end{array}$

$\begin{array}{lll}38 & 25 & 15\end{array}$

$83 \quad 65$

148

(1117) (102) (219)

(66) (77) (99)

(51) (46) (24)

$310 \quad 273$

583

Malignane disease to

(10) $\quad(6) \quad(3)$

(133) (157) (143)

(351) (324)

(675)

Cardiovascular disease :

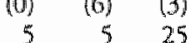

$\begin{array}{lll}5 & 12 & 27\end{array}$

$30 \quad 21$

51

$\begin{array}{llllll}55 & 86 & 78 & 145 & 109 & 254\end{array}$

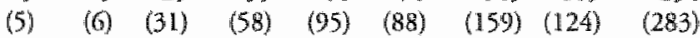

COPD [ [R9 I/RGS/R9G]

$\begin{array}{llllll}14 & 13 & 8 & 19 & 21 & 26\end{array}$

$70 \quad 31$ 
current bealth and physical functioning. For example, prevalence of active and total presbyacusia (H84) is exactly the same, presumably as the impact of age-associated hearing loss for daily functioning is permanent, but consequences of a disease such as angina pectoris (K74) may in fact disappear after initiacion of proper treatment.

All single codes in Table 9.1 $(n=43)$ were entered in the analyses for total morbidity and the codes marked with an asterisk $(n=31)$ were used in the analysis of active morbidity. Table 9.2 displays the results of regression analysis of age, sex, educational level, and specific ICPC-morbidity codes on cognitive outcome variables. The regression coefficients in the first column demonstrate that age and education are highly associated with all cognitive parameters and that women ourperform men on memory, cognitive flexibility and letter / digit copying. Together the variance in performance explained by age, sex, and educational level ranged between $17 \%$ for fluency and $48 \%$ for sensorimotor speed. To illustrate the strong agedependency of the cognitive variables more closely, the differences in standardized cognitive performance scores were calculated for each age category, compared to young adults as a reference group (Figure 9.1). This picture indicates, firstly, that the rate of age-related decline varies over cognitive measures. Thus, performance on self-paced tasks such as fluency and verbal word learning shows a more gradual course as a function of age than performance on the other rasks where speed of performance is the critical factor (cf. the regression coefficients for age in Table 9.2).

Final regression models that include significantly contributing morbidity codes are displayed in Table 9.2, for active (column 2) and rotal morbidity codes (column 3). All morbidity codes that remained in the models were negatively associated with the performance scores. Most consistently diabetes (T90) was associated with lower performance scores on all cognitive parameters, the effect ranging from -.36 times $S D$ in memory score to -.52 times $S D$ in cognitive flexibility score (Table 9.2, collumn 2: acrive morbidity), adjusted for all other factors in the model. Other associations between morbidity codes and cognitive were more sporadic, but consistent in the analyses for both active and total morbidity. Chronic bronchitis (R91) remained in the models for sensorimotor speed and cognitive flexibility. Presbyacusia (H84) was present in the model that was fitted for memory, while cholecystitis (D)8) accounted for variance in the cognirive flexibility score only when coded as total (column 3). Two other morbidity categories coded as total were present in the model fitted for verbal Aluency only: hyperthyroidism (T85) and disturbances in atrial rhythm (K78).

Similar analyses were repeated with the aggregated morbidity codes, as displayed in Table 9.2. For active and total morbidity separately. No single significant relation was found berween these new variables and cognitive performance levels.

Given the strong association between diabetes and cognitive test performance, additional post hoc tests were performed with diabetes as independent variable (coded active), firstly to evaluate a potential age by diabetes interaction, and secondly, to differentiate between associations with cognitive function for insulin- and non-insulin dependent diabetes mellitus (IDDM and NIDDM, respectively). When diabetes and the age by diabetes interaction term were entered in the regression models, no significant interaction was present on any cognitive parameter on a $p \leq .05$ level. This indicates that the association between diabetes and cognitive function is not dependent on age. Then the analysis was repeated after dividing the diaberes 
group in insulin users and non-fisulin users $(n=15$ and $n=35$, mean ages 59.6 (SD 14.9) and $69.9(S D$ 10.1), respectively, $p<.05)$, based on reported information about medication use by the participant (Table 9.3). Except for werbal fuency in the NDDM group, all remaining cognirive ourcome measures were negatively associated with both types of diabetes. Regression coefficients for both types of diabetes were quire comparable in size in all models.

Table 9.2. Resule of regression analyses of demographic variables (after step 1) and active or total morbidity (final models) on cognitive performance measures. Shown are the regression coeffecients $B$ and its standard error, the associated p-value and the total proportion of variance explained $\left(R^{2}\right)$.

\begin{tabular}{|c|c|c|c|c|c|c|c|c|c|}
\hline & \multicolumn{3}{|c|}{$\begin{array}{c}\text { Srep l: } \\
\text { dentographic variables }\end{array}$} & \multicolumn{3}{|c|}{$\begin{array}{l}\text { Final nodel: } \\
\text { active morbidity }\end{array}$} & \multicolumn{3}{|c|}{$\begin{array}{l}\text { Final model: } \\
\text { total morbidity }\end{array}$} \\
\hline & $B \quad(S E)$ & $p$ & $R^{2}$ & $B(S E)$ & $p$ & $R^{2}$ & $B(S E)$ & $p$ & $R^{2}$ \\
\hline \multicolumn{10}{|l|}{ Mernary } \\
\hline Agrea & $.024(001)$ & .00 & & $.022(.001)$ & .00 & & $-.022(.001)$ & .00 & \\
\hline $\operatorname{Sex} 6$ & $.481(043)$ & .00 & & $.472(.042)$ & .00 & & $.777(.042)$ & .00 & \\
\hline Education & $.102(012)$ & .00 & & $.101(012)$ & .00 & & $.101(.012)$ & .00 & \\
\hline To0-Diaberese & & & & $.462(.113)$ & .00 & & $-.439(.105)$ & .00 & \\
\hline H84-Dresbyacusia & & & & $-.374(.143)$ & .01 & & $-.377(.144)$ & .01 & \\
\hline & & & .327 & & & .339 & & & .339 \\
\hline \multicolumn{10}{|l|}{ Semsarimotor speed } \\
\hline Age & $-.027(.001)$ & .00 & & $-.025(.001)$ & .00 & & $.026(.009)$ & .00 & \\
\hline Sex & $.054(032)$ & .09 & & $.045(032)$ & .16 & & $.051(.032)$ & .11 & \\
\hline Education & $.120(.009)$ & .00 & & $.118(, 009)$ & .00 & & $.118(.009)$ & .00 & \\
\hline T90-Diaberes & & & & $-369(.085)$ & .00 & & $-.301(.080)$ & .00 & \\
\hline R91 -.. Chronic bronchütis & & & & $-.338(.100)$ & .00 & & $-.281(.093)$ & .00 & \\
\hline \multicolumn{9}{|l|}{ Coggnitiwe flexibility } & .85 \\
\hline Age & $-.029(.001)$ & .00 & & $-.027(.001)$ & .00 & & $-.027(.001)$ & .00 & \\
\hline Sex & $.103(.036)$ & .00 & & $.092(.036)$ & .01 & & $.114(.036)$ & .00 & \\
\hline Education & $.139(.010)$ & .00 & & $.137(010)$ & .00 & & $.136(.010)$ & .00 & \\
\hline T90-Dialbeters & & & & $-523(096)$ & .00 & & $-.410(.090)$ & .00 & \\
\hline R91 - Chronic bronchitis & & & & $-.369(.113)$ & .00 & & $-.328(.105)$ & .00 & \\
\hline De8 - Cholecystitis & & & & & & &. $.235(.082)$ & .00 & \\
\hline & & & .458 & & & .474 & & & .474 \\
\hline \multicolumn{10}{|l|}{ 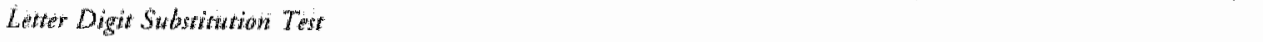 } \\
\hline Agc & $-.033(001)$ & .00 & & $-.033(.001)$ & .00 & & $.033(.001)$ & .00 & \\
\hline $\operatorname{sex}$ & $.135(039)$ & .00 & & $.134(.039)$ & .00 & & $.137(.039)$ & .00 & \\
\hline Education & $.141(011)$ & .00 & & $.142(.011)$ & .00 & & $.142(011)$ & .00 & \\
\hline T90-Diaberes & & & & $-364(.104)$ & .00 & & $-.283(.097)$ & .00 & \\
\hline \multicolumn{9}{|l|}{ Fluengy } & .493 \\
\hline Age & $-.013(.002)$ & .00 & & $-.012(.014)$ & .00 & & $.011(.002)$ & .00 & \\
\hline Sex & $.042(.050)$ & 39 & & $.041(050)$ & $.4 \|$ & & $.052(.050)$ & .29 & \\
\hline Educarion & $.150(.014)$ & .00 & & $.150(.014)$ & .00 & & $.149(.014)$ & .00 & \\
\hline T90-Diaberes & & & & $-.414(.133)$ & .00 & & $-.321(.124)$ & .01 & \\
\hline T85 - Hyperchyroidasm & & & & & & & $-.618(.236)$ & .01 & \\
\hline \multirow{2}{*}{\multicolumn{2}{|c|}{ K78 - Arrial fibrillation/Anuter }} & & & & & & $-.491(.186)$ & .01 & \\
\hline & & & .168 & & & .174 & & & 181 \\
\hline
\end{tabular}

Note a Age is chronological age; b Sex: $0=$ men, $1=$ women; Morbidity codes: $0=a b$ sent, $1=$ present. 

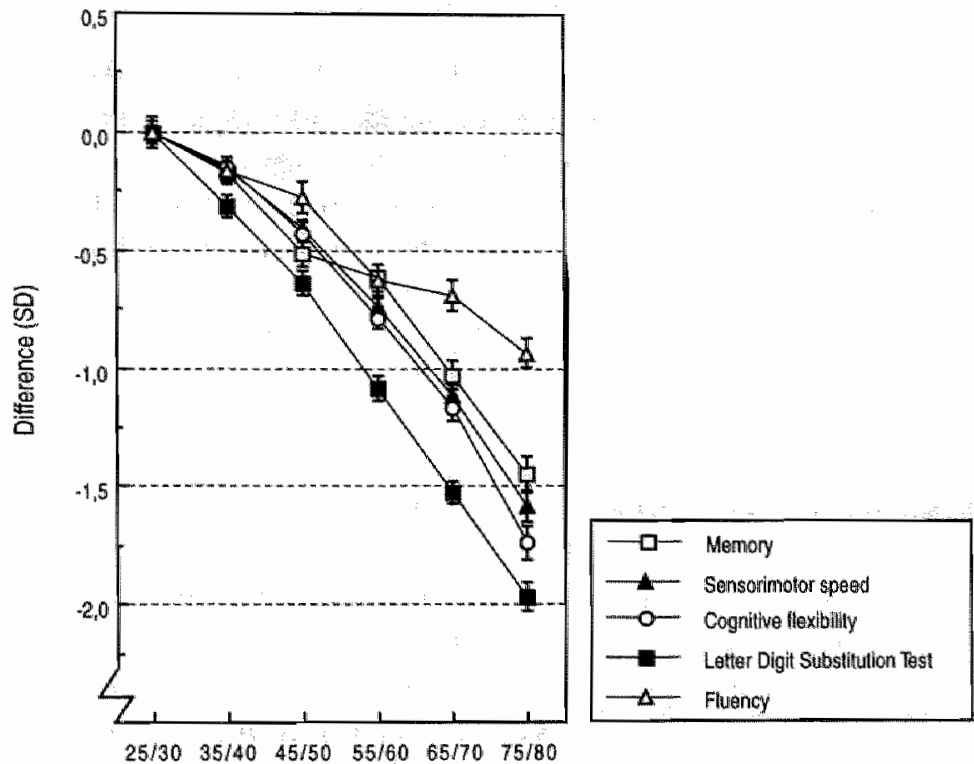

Age class

Figure 9.1. Differences in average standardized cognitive performance scores $(+S E M)$ berween the youngest age class (25-30 years) and each subsequent age class. Speed-G: sensorimotor speed; Speed-C: cognitive fexibility: LDST: Letter Digit Substitution Test.

Table 9.3. Regression of accive insulin- and non-insulin dependent diabetes $(n=15$ and $n=35$, respectively) on cognitive outcome measures: displayed are regression coefficients $(B$, and $S E$ of $B)$ and proportion of explained variance $\left(R^{2}\right)$ after each step.

\begin{tabular}{|c|c|c|c|c|c|c|c|c|c|}
\hline & \multicolumn{4}{|c|}{ Entered on step I } & \multirow[b]{3}{*}{$R^{2}$} & \multicolumn{3}{|c|}{ Entered on step 2} & \multirow[b]{3}{*}{$R^{2}$} \\
\hline & Agea & Sexb & \multicolumn{2}{|c|}{ Education } & & IDDMc & \multicolumn{2}{|c|}{ NIDDM } & \\
\hline & $B \quad(S E)$ & $B \quad(S E)$ & $B$ & (SE) & & $B \quad(S E)$ & $B$ & $(S E)$ & \\
\hline Memory & $-.023(.001)^{* * *}$ & $.479(.042)^{* * *}$ & .102 & $(.012)^{\mathrm{k***}}$ & 327 & $-.505(.202)^{*}$ & -.449 & $(.135)^{* * * *}$ & $.33 \%$ \\
\hline Sens. speed & $-.026(.001)^{* * * *}$ & $.052(.032)$ & .119 & $(.009)^{* * * *}$ & .476 & $-.304(.152)^{*}$ & -.396 & $(.102)^{* .4 *}$ & .483 \\
\hline Cogn flexibility & $-.027(.001)^{* * * *}$ & $.101(.036)^{* *}$ & .139 & $(.010)^{* * * *}$ & .458 & $-.576(.171)^{* * * * *}$ & +.498 & $(.114)^{* * * *}$ & .470 \\
\hline LDSTd &. $.033(.001)^{m+* * *}$ & $.134(.039)^{* * * *}$ & .142 & $(.011)^{* * * *}$ & .491 & $-.442(.1184)^{*}$ & -.330 & $(.123)^{* * *}$ & .495 \\
\hline Fluency & $-.012(.002)^{* * * *}$ & $.043(.050)$ & .151 & $(.014)^{* * * *}$ & .168 & $-.771(.236)^{* * *}$ & -.258 & $(.158)$ & .176 \\
\hline
\end{tabular}

Note a Age is chronological age; $b$ Sex was coded 0 for men, 1 for women; $c$ (N)IDDM: (Non-) Insulin Dependent Diaberes Mellitus; d LDST: Letrer Digit Substitution Test.

$* 0.05 ; * * 0.01 ; * * * \leq .001$. 


\section{DISCUSSION}

Associations between active and total ICPC morbidity, and objective neurocognitive test performance were investigated in a healthy adult population sample. Significant negative associations were found between diabetes and all seudied cognitive domains, and, more sporadically, between presbyacusia and memory performance, and also between chronic bronchitis and performance speed (psychomotor speed and cognitive flexibility). Other single associations were only related to codes of total morbidity, including cholecystitis, hyperthyroidism, and disturbances of atrial thythm. However, related morbidity codes that were aggregated in newly formed clusters did not add to the proportion of explained variance in cognitive measures. Several issues need to be discussed before conclusions can be drawn from these data.

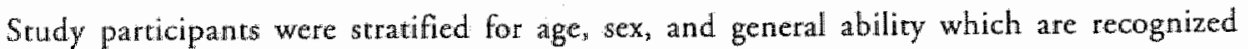
confounding variables in cognitive research. Although demographically this group is not a representative sample of the general population, possible sampling bias due to the stratification procedure was adjusted for by controlling these variables in the regression analyses.

Several specific disease entities that are theoretically important with respect to brain function (e.g. hepatic cirrhosis) were not included in the present analyses as their prevalence did not reach the $1 \%$ level criterion. Potential significant relations of relatively rare diseases with measures of mental efficiency are unlikely to be picked up, because the standard error - and thus the significance - of regression coefficients strongly depends on the number of prevalent cases in the study population. This problem was partially bypassed by combining related morbidity categories in larger clusters, but this procedure inevitably leads to loss of disease specificity.

Two factors which, at least theoretically, can moderate morbidity / cognition relations were not included in our modells because they could not be reliably assessed: disease duration and (the succes of) intervention. Firstly, although it seems fair to expect that the impact of disease on cognitive processes is mediated by the duration of exposure to the disease, it was considered that in most cases the available 'date of diagnosis' by the general practitioner as an inexact indicator of disease duration. In general practice, the date of diagnosis is for a large part dependent on patient and physician related characteristics, that are not associated with the actual onser of a disease process: unless identified as a health problem by one or borh parties a disense may therefore remain undetecred. Secondly, adequacy or success of therapeutic intervention is disease-specific and may nor be defined in a straightforward sense for purposes such as in ihis srudy.

It has been suggested that problems with information processing in patients with a chronic disease are relared to restrictions in functional health (McSweeny et al., 1985). However, not all participants with a chronic disease in this study experience functional limitations in daily life. An explanation for the absence of a relationship in our data between chronic diseases and cognitive function may be found in selective participation of relatively fit and healthy patticipants in this study. This possibility cannot be ruled out encirely, but earlier analyses have shown that participants in MAAS did not differ with the original Registration Network sample with respect to the number of active or total number of morbidity codes Jolles et 
al., 1995). This observation makes a strong health selection bias due to the inclusion procedure less likely.

The observed associations between $\mathbb{C} C \mathrm{PC}$ morbidity and cognitive function in part corroborate earlier findings. Diabetic parients have been found to perform worse on tasks of memory and learning, psychomotor speed and problem solving when compared to healthy controls, possibly due to cerebral changes in blood supply and metabolism, but the affected cognitive domains and the extent of performance deficit vary widely across studies (Biessels, Kappelle, Bravenboer, Erkelens \& Gispen, 1994). Elderly NIDDM patients have repeatedly performed worse than controls on verbal and complex cognitive tasks (Reaven, Thompson, Nahum \& Haskins, 1990; U'ren, Riddle, Lezak \& Bennington-Davis, 1990; Worrall, Moulton \& Briffett, 1993). In this study the domains of verbal memory and information processing speed were also negatively related to diaberes, irrespective of age and insulin-dependency. More importantly, comparison of the regression coefficients for IDDM and NIDDM in Table 9.3 suggests that the strength of association was not substantially different in both types of diabetes. AT first this observation may seem remarkable when disease duration is considered. As was mentioned earlier, reliable information on the duration of disease was not available in this group. Generally, however, IDDM is of the early onset type which would suggest a longer exposure time and consequently more structural organ damage in afflicted subjects, resulting in more cognitive impairment in IDDM than in NIDDM. One possibility is that progression of cognitive functional loss is limited in the early phase of IDDM in young adulthood to middle-age, when the brain has more reserve capacity to compensate for the loss of functional inregrity than the brain in older patients with NIDDM (Satz, 1993), but this explanation remains largely speculative.

Lowered auditory thresholds have been implicated in reduced performance on verbal memory when stimuli are presented acousrically (Rabbitt, 1991). In this study target words were presented visually, to minimize the negative effect of hearing disorders on performance. Still, if older individuals experienced more difficulty in understanding the verbal instruction to a task, the observed negative association between presbyacusia and memory performance may reflect a procedural artefact that needs further consideration.

Interestingly, we did not find relations between single or aggregared cardiovascular morbidity codes and cognitive performance, apart from an isolated single association between word fluency and atrial rhythm disturbances. Other studies have suggested that cardiovascular disease and its risk factors, such as hypertension, may be particularly involved in cognitive decline and dementia (Skoog, 1994; Waldstein, 1995). However, cross-sectional studies with a wide age range such as ours may be biased towards underestimating such associations, as vascular disease is the most important cause of death in middle-aged groups, thereby yielding older groups with different vascular risk profiles.

As this study was performed in participants with no overt signs of a cognitive disorder such as dementia it can be difficult to interpret the clinical relevance of the found associations between several health problems and performance. One way to describe the predictive value of one type of morbidity for cognitive performance - in the absence of age by morbidity interactions - is to express it's impact in terms of another predictor in the statistical model, in this case chronological age. For example, one can calculate the average number of years that 
specific groups of patients are cagnitively older, by taking the ratio between the regression coefficients associated with the morbidity code and with age - in years. Thus, active diaberes in out model adds $-.462 /-.022=21$ years to the cognitwe age with respect to memory function, and $-.523 /-027=19$ years in the case of cognitive flexibility. Even though no direcr inferences can be made regarding causdity, this may seem a rather dramatic notion.

On it more general level, it can be argued that puevalent morbidity does not explain a large proportion of individual differences in cognitive abilities. For example, addirional variance explained after entry of all active morbidity codes ranged from $1.5 \%$ (not significant) to $3.5 \%(p<.001)$, for digit copying and word fluency, respectively. This observation may cast some doubt on the contention that physical health is an important determinant of cognitive aging (Albert, 1993; Elias et al, 1990; Houx \& Jolles, 1994; Houx, Vreeling \& Jolles, 1991; Nolan \& Blass, 1992). The prewalence of many health problems correlates strongly with chronological age (Table 9.1), albeir age itself still remains the most powerful predictor of cognitiwe abilities. Other as yet covert individual characteristics related to age need to be identified to account for this age-associated pool of variance:

In conclusion, the strong negative association berween both IDDM and NIDDM and a broad spectrum of cognitive abilities may warrant careful follow-up of these functions by the playsician in attendance from the time of diagnosis onwards, and should be considered as a possible mediaring factor when cognitive dysfunction is found.

\section{REFERENCES}

Aberr, M. (1993). Neuropsychological and neurophysiological changes in healthy adult humans across the age range. Nextrobiology of Aging, 14,623-625.

Biessels, G. J., Kappelle, A. C., Bravenboer, B., Erkelens, D. W. \& Gispen, W. H. (1994). Cerebral Function in diaberes mellitus. Diabetologia, 37, 643-650.

Colsher, P. L., \& Wallawe, R. B. (1991). Epidemiologic considerations in studies of cognicive function in the edderly Methodology and nondementing acquired dysfunction. Epidemiologic Revieters, 15, 1-27.

Elias, M. I., Elias, J. Wi \& Elias, P. K. (1990). Biological and healdh influences on behaviour. In J. E. Büren \& K. W. Schaie (Eds.), Handbook of the psychology of aging. (3 ed., pp. 79-102). San Dicgo: Academic Press.

Houx, P. J., \& Jolles, J. (1993). Age-related decline of psychomotor speed: Effects of age, brain health, sex, and education. Perceptual and Mosor Skills, $76,195-211$.

Houx, P. I. B Jolles J. (1994). Vulnerability factors for age-related cognitive decline In R. L. Isacson \& K. F. Jensen (Eds.). Toxing in atir and water, (pp. 25 41 ). New York: Plenum Press.

Houx, P. J., Veceling, F. W, \& Jolles, J. (1991). Agewassociated cognitive decline is related to biological life cents. In K. Iqbal, D. R. C. McLachlin, B. Winblad, \& H. M. Wisniewski (Eds.). Aleheimer's diversue: Basic wecharism, diagnosis and therapewic srrategies, (pp. 353-358), Chichester, UK: Wiley.

Jolles, J. Houx, P. J., van Boxtel, M. P. J., \& Ponds, R. W. H. M. (Eds). (1995). Manstriche Aging Sady: Deteminants of cogninive aging. Maastricht: Neuropsych Publishers.

Knotnerus, J. A., Metsemakers, J.s Hoppener, P., Le Limonard, C. (1992). Chronic illness in the communicy and the concept of "social prevalence". Fits ity Practice, 9, 15-21.

Lamberts, H., \& Wood, M. (1987). ICPC. International clasification of primaty care. Oxford: Oxford Universivy Press.

McSweeny, A. J., Grant. I., Heaton, R. K., Prigarano, G. P., \& Adams, K. M. (1985). Relacionship of neuropsychological status to everyday functioning in healthy and chronically ill persons. Journat of Clinical and Experimental Nearapsychology, 7,281-291.

Metsemakers, J. F. M., Hoppener, P., Knotmerus, J. A., Kocken, R. J. J., \& Limonard, C. B. G. (1992). Computerized health information in the Netherlands: A registration nerwork of family practices. British Jourthal of General Practice, 42, 102-106.

Nolan, K. A., se Blass, 1. P. (1992). Preventing cognitive decline. Clinics in Geriatric Medicine, 8, 19-34. 
Poon, L. W. (1985). Differences in human memory with aging: Nature, causes and clinteal implicarions. In J. E. Birren \& K. W. Schaie (Eds.). Handbook of the psyolbology of agings. New York: Yan Nostrund Reintrold.

Rabbitt P. (1991). Mild hearing loss can cause apparent memory failures which incerese wich age and reduce widt IQ. Acta Otolarygrgol Stappl Srock $476,167-176$.

Reawen, G. M., Thompson, L. W., Nahum, D., \& Haskins, E. (1990). Relarionship berween layperglycatmia and cognirive function in older NIDDM patients. Diabetes Care $13.16-21$.

Salthouse, T. A. (1989). Age-rellated changes in basic cognitive processes. In M. Storandr \& G. R. Vandenbos (Eds.). The adults years: Continutity and change, (pp. 5-40). Washington: American Psychological Association.

Salthouse, T. A. (1992). Mechanisms of agercognition relations in adulthood. Hillsdale, NI: Lawrence Erlbatum Associates.

Sacz, P. (1993). Brain reserve capacicy on symptom onser after brain injury: A formulation and review of evidence for treshold theory. Nearapsychology, 7, 273-295.

Slroog 1. (1994). Risk facrors for vascular dementia: A review. Demuentia, 5, 137-144.

Tarter, R. E, van Thiel, D. H., \& Edwards, K. L. (1988). Medical Newropsychology: The impant of diseasse on behourar. New York: Plenum Press.

U"rem, R. C., Riddle, M. C. Lezak, M. D., \& Bernington-Davis, M. (1990). The mental efficiency of the elderly person wirh Type II diabetes mellitus. foranal of the American Geriarrics Society, 38, 505-510.

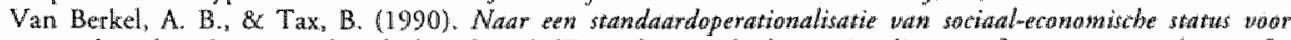
epidemiologisch en socialat-medisch onderzoek /Towards a standard operationalization of socio-econamiond status for epidemiological and socio-economical researeh]. Den Haag: Ministeric van Welzijn "Volksgezondheid en Cultuur.

Waldstein, S. R. (1995). Hypercension and neuropsychological function: $A$ lifetime perspective. Exparimevert Aging Research, 21, 321-352.

Worrall, $G_{n}$, Moulton, N., \& Briffet, E. (1993). Effect of type II diabetes mellitus on cognicive function. Journal of Framily Practice, 36, 639-643.

Writing Committee Lancer Conference. (1996). The challenge of the dementias. Lamot, 347, 1303-1307. 
$\therefore$ का

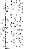

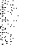




\section{Chapter 10}

\section{Concluding remarks}

In the experimental chapters of this thesis the relationship was assessed berween several distinct health-related factors, such as vascular risk factors, self-reported physical health, prevalent morbidity, and cognitive outcome measures. Some general points should be made before the final conclusions of this research are presented.

\section{Measurement of cognitive finction}

The outcome measures used in this thesis are derived largely from objective tests of cognitive performance that are also common in neuropsychological assessment. Tests were selecred for their sensitivity to chronological age and their established capability to measure subtle group differences or individual changes in performance due to cerebral damage (Jolles, 1985; Jolles, Houx, van Boxtel \& Ponds, 1995). These tests probe a wide range of cognitive abilities but may differ in domain-specificity in that the outcome of a test may express the cumulative efficiency of several different cognitive subsystems. For example, the Stroop Color-Word Test can be used to measure a subject's susceptibility to perceptual interference (Lezak, 1995, pp. 373-376) and can best be regarded as a test of both simple and complex information processing speed (Houx, Jolles \& Vreeling, 1993). However, the time required to complete the complex condition (naming of the ink color of a color word) is also affected to some extent by elementary sensorimotor processes, such as stimullus encoding, response selection, and motor response. As another example, word recall requires some form of attention or concentration to enable adequate encoding, storage, and retrieval of the target words. Thus, it is difficult to make a strict classification of test parameters based on the cognitive domain that is intended to be measured. For most studlies described in this thesis, the large set of avaliable cognitive outcome measures were reduced to yer a few, distinct parameters that provide uniquie information about different aspects of cognitive function. Compound measures for sensorimotor and complex speed were distinguished on the basis of the underlying neuropsychological constructs of each test (LaRue, 1992; Salthouse, 1992, pp. 3-35), as has been applied in related research areas (e.g. Houx, 1991; Elias et alı, 1993). Analogous strategies for datä-reduction are established in psychometrics, for example in intelligence measurement and dinical indices of impairment, such as the Halstead-Reitan Impairment Index (Lezak, 1995, pp. 709-713). However, it cannot be concluded at this point that the method that was used for the reduction of raw data in the present studies is the optimal solution and that other combinations of raw test scores are less valid. For this reason, a confirmatory analysis must be performed, using the total data set of MAAS, in order to determine the discriminant validity of the structure of the compound measures, in accordance with suggestions from the statistical literature (e.g. Walsh \& Betz, 1990, p. 69). 


\section{Limitations of a cross-sectional methodology}

In this cross-sectional phase of the MAAS study, cognitive aging was studied under the assiumption that the varbation in cognitive abilities in successive birth cohorts represent actual cognitive aging trajectories. However, this may well be an oversimplification of the actual aging process, as we deal with age group differences and not with changes occurring over time within a specific age group (Bromley $1920, \mathrm{p} .337$ ). The differences found between successive age groups not only reflect the aging process but also incorporate the effect of cohort membership, in orther words: age and cohort are confounded (Williams \& Klug, 1996). Examples of such cahort effects are secular trends in accessibility of health care or educational facilities, or lifetime exposure to environmental hazards, which all may have repercussions on the integrity of brain function (Satz, 1993). It has been argued that, as the result of this confounding, cross-sectional studies tend to overestimate to some extent the true effect of age on cognition (Schaie, 1988). The scarce longitudinal studies devoted to aging patterns in cognitive function have in fact suggested non-linear relationships between chronological age and cognitive abilities: in these studies most cognitive abilities remain stable or even demonstrate a subtle gain from young adulthood to middle age (Schaie, 1994). Undoubtedly, only longitudinal studies enable examination of the processes of aging as they interact (Schroots \& Birren, 1993), but when such a design is chosen one has to deal with other sources of bias, such as confounding of age with period effects, or selective attrition (Hayslip \& Panek, 1989). Although the limitations of cross-sectional research are well-known, the bulk of our knowledge in the field of cognitive gerontology is based on cross-sectional studies (Bromley, 1990). The strength of the design lies in its potential to generate, within a relatively short time frame, hypotheses about causal relationships which can be tested in a longitudinal study or in subsequent dedicated studies, thereby safeguarding a steady progress in this research domain.

\section{Nature and stability of risk factors}

The studies presented in this thesis are in fact experiments of nature in that one cannot manipulate the individual risk factor level and one has to rely therefore on data from relatively large samples from the population. The hypothesized predictors of cognitive dysfunction that were addressed are proximal in nature, in that they reflect a health-related quality of the individual which is at best valid at the time of the assessment, bur which may be less indicative for the historical (or distal) risk factor profile. For example, generalizability of the habitual physical activity at one point in life to lifetime activity habits is limited, as many influences in the course of a liferime may affect the activity lifestyle. Theoretically, time may be a critical factor in that not only the actual level of a risk factor but also the duration of exposure to the risk factor should be incorporated in an explanatory model of age-related cognitive dechine. Conversely, it seems obvious that reliable information on risk factor starus in the past is extremely difficult or even impossible to obtain. One vallid way to circumvent this problem is to collect information on risk factor status and cognitive function prospectively and to construct indices of risk factor exposure, for example by calculating the area below the risk. factor sratus by time curve (or integrah). 
Another relevant issue when studying predictors of age-related functions is that little is known about the stability of risk factors over time (Fozard, Metter, Brant, Pearson \& Baker, 1993). Thus, risk factors that are present during middle age may have different associations with indices of functional status or disease than those that are present in old age. In some experiments in the present thesis this problem could be partially resolved by performing age-stratified analyses. It seems that, ultimately, only a better understanding of the basic neurobiological mechanism of cognitive aging can refine our research design. Given the current state of our rather patchy knowledge it is not unlikely that risk factors for cognitive decline represent a proxy measure of yet another, basic neurobiological factor that is more directly involved in the pathogenesis of disturbances in brain function. Furthermore, when the relation between health-related variables and cognitive function is studied in a cross-sectional fashion, participation in such a study will depend to some extent on the individual risk factor profile. This may result in cohorts containing relatively large proportions of successfully aging older adults.

An issue related to risk factor stability over time is brought up by recent evidence that vascular risk factor profiles may be different for men and women, particularly post-menopausal women. In a quite recent study by Prince, Lewis, Bird, Blizard and Mann (1996) evidence was found that in a hypertensive sample of 2,584 individuals in the age between 65 and 74 years, who were followed up for 54 months, the decline in performance over time on a test of semantic memory (Paired Associated Learning Test) was more prominent in women than men. If accelerated atherosclerosis after the menopause is the basic reason behind a sex-related differential decline of function this finding may call for sex-stratified analysis when studying cognitive aging patterns in older indiwiduals.

With respect to the present data, the methodological difficulties outlined above cannot be resolved satisfactorily at present. Ultimately, longitudinal data will come available in the MAAS study when the cross-sectional measurements in the same population are repeated after distinct time intervals (chapter 3). This procedure permits the separate assessment of effects related to age, cohort membership and interactions between age and cohort (cF. Nolan \& Blass, 1992). Until that time prudence is called for when inferences are made about patterns of cognitiwe aging on the basis of cross-sectional data only.

\section{Cognitive aging: a statistical model}

The outcome of cognitive test performance may vary as a funcrion of age and educational level - or vocational achievement - and this is why age- and education-graded norms were made available for most accepted neuropsychological tests (Lezak, 1995, pp. 99-101). In addition, even though no overall differences in intellectual ability exist between the sexes, there may be differences in the parterns of ability between men and women (Kimura, 1992). For these reasons it is necessary to control these background variables (or covariates) when studying associations between potential risk factors and cognitive function. This may be achieved by restrictive selection of the study sample, but only at the risk of reducing the external vallidity of the study outcome (Altman, 1991). Another approach is to use statistical controll procedures, as employed in the present studies. A linear multiple regression approach was adopted for 
population samples that were stratified for age, sex, and general ability, in order to assess the unique association of specific independent variables with cognitive outcome measures after the effects of age, sex, and edtacation were accounted for. Thus correlational techniques, such as regression analyses, may be quite informative even if they do not permit inferences about causality. Indeed, it has been argued that linear models are applicable to normal cognitive aging (Salthouse, 1992, p. 12), provided that the study population is free of dementia (Jorm, 1994). In some cases the correlation between predictor and cognitive outcome measure may wary as a function of the level of yer another variable, such as age. For example, as a rule, the impact of disease on functional status can be much more dramatic in older individuals when compensatory mechanisms fail. Under such circumstances one could speak of moderation of the age-cognition relationship by a third variable, in this case health (Baron \& Kenny, 1986) and age-stratified analysis would be the preferred analytic approach. Howewer, when the distribution of a predictor variable is not approximately the same in the different strata - which is true in most of the studies described here - interaction terms can be typically introduced in the regression model to improve the 'goodness-of-fir'.

A slightly different approach is used when one aims at explaining effects of age on cognitive function in terms of intermediate variables, or mediators (Baron \& Kenny, 1986). The central issue of such an approch was rather cloquently stated by Bromley.(1991):

"Chronological age is no more than a convenient tinue marker in terms of which the complex biopsychological causal pathways involved in buman ageing can be compared and related. (...) It is obvious then that what produces the ageing effects we are interested in must be the various biomedical, psychological, social and environmental processes and sequences that occupy time and produce effects that accumulate and interact over time". (Bromley, 1990, p. 318).

Or, as P. Houx (personal communication, March 9, 1996) put it more boldly: "...age is time, and time is nothing...": the generally observed age effect on cognitive outcome measures is an accumularion of effects of covert (age-related) variables that in fact need to be identified. In essence, this notion indicates that in studies of cognitive aging, the proportion of variance in test performance associated with age is not relevant as it is. Rather, the variance should be split up into smaller proportions of variance that each can be uniquely attribured to more specific individual characteristics that are related to the cognitive domain under study and that also show age-dependence (Salthouse, 1992). This would imply that the generally observed relation berween chronological age and cognirive function is mediated by age-related factors that are linked in a more meaningful way than age itself to the chain of meurobiological events that eventually lead to cognitive decline. Figure 10.1 represents the theoretical relationships between age, a mediator variable, and cognitive performance. Venn diagrams depict the total proportion of variance in each variable, which may be shared to some extent with the other variables in the model. Here, the mediator is defined as a variable that is placed berween age and cognition and that in part can explain the relation between these variables (represented by the shared area marked 1 in the figure). In addition, there may be a mediator-independent relation between age and cognition (area 2) or an age-independent relation between the mediator variable and the cognitive parameter (area 3). Analysis of these relarions by using a regression approach implies that, after introduction of a potential predictor (or mediator) 

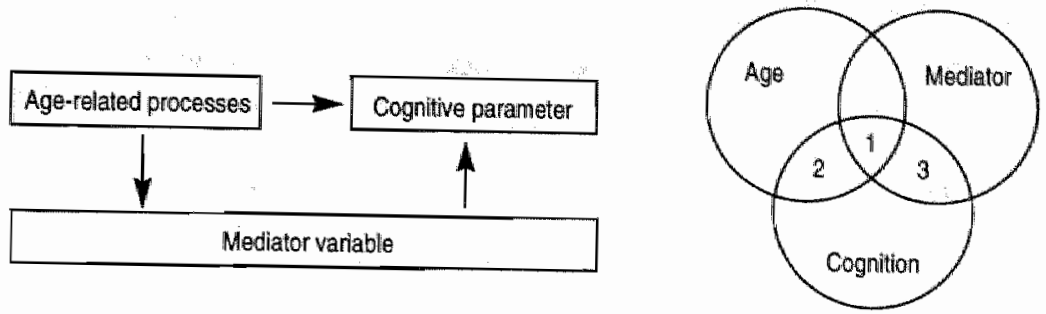

Figure 10.1. Schematic representations of possible relationships between age, mediacor wariable, and measures of cognitive function: an the left the pathways of action by which age-related processes may exert their effect on cognition, on the right the representation of the variance in the three variables with their potential overlap, or shared wariance (see text for the interpretation of the numbered areas; adapted from Saluhouse, 1992).

one should not only inspect the potential increase in variance explained by the regression model - which can be low when the shared variance with chronological age is large - but should also contrast the relevance of the predictor variable with that of age itself, for example by evaluating the (standardized) regression weights. The experimental data presented in the chapters 4 to 9 were therefore analyzed along these lines and are discussed together in the following section.

\section{Towards a synthesis: did we study "mediators of age-related cognitive decline?}

It may be illustrative to express the outcome of the studies presented in this thesis in terms of a mediator model of cognitive aging. A mediator of age-relared cognitive decline was defined above as a variable placed between age and cognitive function with shared variance in both (Fig* 10.1). According to the definition of Salthouse (1992), in order to be a true mediator a variable must firsty at least cotrelate with both age and the cognitive outcome measure. Secondly, the importance of the mediator is reflected in the reduction of the shared variance between age and cognitive function when the mediator is controlled for, which nay be expressed as the percentage of mediator-related variance, or \%MRV). Table 10.1 summarizes information derived from the different studies presented here about the relations berween chronological age and cognitive outcome measures, with and without controlling for the health-related variables under study. Here, these wariables are treated as potential mediators of the age / cognition relationship. To this end, the associations between cognitive parameter and educational level or sex were kept constant.

These data may seem a bit puzzling at first sight, but several interesting inferences can be made from them. Firsty, the correlations between age and mediator variables are in the expected direction, i.e. lower activity level, lower aerobic capacity, higher blood pressure, lower night-time reduction in systolic blood pressure, and presence of diabetes all are associated with older age. Systolic blood pressure and $\mathrm{VO}_{2-\max }$ are highly correlated with age, but this relation is virtually absent for the night-time "dipping" of blood pressure (shared 
Table 10.\%. Corretaton beween nediator and age $(r M A)$ between mediato and cognive oucome

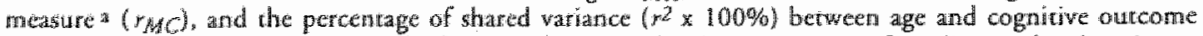

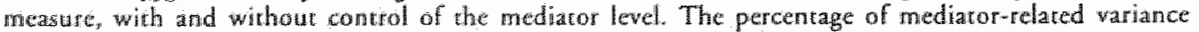

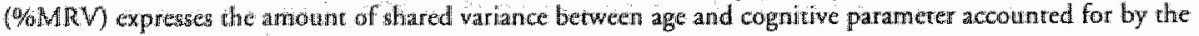
Hediacor.

\begin{tabular}{|c|c|c|c|c|c|c|c|c|}
\hline Medis all or & Chapter & $\begin{array}{r}\text { Total } \\
N\end{array}$ & $\begin{array}{r}\text { Age range } \\
\text { (yedrs) }\end{array}$ & $r_{M}$ & rma & $\begin{array}{l}{ }^{2} A C \\
(\%)\end{array}$ & $\begin{array}{r}F^{2} A C M \\
(\%)\end{array}$ & OMRWD \\
\hline$A P Q$ & 4 & 80 & 55.85 & -.15 & .19 & 34 & 33 & 4 \\
\hline $\mathrm{NO}_{2+\sin }$ & 5 & 132 & $24-76$ & .66 & 47 & 30 & 13 & 57 \\
\hline $5 B P$ & 7 & 936 & $24-81$ & .50 & -28 & 27 & 21 & 23 \\
\hline$\Delta$ daly / night SBP & 8 & 115 & $29-81$ & -.05 & 27 & 12 & 12 & 0 \\
\hline Diaberesc & 9 & 1,360 & $24-81$ & .18 & .21 & 26 & 24 & 7 \\
\hline
\end{tabular}

Notes. APAQ = actual physical activity questionnaire: $V \mathrm{O}_{2 \text { max }}=$ maximal aerobic capacity, corrected for boody fat: $S B P^{x}$ = systrolic blood pressure.

a Outcome measure is cognitive flexibitity, except for day / night difference in systolic blood pressure, where memory was used as being the primary affected measure. All cognitive parameters were adjusted for their association with sex and educational level.

b\%MRV (\% mediator-related variance) is calculated as $100 \times\left(r_{A C}^{2}-r^{2} A C P\right) / r^{2} A C$ where $r^{2} A C$ is the squared xero-order correlation between age and the cognitive variable and $r^{2} A C P$ the squared partial correlation between age and cognitive variable, with the level of predictor controlled for (Hair, Anderson \& Tatham, 1987, pp. 46-47). This is equivalent to $100 \times($ area 1)/ (area 1+2) in Fig. 10.1 (Salthouse, 1992).

" Diabeter coded as $0=$ absent, $1=$ present.

variance is $.0025 \%)$. Secondly, all mediator variables are associated with the cognitive outcome measure in the opposite way compared to age, with shared variance ranging from $4 \%$ (APAQ) to $22 \%\left(\mathrm{VO}_{2-\max }\right)$ : higher values for these variables are associated with poorer performance. Thus, all variables comply to some extent with the basic conditions for being a mediator between age and cognition. When the common variance between age and cognitive measure is inspected, and it becomes clear that this relation is attenuated by controlling for the level of the mediator variable "it can be readily concluded that systolic blood pressure and $V \mathrm{O}_{2-\text { max }}$ are by far the most important mediators, with associated mediator-related variances of 23 and $57 \%$, respecrively. It seems however counterintuitive to regard these two variables as important mediators of age-related cognitive decline as we have demonstrated that no variance in performance is independently explained by blood pressure (not even in an age-stratified analysis, of. chapter 7) and only a small amount is explained by $\mathrm{VO}_{2-\max }$ (chapter 5). Absence of an age-independent association between cognitive function and a mediator with a large mediator-related variance can only imply that all its shared variance with cognitive performance will coincide with that of age and cognition. In fact, any variable which varies systematically with age, such as hair grayness or skin elasticity (correlation $(H)$ with age is .82 and .64, respectively, Anstey, Lord \& Smith, 1996), will to some extent share variance with measures of cogrative function. One important difference between other age-related physiological variables and blood pressure or $\mathrm{VO}_{2-\max }$ is, however, that indirect evidence points to the existence of a causal link between these variables and the integrity of cognitive function, even if this evidence is far from conclusive. True mediation seems less convincing in the absence of independent predictive power of these variables, such as was found for night-time 'dipping" of blood pressure and prevalent diabetes. In our opinion, diabetes has the largest 
potential for being a true mediaror because this condition is directyy related to both age and cognitive function and additionally shows an age-independent relation with cognitive function.

Conversely, night-time dipping of blood pressure was unrelated to age. This seems odd when a blunted night-time dip is considered to be the result of a parhophysiological process. Two explanations are conceivable. First, non-dipping reflects a genetic predisposition, of which the clinical expression is relarively independent of other aspects of physiological aging. Even in the virtual absence of longitudinal tesearch on blood pressure dipping, this possibility seems, however, rather unlikely, because non-dipping is associated with a number of systemic disorders in which it seems at least partially reversible after appropriare treatment (e.g. pheochromocytoma or Cushing's syndrome, Pickering, 1991, pp. 5.9-5.10). The second possibility is that non-dippers make up a distinct risk category of individuals who may develop disease relatively early in life, which reduces their ability or eligibility to take part in a cross-sectional aging study like MAAS, thus causing selection bias. For now the latter explanation seems the most plausible, because this type of bias is the major source of error variance in any developmental study using a cross-sectional design (Hayslip \& Panek, 1989).

The issue of mediation of age effects on cognitive function by means of factors related to vascular disease cannot be resolved satisfactorily using a cross-sectional study design. For our purpose a longitudinal approach will bypass several sources of bias, including the confounding of age and cohort, but only then if other typical sources of bias such as selective attrition and confounding of age with period effects can be adequately accounted for. It may be expected that only repeated measurement of cognitive function in association with assessment of the risk factor profile in the same population can ultimately demonstrate true causal mechanisms at work in mediator (or moderator) models of cognitive aging.

\section{Implications of current findings for health care and future research}

As mentioned earlier, the cross-sectional nature of the present data does not permit straightforward inferences about cause-and-effect relationships. With respect to an intermediary role of the studied risk factors in the age-cognition relationship, it can be concluded that cross-sectional data may at best suggest true mediation. Longitudinal follow-up of this population and, in particular, a more basic knowledge about the neurobiological mechanisms of associations berween risk factor and integrity of brain function, is essential to substantiate these notions. The associations found between healeh-related factors and cognirive outcome measures will particularly direct the focus of research in the longitudinal phase of the MAAS project, when the predictors of actual performance today may prove to be the true mediators of decline in performance at follow-up.

Evidence was found that aerobic finess is positively related to the speed of information processing in healthy adults. This indicates that older individuals may benefit from training programs that aim at improving the lewel of aerobic fitness by expanding their functional brain reserve capacity. It seems unlikely that the definite study to underpin this assertion will ever be performed, due to the high costs, large effort and procedural difficulties associated with a large-scale and long-term intervention program. However, a larger cognitive decline at follow-up in the less active or aerobically less fit individuals, compared to an attenuated 
pattern of decline in theit fit age peers, will be in line with our prediction. Until then, we believe that the advocacy of training programs to improve aerobic fitness in older individuals for the sole reason to slow down cognitive decline is not sufficiently grounded. The importance of such measures which are intended to aneliorare the quality-of-life is probably much larger in other functional domains, such as those related to the locomotor and cardiovascular system - provided that they ate implemented under expert supervision to minimize the risk of health. hazards.

It whs shown that the within-subject variability of blood pressure varies considerably as a function of age. This finding has practical implications for the clinical assessment of blood pressure status. As a rule, the blood pressure level in older subjects will be overestimated when the relatively strong adaptation of blood pressure over time in these individuals is not taken into account, and one relies on a limited number of measurements during a patient contact. Overdiagnosing hypertension will lead to unnecessary drug therapy in older individuals, which in turn could enhance latrogenic disorders in this relatively vulnerable group, such as episodes of hypotension, or falls. We suggest to rely therefore not only on repeated measurements of blood pressure but also to consider the measurements taken after a 10-15 minute interval as the only reliable estimates of the habitual blood pressure. In general practice, where patient contacts are of relatively short duration, this guideline may be impractical to implement for screening purposes. We cherefore advocate a more widespread use of reliable automatic recording devices in this particular setting, which has the additional advantage that the probability of erroneously high readings due to a pressor response in some individuals is substantially reduced.

Associarions berween blood pressure or other vascular risk factors (body mass index, waist-to-hip ratio, smoking) and cognitrive performance were absent, which casts doubt on the role of these factors in the normal cognitive decline seen with increasing age. Still, repeated assessment of the vascular risk factor profile at follow-up will provide important information about the evolution of risk facror status in relation to cognitive functioning. For example, it has been demonstrated that prolonged exposure to vascular risk factors such as hypertension may well be associated with lower performance levels, even when they are the non-pathological range of cognitive funcrioning (chapter 7). This makes it worthwhile to continue the assessment of the risk factor profile at the follow-up measurements in MAAS.

It was demonstrated that attenuation of the physiological 'dipping' of blood pressure - an established risk factor for target organ damage in hypertensive patients - was quite specifically related to lower performance on memory rests. As mentioned earlier; this finding should be reassessed in an independent sample, but may point at a specific category of individuals who are at risk of accieletated decline. The independence of the day-time / night-time blood pressure difference of mean average day-time blood pressure needs to be examined more closely. More specifically, a case-control study in hypertensive an normotensive individuals that includes neurocognitive assessment, 24-hour ambulatory blood pressure monitoring and brain-imaging (MRI) can provide essential information in this respect. A study of this kind is projected in the course of 1997, in collaboration with the Department of Internal Medicine of the Uniwersity of Masstricht. 
Borh insulin-and non-insulin-dependent diaberes were negatively associated with indicators of cognitive function, while other existing morbidity in the participants was not. It has been suggested that the negative effects of diabetes on higher corrical processes are primarily of vascular origin. It remains unclear which aspects of the disease are most relevant in the etiology of cognitive dysfunction. To this end, a prospective study is needed in diabetes parients and age-marched controls that incorporate comprehensive assessment of both neurocognitive function and disease evolution, such as disease control, target organ damage, and therapy adherence. Such a study is currendy prepared for the near future as a sidearm project of MAAS.

\section{REFERENCES}

Altman, D. G. (1991). Practical statistics for medical research. (1st ed.). London: Chapman \& Hall.

Anstey, K. J., Lord, S. R. \& Smith, G. A. (1996). Measuring human functional age: A review of empirical findings. Experimental Aging Research, 22, 245-266.

Baron, R. M., \& Kenny, D. A. (1986). The moderator-mediator variable distinction in social psychological research: Conceptual, strategic, and staristical considerations. Joumal of Personality and Social Psychology, 51 . 1173-1182.

Bromley, D. B. (1990). Behavioural Gerontology: Central issues in the psychology of ageing. Chichester (UK): John Wiley \& Sons.

Elias, M. F., Wolf, P. A., D'Agostino, R. B., Cobb, J.\& \& White, L. R. (1993). Untreated blood pressure level is inversely related to cognitive functioning: The Framingham Study. American fourval of Epidemiology. 138 , 353-364.

Fozard, J. L., Metrer, E. J., Brant, L. J. Pearson, J. D., \& Baker, G. T. (1993). Goals for the next generation of longitudinal studies. In J. I. F. Schroots (Ed), Aging, hexhlth and competewe, (pp. 35-52). Amsterdam: Ellsevier.

Hair, J. E., Anderson, R. E., \& Tatham, R. L. (1987). Muttivariate data analysis. New York: Macmillan.

Hayslip, B., \& Panek, P. E. (1989). Adult developement and arging. New York: Harper \& Row.

Houx, P. J (1991). Cogritive aging and health related factors. Doctoral Thesis, Uniwersity of Maastricht.

Houx, P. J., Jolles, J., \& Vreeling, F. W. (1993). Stroop interference: Aging effects assessed with the Stroop ColorWord tesc. Experimental Aging Research, 19.209-224.

Jolles, J. (1985). Early diagnosis of dementia: possible contributions from neuropsychology. In W. H. Gispen \& J. Traber (Eds.), Aging of the brain, (pp. 84-100). Berlin: Springer.

Jolles, J., Houx, P. J., van Boxtel, M. P. J. \& Ponds, R. W. H. M. (Eds.). (1995). Maastricht Aging Study.

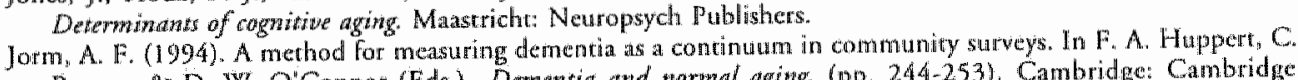
Brayne, \& D. W. O'Connor (Eds.), Dementia and nomanal aging, (pp. 244-253). Cambridge: Cambridge University Press.

Kimura, D. (1992). Sex differences in the brain. Scientiffe Americton, 267, 81-87.

LaRue, A. (1992). Aging and neuropsychological assessment. New York: Plenum Press.

Lezak, M. D. (1995). Nenropsychological Astessment. (3rd ed.). New York: Oxford Uniwersity Press.

Nolan, K. A., \& Blass. J. P. (1992). Prewenting cognitive decline. Clintics in Geriatric Medicine, 8, 19.34.

Pickering, T. G. (1991). Ambulatory monitoring and blood pressure tariability. London: Science Press.

Prince, M., Lewis, G., Bird, A., Blizard, R. \& Mann, A. (1996). A longitudinal study of factors predicting change in cognirive test scoress aver time, in an oider hypertensive popularion. Prychological Medicine, 26, 555-568.

Salthouse, T. A. (1992). Mechanism of age-cognision relations in adulthood. Hillsdale, NJ: Lawrence Erlbatum.

Satz, P. (1993). Brain reserve capacity on symptom onser after brain injury: $A$ formulation and review of evidence For treshold theory. Newropsychology, 7,273-295.

Schaie, K. W. (1988). Internal validity threats in studies of adult cognitive developement. In M. L. Lowe \& C. J. Brainerd (Eds.). Cognitive development in adulthood. New York: Springer Verlag.

Schaie, K. W. (1994). The course of adult incel lectual development. Ameritan Pyothologist, 49, 304-313.

Schroots, J. J. F., \& Birren, J. E. (1993). Theorenical issues and basic questions in the planning of longitudinal studies of health and aging. In J. J. F. Schroots (Ed.), Aging bealth and competence, (pp. 3-34). Amsterdam: Ellsevier.

Walsh, W. B., \& Betz, N. E. (1990). Tests and assessment. (2nd ed.). Englewood Cliffs, NJ: Premtice-Hall.

Williams, J. D., Klug, M. G. (1996). Aging and cognition: Mechodological differences in outcome. Experimental Aging Research, 22, 219-244. 



\section{Summary}

A decline in cognitive abilities, such as memory or speed of information processing, is usually considered to be an inevitable aspect of the aging process. Recent research has shown that risk factors or protective factors can be identified in so-called pathological cognitive decline - e.g. dementia - that could mediate the onset of cognitive symptomatology. However, little is known about the normal or usual decline of cognitive funcrion with age: which funcrions deteriorate, is the rate of decline the same for different functions, and which differences exist between individuals that could explain differential aging patterns?

This thesis deals with individual differences in cognitive ability that are either directly or indirectly related to the health status. It is investigated if these differences can explain the variance in cognitive funcrioning that can be observed in the general population and that tends to increase with age. Particular emphasis is put on factors which are generally related to the condition of the vascular system.

Chapter 1-This introductory chapter provides the rationale of the research described in this thesis and outlines the contents of the different subjects at stake.

Chapter 2- The concepts of age, bealth, and cognition are defined and the relation between these concepts is reviewed on the basis of previous research. Different, as yer hypothetical, forms of cognirive aging are described: primary or successful aging, characterized primarily by ageintrinsic factors laid down in the genome; usual aging, in which pathological deficiencies exist in addition to intrinsic factors; secondary or pathological aging, where aging effects are enhanced by physical disease; and finally tertiary aging, which is characterized by superimposed funcrional loss as the result of terminal illness. The borderline berween usual and pathological aging is explored: from a medical perspective a sharp distinction is often made between an age-congruent decline of cognitive functions and pathological states, such as in dementia. The theorerical model of brain reserve capacity (BRC) rather assumes a maximal cognitive processing capacity that is determined primarily by genetic and environmental factors. According to this model, cognitive aging can be understood as a gradual transition of normal cognitive function, in which functional compensation of structural damage to the substrate (the brain) is still possible, towards pathological function when the point is reached that compensatory mechanisms fail.

The second part of chapter 2 reviews the available literature on the potential role of vascular risk factors in cognitive aging. Elevated blood pressure, or hypertension, and physical fitness, or aerobic activity / capacity, have in particular been tested with varying success for a relationship with cognitive variables in normal aging populations. However, the methodological differences and deficiencies in these studies do not permit a clear judgement of the detrimental or protective effects of these factors for brain function.

Chapter 3 - The Maastricht Aging Study (MAAS) provides the scientific framework for all studies deseribed in this thesis. Rationale and methodology of MAAS are presented in chapter 3 . The core program of MAAS is made up by a cross-sequential study in nearly 2,000 
individuals aged between 24 and 81 years. These subjects were recruited from a patient register of collaborating general practioners in the Mastricht region (Registrarion Network Family Practices, or RNH, in Dutch). The study population was stratified for age (12 discontinuous age dasses berween 23 and 82 years at baseline), sex, and level of occupational achevement as an index of pemorbid functioning. MAAS intends to followup all participants for 12 years, at 3 or 6 year intervals depending on age. The most important goal of this research program is to find an explanation for differences between the individual trajectories of cognitive aging. More specifcally; it addresses the relationship berween health-related factors, psychosocial factors, and cognitive outcome measures. On finalization of this thesis, the dara collection and analysis of threequarters of the fint, cross-sectional measurement had been completed.

Chapter 4 - In prewous studies a relationship was observed between the degree of habirual physical activity and the performance on primarily speeded cognitive tasks. The supposed mechanism behind this relationship is an increase in cerebral oxygen supply, or a direct stimulation of brain areas related to sensorimotor function, als the direct result of physical training. Chapter 4 describes the results of a study in 80 healthy individuals aged 55 years and older dealing with the relationship between habitual physical activity and cognitive functioning. For this purpose, an activity questionnaire was used that was designed for use in older populations and which reflects the habitual activity level (including sports) in terms of daily caloric expenditure. In addition, a questionnaire was used to probe the experienced health of all participants. Aging effects were found on measures of cognitive speed, but not on verbal memory. Women performed worse on an index of simple sensorimotor speed than men, but were better on memory. No direcr relation was found between physical activiry and cognirive test performance. However, activicy did interact with age on both measures indexing cognitive speed, and the levell of experienced health was positively related to the same speed measures. The latter observacion confirms the relevance of general health for cognitive function. The absence of a uniform relacionship between activity and cognition may be the result of a relatively small wariance of activity level and rhe abovemaverage mean level of activity in this sample, Other possible causes for not finding a relationship are discussed.

Chapter 5 - A more direct measurement of physical fitness is the determination of the maximum aerobic capacity $\left(\mathrm{VO}_{2-\max }\right)$. In the first $\mathrm{MAAS}$ panel study, $\mathrm{VO}_{2 \text { max }}$ was derermined in 132 participants in the age between 24 and 76 years. Participation in this additional protocol was on a voluntary basis, but to limit the health hazard, individuals with significant cardiovascular or musculoskeletal complaints or disorders were not admitted. Participants were engaged more hours per week in sporting activities and judged their general health better than non-participants. After correction for age, sex, and the level of general intelligence, a small increase in explained variance in performance was observed when $\mathrm{VO}_{2 \text {-max }}$ w corrected for far-free mass - was introduced in the regression models. This was observed for both speed measures that, when combined, constitute the cognitive flexibility score (letter / digit wersion of the Concept Shifting Test, and color / word interference of the Stroop tesit). No relationship was found between memory performance and $\mathrm{VO}_{2-\max }$. The relation between measures of information processing speed and aerobic capacity may implicate a protective 
effect of physical fitness on cognitive function, ewen though the observed associarions were modest."

Chapter 6 - High blood pressure is an important risk factor for cardiovascular and cerebrovascular disease. Determination of the habitual blood pressure level is often hampered by several methodological pirfalls. The outcome of casual (sphygmomanometric) blood pressure measurement varies considerably within individuals and between observers. The candiovascular orienting response that is observed on blood pressure measurement does not seem to habituate in some individuals, a phenomenon sometimes referred to as white cont ffect because the presence of an observer generally is the causative factor. As a preparatory step in advance to the studies described in chapters 7 and 8 in which the relevance of blood pressure status for cognitive function is the key issue, this chapter describes which demographical variables may affect habituation of repeatedly measured blood pressure under standard laboratory conditions and what should be regarded as the optimall estimate of the habitual blood pressure level. For this purpose, blood pressure was measured 5 times within 20 minutes in all 469 participants of the first panel study, in the absence of an observer. Habituation of both systolic and diastolic blood pressure within the 20 minute period was clearly more outspoken in the older age groups. On a group lewel no further decrease of blood pressure was observed after 15 minutes. From these findings it can be concluded that the importance of an adequate rest period (and possibly also habituation to the measurement itself) preceding the blood pressure measurement in older individuals should not be underestimated. In addition, the outcome of automatic blood pressure measurement was compared with average day-rime and night-rime blood pressure levels in a subgroup of 135 participants. The relatively low concordance between these parameters (weighed Kappa 0,42-0,51) indicates that, in spite of standardization of measurement, the outcome of laboratory measurement gives only a limited indication of the average blood pressure level in daily life.

Chapter 7 - In the first two panel studies $(N=936)$, the habitual blood pressure and other vascular risk factors (smoking habits, alcohol consumption, body mass index, and waist-to-hip ratio) were related to cognitive outcome measures. Blood pressure and other risk factors did. not explain additional variance in cognitive performance, after control for age, sex, and educational level, both in the total group and in the group without cardiovascular diseases or antihypertensive medication usage $(n=720)$. Stratified analyses within four age classes $(25-35$. $40-50,55-65$, and $70-80$ years) did not reveal an association between blood pressure and cognitive function. It is concluded that in this population in which in general the rreatruent of hypertension is pursued with great vigor, the relation between blood pressure status and cognitive function is of no true dinical relevance.

Chapter 8 - In this chapter the focus is on cognitive outcome as a function of ambulant blood pressure level (mean day-rime and night-time pressure, and the day/night pressure difference) in participants of the 24-hour blood pressure measurement protocol. The absence of the physiological nocturnal decrease in blood pressure was considered to be an additional risk factor in this respect. It has been demonstrated repeatedly in patients with hypertension that 
now-dippers show more frequent and more exrensive end organ damage - including the brain. Day-the and night-time mean blood pressure levels were unelated to cognitive parameters, in line with earlier findings wirh respect to laboratory blood pressure (chapter 7). However, the difference between day-time and night-time blood pressure was highly predictive for werbal memory function $(8-9 \%$ of unque variance explained in memory performance): non-dippers performed clearly worse than dippers, even after control of vascular morbidity and medication usage. This finding may implicate that an attenuated or absent nocturnal blood pressure decrease is related to a quite specific cognitive deficit. However, the mechanism underlying this relationship remains as yet uncertain and replication of this finding in an independent sample is necessary.

Chapter 9 - Prevalent diseases as recorded by the general practitioner are related with the cognitive outcome measures. Of all participants in the first three panel studies $(N=1.360)$, the information on existing health problems, which were identified in the patient record according to a strict classification system, were anonymously linked to the test data. Morbidity thar was. present in at least $1 \%$ of the population as active or inactive health problem, was tested in separate regression analyses for an association with cognitive function, after correction for demographical background characteristics. Both insulin dependent and non-insulin dependent diabetes mellitus was strongly predictive for lower performance within all investigated cognitive domains: the strength of the association was in some models comparable to adding 20 years to the chronological age. Furthermore, chronic bronchitis was negatively associated with simple and complex cognitive speed, and presbyacusia was related to lower memory performance. Remarkably, apart from diaberes no vascular disorders such as hypertension or coronary heart disease contributed to the explanation of wariance in the different regression models.

Chapter 10-Several basic methodological assumptions that are at the basis of these studies are discussed in more detail. In is argued that age as such cannot explain age-related deterioration of cognitive decline, but instead it is important to identify those factors, or mediators, which can explain, ar least party, the strong relation between age and cognitive function. When the findings from the different studies described in this thesis are brought together, it becomes clear that a relationship beween age and vascular risk factor on the one hand and berween cognitive performance and risk factor on the other does not always imply that such factor mediates the relationship berween age and cognition. Indeed, it is argued that a potential mediator should always explain variance in cognitive performance independent of age itself.

All findings from MAAS are to date cross-sectional in nature. The issue of causalicy can only be addressed in the longitudinal phase of this research program. 


\section{Samenvatting}

Doorgaans wordt de achteruitgang van cognitieve vaardigheden, zoals geheugenfunctie en de snelheid warmee complexe informatie wordt verwerkt door her brein, beschouwd als cen onvermijdelijk gevolg van het verouderingsproces. Wranneer gekeken wordt naar pathologische cognitieve achteruitgang, zoals bij het dementiesyndroom, wordt het steeds duidelijker dat er risicofactoren of juist beschermende factoren in het spel kunnen zijn die de kans op het vroeg ontstaan van een dergelijke stoornis kunnen beïnloeden. Over de gangbare achteruitgang van cognitieve functies is echter relatief weinig bekend: om welke functies gaat het precies, gaan deze allemaal achteruit met het ouder worden, en zijn er verschillen tussen individuer die kunnen verklaren dat sommige mensen nauwelijks achteruitgang ondervinden terwijl anderen juist al vroeg cognitief oud lijken te worden. Dit proefschrift handett over individuele werschillen in cognitief functioneren welke direct of indirect te maken kunnen hebben met verschillen in de gezondheidstoestand. Onderzocht wordt of deze verschillen een verklaring kunnen bieden voor de spreiding in cognitief functioneren die in de populatie wordt gevonden en die lijkt toe te nemen met het ouder worden. In het bijzonder wordt onderzocht de rol wan factoren die samenhangen met de toestand van het vasculaire systeem, zoals lichamelike fitheid, bloeddrukstarus, en suikerziekte.

Hoofdstuk. I - In dit inleidende hoofdstuk wordt de rationale van het beschreven onderzock uiteengezet en wordt een overzicht gegeven van de verschillende onderwerpen die in dir proefschrift aan de orde komen.

Hoofdstuk 2 - In het eerste deel wordt een overzicht gegeven van wat doorgaans onder de begrippen leeftijd, gezondheid, en cognitie verstaan wordt en wordt geprobeert de verbanden hiertussen te inventariseren aan de hand van eerder onderzoek. Verschillende, vooralsnog hypothetische, vormen van cognitieve veroudering worden beschreven: primaite of succesvolle veroudering, die voornamelijk wordt bepaald door leefrijds-intrinsieke factoren zoals vastgelegd in het genoom, de gangbare veroudering, waarbij bovenop de intrinsieke factoren niet-pathologische deficiënties kunnen bestaan, secundaire of pathologische veroudering, walar verouderingseffecten versterkt worden door lichamelijke aandoeningen, en tertiaire veroudering tenslotte, waarbij er sprake is van gesuperponeerd functieverlies als gevolg van terminale ziekte. Het grijze overgangsgebied tussen de gangbare en pathologische veroudering wordt verkend: het medisch model maakt doorgaans een scherp onderscheid tussen leeftijd-congruente achteruitgang van cognitieve funcries en pathologische vormen zoals in dementie. Het theoretische model van hersenreservecapaciteit (brain reserve capacity, of $\mathrm{BRC}$ ) veronderstelt dat er veeleer sprake is van een door genetische factoren en omgevingsfactoren bepaalde maximale cognitieve verwerkingscapaciteit. Volgens dit model is cognitieve veroudering een graduele overgang van normale cognitieve functie, waarin compensatie van structurele schade aan het substraat, i.c. de hersenen, nog mogelijk is, naar pathologische functie wanneer het punt wordt bereikt dat compensatiemechanismen ontoereikend worden.

Het tweede deel van dit hoofdstuk behandelt de beschikbare literatuur aan de hand waarvan de mogelijke rol van vasculaire risicofactoren in cognitieve veroudering verduidelijkt wordt. In 
bet verleden zijn met name een verhoogde bloeddruk (hypertensie) en lichamelijke fitheid (gemeten als aerobe activiteit, c.g. capaciteit) met wsselend resultat onderzocht op een samenhang met cogniteve varibelen in nomal yerouderende populaties. De methodologische verschillen tussen en onvolkomenheden in deze studies laten echter niet alcijd cen duidelijke wirspratk toe over de schadelijke, dan wel beschermende effecten van deze factoren voor de hersenfunctic.

Hooflswh 3 - De Mastricht Aging Study (MAAS) vormt het kader waarbinnen het onderzoek zoals beschreven in deze thesis is uirgevoerd. De rationale en methodologie wan MAAS wordt in dit hoofdstuk beschreven. Het basisprogramma van MAAS wordt gevormd door een crosssequentiele studie in bijna 2.000 personen in de leeftijd tussen 24 en 81 jaar. Deze personen werden gerectuteed uit een patientenregister van samenwerkende geacademiseerde huisartspraktijken in de regio Maastricht (Registratienet Huisartsprakrijken, of RNH). De onderzoekspopulatie werd gestratificeerd nar leeftijd (12 discontinue leefrijdsklassen tussen 23 en 82 jaar bij aanvang wan her onderzoek), sexe en her niveau van beroepsmatig functioneren, als index woor her premorbide functioneren. Het ligt in de bedoeling deze populatie gedurende 12 jaar in de tijd te volgen met follow-up intervallen die afhankelijk zijn van de leeftijd bij aanvang; iedere drie jaar voor personen van 49 jaar en ouder, iedere zes jaar bij personen jonger dan 49 jaar. De belangrijkste wraag in dit onderzoeksprogramma is welke factoren verantwoordelijk kunnen zijn voor de wargenomen verschillen in de wijze warop en de mate warin men cognitief veroudert. In het bijzonder is het onderzoek gericht op de samenhang tussen gezondheids-gerelaterde factoren, psychosociale factoren en cognitieve prestatiematen. In dit proefschrift wordt gerapporteerd over de resultaten uit de eerste drie wan in totaal vier panelstudies waruit MAAS bestaat.

Hoofdstuk 4-In eerder onderzoek is een verband gelegd tussen de mate warin men lichamelijk actief is en de prestatie op cognitieve tests, vooral wanneer deze op snetheid gebaseerd zijn. Het veronderstelde nechanisme hierbij is dat als gevalg van de lichamelijke training de cerebrale zuurstofvoorziening verbetert, dan wel dat raining een direct stimulerend effect heeft op hersendelen die berrokken zijn bij de sensomotoriek. Dit hoofdstuk beschrijft de resultaten van een studie naar de relatie tussen habituele lichamelijke activiteit en cognitief functioneren its 80 gezonde personen van 55 jaar en ouder. Hiertoe werd gebruik gemaakr van een special voor ouderen ontwikkelde vragenlijst, warmee de totale lichamelijke activiteit van alledag - waronder sport - kan worden omgerekend naar een index van het calorische verbruik als gevolg van deze activiteit. Tevens werd een vragenlijst afgenomen naar het subjecrieve gezondheidswelbevinden van de deelnemers. Leeftijdseffecten werden gevonden op de cognitieve snelheidsmaten, maar niet op het verbaal geheugen. Vrouwen scoorden lager op de index voor simpele snelheid dan mannen, maar hoger op verbaal geheugen. Er werd geen direct werband gevonden russen lichamelijke activiteit en cognitieve testprestatie. Wel bleek activiteit te interacteren met leefrijd op de twee cognitieve snellheidsmaten, en was de mate watarin men zichzelf als gezond beschouwde posit ief gecorreleerd aan dezelfde snelheidsmaten. Met deze latste observatie lijkt het belang van gezondheid voor cognitieve functie opnieuw bewestigd. Het ontbreken van een verband tussen activiteir en cognitie kan samenhangen met de 
relatief geringe spreiding in deze parameter en het hoge gemiddelde niveau van activiteit in deze groep. Andere mogelijke oorzaken voor het niet vinden van een verband worden besproken.

Hoofdstuk 5 - Een meer directe meting wan de lichamelike fitheid is het vaststellen van de maximale aërobe capaciteit ( $\mathrm{VO}_{2 \text { max }}$ ). Deze werd bepaald in een submaximal fietsergometerprotocol bij 132 deelnemers an de eerste panelstudie van MAAS, in de leefijd tussen 24 en 76 jaar. Men nam vrijwillig deel aan dit anvwllende onderzoek, waataan overigens ter beperking van het gezondheidsrisico alleen personen mochten meedoen zonder significante cardiovasculaire klachen of aandoeningen, of problemen met het bewegings-apparatat. Deelnemers besteedden in vergelijking met niet-deelnemers gemiddeld meer uren per week aan sporbeoefening en bleken de eigen gezondheid als beter te beoordelen. Na correctie voor de effecten van leeftijd, sexe en algemeen intelligenrieniveau werd een toename van verklaarde variantie gevonden na introductie van $\mathrm{VO}_{2}$ max in het regressiemodel, voor de twee snelheidsmaten die samen de cognitieve Aexibiliteitsscore vormen (letter / cijfer versie van de Concept Shifting Test, en de kleur / woord interferentie katar III van de Stroop-test). Geen verband werd angetoond tussen geheugen en $\mathrm{VO}_{2 \text { max. }}$. De gevonden samenhang russen de maten voor informarie-verwerkingssnellieid en aërobe capaciteit kan wijzen op een beschermend effect van lichamelijke fitheid op cognitie, al waren de gevonden relaties in omvang bescheiden.

Hoofdstuk 6 - Hoge bloeddruk is een belangrijke cardiovasculaire en cerebrovasculaire risicofactor. Her vaststellen van de habituele bloeddruk kent echter verschillende methodologische problemen. De uitkomst van een handmatige bloeddrukmeting met auscultatie varieert sterk binnen individuen en tussen beoordelaars. Er kan sprake zijn van een orientatiereaktie die na herhaalde metirgen niet verdwijnt en aanleiding geeft cot verhoogde meetwaarden, wat een gevolg kan zijn ofwel van de meting zelf ofwel van de anwexigheid van een observator (witte-jas effect). Als voorbereiding op de hoofdstukken 7 en 8, warin her belang wan de bloeddrukstatus voor cognitieve functies central staat, wordt in dit hoofdstuk nagegaan welke demografische factoren invloed hebben op de habituatie van herhald gemeten bloeddruk en wat onder gestandaardiseerde testcondiries de optimale schatter is van de habituele bloeddruk. Hiertoe werd de bloeddruk bij alle 469 deelnemers an de cerste paraelstudie gedurende 20 minuten 5 mal automatisch gemeten met een oscillometrische rechniek (Dinamap ${ }^{\mathrm{T} M}$ ), in afwezigheid van de proefleider. Habituarie van zowel de systolische als diastolische bloeddruk over 20 minuten was beduidend sterker bij oudere leefijdsgroepen. Op groepsniveau vond geen significante daling wan de bloeddruk meet plaats na 15 minuten. Hieruit kan worden afgeleid dat juist bij ouderen het belang van een rustperiode, en mogelijk ook de gewenning aan de meting zelf, voor een betrouwbare bloeddrukmeting niet moet worden onderschat. Verder werden de uirkomsten van de automatische meting vergeleken met de gemiddelde dag-en nachtbloeddruk, verkregen uit 24-uurs ambulante bloeddrukmeting bij een deelgroep van 135 personen. De relatief lage concordanties die tussen deze parameters werden gevonden (gewogen Kappa 0,42-0,51) wijzen erop dat ondanks standaardisavie de witkomsten van de laboratoriummering slechss beperkt generalisecrbaar zinn naar de gemiddelde bloeddruk-waarden in her dagelijkse leven. 
Hoofdstuk 7 - In de eerste twee panelstudics $(N=936)$ werd de relatie onderocht van habivuele bloeddruk en andere vasculaire risicofactoren rookgedrag, alcoholgebruik, Queteletindex; en walle / heup-itatio, met de verschillende cognitieve uitkomstmaten. Bloeddrukstatus en de owerige risicofactoren verklarde geen additionele variantie in cognitieve prestatie, na controle voor leefind, geslacht en opleidingsnweat. Dit goldt zowel voor de totale groep als voor de groep opgeschoond voor personen met cardiovasculaire aandoeningen of gebruikers van antihypertensieve medicatie $(n=720)$. Gestratificerde analyses in 4 leefujdsgroepen $(25-35$, 40-50,55-65 en 70-80 jara lieten eveneens geen relaties tussen bloeddruk en cognitieve functie zien. Geconcludeerd wordt dat in deze groep personen, die in geval bestaande hypertensie doongans adequaat medicamenteus behandeld worden, de relatie tussen de bloeddrukstatus en cognitieve functie niet van klinische relevantie is.

Hoofdstuk 8 - Dit hoofdstuk richt zich op de relatie tussen ambulante bloeddrukwarden (gemiddelde bloeddruk overdag en 's naches, en het verschil hiertussen) en de drie samengestelde cognitiewe uitkomstmaten in de groep personen die meededen aan de 24-uurs registratie van de bloeddruk. Het uitblijen van de fysiologische bloedrukdaling gedurende de nacht werd hierbij als additionele vasculaire risicofactor beschouwd. Uit onderzoek bij hypertensiepatienten is bij herhaling natr woren gekomen dat deze zogenaamde non-dippers vaker en meer uirgebreide eindorgaanschade te zien geven, inclusief in her brein. Zoals reeds voor de laboratoriumbloeddruk werd wastgesteld kon ook voor de ambulante gemiddelde bloeddrukwaarden geen unieke relatie met cognitiewe functie worden aangetoond. Het verschil tussen zowel systolische als diastolische dag-en nachtdruk bleek echter sterk voorspellend voor de verbale geheugenfuncrie, overeenkomend met $8-9 \%$ uniek verklaarde variantie in de geheugenscore: mon-dippers presteerden duidelijk slechrer dan dippers, ook wanneer werd gecontroleerd voor vasculaire morbiditeit en medicijngebruik. Dit kan betekenen dat afvlakking of afwezigheid van de nachtelijke bloeddrukdaling verband houdt met vrij specifieke cognitieve afwijkingen, al bliff het onderliggend mechanisme vooralsnog onopgehelderd en is replicatie van deze bevinding in een onafhankelijk cohort noodzakelijk.

Hoofdsuk 9 - Informate over het bestann van specifieke ziekten, zoals gediagnostiseerd door de huisarts, wordt in dit hoofdstuk in verband gebracht met de cognitieve testprestaric. Van alle deelnemers an de exrste drie MAAS-panelstudies $(N=1.360)$ werden de gezondheidsproblemen zoals volgens strikte criteria gecodeerd op de patientenkaart van de huisarts op anonieme wijze gekoppeld aan de testgegevens. Het bestaan van morbiditeit welke buj minimal $1 \%$ van de deelnemers als totaal of actief probleem bekend was, werd in verschillende regressieanalyses onderzocht op een samenhang met cognitieve functie, waabij werd gecontroleerd voor leefijd, sexe en her opleidingsniveau. Zowel insulineathankelijke als niet-insulineafhankelijke diabetes mellitus was sterk voorspellend voor een lagere prestatie op alle onderzochte cognitieve deelfuncties: de sterkte van dit verband was in sommige modellen vergelijkbaar met het behoren tot een 20 jaar oudere leefrijdsgroep. Verder hing chronische bronchitis negatief samen met simpele en complexe cognirieve snelheid, en kon ouderdomsslechthorendheid in verband worden gebracht met een slechtere geheugen-prestatie. Opmerke- 
lijk was dat behalve diabetes de overige vasculaire aandoeningen zoals hypertensie en coronaitlijden geen bijdrage leverden aan de verschillende regressiemodellen.

Hoofdstuk 10 - In dit hoofdstuk worden een aantal methodologische uitgangspunten van de beschreven studies nader toegelicht. Betoogd wordt dat leeftijd op zichzelf geen verklaring kan bieden voor leeftijd-gerelateerde cognitieve achteruitgang. Veeleer moet worden gezocht naar factoren (mediatoren) die een deel van de samenhang tussen leeftijd en cognitieve funcrie kunnen verklaren. Wanneer de afzonderlijke bevindingen uit de verschillende beschreven studies worden samengebracht blijkt dat een verband tussen leeftijd en vasculaire factor enerzijds, en tussen cognitieve prestatie en vasculaire factor anderzijds niet zonder meer betekent dat de betreffende factor een mediërende rol speelt in de relatie tussen leeftijd en cognitie. Er wordt geconcludeerd dat een potentiële mediator altijd ook variantie in cognitieve prestatie moet kunnen werklaren, onafhankelijk van de factor leefrijd.

Er wordt ingegaan op het belang van deze studies voor verder onderzoek. Voorlopig zijn alle resultaten uit MAAS van cross-sectionele aard. De vraag naar causaliteit zal in de longitudinale fase van MAAS aan de orde komen. 
$\therefore \quad 3 \quad=$

$\therefore \%$ क

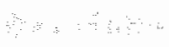

४ $\quad \cdots \quad \therefore=$

$\therefore$ 


\section{Curriculum vitae}

Martin van Boxtel werd in 1959 geboren te Tilburg. Hij doorliep daar het gymnasium $B$ aan het Theresialyceum waarvan in 1978 het diploma werd behaald. Vervolgens was hij twee jaar werkzaam in de detailhandel als in-/verkoopmedewerker van een bedrijf in consumentenelectronica. In 1981 behaalde hij het propedeutisch diploma in de psychologie aan de Katholieke Universiteit Brabant (voorheen Katholieke Hogeschool Tilburg), als opmaat voor de studie geneeskunde in Maastricht. Deze werd in 1988 afgerond met het behalen van her basisartsgetuigschrift.

Van 1988 tot 1992 werkte hij als medisch supervisor en projectleider aan het Instituut voor Geneesmiddelen, Veiligheid en Gedrag (IGVG, tegenwoordig het Institute for Human $P_{\text {sycho- }}$ pharmacology, IHP). Vanaf 1992 is hij verbonden aan de vakgroep Psychiatrie en Neuropsychologie, sectie Neuropsychologie en Psychobiologie, annvankelijk als toegevoegd onderzoeker en vanaf november 1995 als universitair docent. Hier geeft hij mede leiding aan de Maastrichr Aging Study, een longitudinaal onderzoeksprogramma naar determinanten wan cognitieve veroudering.

Marcin van Boxtel is getrouwd met vertaalster Paulien Copper en heeft twee kinderen, Lotte (1991) en Simon (1994). 



\section{Dankwoord}

Het voorliggende proefschrift is naruurlijk mede tot stand gekomen dankzij de inzet van vele personen en instanties. Hiervan will ik er een aantal in her bijzonder vernoemen.

Allereerst dank ik alle deelnemers aan het MAAS onderzoek die zich door ons in meerdere opzichten uitputtend lieten onderzoeken. Zonder hun belangeloze medewerking en betrokkenheid zou dit onderzoek niet mogelijk zijn geweest.

Mijn promoror Jelle Jolles betoonde zich een geduldige en inspirerende begeleider, die mij wooral het strategisch denken theeft bijgebracht en over menig dood punt heeft heen geholpen.

Van de naaste MAAS-collega's dank ik mijn ex-kamergenoor Peter Houx voor zijn. erudiete inbreng in nagenoeg alle fasen van het onderzoek, Rudolf Ponds onder meer voou zijn genuanceerde visie op de mogelijkheden en beperkingen van de neuropsychologie, Frans Verhey voor het klinische reliêf. Huub Hamers voor de strenge bewaking van de integriteit van de data, Martin Klein voor een niet aflatende stream of conciousness, Nico Rozendaal voor zijn probleemoplossend vermogen waar het ging om databewerking, Ilse van Engelshoven en Astrid Quist vooral voor hun logistieke kwaliteiten, Germa Wijnen en Carleun Karimoen voor hum suggesties inzake her resconderzoek, en verder de MAAS onderzoeksmedewerkers Marianne van der Kruijs, Riet Landeweerd, Helma de Verh, Jaqueline Arts, en Irenea Sikken die garant stonden voor een continue siream of data van hoge kwaliteit.

Mer mijn gewaardeerde collega's Paul Ganzevles, Fred Vreeling, Wim Riedel, Jeanette Dijkstra, en Charlie Kaplan heb ik vele stimulerende gesprekken gevoerd. Mijn voormalige werkgever Jim O'Hanlon heeft mij het belang leren kennen wan wetenschap voor het bedrijfsleven, en omgekeerd. Hij bepaalde mede mijn keuze voor de wetenschap.

In de verschillende interne projecten heb ik bijzonder plezierig samengewerkt met Peter de Leeuw, Carlo Gaillard, Monique Fuss, Inez Risselada, en Paul van Es (huidige en woormalige leden van de vakgroep Interne Geneeskunde) en met Jos Adam, Fred Paas, Frans Verstappen en Joep Teeken van de vakgroep Bewegingswetenschappen. Ik dank André Knottnerus, Frank Buntinx, Job Metsemakers, en Marjan van de Akker van de vakgroep Huisartsgeneeskunde, en verder alle RNH-huisartsen en hun praktijkassistenten voor hus in het project gestelde vertrouwen en hun belangrijke inhoudelijke bijdragen. Ilk ben wat betreft het dababeheer deskundig ondersteund door Gregor Franissen, Jan Bergers, Ruud Schmeitz, Alfons Schrooten en Charles Limonard van het MEMIC. Hubert Schouten en Gerard van Breukelen van Methodologie en Statistick gaven waardevolle adviezen inzake de statistische bewerkingen.

Marc van Zandvoort dank ik wooral woor zijn loyale inzet voor het project via de NESTOR-stuurgroep, en Dorly Deeg, Carolien Smits en Jan Smit vam LASA (Amsterdam) voor de gezellige en vruchtbare werkgroepbijeenkomsten, al of niet in NESTOR-verband.

Jane Bär-Sykes en Paulien Copper hebben mij voor menige blunder in de Engels taal behoued.

Om uiteenlopende redenen bedank ik de volgende personen special voor hur steun en inspiratie op werschillende - en soms beslissende - momenten in mijn leven: mijn vader en moeder, mijn goede vriend Kees van Dun, en Anton Slaats, Vic Dubois en Henk van Mameren.

Tot slot, het zijn vooral Paulien, Lotte en Simon geweest die met hun onbeperkte liefde en geduld in deze exercitie blewen geloven en deze mede tor een goed einde hebben gebracht. 


\section{List of publications}

\section{Articles}

Adam, J. J, Teeken, I C, Pats, F, G, W. C., van Boxne, M. P. J., Houx, D. J., \& Jolles, J. Effects of age and gender on performance in a spatial precuing task Submitred for publicanion.

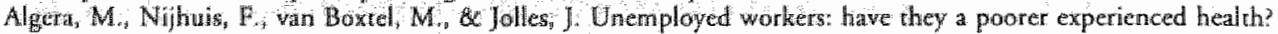
Submited for pulilication.

Buntinx, F., Knotnerus, J. A. Jolles, J, wan Boxtel, M. P. J., Muris, J. W. M., Schouten, H. J. A., \& Höppener, P. (1996). Dementia in general practicer incidence, prevalence, social prevalence and co-morbidity. Archives of Public Heath $52,475-487$;

Martens, M. In. I., Nithuis, F. J. M. wan Boxrel, M. P. J. \& Knottnerus, I. A. (1995). Flexibele arbeids. omitandigheden en gezondheidsklactiren. Gedrag en Organisatie $1,50-59$.

Mattens, M. F. J, Nighuis, F. J N., wan Boxiel. M. P. J., \& Knottnerus, J. A. Flexible working conditions and mental and physical health. Submited for publication.

Rieded, W. J., Peters, M. L. A., van Boxtel, M. P.J., \& O'Hanlon, J. F. The influence of piracetam on acrual driving behaviour and postural scability of elderly subjects. Submitted for publication.

Teeken, J. C., Adam, J. J. Paas, E. G. W. C., wan Boxtel, M. P. Jo, Houx, P. J. \& Jolles, J. (1996). Efecrs of age and gender on discrete and reciprocal aining movements. Psychology and Aging, 11, 195-198.

Van Boxted, M. P. J. (4997). Book revew 'Behavioural gerontology' by D. B. Bromley. Journal of Chemical Neurownatasny, 12, in presen

Van Boxtel, M. P. J., Buntinx, F, Houx, P. J., Mersemakers, I., \& Jolles, J. The relation berween morbidiry and cognitive pefformance in a normal aging popularion. Submitted for publication.

Van Boxtel, M. P. J., Gaillard, C., Houx, P. J, Buntinx, F, de Leeuw, P. W., \&olles, J. Can blood pressure predict cognitive task performance in a healchy population sample? Submitted for publication.

Van Boxtel, M. P. J., Gaillard, C. Howx, P. J., Buntinx, F., de Leuw, P. W, \& Jolles, J. Is cogritive inpairment related to a reduced nockurnal blood pressure drop? Subminted for publicarion.

Van Roxrel, M. P. J., Gaillard, C. van Es, P. N., Jolles, J., \& de Leeuw, P. W. (1996). Repeated automatic versus ambulatory blood pressure measurement: The effects of age and sex in a normal ageing population. Journal of Hyppertevsion, $14,31-40$.

Van Boxtel, M. P. J., Langerak, K., Houx, P. J, \& Jolles, J. (1996). Self-reported physical activity, subjective health, and cognitive performance in older adults. Experimental Aging Research. 22, 363-379.

Wan Boxted, M. P. J., Paas, F. G. W. C., Houx, P. J., Adam, J. J." Teeken, J, C., \& Jolles, J. (1997). Aerobic capacity and cognitive performance in a cross-sectional aging study. Medicine and Scietuce in Sports and Exercise in press.

\section{Book sections}

Buntirx, F., Knottnerus, J. A., Mersernakers, I., wan Boxtel, M. P. I. \& jolles, J. (1995). The Registration Network. of Family Practices and cognitive aging research. In J. Jolles, P. J. Houx, M. P. J. van Boxteh, \& R. W. H. M. Ponds (E.ds.). The Mastrich Aging Stady: Determinants of rognitive aging (pp. 171-176). Maastricht: Natopsycls Publishers.

Dijkstra, J. B., Houx, P. J., van Boxtel, M. P. J., \& Jolles, J. (1997). An operation under general anaesthesia as a risk factor for agito-related cognative decline Results from a large cross-sectional population study. In J. B. Dijkstra

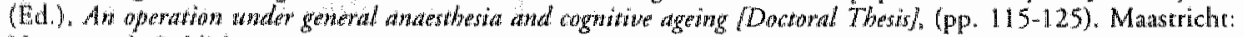
Neuropsych Publishers.

Hogervorst, E., Riedel, W. J., Rozendaal, N., van Boxrd, M. P. J., \& Jolles, J. (1995). Smoking and cognirive complains. In J. Jolles, P. J. Houx, M. .J. J. van Boxel, \& R. W. H. M. Ponds (Eds.), The Maassrichr Aging Shady: Deteraminamts of cognimive aging, (pp. 105-110). Maastricht: Neuropsych Publishers.

Houx, P. J., vint Boxrel, M. P. J., \& Jolles, J. (1995). Cognitive performance, age, and healch-related factors. In J. Jolles, P. J. Houx, M. P. J. van Boxtel, \& R. W. H. M. Ponds (Eds.). The Maaserabi Aging Study: Deternninants

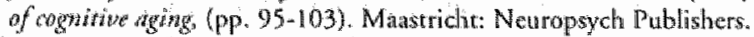

Jolles J. Houx. P. J., wan Boxted, M. P. J., \& Ponds, R. W. H. M. (Eds.). (1995). Matastrichi Aging Study: Determinants of cogitive aging. Maastricht: Neuropsych Publishers.

Jolles, I., vari Boxfel, M. P. J., Ponds, R. W. H. M., \& Houx, P. J. (1996). Veroudering van hersenfuncries en geheugen. In M. Sanwoont \& M. Spanjer (Eds.), Ouder warden, gezond en wel, (Vol. II, pp. 87-95). Utrecht: $\mathrm{N} \rrbracket \mathrm{G}$.

Paas, F. G. W. C. Adtm, J. J., Teeken, J. C., Verstappen, F., van Boxtel, M. P. J., Houx, P. J., \& Jolles, J. (1995). Vilality and cognitive aging. In J. Jolles, P. J. Houx, M. P. I. van Boxtel, \& R. W. H. M. Ponds (Eds.), The

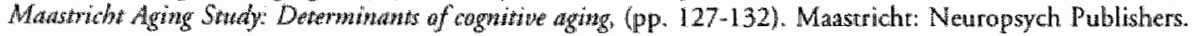


Van Boxtel, M. P. J., Gaillard, C., de Leeuw, P. W. \& Jolles, J. (1995). Habitual blood pressure and cognitive performance. In J. Jolles, P. J. Houx, M. P. J. van Boxtel, \& R. W. H. M. Ponds (Eds.), The Madatrikgt Aging Strudy: Determinants of cognitive agirg, (pp. 119-125). Maastriche: Neuropsych Publishers.

\section{Abstracts}

Adam, J. J., Teeken, J. C., Paas, F. G. W., van Boxtel, M. P. J., Houx, P. J., \& Jolles, J. (1994). Aging effects in a spatial precuing task. Jowrmal of Sport and Extercise Psylology. 16, 525.

Adam, J. J., Teeken, J. C., Paas, F. G. W. C., Boxtel, M. P. J. x. Houx, P. J.; \& Jolles, J. (1994). Effect of age or speeded performance in a 4-choice reacrion time task: The bowed serial position effect. Jountal of Spart and Excerise Psychology, 17, S19.

Hogervarst, E., Riedel, W., van Boxtel, M., Visser, P., Hanneleers, P., Sey, S., \& Iolles, I. (1996). Hypoxia and hyperventilarion as models for cognitive deficiencies. Europedr Netropsychopharmatolagy, 6 (Suppol 3) 145.

Houx, P. J., Ponds, R. W. H. M., van Boxtel, M. P. J., \& Jolles, J. (1996, 25-28 April). Manatricht Aging Snuty (MAAS): Fine-years follow-itp of the first cross-sectional study. Poster presented at the Cognitive Aging Conference, Aclanta, GA. Abstractno, $11-36$.

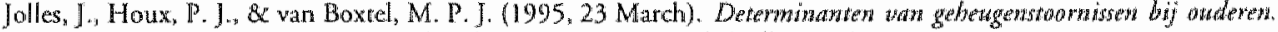
Paper presented at the symposium 'Onderen, werenschap en beleid', Urrechr.

Jolles, J.. Houx, P. J., \& wan Boxrel, M. P. J. (1995, 30 August-2 September). Individual panterns in agraitwe aging: Results from a large cross-sectional population study. Paper presented at the MIrd European Congess of Gerontology, Amsterdam, Abstractno, 062-1111.

Jolles, J., var Boxtel, M. P. J., \& Houx, P. J. (1995, 30 August-2 September). Health and cognition. Resulus from cognitive aging studies. Paper presented at the Submitred Symposium on the IIl rd European Congess of Gerontology" Amsrerdam.

Teeken, J. C., Paas, F. G. W. C., Adam, J. J. van Boxtel, M. P. J., Houx, P. J., \& لolles, J. (1994). Effects of aging on movement time in discrete and reciprocal aiming rasks. Jorryal of Spart and Excercise Psychology, $16, \$ 114$.

Van Boxtel, M. P. J. (1993, 1-2 Aprill). Samatische fattoren en cognivieze veroudering. Paper presented at 'De Geriatrische Reuzen", Rerrate NWO dwarswerband Gerontologie en Geriatrie / NESTOR, Amersfoort.

Van Boxtel, M. P. J. (1994, 23 June). NMAP. bet Madatrit'ste verouderngsproject. Paper presented at the Werkgroep Huisartsgeneeskundig Klinisch Epidemiologisch Onderzoek - Hakleon, KUL, Leuwen (Belgium).

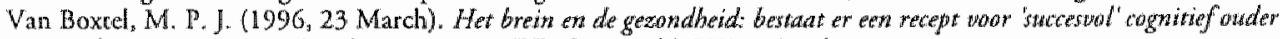
tworden? ' Paper presented at the symposium 'War heet oud?', UBV, Utrecht.

Van Boxiel, M. P. J., Houx, P. J., \& Jolles, J. (1995, 30 August-2 September). Health-related factors and cognitive agying. Paper presented at the MIrd European Congess of Gerontology. Ansterdam. Abstractno. 022-0311.

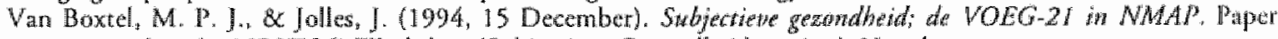
presented an the NESTOR Workshop 'Subjectieve Gezondheidsmering", Utrecht

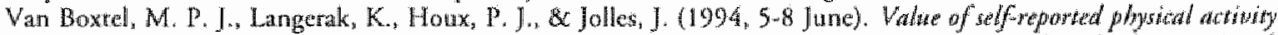
and perceived healsh as predictors of fognitive performance in healdhy plderly. Paper presented at the lintervational workshop on the borderland between normal and parthological mental aging International Psychogeriatejc Association - IPA. Amsterdam.

Van Boxtel, M. P. J. Calllard, C., Houx, P. I. de leeuw, P. W., \& Jolles, J. (1996, 25-28 Aprill). The relaiom

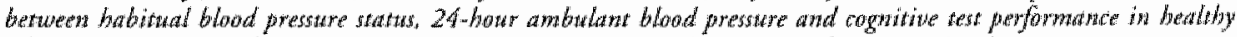
atdults. Poster presented an the Cognitive Aging Conference, Avlanta, GA. Abstractno. III-49.

\section{Registered reseanch reports}

Ramackers, J G., van Boxcel, M. P. J., \& O'Hanlon, J. F. (1992). A study wo compare acrivastine's and terfenadime's effects on several aspects of driving perfarmatuce ass a function of dose and time after dosing (92.25). Manstrichu: Insritute of Human Psychopharmacology.

Van Boxtel, M. P. J. De Silva de Freitas, C., OHanlon, I. F. (1992). The effect of diazepam an alectroptysio-

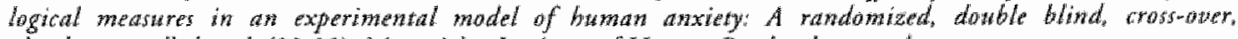
placebo-controlled study (92-08). Mastricht: Institute of Human Psychopharmacology.

Van Boxtel, M. P. J., Robbe, H. W. J., Westerink, B. H. C. \& O'Hanlon, J. F. (1990). The effects of elroprazime arud diaxepam on aggressive and anxions arousal in bealkhy woltanteens (90-14). Maastrichr: lnstitute of Human Psychopharmacology. 